HEDL 6859

THE DEVELOPMENT OF AN EMERGENCY AIR-CLEANING SYSTEM FOR LIQUID-METAL REACTORS

\author{
Submitted to: \\ Dr. W. A. Scheffler \\ University of Washington \\ and \\ - - \\ The Joint Center for Graduate Study \\ Richland, Washington
}

\author{
By \\ Richard K. Owen* \\ Chemical Engineering Masters' Degree Candidate \\ November 1980
}

*Employe of Westinghouse Hanford Company/A subsidiary of Westinghouse Electric Corp/Operating the Hanford Engineering Development Laboratory for the USDOE 


\section{DISCLAIMER}

Portions of this document may be illegible in electronic image products. Images are produced from the best available original document. 
Operated by

Westinghouse

A Subsidiary of

Hanford Company

Westinghouse Electric

for the U.S. DOE

Corporation

Contract No.

P.0. Box 1970

DE-AC14-76FF02170

Richland, WA 99352

\section{Hanford Engineering Development Laboratory}

INFORMATION CONCERNING USE OF THIS DOCUMENT

NOTICE

This document was prepared as an account of work sponsored by the United States Government. Neither the United States nor the U.S. DOE, nor any of its employes, nor any of its contractors, subcontractors or their employes, makes any warranty. expressed or implied, or assumes any legal liability or responsibility for any third party's use or the results of such use of any information, apparatus, product or process disclosed in this report, or represents that its use by such third party would not infringe privately owned rights.

PRELIMINARY DOCUMENT

This document contains information of a preliminary nature prepared in the course of work under U.S. DOE Contract DE-AC14-76FF02170. This information is subject to corrections or modification upon the collection and evaluation of additional data. 
HEDL 6859

\title{
THE DEVELOPMENT OF AN EMERGENCY AIR-CLEANING SYSTEM FOR LIQUID-METAL REACTORS
}

\author{
Submitted to: \\ Dr. W. A. Scheffler \\ University of Washington \\ and \\ The Joint Center for Graduate Study \\ Rich land, Washington
}

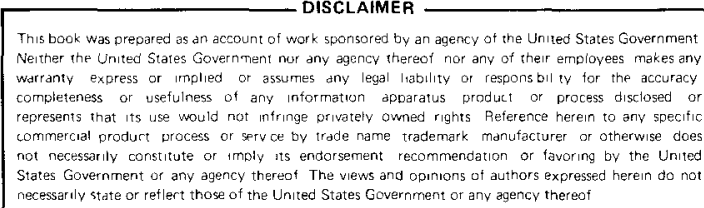

By

Richard K. Owen*

Chemical Engineering Masters' Degree Candidate

November 1980

*Employe of Westinghouse Hanford Company/A subsidiary of Westinghouse Electric Corp/Operating the Hanford Engineering Development Laboratory for the USDOE 
-

1

$\checkmark$

- 
HEDL 6859

THE DEVELOPMENT OF AN EMERGENCY AIR CLEANING SYSTEM

FOR LIQUID METAL REACTORS

R. K. Owen

\section{ABSTRACT}

A novel air cleaning concept has been developed for potential use in venting future commercial liquid metal fast breeder reactor containment buildings in the unlikely event of postulated core disruptive accidents. The passive concept consists of a submerged gravel bed to collect the bulk of particulate contaminates carried by the vented gas. A fibrous scrubber could be combined with the submerged gravel scrubber to enhance collection efficiencies for the smaller sized particles. The submerged gravel scrubber is unique in that water flow through the packed bed is induced by the gas flow, eliminating the need for an active liquid pump. In addition, design gas velocities through the packed bed are 10 to 20 times higher than for a conventional sand bed filter.

A series of development tests has been performed on an engineering scale model with a gravel bed area of $0.07 \mathrm{~m}^{2}$. Hydraulic tests indicate that the scrubber can be designed to operate at superficial gas velocities of 0 . to $0.50 \mathrm{~m} / \mathrm{s}$. Aerosol tests were performed with a variety of sodium fire aerosols. The aerosol mass removal efficiency for the submerged bed scrubber was 99.8\% and the efficiency for the two-stage system exceeded 99.99\%. Scale-up tests were made to evaluate gas distribution on a larger bed. The results indicated that the self-cleaning gravel bed can be scaled up to the sizes required for full-scale containment applications.

A submerged gravel scrubber conceptual design was made for application to a $975 \mathrm{MW}$ th liquid metal fast breeder reactor plant. The design has the option of including fibrous scrubber elements, and demonstrates application of development testing results. 
-

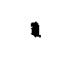

- 


\section{CONTENTS}

$\underline{\text { Page }}$

Abstract

i i

1.0 Introduction

2.0 Concept Description 2

3.0 Deve lopment Work 4

3.1 Model 5

3.2 Hydraulic Tests 16

3.3 Efficiency Tests 31

3.4 DOP Tests 79

3.5 Scaleup Tests 82

4.0 Theoretical Considerations 82

4.1 Hydraulics $\quad 84$

4.2 Aerosol Collection 86

5.0 Accident Conditions and System Criteria 96

5.1 Thermal Conditions 99

5.2 Chemical Forms of Aerosol and Gases 99

$\begin{array}{lll}5.3 & \text { Aerosol Properties } & 101\end{array}$

5.4 Gas Flow Rate 101

$\begin{array}{lll}5.5 & \text { Aerosol Mass Collected } & 106\end{array}$

5.6 Required Removal Efficiency 106

$\begin{array}{lll}5.7 & \text { Other Considerations } & 106\end{array}$

$\begin{array}{lll}6.0 & \text { Scrubber Conceptual Design } & 108\end{array}$

6.1 Bed Dimensions 109

$\begin{array}{ll}6.2 \text { Packing } & 109\end{array}$

6.3 Inlet Duct 112 
6.4 Bed Skirt

6.5 Bed Screens

6.6 Tank

6.7 Blower

6.8 Flow Control

6.9 Instrumentation

6.10 Assembly

6.11 Acceptance Testing

$\begin{array}{ll}8.0 \text { Summary and Conclusions } & 125\end{array}$

$\begin{array}{ll}9.0 \text { References } & 127\end{array}$

Appendix $A$ Test Facility Description A-1

Appendix $B \quad$ Calculating Aerosol Particle Size from Impactor Measurements

Appendix C Spherical Bed Model Development C-1

Appendix D Channel Model Development D-1 


\section{FIGURES}

Figure

1 Merging of a Sand and Gravel Filter and a Pool Scrubber 3

2 Experimental Scrubber 6

3 Bed Supports 7

4 Bed Stand 9

$5 \quad$ Test Bed Schematic 10

6 Scrubber Tank 12

$7 \quad$ Gas Outlet Duct $\quad 13$

$8 \quad$ Gas Inlet Duct $\quad 15$

9 Blower Performance Curve 16

10 Water Pulse Velocity 19

11 Water Pulse Amplitude 20

12 SGS Pressure Drop 20

13 Dry Bed Pressure Drop 22

14 Drain Ring 23

15 Liquid Superficial Velocity, Configuration A 24

16 Liquid Superficial Velocity, Configuration B 24

17 Liquid Superficial Velocity, Configuration C 26

18 Liquid Superficial Velocity, Configuration D 26

$19 \quad$ Liquid Superficial Velocity, Configuration $E \quad 27$

20 Liquid Superficial Velocity, Configuration $F \quad 27$

21 Liquid Superficial Velocity, Configuration G 28

22 Liquid Superficial Velocity, Configuration $H \quad 28$

23 Liquid Superficial Velocity, Configuration I 29 
FIGURES (Cont'd)

\section{Figure}

24 Packing Size Effect on Liquid Velocity

25 Bed Height Effect on Liquid Velocity 30

26 Inlet Duct Submergence Effect on Liquid Velocity 30

27 Filter Holder

28 Circular Jet Impactor

29 Rectangular Jet Impactor

30 Source Aerosol Concentration, Test SGS-AC3

Source Aerosol Concentration, Test SGS-EI

Source Aerosol Concentration, Test SGS-E2

Source Aerosol Concentration, Test SGS-E3

Source Aerosol Concentration, Test SGS-AC4

42 Scrubber Temperatures, Test SGS-AC5

Source Aerosol Concentration, Test SGS-AC5

37 Scrubber Temperatures, Test SGS-AC3

38 Scrubber Temperatures, Test SGS-ET 45

39 Scrubber Temperatures, Test SGS-E2 46

40 Scrubber Temperatures, Test SGS-E3 46

41 Scrubber Temperatures, Test SGS-AC4 47

43 Scrubber Temperatures, Test SGS-AC6

47

4

44 Gas Superficial Velocity, Test SGS-AC3

48

45 Gas Superficial Velocity, Test SGS-E1

54

46 Gas Superficial Velocity, Test SGS-E2 


\section{FIGURES (Cont'd)}

Figure

Page

47 Gas Superficial Velocity, Test SGS-E3 57

48a Gas Superficial Velocity, Test SGS-AC4 58

48b Gas Superficial Velocity, Test SGS-AC4 (Cont'd) 58

49 Gas Superficial Velocity, Test SGS-AC5 59

50 Gas Superficial Velocity, Test SGS-AC6 60

51 Bed Penetration vs Gas Velocity, Test SGS-AC3 61

52 Bed Penetration vs Gas Velocity, Test SGS-E1 62

53 Bed Penetration vs Gas Velocity, Test SGS-E2 62

54 Bed Penetration vs Gas Velocity, Test SGS-E3 63

55 Bed Penetration vs Gas Velocity, Test SGS-AC4 63

56 Bed Penetration vs Gas Velocity, Test SGS-AC5 64

57 Bed Penetration vs Gas Velocity, Test SGS-AC6 64

58 Bed Penetration vs Inlet Concentration, Test SGS-AC3 65

59 Bed Penetration vs Inlet Concentration, Test SGS-E1 65

60 Bed Penetration vs Inlet Concentration, Test SGS-E2 66

61 Bed Penetration vs Inlet Concentration, Test SGS-E3 66

62 Bed Penetration vs Inlet Concentration, Test SGS-AC4 67

63 Bed Penetration vs Inlet Concentrations, Test SGS-AC6 68

64 Demister Element $\quad 71$

65 SGS/HEFD Unit 73

66 SGS/HEFD Penetration vS Inlet Concentration, Test SGS-AC4 76

67 Demister Pad 77

68 Scaleup Test Bed 83 
FIGURES (Cont'd)

Figure

Page

69 Submerged Packing Flow Patterns

70 Sphere Model Penetration Prediction

71 Channel Model Penetration Prediction

72 Scrubber Performance Correlation

73 Postulated RCB Atmosphere Temperature

74 Postulated RCB Aerosol Size Concentration

Postulated Aerosol Size Distribution

103

Postulated Vent/Purge Gas Flow Rate, Actual Conditions

104

77 Postulated Vent/Purge Flow Rate, Standard Conditions

105

Integrated Mass Loading

107

79

Scrubber Installation

80 Scrubber Conceptual Design

81 Conceptual Bed Supports

82 Solubilities of $\mathrm{NaOH}$ and $\mathrm{Na}_{2} \mathrm{CO}_{3}$

83 Viscosities of $\mathrm{NaOH}$ and $\mathrm{Na}_{2} \mathrm{CO}_{3}$

SGS/HEFD System Conceptual Design

A-1 Containment Systems Test Facility

A-2 Large Scale Sodium Facility

B-1 Sample Calculation Particle Size Distribution Plot

B-2 Particle Size Distribution Plot, SGS-AC3

B-3 Particle Size Distribution Plot, SGS-E1

B-4 Particle Size Distribution Plot, SGS-E1 


\section{FIGURES (Cont'd)}

Figure

Page

B-6 Particle Size Distribution Plot, SGS-E2

B-7 Particle Size Distribution Plot, SGS-E2

B-8 Particle Size Distribution Plot, SGS-E2

B-9 Particle Size Distribution Plot, SGS-E3

B-10 Particle Size Distribution Plot, SGS-E3

B-11 Particle Size Distribution Plot, SGS-E3

B-12 Particle Size Distribution Plot, SGS-AC4

B-13 Particle Size Distribution Plot, SGS-AC4

B-14 Particle Size Distribution Plot, SGS-AC4

B-15 Particle Size Distribution Plot, SGS-AC6

B-16 Particle Size Distribution Plot, SGS-AC6 
Table

$1 \quad$ Hydrau Tic Test Bed Configurations

2 Aeroso 1 Test Conditions

3 SGS Penetration, Test SGS-AC3

4 SGS Penetration, Test SGS-E1

5 SGS Penetration, Test SGS-E2

6 SGS Penetration, Test SGS-E3

7 SGS Penetration, Test SGS-AC4

8 SGS Penetration, Test SGS-AC5

9 SGS Penetration, Test SGS-AC6

10 SGS Aerosol Test Results

11 SGS/HEFD Penetration, Test SGS-AC4

12 SGS/HEFD Penetration, Test SGS-AC5

13 SGS/Demister Pad Penetration, Test SGS-AC6

14 SGS System Aerosol Test Results 79

15 DOP Penetration

B-1 Stage Reference Cut Diameters For Circular Jet Impactor

B-2 Stage Reference Cut Diameters for Rectangular Jet Impactor

B-3 Example Treatment of Cascade Impactor Data

B-6

D-1 Experimental Values of J, Channel Width

D-3 


\subsection{INTRODUCTION}

The United States Department of Energy (DOE) is presently engaged in a development program to address the safety issues related to future commercial liquid metal fast breeder reactors (LMFBRs). One particular area of study relates to evaluation of hypothetical reactor accidents in which it is assumed that the core is disrupted and that the core theoretically melts through the reactor vessel and the reactor guard vessel. Subsequently, the reactor cavity liner is assumed to fail, allowing sodium and core debris to interact with the cavity concrete floor.

This interaction may release a large amount of energy and a significant quantity of hydrogen. The cavity area is vented to the containment building; therefore, the containment structure might experience an overpressurization due to energy released from reactor cavity sodium-concrete reactions, containment sodium-oxygen reactions, and deflagrations of accumulated hydrogen.

The containment building could be vented to prevent overpressurization and, if necessary, purged to reduce the hydrogen concentration below the flammability limit. The LMFBR has a large inventory of plutonium, as fuel, and metallic sodium, as coolant. In a hypothetical accident, these constituents might be present in the reactor containment as aerosols. To mitigate, with in allowable limits, the radiological and chemical reactivity hazards of releasing this aerosol to the environment during venting and purging, the released gas could be processed through an air cleaning system.

Industrial air cleaning devices have been previously evaluated for this type of application(1-3). In general, conventional air cleaning systems fail to satisfy all of the design objectives. The system must effectively remove large quantities of sodium aerosols with a minimum of energy consumption and little operator attention. The system must be highly reliable on startup and during operation. A compact design and a small capital investment are additiona 7 objectives. 
A novel device has been proposed (4) (A. K. Postma, Hanford Engineering Development Laboratory) which satisfies these objectives. This report covers the development of this concept to the extent that a conceptual design of an air cleaning system is made for a 975 MWth reactor.

\subsection{CONCEPT DESCRIPTION}

The proposed concept combines the desirable features of a pool-type scrubber and a sand and gravel filter into a hybrid scrubber. This combination is represented schematically in Figure 1.

A pool-type scrubber consists of a gas inlet duct projecting down into a pool of liquid. The gas flows out of the inlet duct, breaks into bubbles, then flows upward through the pool. Aerosols are removed from the gas in the bubbles by various forces, which generally are dependent on the bubble diameter. Although various modifications can be made to the outlet of the gas duct to reduce the bubble size, this type of system characteristically produces relatively large gas bubbles. The aerosol removal is correspondingly low. However, the pool scrubber has the desirable feature of handling a large mass of collected material.

A sand and gravel filter uses layers of graded granular material, with the largest size rock layer normally located on the bottom and succeedingly finer layers placed on top. Gas containing aerosol passes from the bottom to the top of the bed. Aerosol is removed by inertial, diffusion, interception, and settling forces. Primarily due to the layers of fine sand granules in the upper layers of the bed, the sand and gravel filter demonstrates a high aerosol removal efficiency. However, due to the limited bed void volume, the filter can handle only a small amount of collected material per unit volume of filter.

The hybrid type of scrubber consists of a bed of gravel submerged in a pool of water. Gas laden with aerosol flows down a central inlet duct to the bottom of the bed. There, gas distributes itself across the bed and flows 


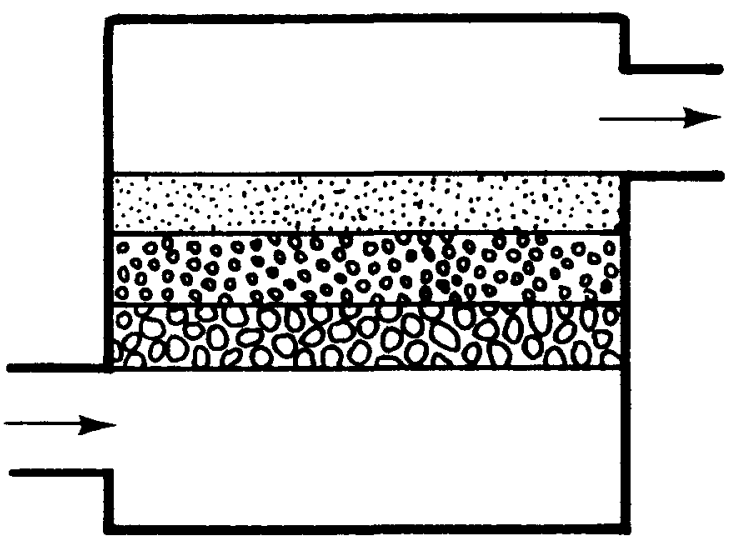

SAND AND GRAVEL FILTER

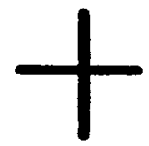

\3

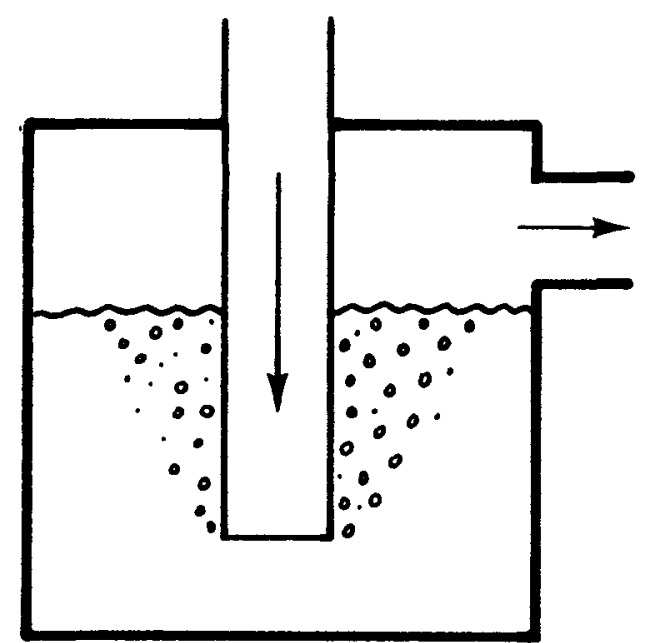

POOL SCRUBBER

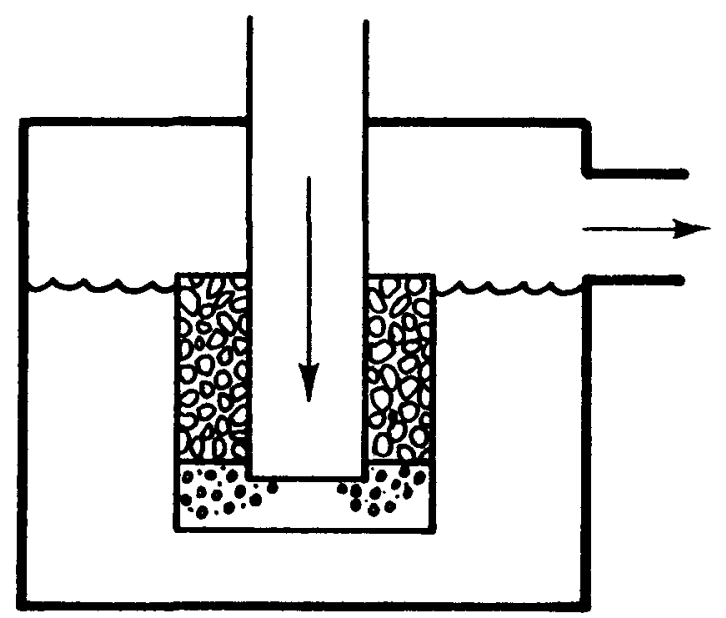

\section{SUBMERGED GRAVEL SCRUBBER}

FIGURE 1. Merging of a Sand and Gravel Filter and a Pool Scrubber. 
upward through small irregular channels formed in the bed interstices. Aerosol is removed from the gas by interception, diffusion, inertia forces, particle growth, and settling. The clean gas exits at the top of the packed bed.

The presence of the gas reduces the apparent density of the fluid inside the bed. Consequently, water outside the bed flows into the bottom of the bed, travels up through the bed, and spills over the top. The collected aerosol is thereby continuously washed from the gravel. The novel feature of this device is the passive, self-cleaning bed.

The hybrid scrubber was designated as the submerged gravel scrubber (SGS). The SGS should effectively remove aerosols. The efficiency of aerosol removal could be adjusted by changing the depth of the bed, the size of the packing, and the velocity of gas through the bed. The SGS would handle any amount of collected material, determined only by the volume of the pool and the solubility of the removed aerosol.

The submerged gravel scrubber is a three-phase aqueous scrubber. The solid phase (rock) is fixed in place, and the gas and liquid phases flow concurrently through the bed. Due to the complexity of the system, it is very difficult to predict a priori scrubber performance. Therefore, a development effort was undertaken to test and develop the concept.

\subsection{DEVELOPMENT WORK}

The purpose of the development work was to demonstrate the validity of the concept and to evaluate the parameters necessary to design a large-scale scrubber. An engineering scale model was built and a series of tests was performed to accomplish these goals. 


\subsection{MODEL}

A photograph of the assembled scrubber is shown in Figure 2. The materials of construction were predominantly transparent acrylic plastic and 300 series stainless steel. The tank, lid, and structural parts of the bed were made of transparent plastic so that the operation of the scrubber would be observable. Stainless steel was chosen for its corrosion resistance to caustic solutions.

The bed consisted of packing, two support plates, a support ring, an outside tube, an inlet gas duct, and a bed stand. The packing used was basalt rock that had been previously quarried from the Hanford Reservation and crushed and screened. The rock is characterized as having no smooth sides. The rock was screened by hand into three segments: (+) $0.64 \mathrm{~cm}$ to $(-) 0.95 \mathrm{~cm}$, (t) $0.95 \mathrm{~cm}$ to $(-) 1.27 \mathrm{~cm}$, and $(+) 1.27 \mathrm{~cm}$ to $(-) 1.59 \mathrm{~cm}$. The plus sign indicates that the rock is retained on a screen with the given opening, and the minus sign denotes that the rock passes through the screen. The measured density of the rock was $2.84 \mathrm{~g} / \mathrm{cm}^{3}$ based on a $0.02-\mathrm{m}^{3}$ sample. The nominal packed bed void fraction was $0.45 \pm 0.05$.

The packing was retained between an upper and a lower support plate. Two types of support plates were made and are shown in Figure 3 . The first was a $30.2-\mathrm{cm}$ diameter plate, $0.64 \mathrm{~cm}$ thick with a series of $0.64-\mathrm{cm}$ diameter holes drilled on $0.95-\mathrm{cm}$ centers in a staggered pattern. The fraction of free area of the plate was $49.4 \%$.

An unperforated area $1.27 \mathrm{~cm}$ wide was left around the outside rim and around a $6.67-\mathrm{cm}$ diameter hole, in the center of the plate, that was drilled for the gas inlet duct. This type of plate was chosen to help distribute the gas across the bottom of the bed and to initially produce small gas bubbles.

A second type of support plate was fabricated for testing that would be simpler and less expensive to construct for a large scale unit. A 30.2-cm diameter, 0.64-cm thick, wheel was cut with a $1.27-\mathrm{cm}$ wide rim, four $1.27-\mathrm{cm}$ wide spokes, and a $1.27-\mathrm{cm}$ wide hub around a $6.67-\mathrm{cm}$ diameter center hole. 


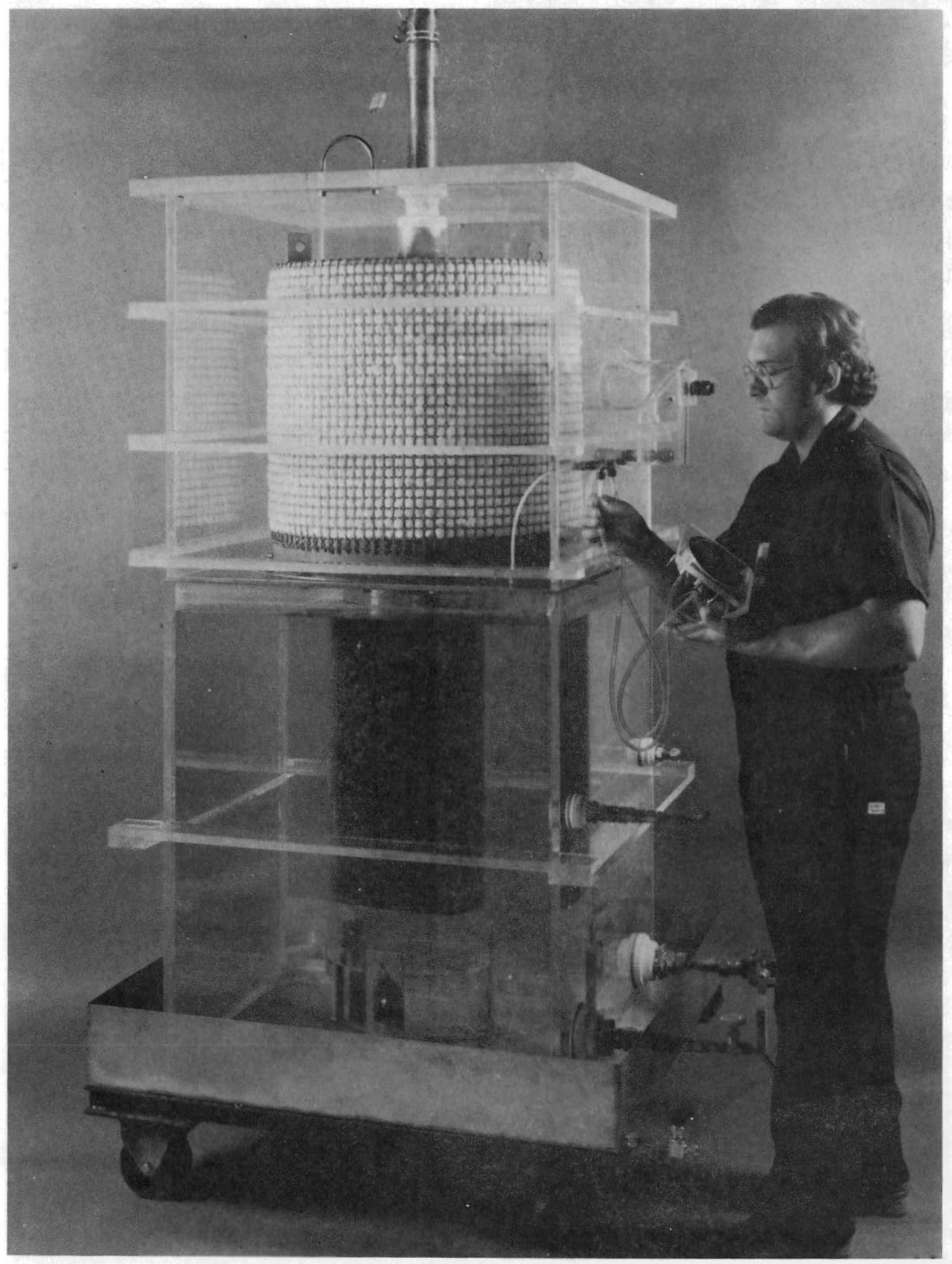

FIGURE 2. Experimental Scrubber. Neg 7908846-1cn 


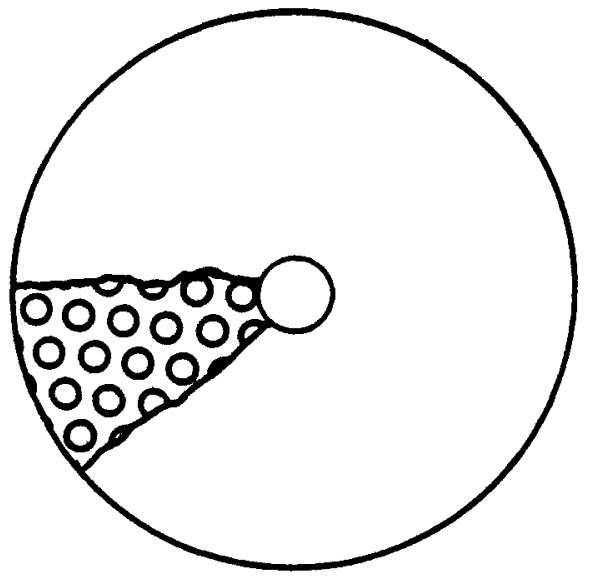

PLATE SUPPORT

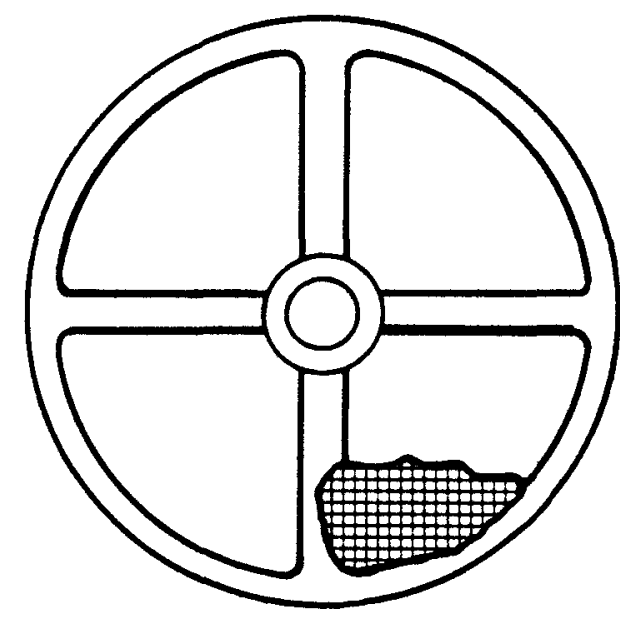

SCREEN SUPPORT

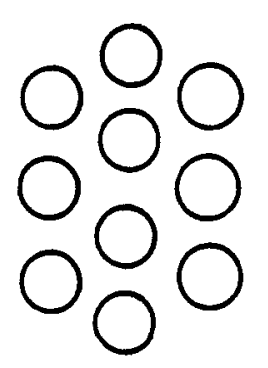

\section{HOLE PATTERN}

$0.64 \mathrm{~cm}$ DIA., 0.95 CENTERS

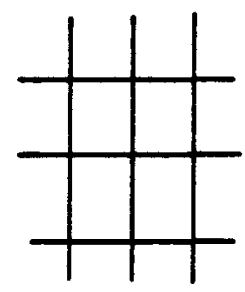

SCREEN

4 MESH

HEDL 8007-104.3

FIGURE 3. Bed Supports. 
A stainless steel screen, with 1.6- $\mathrm{mm}$ wire and $4.75-\mathrm{mm}$ opening, was welded to the wheel to cover the area between the spokes.

The packing was placed with in a transparent acrylic tube. The tube measured $30.8 \mathrm{~cm}$ outside diameter, with a $0.95-\mathrm{cm}$ thick wall, and was $0.76 \mathrm{~m}$ long. A vendor fabricated the tube by rolling a $0.95-\mathrm{cm}$ thick sheet of plastic.

The tube rested on a bed stand, shown in Figure 4, which consisted of three upright steel prongs. The stand held the tube $15 \mathrm{~cm}$ off the bottom of the tank and provided a reference support point for the bottom plate.

A support ring was placed between the bed stand and the bottom support plate, as illustrated in Figure 5. The support rings were cut from an acrylic tube measuring $30.5 \mathrm{~cm}$ outside diameter, with a $0.64-\mathrm{cm}$ thick wall. By changing the length of the support ring, the height of the bottom plate above the bed stand could be varied, thus accommodating various bed depths while maintaining the top of the bed at a constant height.

The bed was assembled by positioning the bed stand and then placing the outside tube on top of the stand. An appropriate length of support ring was inserted inside the outside tube such that the ring also rested on the bed stand. A support plate was set on the ring. The gas inlet tube, a $1.5-\mathrm{m}$ long section of 304 S.S., 14 gauge wa $11,6.4-\mathrm{cm}$ OD pipe was inserted down through the outside tube and into the center hole in the plate. Rock was then added on top of the support plate until the level reached $2.5 \mathrm{~cm}$ below the top of the outside tube. The top support plate was slid over the inlet duct onto the top of the rocks and was bolted to the side of the outside tube using three equally spaced angle brackets.

The bed sat in the center of a plastic tank. The tank measured $0.78 \mathrm{~m}$ long by $0.78 \mathrm{~m}$ wide by $0.93 \mathrm{~m}$ deep (see Figure 6 ). The walls and floor of the tank were $1.9 \mathrm{~cm}$ thick. Two sets of $7.6 \mathrm{~cm}$ wide by $1.9 \mathrm{~cm}$ thick NPT polyvinyl ch Toride heavy duty tank fittings, with neoprene gaskets, were installed through the lower side of one tank wall. At the middle of the 


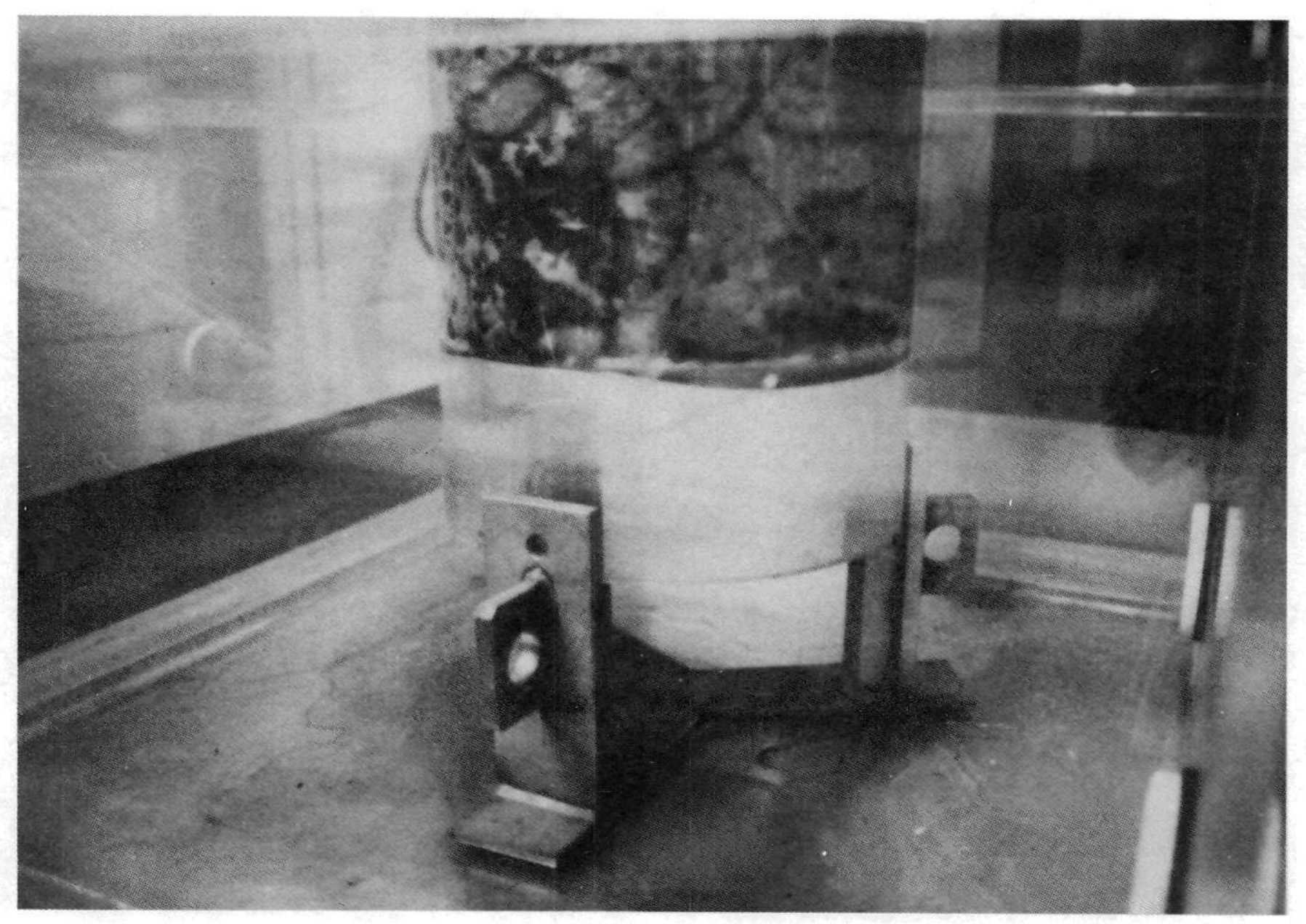

FIGURE 4. Bed Stand. Neg 8000152-2cn 


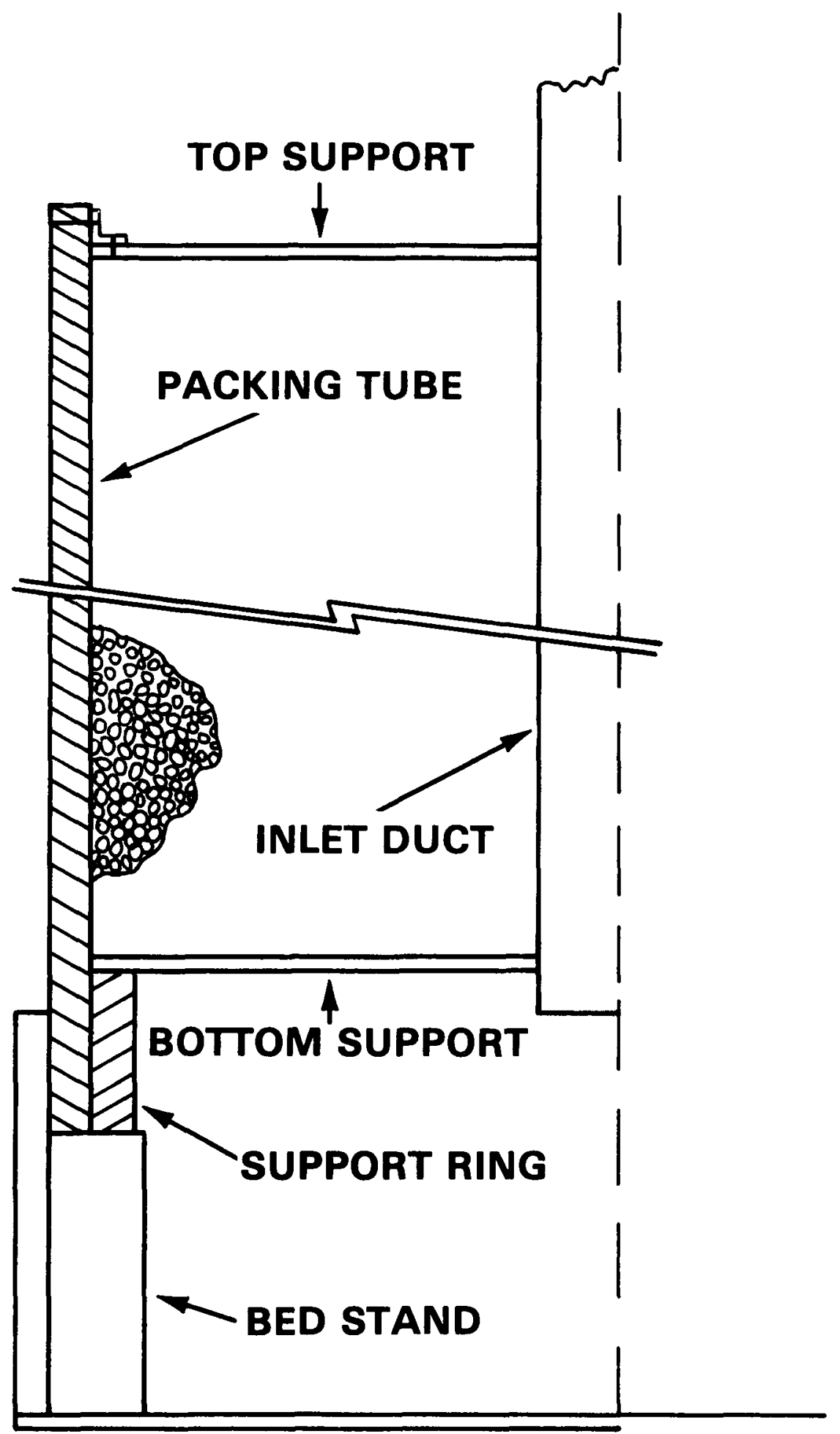

FIGURE 5. Test Bed Schematic. 
same wall, two similar 2.5-cm NPT fittings were added. These fittings served as penetrations for a drain, a water supply line, a liquid sample port, and a thermocouple for measuring liquid phase temperature.

A plastic lid, fabricated to the same $O D$ as the tank, was $33 \mathrm{~cm}$ high and had one set of support strips. A $6.7-\mathrm{cm}$ diameter hole was cut through the center of the lid to accommodate the gas inlet duct. At the center of one side, a reinforced gas outlet duct was fabricated as shown in Figure 7 . A $10-\mathrm{cm} \mathrm{OD,} \mathrm{0.95-cm} \mathrm{wa11,} \mathrm{plastic} \mathrm{tube} \mathrm{was} \mathrm{cut} \mathrm{at} \mathrm{a} \mathrm{45-deg} \mathrm{angle,} \mathrm{rotated} \mathrm{and}$ glued to form a 90-deg bend, and then glued to the lid. A 3.2-mm tubing fitting was added through the side of the outlet duct for a thermocouple probe. At the end of the bend, a $1.3-\mathrm{cm}$ tubing fitting was added as a port for sampling the outlet gas aerosol concentration. A sealing strip was glued to the inside perimeter of the lid such that the overhanging portion of the strip would fit inside the tank. A strip of tape was used to seal the lid to the tank. To seal the lid to the inlet duct, a block of plastic was machined to accept an 0-ring. The sealing block was adhered to the top of the lid with silicone grease and the duct was sealed to the block with tape.

The tank was placed inside a $1.0 \mathrm{~m}$ by $1.0 \mathrm{~m}$ by $15 \mathrm{~cm}$ high catch tray formed from 16 gauge stainless steel. The tray rested on a carbon steel wheeled stand.

The scrubber inlet and outlet gas connections were made with 10-cm ID polypropylene flexible tubing with the ends of the tubing being secured with hose clamps. An adapter piece was fitted to the gas inlet duct, as illustrated in Figure 8 . The adapter piece provided a port through which to sample the inlet aerosol concentration and a fitting for a thermocouple. The outlet gas duct was connected with tubing to a backup filter, a gas flowrate measuring tube, and a blower. The filter and flow tube were mounted on a movable cart. 


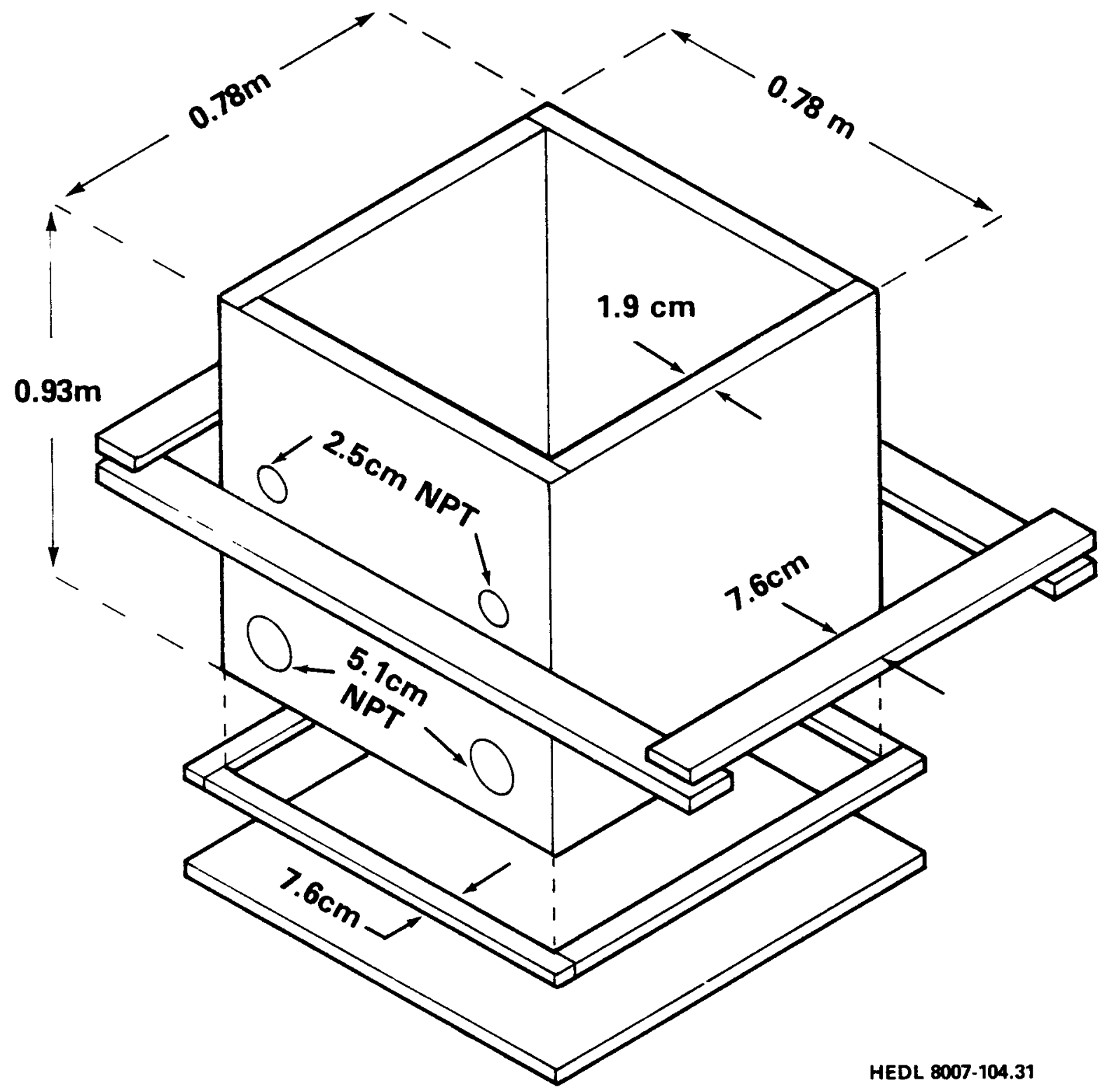

FIGURE 6. Scrubber Tank. 


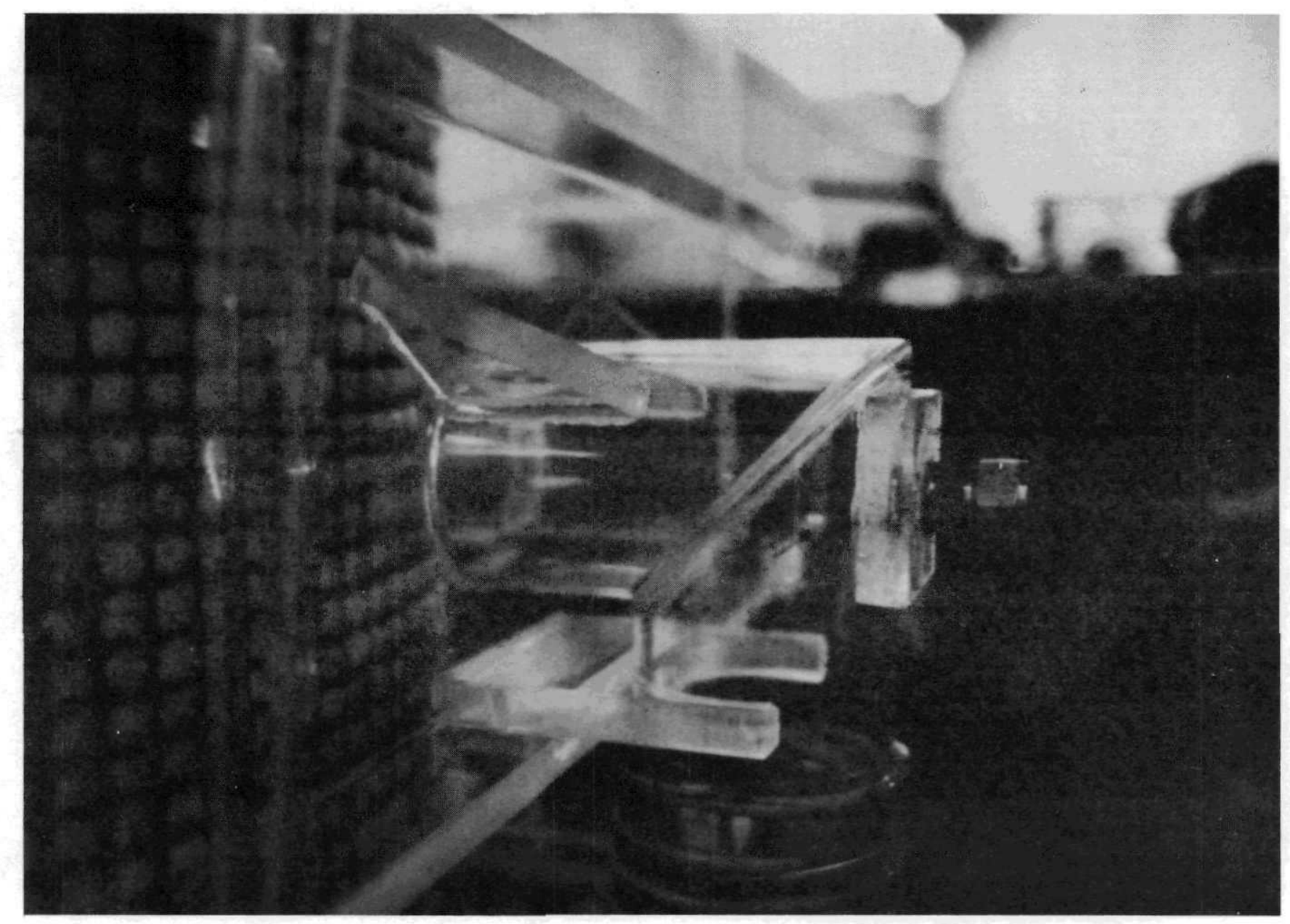

FIGURE 7. Gas Outlet Duct. Neg 800152-3cn 
The backup filters used were high efficiency particulate air (HEPA) filters, manufactured by Cambridge Filter Corporation. * The filters were made from corrugated sheets of fiberglass fibers, and were rated at a 99.993\% removal efficiency of DOP (a standard test for air filters). The filters measured $30 \mathrm{~cm}$ on each side and were sized for $3.8 \mathrm{~m}^{3}$ (STP)/min. at a 220 pascal pressure drop.

The backup filter was connected to a section of pipe used to measure the flowrate of gas through the scrubber. The flow tube was made from $10-\mathrm{cm} 0 D$, 32-m gauge wal1, 304 stainless steel pipe. The flow tube consisted of a 1.2-m long section and a 0.6-m long section, and flat 15.6-cm diameter flanges were welded to one end of each section. Pressure taps were made one pipe diameter upstream of the flange on the long section and one-half pipe diameter downstream of the flange on the short section. Orifice plates were designed to Reference 5 and constructed from 3.2-m thick stainless steel plate. The pressure difference was measured by using a Dwyer ${ }^{\star \star} 0-15 \mathrm{~cm}$ water manometer, catalog number 246.

Gas flow was induced through the scrubber system by a Ram I Gast ${ }^{\star \star \star}$ 3-hp blower, Model No. P180-102-J901, operated as an exhauster. The performance curve is given in Figure 9. A pipe tee was fitted to the blower inlet and a $5-\mathrm{cm}$ globe valve was added to one leg of the pipe tee to function as a bypass valve for controliing the flowrate of air through the scrubber. The other end of the tee was attached to a $5-\mathrm{cm}$ to $10-\mathrm{cm}$ reducer, and flexible tubing was used to connect the reducer to the flow tube.

Instrumentation consisted of four K-type alumel/chromel thermocouples, four differential pressure gauges, and two differential pressure transducers. The thermocouples were 3-mm stainless steel sheathed, ungrounded, and were inserted into the inlet stream, the scrubber liquid, the scrubber outlet gas

* Cambridge Filter Corporation, Syracuse, New York 13201 **Dwyer Instrument Company, Michigan City, Indiana 46360

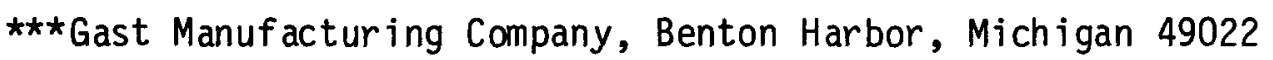


0

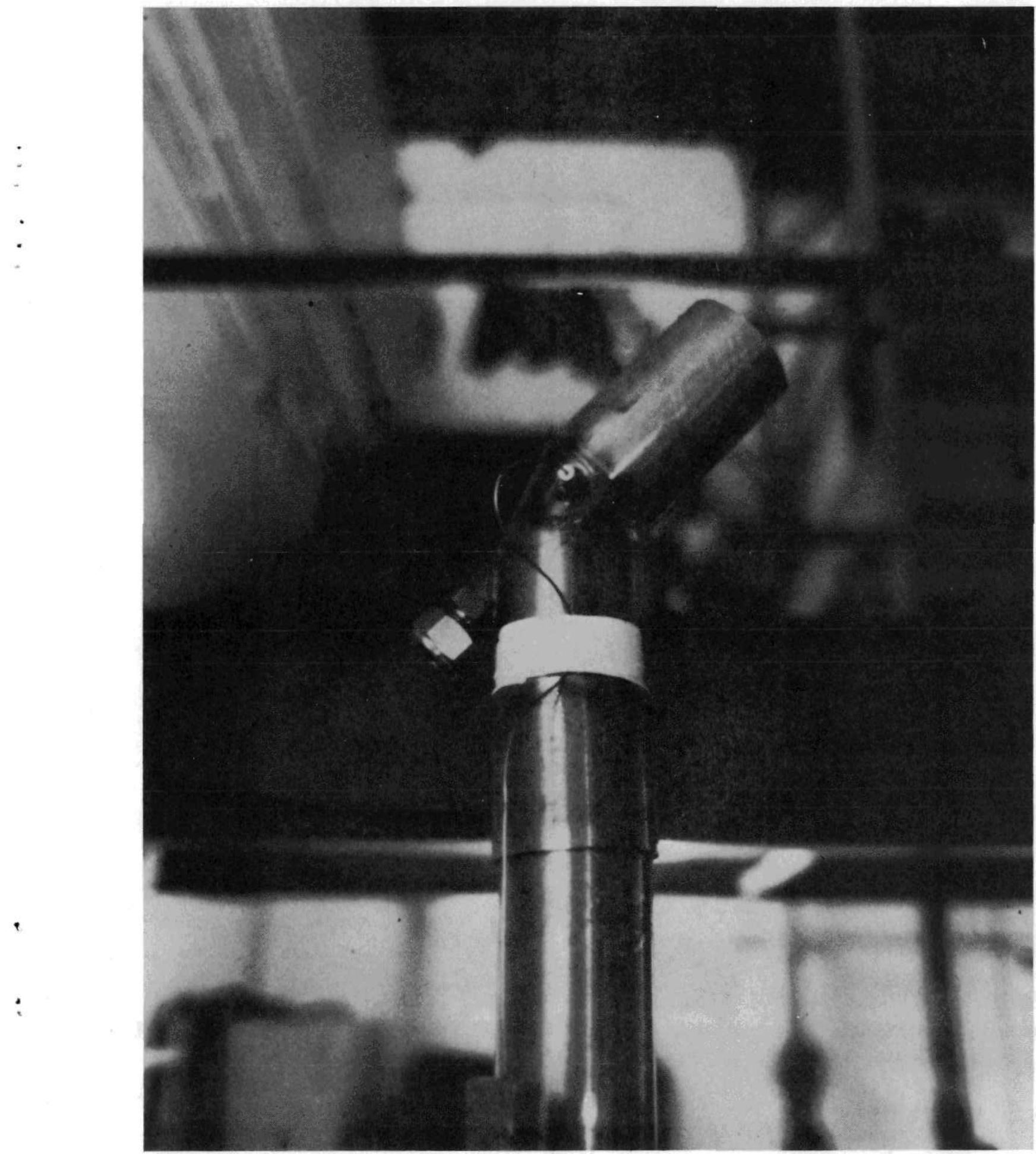

FIGURE 8. Gas Inlet Duct. Neg 800152-12cn 


\section{3-Hp RAM I BLOWER}

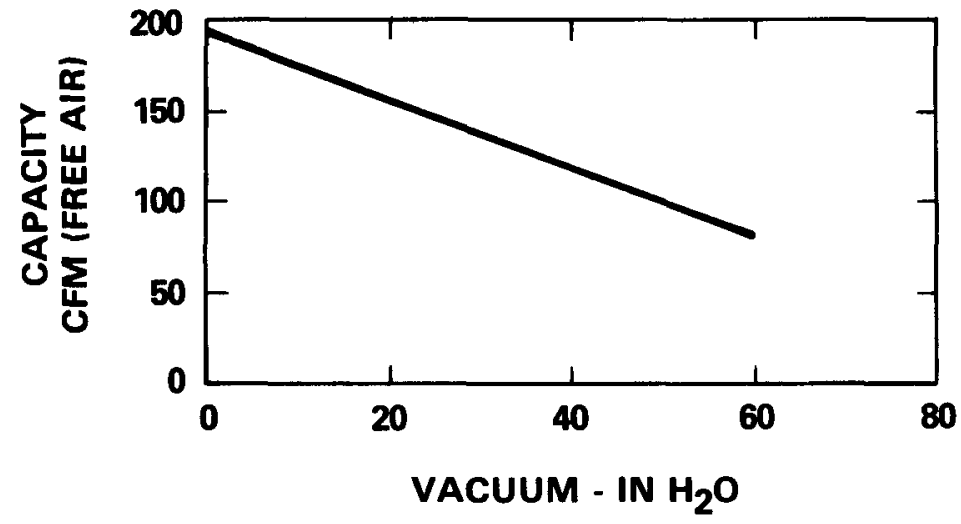

*TAKEN FROM MANUFACTURERS BROCHURE, 10-140, GAST MFG. CO., BENTON HARBOR, MICH. 49022

HEDL $8007-104.6$

FIGURE 9. Blower Performance Curve.

8007969-4

stream, and the gas downstream of the orifice. The differential gauges, available as Magnahelic gauges ${ }^{*}$, were used to measure the pressure drop across the gravel bed and the HEPA filter, and to measure the static pressure of the scrubber outlet and the blower inlet. The transducers were used to record the pressure drop across the packed bed and the orifice plate.

\subsection{HYDRAULIC TESTS}

A series of tests was performed to characterize the pressure drop across the scrubber and the water circulation rate through the bed for various bed configurations and operating conditions. The pressure drop dictates the energy requirements to operate the scrubber. The water circulation rate becomes important in assuring that enough water is present to cool the hot inlet gas stream and to dissolve and wash the collected aerosol from the bed. The

*Dwyer Instrument Company, Michigan City, Indiana 46360 
hydraulic tests were performed using room air and process water. The bed configurations tested, labeled $A$ through $\mathrm{H}$, are given in Table 1 . The bed labeled $A$ is the base bed design, and the experimental results discussed are generally for this case.

The submerged bed was observed during these tests to behave in an osci1latory manner. At low gas flowrates, gas from the inlet duct flowed up through the bed as discrete bubbles. Water flow through the bed was induced by the density difference of the liquid outside the bed and apparent density of the gas/liquid mixture inside the bed.

If the gas flowrate was increased further, the bed underwent a transition from bubble flow to slug flow. Gas then flowed upward through continuous channels in the bed. A layer of gas formed across the bottom of the bed which oscillated in thickness. Observations indicated that when the gas layer was increasing, water occupied a relatively large fraction of the bed

voids. The pressure drop through the bed was large enough that the gas entered the gas layer from the inlet duct faster than it could flow up through the bed. Eventually, the pocket of gas grew deep enough and the pressure 1 arge enough to force some of the interstitial water upward and out of the bed voids. This increased the area available for gas flow and the gas began to flow upward from the layer at a greater rate than the gas entered the layer. The gas layer shrank until the water contacted the bottom of the bed and began to fill up the voids. The gas entering from the inlet duct then began to form a new layer. The water slug that filled the lower portion of the bed was pushed upward by the gas. Part of the slug remained within the channels, again reducing the space available for gas flow and starting the cycle over.

The transition to oscillatory slug flow was gradual and occurred over the range of superficial gas velocities of 0.05 to 0.15 meters per second. The frequency of the pulses was about 27 cycles per minute and remained essentially constant over gas velocities of 0.13 to 0.51 meters per second. The 
TABLE 1

\section{HYDRAULIC TEST BED CONFIGURATIONS}

\begin{tabular}{cccl}
$\begin{array}{c}\text { Config- } \\
\text { uration }\end{array}$ & $\begin{array}{c}\text { Bed } \\
\text { Length } \\
(\mathrm{cm})\end{array}$ & $\begin{array}{l}\text { Type of } \\
\text { Support }\end{array}$ \\
\hline A & 61 & Screen \\
B & 61 & Plate \\
C & 61 & Plate \\
D & 61 & Plate \\
E & 46 & Plate \\
F & 46 & Plate \\
G & 61 & Plate (lower on ly) \\
& & \\
H & 46 & Plate \\
I & $-\cdots$ & ---
\end{tabular}

\begin{tabular}{ccc}
$\begin{array}{c}\text { Inlet } \\
\text { Duct } \\
\begin{array}{c}\text { Submergence } \\
(\mathrm{cm})\end{array}\end{array}$ & $\begin{array}{c}\text { Bed } \\
\text { Submergence } \\
(\mathrm{cm})\end{array}$ \\
\cline { 1 - 1 } 66 & & 0 \\
66 & & 0 \\
76 & & 0 \\
66 & & 0 \\
51 & & 0 \\
66 & & 18 \\
66 & & 0 \\
66 & & 0 \\
66 & & --
\end{tabular}

_-_._. Parameter Studied

Base Case

Type of Support

Inlet Duct Submergence

Packing Size

Bed Height/Inlet Duct Submeraence.

Bed Submergence

Bed Compression

(No top bed support)

Bed height

No packing 
velocity of the pulse of water moving up the bed and the amplitude, or maximum thickness of the gas layer, were measured at different gas velocities and the results are plotted in Figures 10 and 11 , respectively.

It is important to point out that the bed behaved in an oscillatory mode of operation for all tests that were performed at the specified flow velocities. Gas blown through the bed rather than pulled did not change the bed operation. Additional tests using other bed configurations, bed depths, blower size, and duct sizes all resulted in the bed oscillating. Thus, the oscillatory motion is believed to be characteristic of the submerged gravel bed, independent of blower and duct design.

The pressure drop across the packed bed for all bed configurations was substantially equivalent to the static head of water. The pressure drop varied, to a minor degree, as the depth of the gas layer changed. The pressure drop is plotted versus the gas velocity in Figure 12. A maximum pressure drop occurs at the gas velocity corresponding to the maximum gas layer thickness

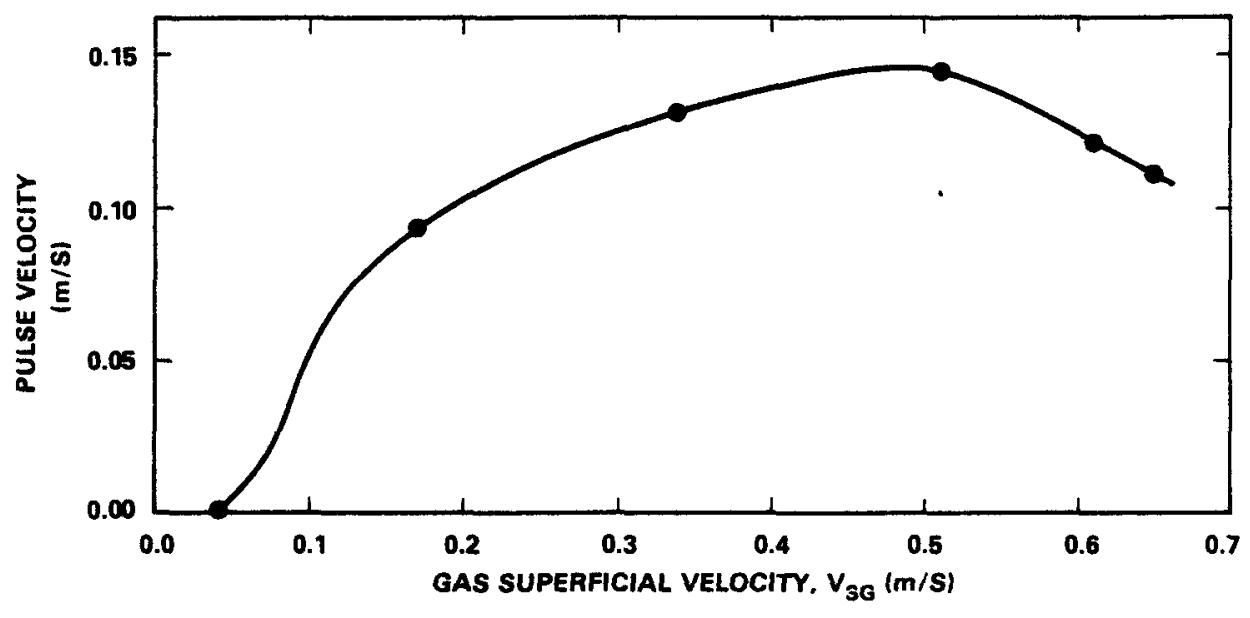

FIGURE 10. Water Pulse Velocity.

$808773-14$ 


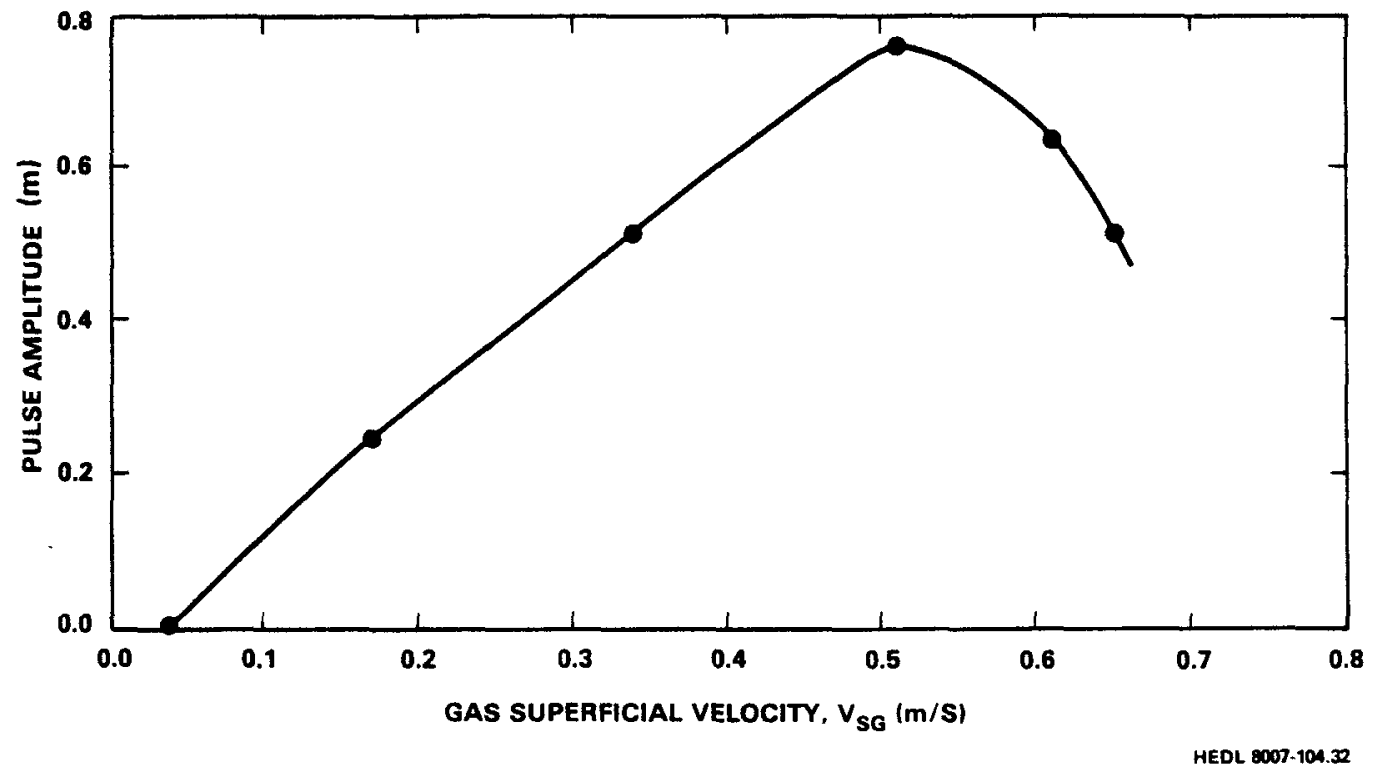

PO $8773-7$

FIGURE 11. Water Pulse Amplitude.

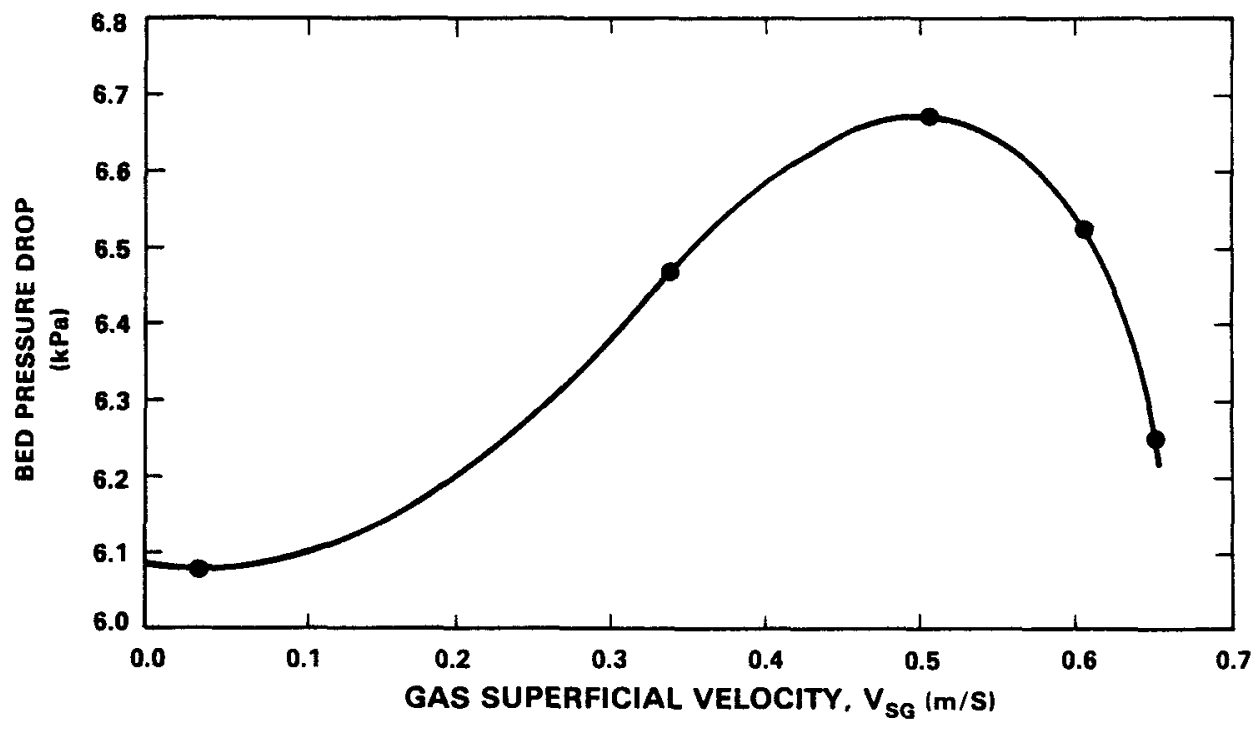

HEOL $8007-104.35$

FIGURE 12. SGS Pressure Drop.

P0 9264-1 
and to the maximum water slug velocity. The pressure drop across a dry bed (Case A configuration) was measured and is plotted in Figure 13. The dry bed packing density was $1.48 \mathrm{~g} / \mathrm{cm}^{3}$.

A drain ring, Figure 14, was fabricated to measure the rate at which water was pumped through the submerged bed. The ring fit over the outer bed support such that water spilling over the top of the bed would drain into the ring. The ring drained into a flexible $5-\mathrm{cm}$ tube that penetrated the wall of the tank and led to a drain. Makeup water was piped through a pair of rotameters and then to a fitting through the side of the tank. By adding water at a rate to keep the tank level constant, the equivalent water overflow rate could be read from the rotameter.

Whereas the bulk of the water was pumped through the bed in pulses, the average flow rate was measured. Figure 15 shows the superficial liquid velocity as a function of the superficial gas velocity. For Configuration $A$, the maximum water pumping rate was observed at a gas velocity of about 0.25 meters per second. The maximum in the curve is attributed to changing driving forces and varying bed resistance. At low gas velocities, increasing the gas flowrate increased the gas-to-liquid ratio inside the bed, thereby reducing the effective liquid density. Water flowed from outside of the bed into the bottom and up through the packing. The packing voids were predominantly filled with water, and thus presented a formidable resistance to the two-phase fluid flow.

At higher gas velocities, pulsing began to occur, as discussed previously. Water entered the bed as a slug and was pushed upward by the gas. Gas mixed with the slug as the slug moved upward, forming a two-phase slug. Increasing the gas velocity resulted in a greater fraction of the slug being evacuated from the bed for each pulse. At a sufficiently high gas velocity, the voids were kept relatively free of fluid and the pulse magnitude was reduced. Water was in contact with the bed for a shorter period of time and less liquid entered the bed at each pulse. At very high velocities, the bed was kept blown dry of liquid and a layer of non-pulsating gas existed across the bottom of the bed. 


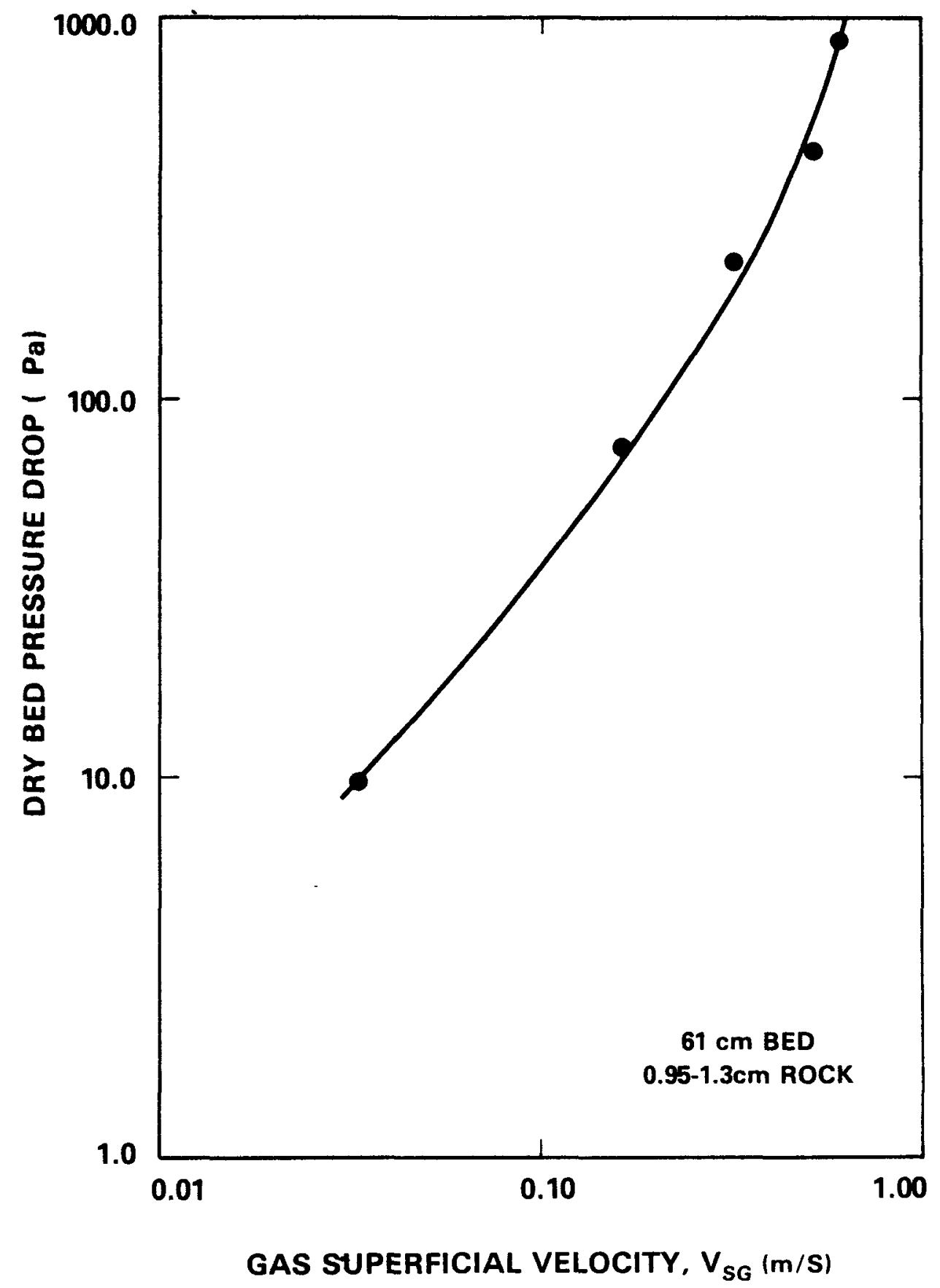

HEDL $8007-104.34$

FIGURE 13. Dry Bed Pressure Drop.

P0 8773-11 

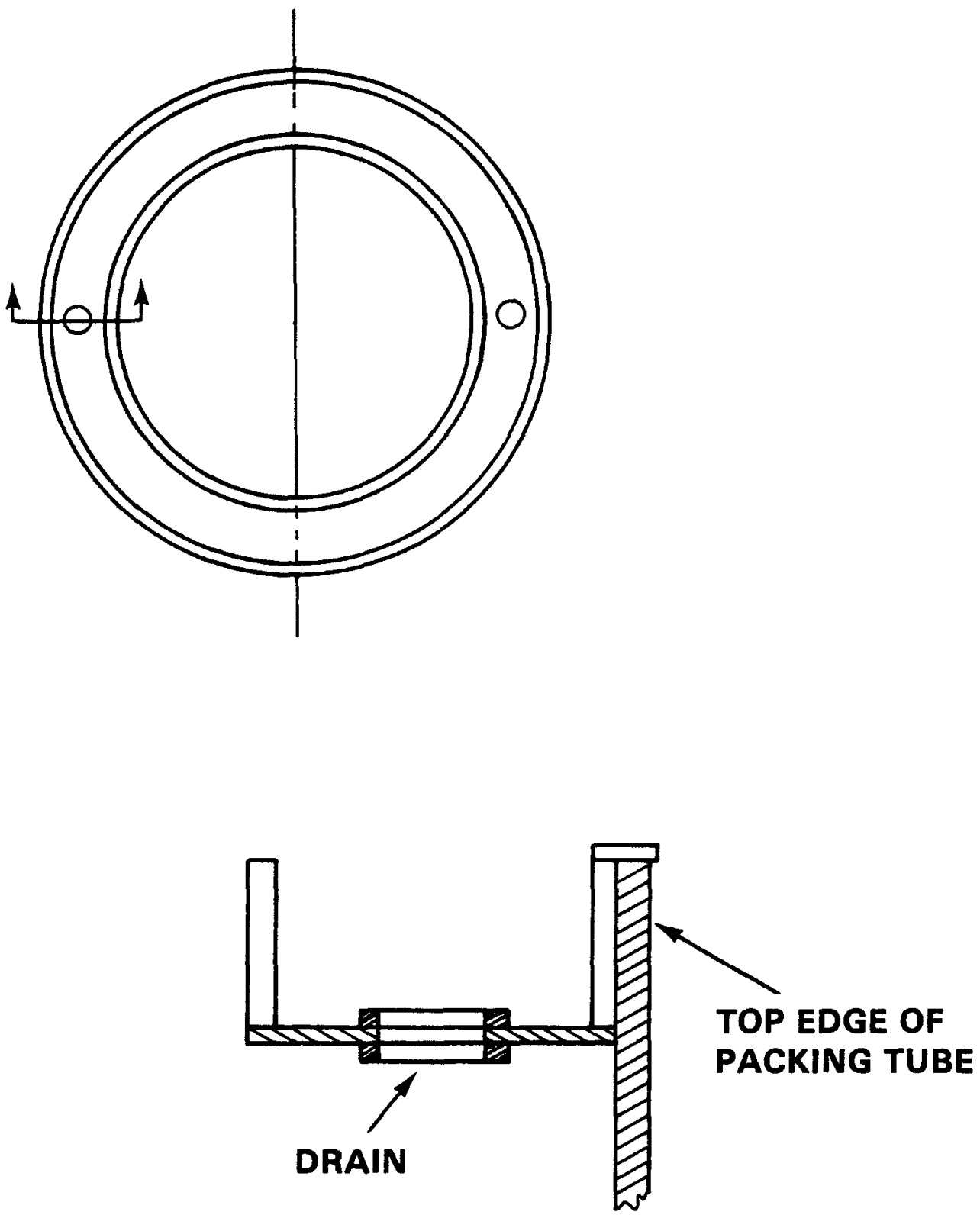

HEDL 8007-104.2

FIGURE 14. Drain Ring. 


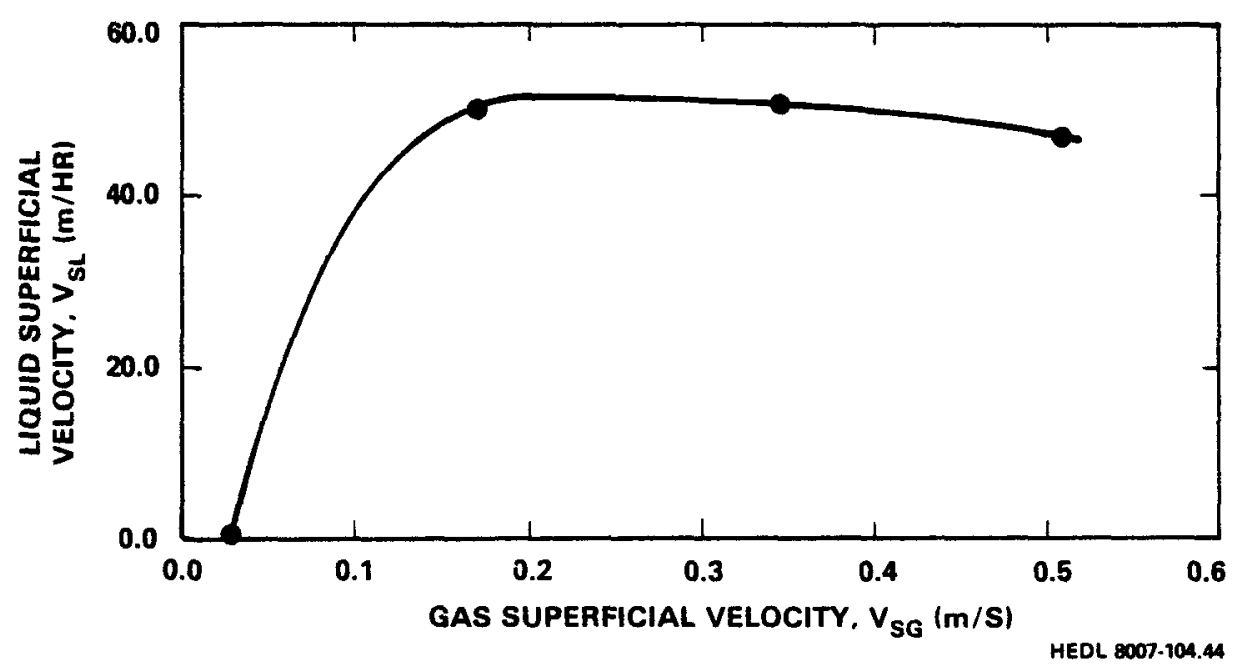

FIGURE 15. Liquid Superficial Velocity, Configuration A.

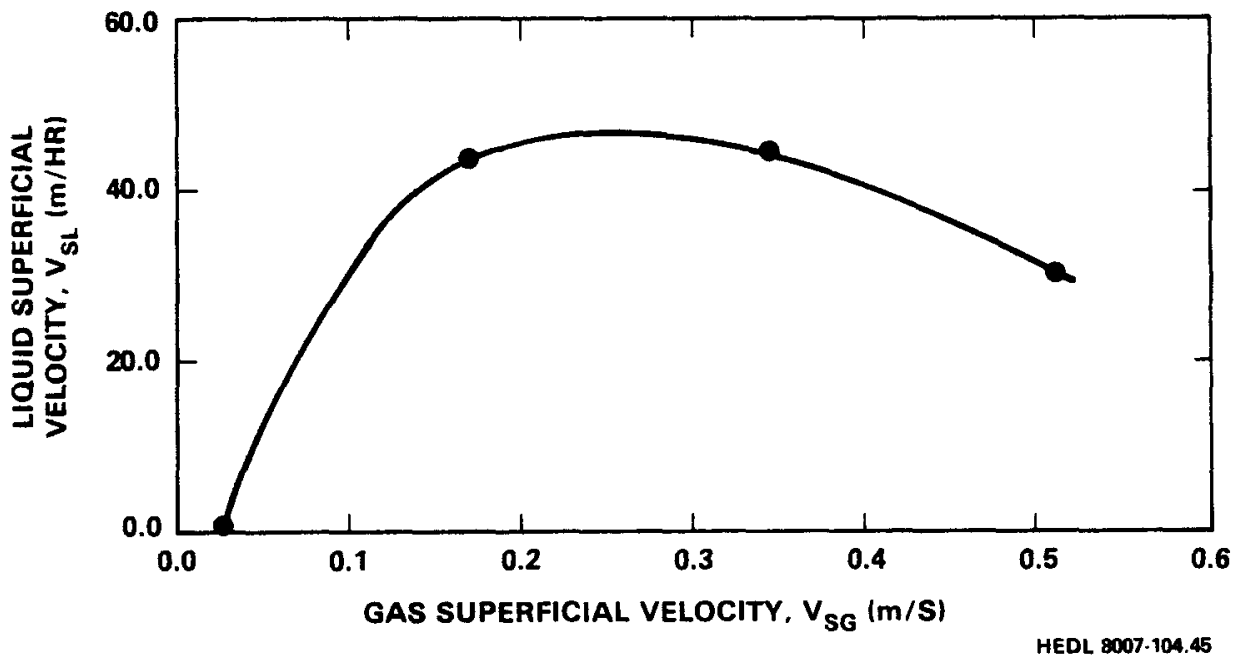

FIGURE 16. Liquid Superficial Velocity, Configuration B. 
Figures 16 through 23 are plots of the average liquid velocity as a function of the gas velocity for the other bed configurations. Each curve exhibits a maximum except Figure 23, which is a graph for a bed without packing. Evaluation of these curves indicates that the packing size, bed length, and inlet duct submergence were important parameters in affecting the liquid pumping rate. Figure 24 is a plot of the liquid velocity as a function of the packing size. The superficial gas velocity is shown as a parameter. Increasing the rock size decreased the bed resistance to fluid flow; therefore, more liquid was pumped.

The liquid velocity as a function of bed depth is shown in Figure 25 . The liquid velocity increased as the bed resistance was reduced by decreasing the bed length. One point is plotted for the case of no packing, or zero bed length. The curves indicate that there is a finite bed length at which no liquid would be pumped through the bed. Increasing the inlet duct submergence, or the depth of the exit of the inlet tube below the surface, increased the liquid pumping rate. This is shown in Figure 26 for a $0.46-\mathrm{m}$ long bed. Additional duct submergence resulted in increased energy delivered to the system that was available for inducing water flow.

A comparison of Figure 15 and Figure 16 shows that the type of packing support has a second-order effect on the liquid pumping rate; the bed configuration using the screen support showed a slightly greater liquid velocity. For a fixed inlet duct submergence, lowering the bed further into the water made no measurable difference in the liquid pumping rate, as shown by comparing Figures 20 and 22.

The hydraulic tests showed that the dominant factor in the pressure drop was the inlet duct submergence. The pressure drop across the bed was influenced by the gas flowrate only in that a gas layer formed across the bottom of the bed, and the thickness of this layer was a function of the gas flowrate. The total pressure drop was equivalent to the inlet duct submergence plus the gas layer thickness. The results also showed that the bed pumped a significant flow of water through the packing and, due to the way in which 


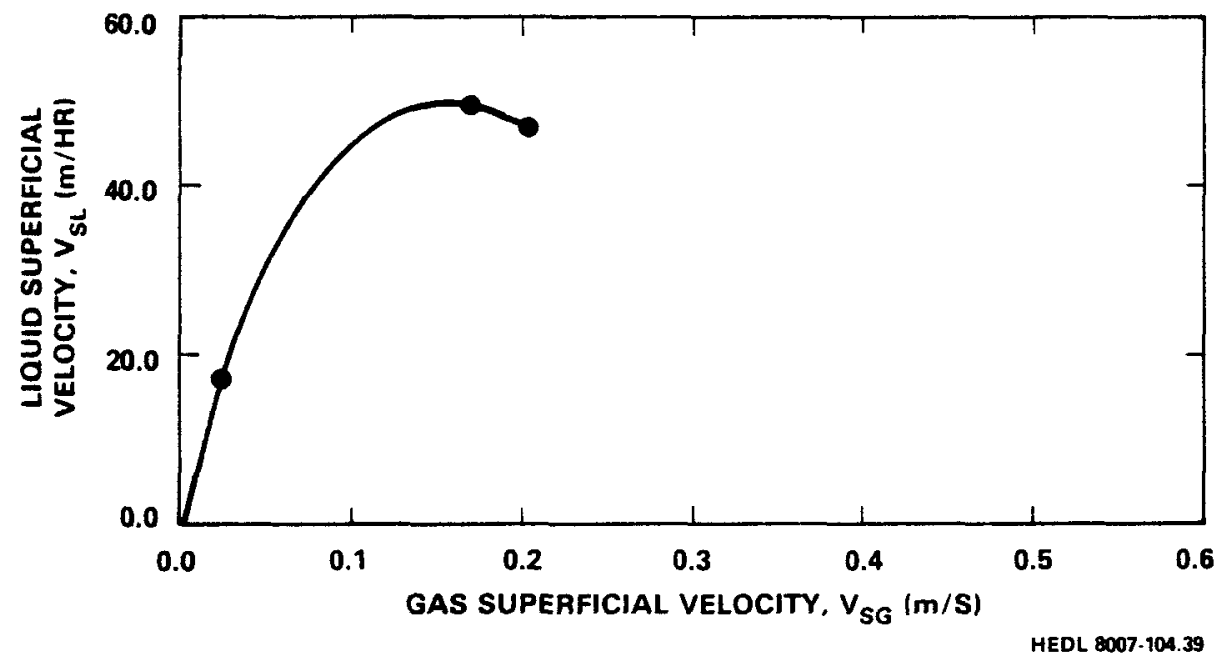

FIGURE 17. Liquid Superficial Velocity, Configuration C.

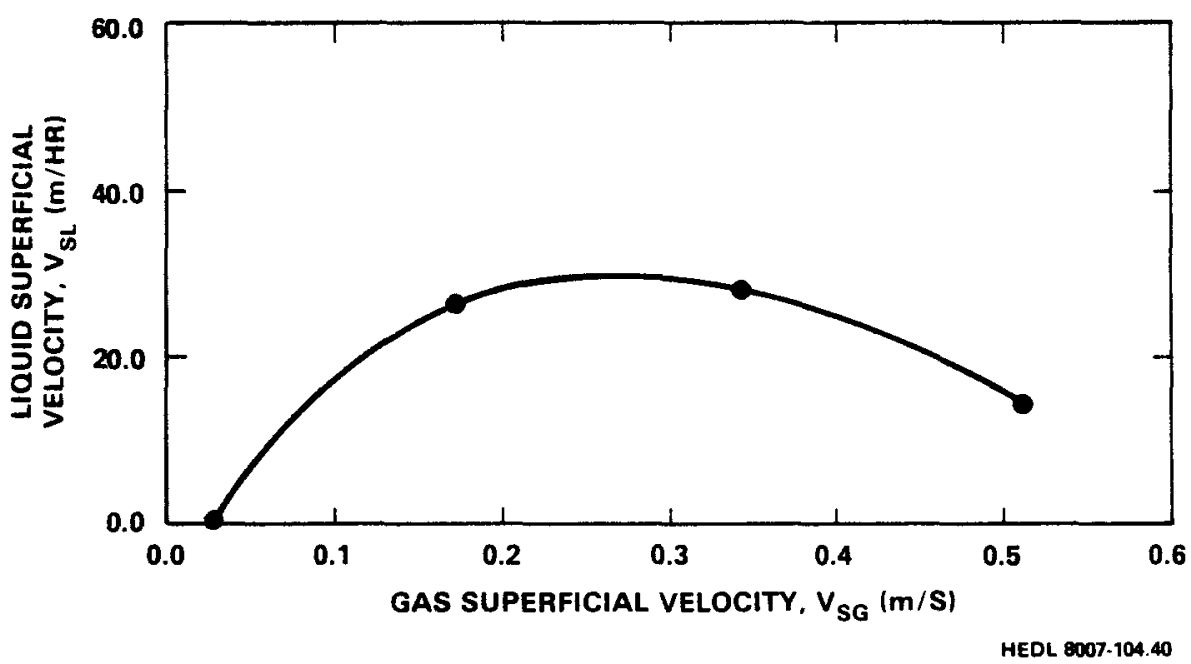

FIGURE 18. Liquid Superficial Velocity, Configuration D. 


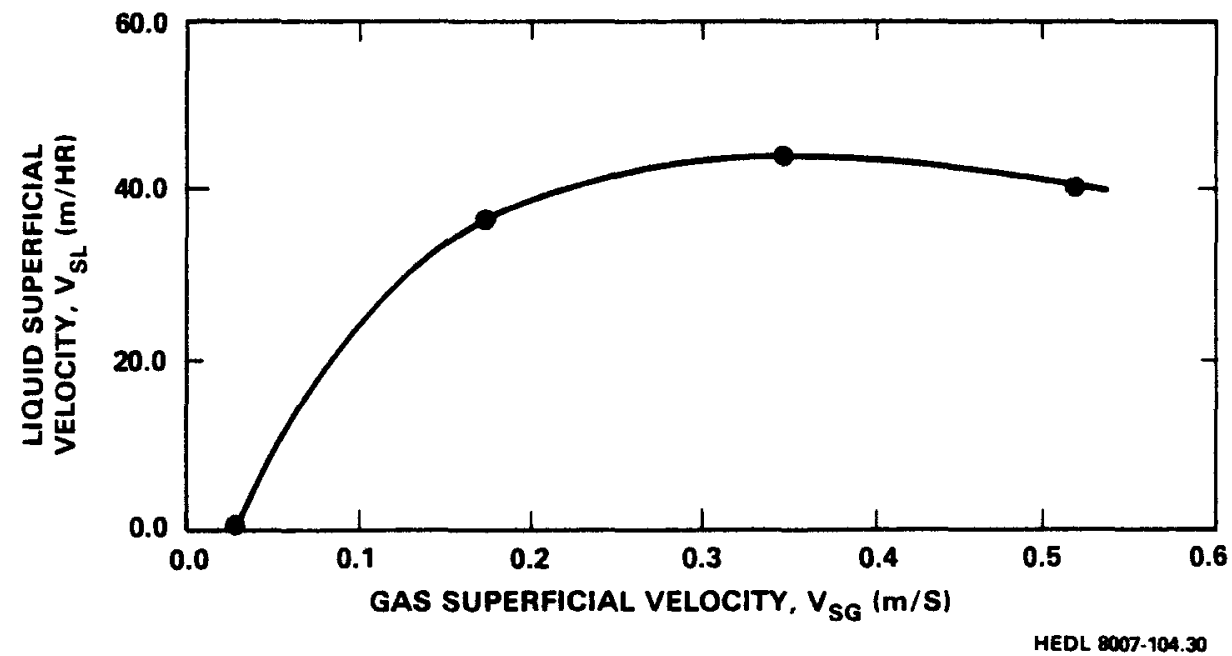

FIGURE 19. Liquid Superficial Velocity, Configuration E.

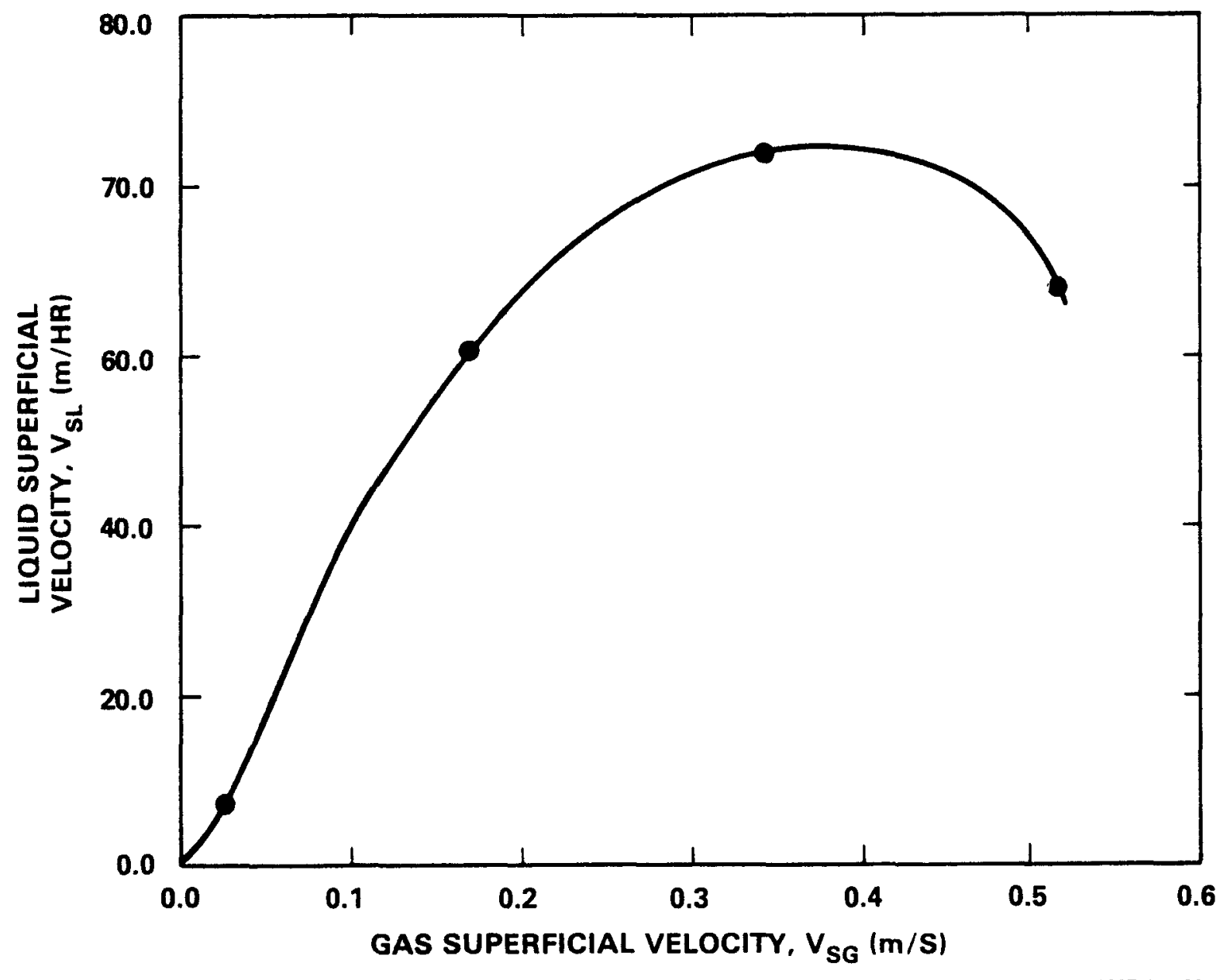

HEDL $8007-104.36$

FIGURE 20. Liquid Superficial Velocity, Configuration F. 


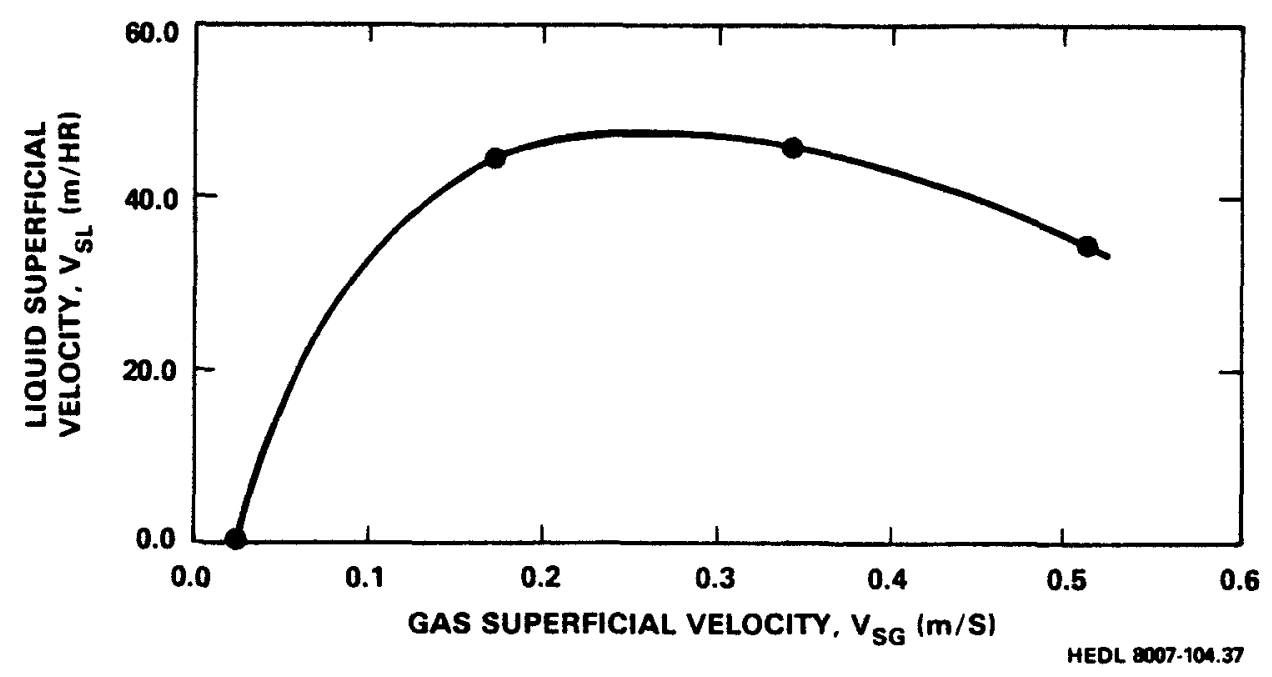

FIGURE 21. Liquid Superficial Velocity, Configuration G.

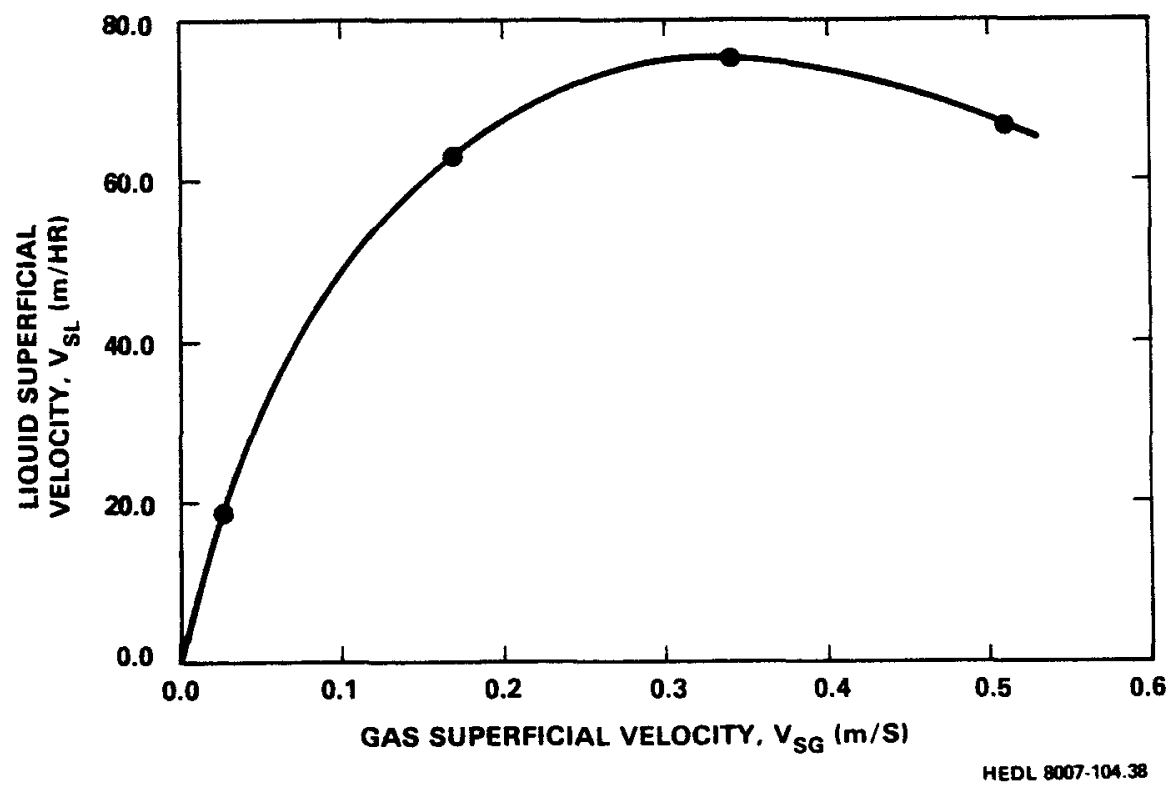

P08773-13

FIGURE 22. Liquid Superficial Velocity, Configuration H. 


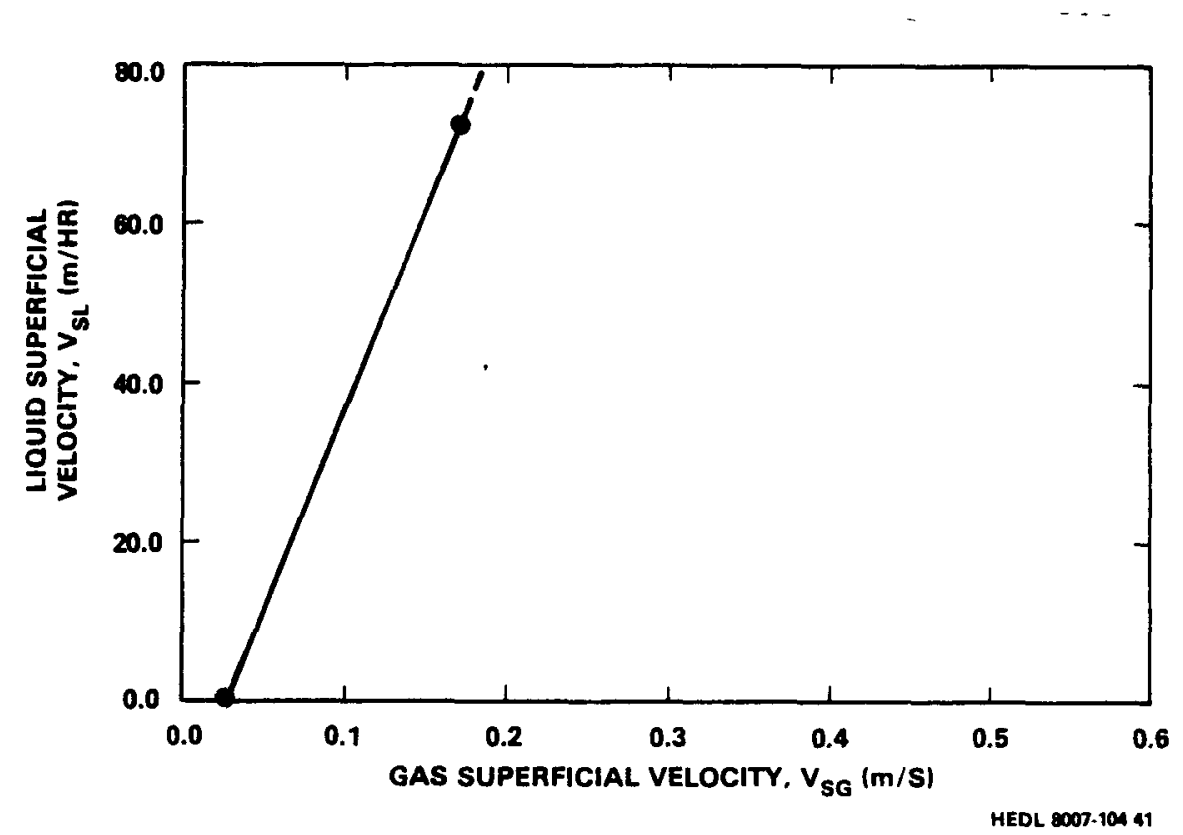

P08773-9

FIGURE 23. Liquid Superficial Velocity, Configuration I.

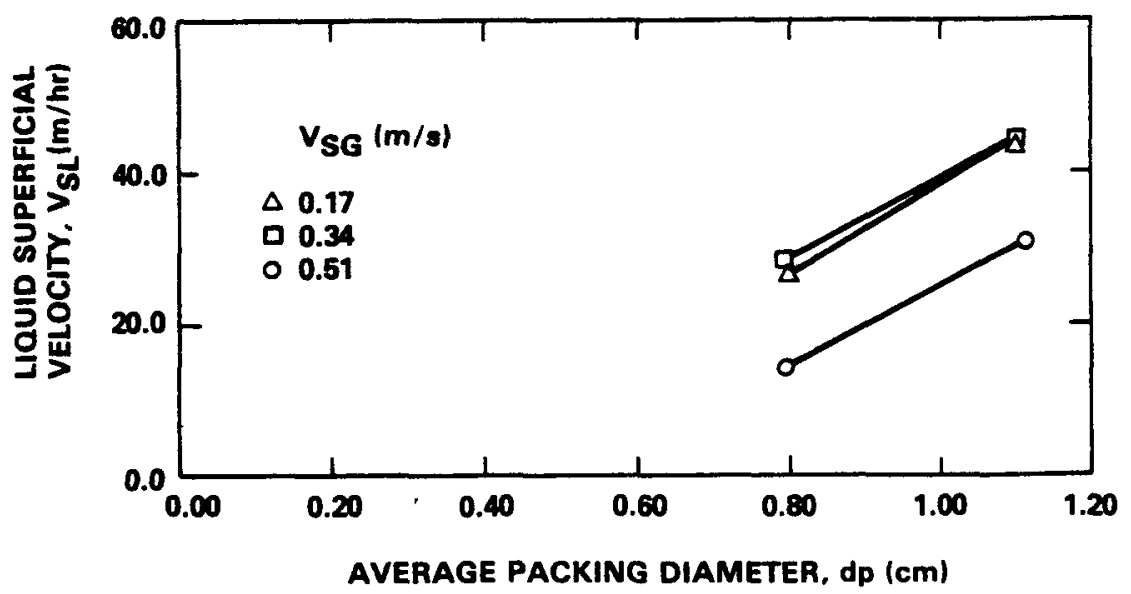

HEDL $2007-2225$

P08941-2

FIGURE 24. Packing Size Effect on Liquid Velocity. 


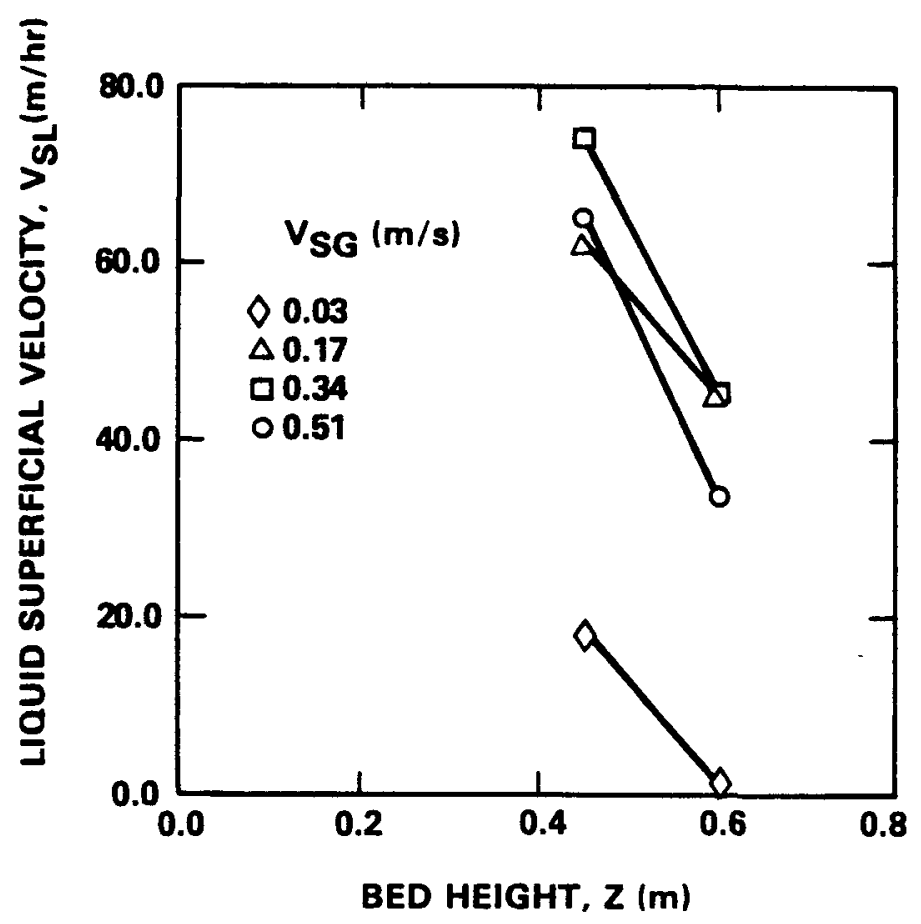

HEDL 8007.202.4

FIGURE 25. Bed Height Effect on Liquid Velocity.

P0894T-3

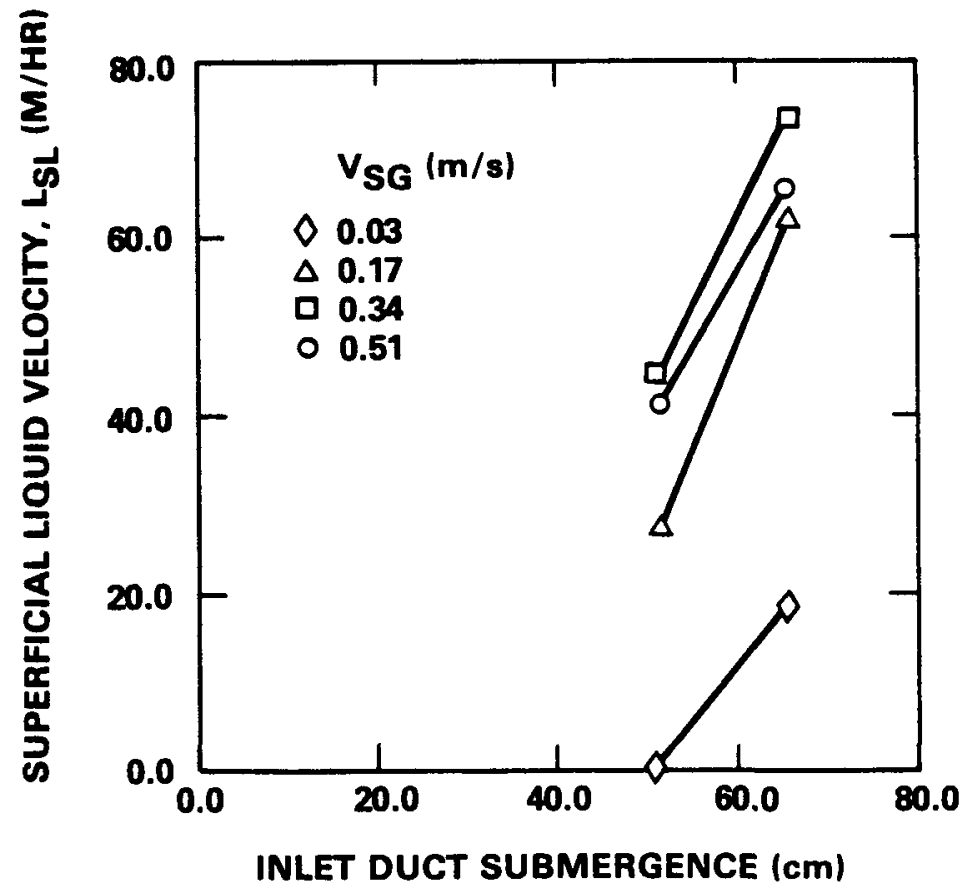

HEDL 8007.222 .6

FIGURE 26. Inlet Duct Submergence Effect on Liquid Velocity. 
the pumping took place, the entire surface area of the packing was washed with each pulse.

Pressure drop considerations dictate a minimum length of bed to reduce the power consumption to operate the bed. Water pumping results indicate that a bed configuration with a short bed, large rocks, and a deep inlet duct submergence would be preferred. To evaluate the effect of these parameters on the aerosol removal capability of the submerged bed, a series of efficiency tests was made.

\subsection{EFFICIENCY TESTS}

Six tests were performed using various sodium aerosols to measure the SGS particulate removal efficiency. The aerosol sources were created for other research efforts and this discussion shall be limited to a description of the aerosol characteristics. Limited information describing the facilities for generating the aerosols are given in Appendix $A$. In general, the aerosols were created by either spilling liquid sodium metal into a shallow pan, or spraying liquid sodium metal through nozzles, in both cases into an air atmosphere. The sodium metal reacted with the oxygen and water vapor in the smoke chamber atmosphere by the following reactions ${ }^{(6)}$ :
(a) $\quad 4 \mathrm{Na}+\mathrm{O}_{2} \longrightarrow 2 \mathrm{Na}_{2} \mathrm{O}$
(b) $\quad 2 \mathrm{Na}+\mathrm{O}_{2} \longrightarrow \mathrm{Na}_{2} \mathrm{O}_{2}$
(c) $\quad 2 \mathrm{Na}+2 \mathrm{H}_{2} \mathrm{O} \longrightarrow 2 \mathrm{NaOH}+\mathrm{H}_{2}$

The products formed produced an aerosol that was carried from the fire by convection currents which eventually dispersed the aerosol throughout the test chamber. The aerosol reacted further with water vapor, carbon dioxide and oxygen in the chamber atmosphere by the following reactions ${ }^{(6)}$ :
(d) $2 \mathrm{NaOH}+\mathrm{CO}_{2}$
(e) $2 \mathrm{Na}_{2} \mathrm{O}_{2}+2 \mathrm{H}_{2} \mathrm{O}$
(f) $\mathrm{Na}_{2} \mathrm{O}+\mathrm{H}_{2} \mathrm{O}$
(g) $\quad 2 \mathrm{Na}_{2} \mathrm{O}+\mathrm{O}_{2}$

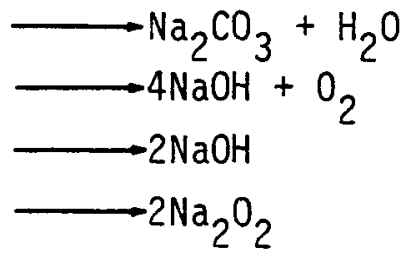


The extent of these reactions depended on the residence time, relative humidity, and atmospheric gas composition. Essentially all the carbon dioxide was used to convert sodium hydroxide to the carbonate form. Very little sodium monoxide existed as aerosol, having been converted to either sodium hydroxide or sodium peroxide.

Aerosol was delivered to the scrubber from the aerosol chamber through a 5.7-m long, 10-cm ID flexible duct. Aerosol losses in the duct were signficant; therefore, inlet aerosol composition was measured at the connecting adapter between the scrubber and this duct.

The aerosol concentration was measured at the inlet and exit of the scrubber by inserting filter holders (stainless steel holders, Gelman ${ }^{\star}$ Catalog no. $2220)$ into the gas streams. The filter holders were connected to a rotameter, vacuum gauge, and a vacuum source. Gas was drawn through the holder at a constant rate for a measured length of time. The filter media for the inlet stream was fiberglass (Gelman ${ }^{\star}$ type $A E$ ). The fiberglass media had a high loading capacity, but contained approximately $0.25 \mathrm{mg} \mathrm{Na}$. This reduced the accuracy of low concentration samples. Therefore, the outlet samples were made with a membrane filter (Ge iman Accupor 3000) with a low background level of approximately $0.02 \mathrm{mg} \mathrm{Na}$. A disassembled filter holder is shown in Figure 27.

Aerosol particle size distributions were obtained by using cascade impactors inserted into the gas stream. Two types of multi-jet impactors, an 8-stage circular jet impactor (Anderson Mark III High Temperature Sampler ${ }^{\star \star}$ ) and a 6-stage rectangular jet impactor (Sierra Model 226 Stack Sampler ${ }^{* * *}$ ) were used. Figures 28 and 29 are photographs of these impactors. The impactor analysis is described in Appendix B.

\footnotetext{
*Gelman Instrument Company, Ann Arbor, Michigan 48106

**Manuf actured by Anderson 2000, Inc., Atlanta, Georgia 30320

$\star \star \star$ Manufactured by Sierra Instrument Company, Carmel Valley, California
} 


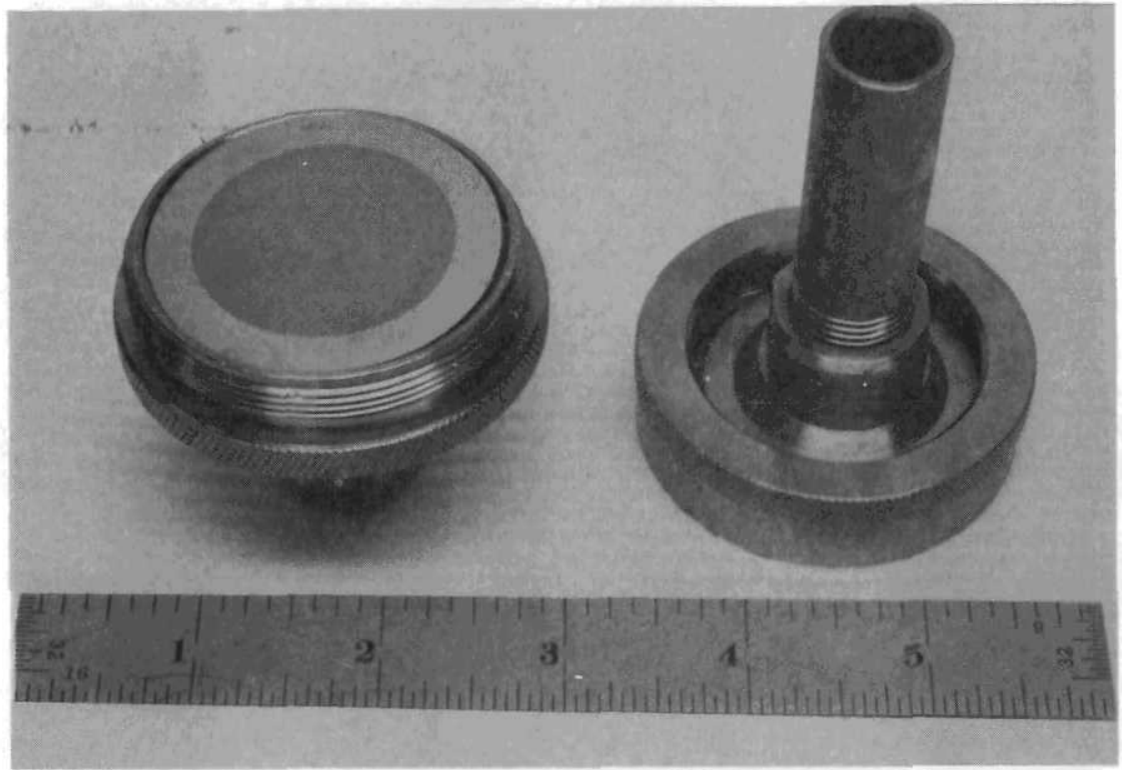

FIGURE 27. Filter Holder.

Neg 7803063-34

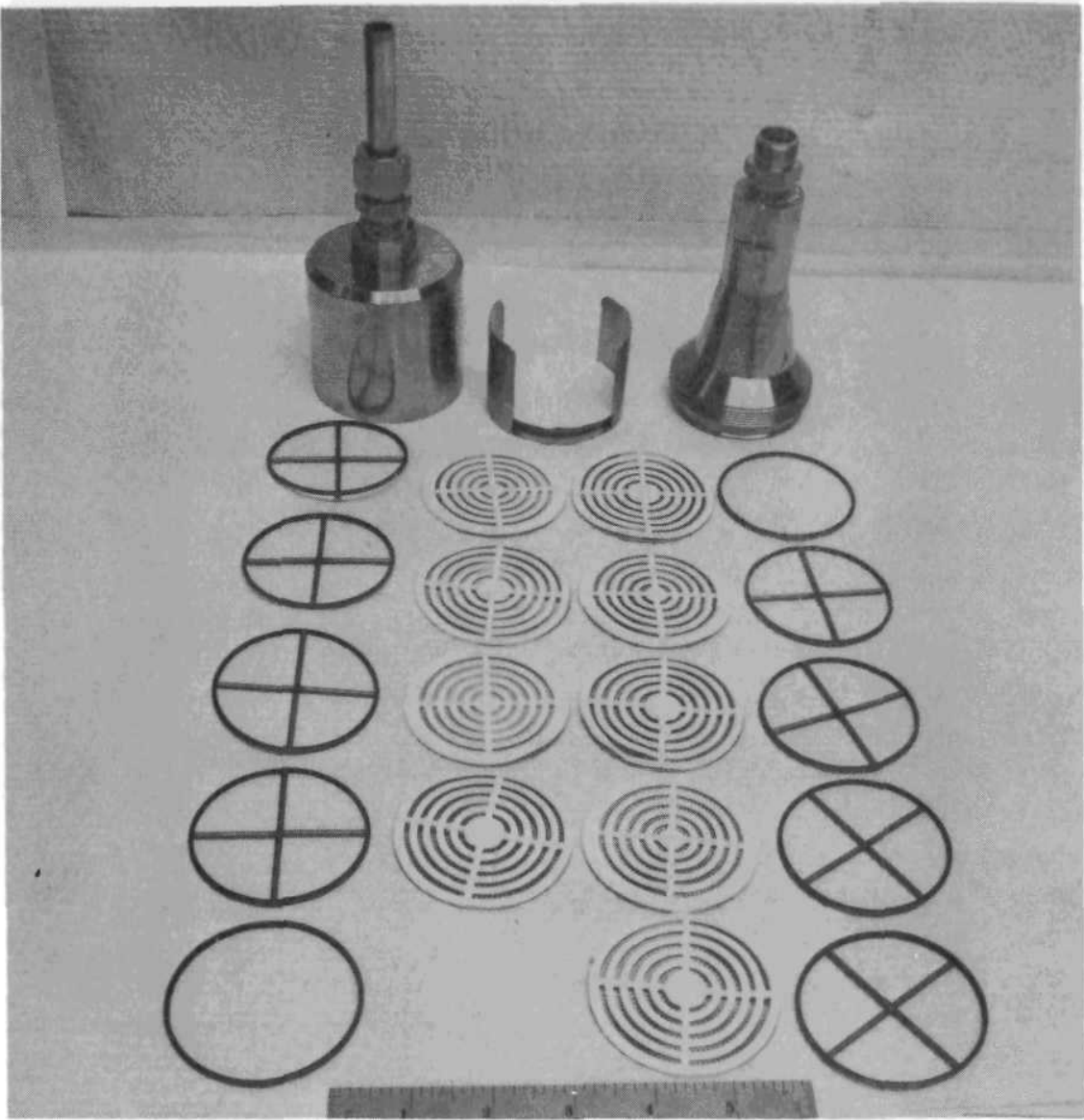

FIGURE 28. Circular Jet Impactor.

Neg 7803063-34 


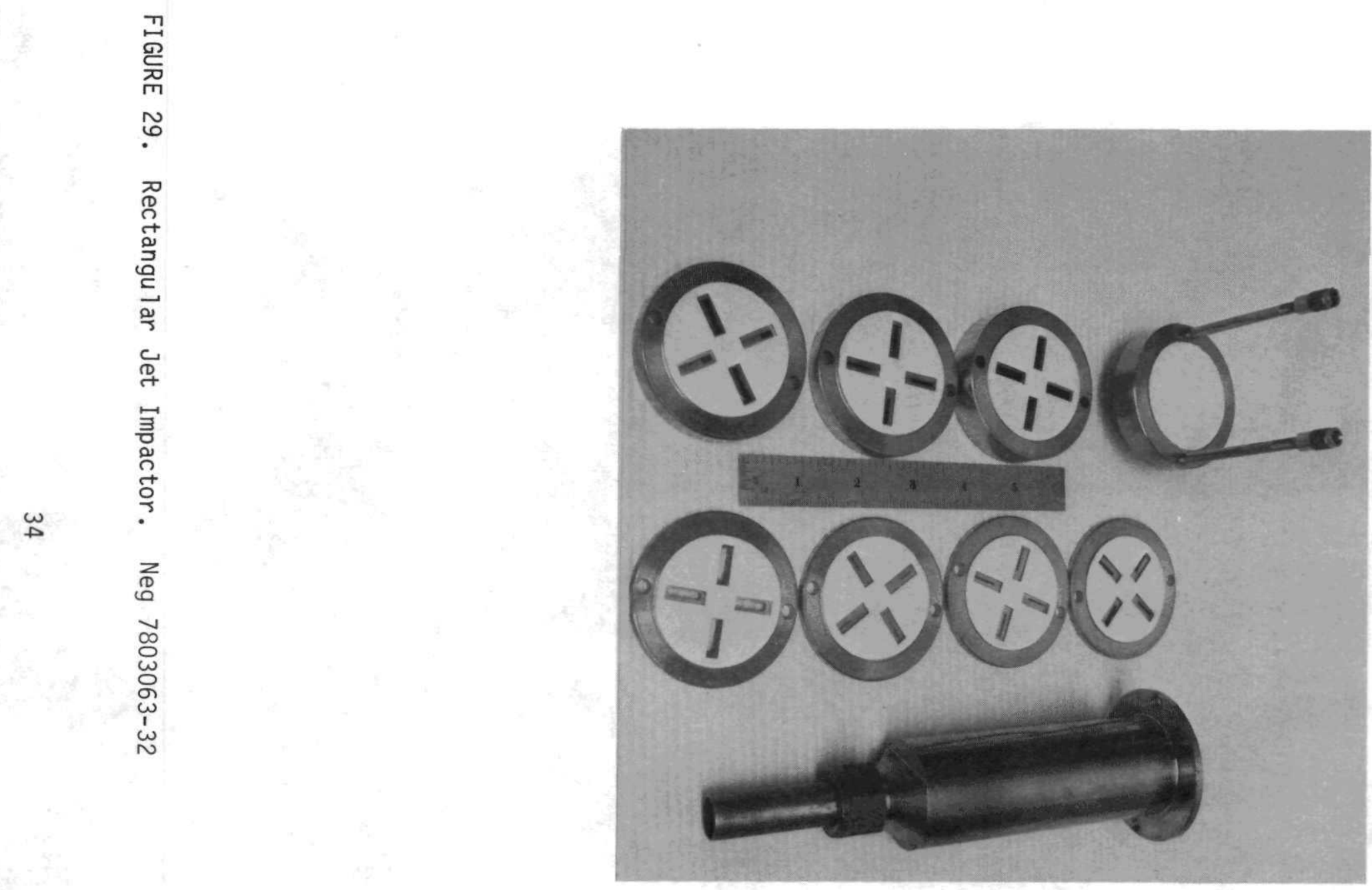

$\bullet$ 
The filter media from the various aerosol samples were leached with demineralized water and analyzed for sodium by acid titrimetry or emission spectrometry. Blank corrections were made to account for background sodium in the filter media and demineralized water.

The chemical forms of aerosol were analyzed by a combination of methods:

- X-ray diffraction provided information on crystalline forms $\left(\mathrm{Na}_{2} \mathrm{O}, \mathrm{NaOH}\right.$ and hydrates).

- Sodium peroxide was determined by reaction with iodide ions, giving free iodine which was then titrated with thiosulfate.

- Sodium carbonate was determined by potentiometric acid titration. Sodium carbonate gives inflections at known pHs. For a sample with a low fraction of carbonate $(\sim 5 \%)$, the $\mathrm{CO}_{2}$ was liberated with acid and the quantity of $\mathrm{CO}_{2}$ released was measured by gas chromatography.

- Sodium hydride was determined by measuring the quantity of $\mathrm{H}_{2}$ released by gas chromatography when the sample was added to water. If metallic sodium was present, hydrogen was released from both sources.

- The total sodium content was determined by flame emission spectrometry of a water solution.

- A material balance was performed to account for all forms detected.

Liquid samples from the scrubber tank were taken before, during, and after each experimental test. The samples were analyzed for sodium by acid 
titrimetry or emission spectrometry. The liquid concentrations, coupled with the tank liquid volume, gave the integrated aerosol mass that had been collected.

The backup HEPA filter was disassembled for each test and leached with demineralized water. The water was analyzed by emission spectrometry for sodium. The average aerosol removal efficiency was then determined using the amount of sodium mass that penetrated the scrubber to the HEPA filter and the total mass that entered the scrubber (sodium in the liquid plus sodium on the HEPA filter).

The test conditions are given in Table 2. The ' $E$ ' type of tests were performed using aerosols generated by a sodium pool fire in a $300 \mathrm{~m}^{3}$ room. The aerosol composition was predominantly $\mathrm{Na}_{2} \mathrm{O}_{2}$. The ' $\mathrm{AC}$ ' type of tests were made in a $850 \mathrm{~m}^{3}$ vessel using a sodium spray. In test $A C 3$, carbon dioxide gas and steam were added to the vessel to form $\mathrm{Na}_{2} \mathrm{CO}_{3}$ aerosol. Steam was injected into the vessel at different rates in tests $A C 4, A C 5$ and $A C 6$, thereby producing $\mathrm{NaOH}$ aerosols with different numbers of associated waters. The scrubber inlet aerosol concentrations were measured by aerosol sampling at the entrance of the scrubber to account for aerosol deposition in the duct. Plots of the source chamber aerosol concentrations for each of the tests are shown as a function of the run time in Figures 30 through 36 . The run time was considered the time in minutes after the initiation of the sodium pool or spray fire.

The sodium reactions are exothermic and as a consequence the source chamber atmosphere heats up. The gas is cooled as it passes through the scrubber by evaporation of water and sensible heat transfer. The scrubber inlet and outlet gas temperatures and the scrubber liquid temperatures are shown in Figures 37 through 43. 
TABLE 2

AEROSOL TEST CONDITIONS

\begin{tabular}{|c|c|c|c|c|}
\hline Test & Aerosol Source (a) & Aerosol Type & Test Duration (hr) & $\begin{array}{l}\text { Gas Superficial } \\
\text { Velocity (m/min) (b) }\end{array}$ \\
\hline SGS-AC3 & Spray Fire, CSTF & $\mathrm{Na}_{2} \mathrm{CO}_{3}$ & 9.7 & $2-30$ \\
\hline SGS-E1 & Pool Fire, LSFF & $\mathrm{Na}_{2} \mathrm{O}_{2} / \mathrm{NaOH}$ & 4.3 & $1.2-22$ \\
\hline SGS-E2 & Pool Fire, LSFF & $\mathrm{Na}_{2} \mathrm{O}_{2} / \mathrm{NaOH}$ & 2.7 & $2-27$ \\
\hline SGS-E3 & Pool Fire, LSFF & $\mathrm{Na}_{2} \mathrm{O}_{2} / \mathrm{NaOH}$ & 4.0 & $0.8-20$ \\
\hline SGS-AC4 & Spray Fire, CSTF & $\mathrm{NaOH} 2 . \mathrm{OH}_{2} \mathrm{O}$ & 24 & $17-27$ \\
\hline SGS-AC5 & Spray Fire, CSTF & $\mathrm{NaOH} 0.2 \mathrm{H}_{2} \mathrm{O}$ & 20 & $10-30$ \\
\hline SGS-AC6 & Spray Fire, CSTF & $\mathrm{NaOH} 1 . \mathrm{OH}_{2} \mathrm{O}$ & 7.4 & $10-20$ \\
\hline
\end{tabular}

(a) CSTF - Containment System Test Facility; $850 \mathrm{~m}^{3}$ vesse 1 LSFF - Large Scale Fire Facility; $330 \mathrm{~m}^{3}$ room

(b) Based on bed cross section area of $0.07 \mathrm{~m}^{2}$ 


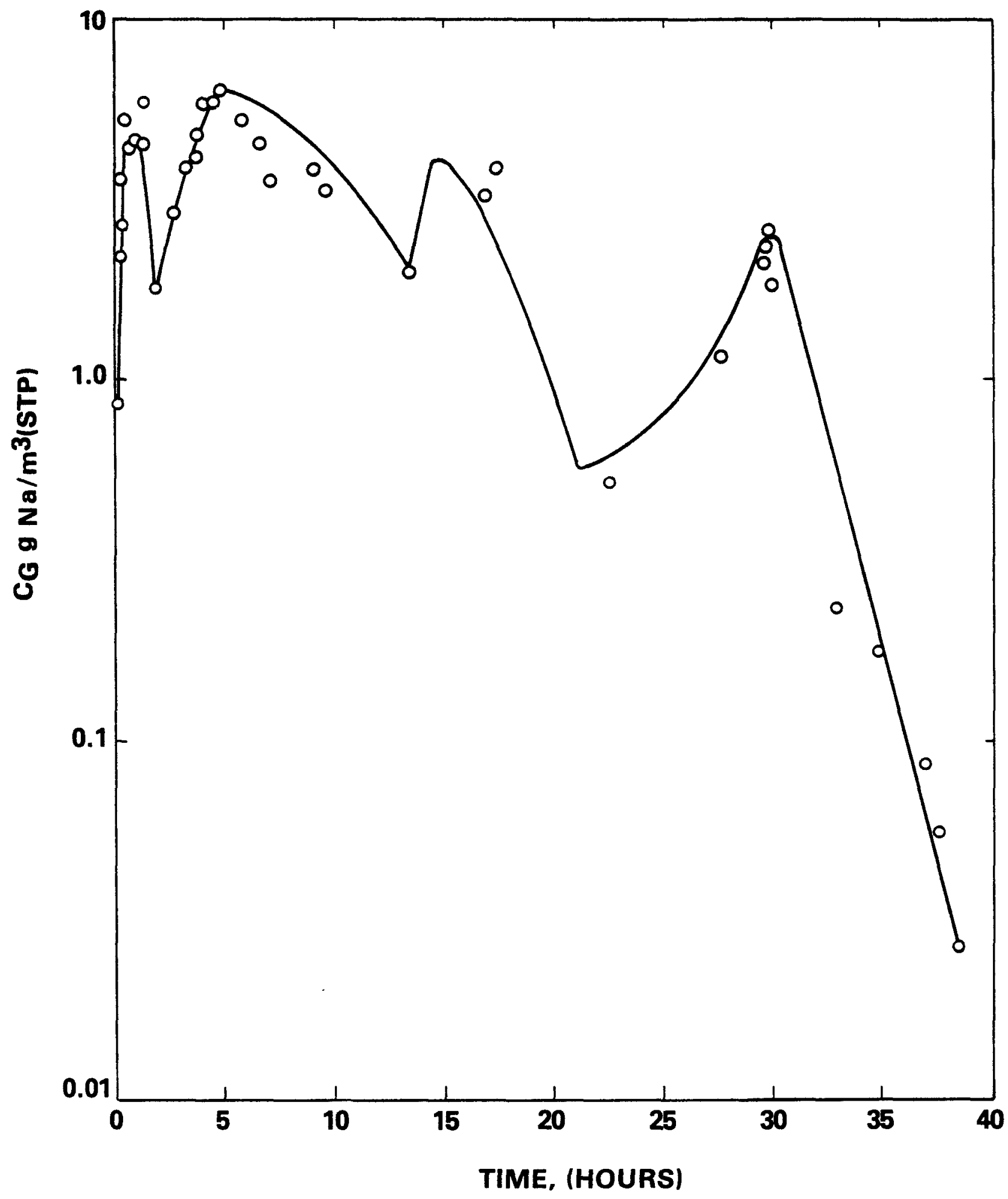

HEDL 8009-290.1

FIGURE 30. Source Aerosol Concentration, Test SGS-AC3. 8010974-1 


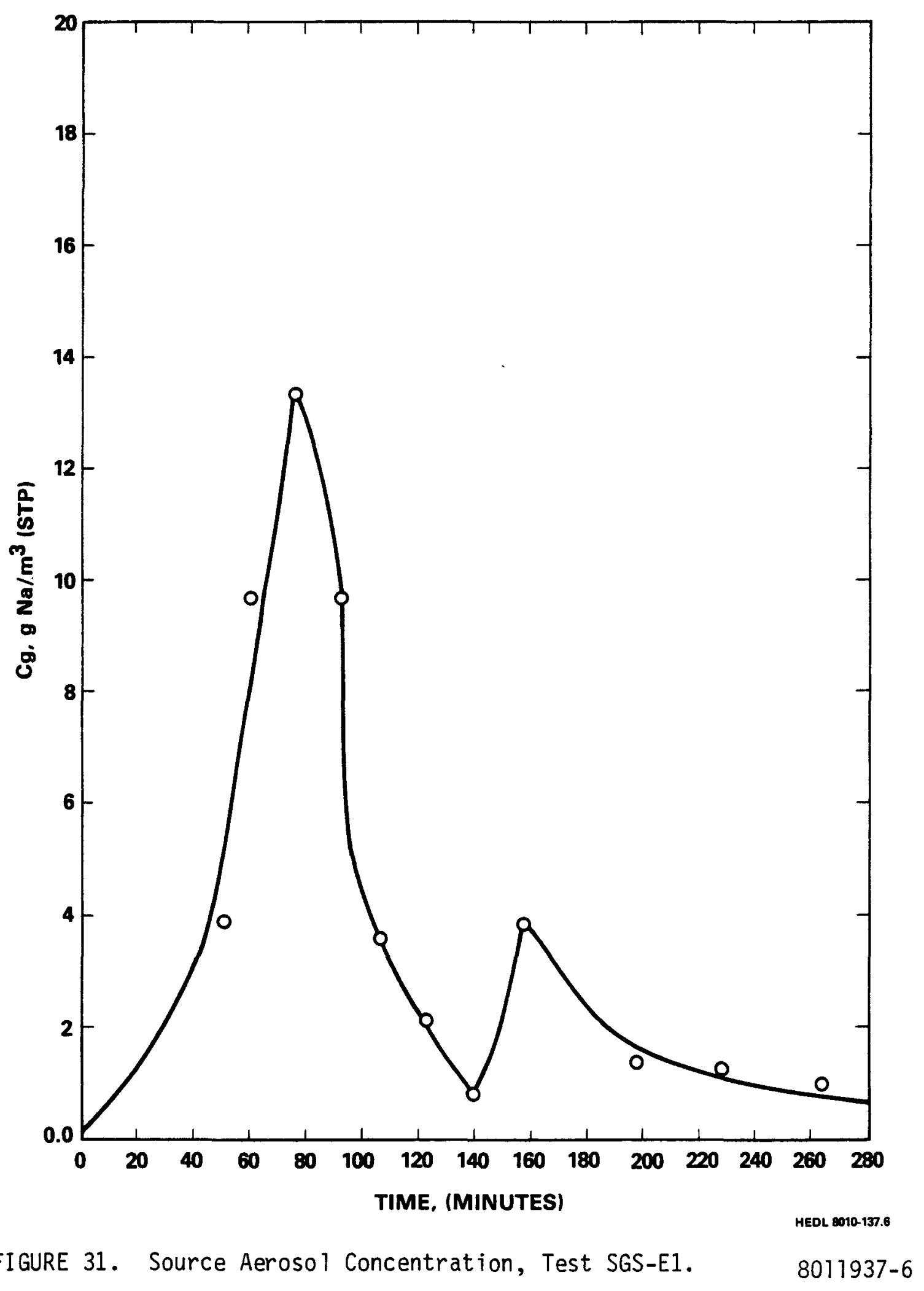




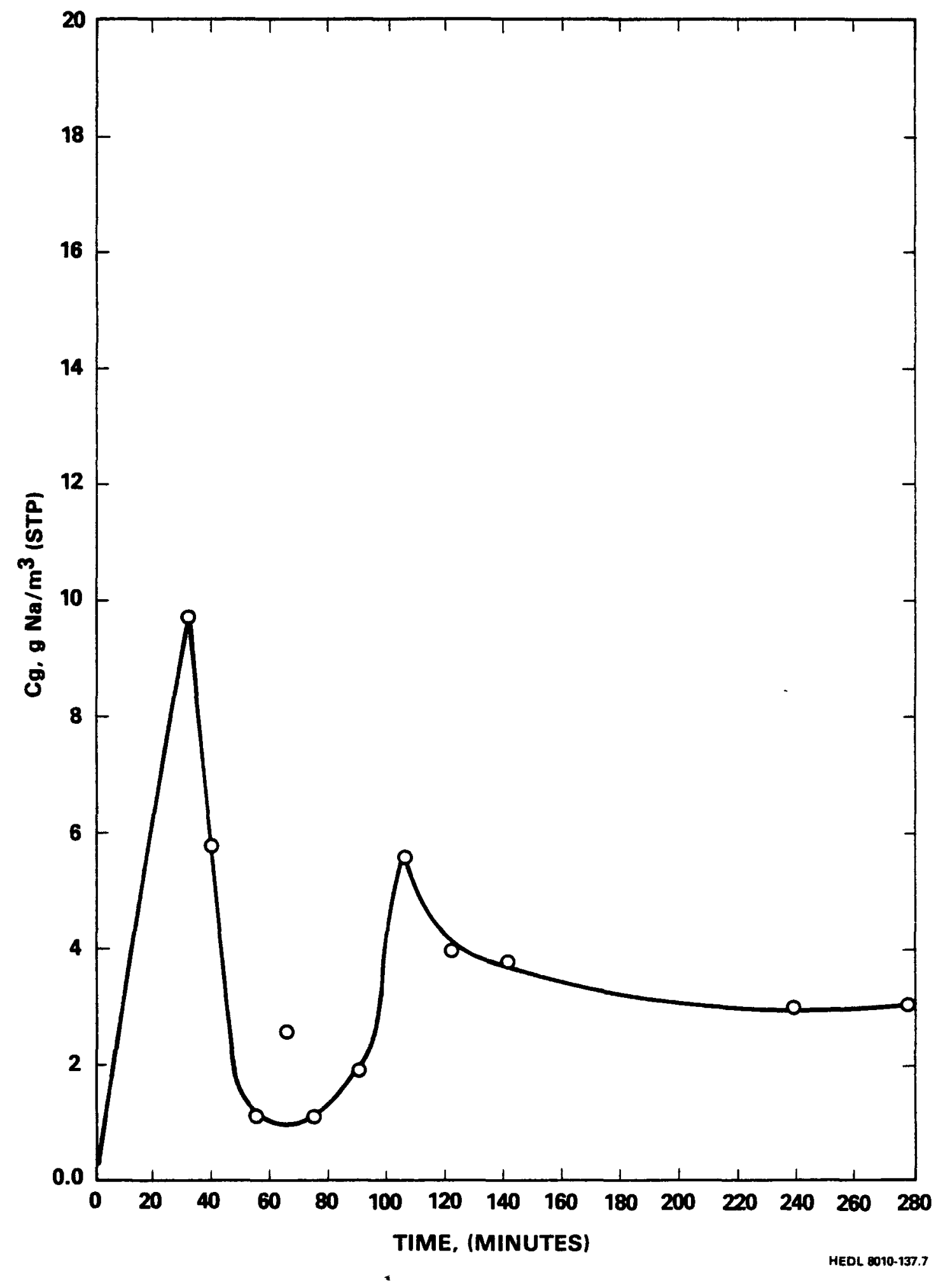

FIGURE 32. Source Aerosol Concentration, Test SGS-E2. 8011937-7 


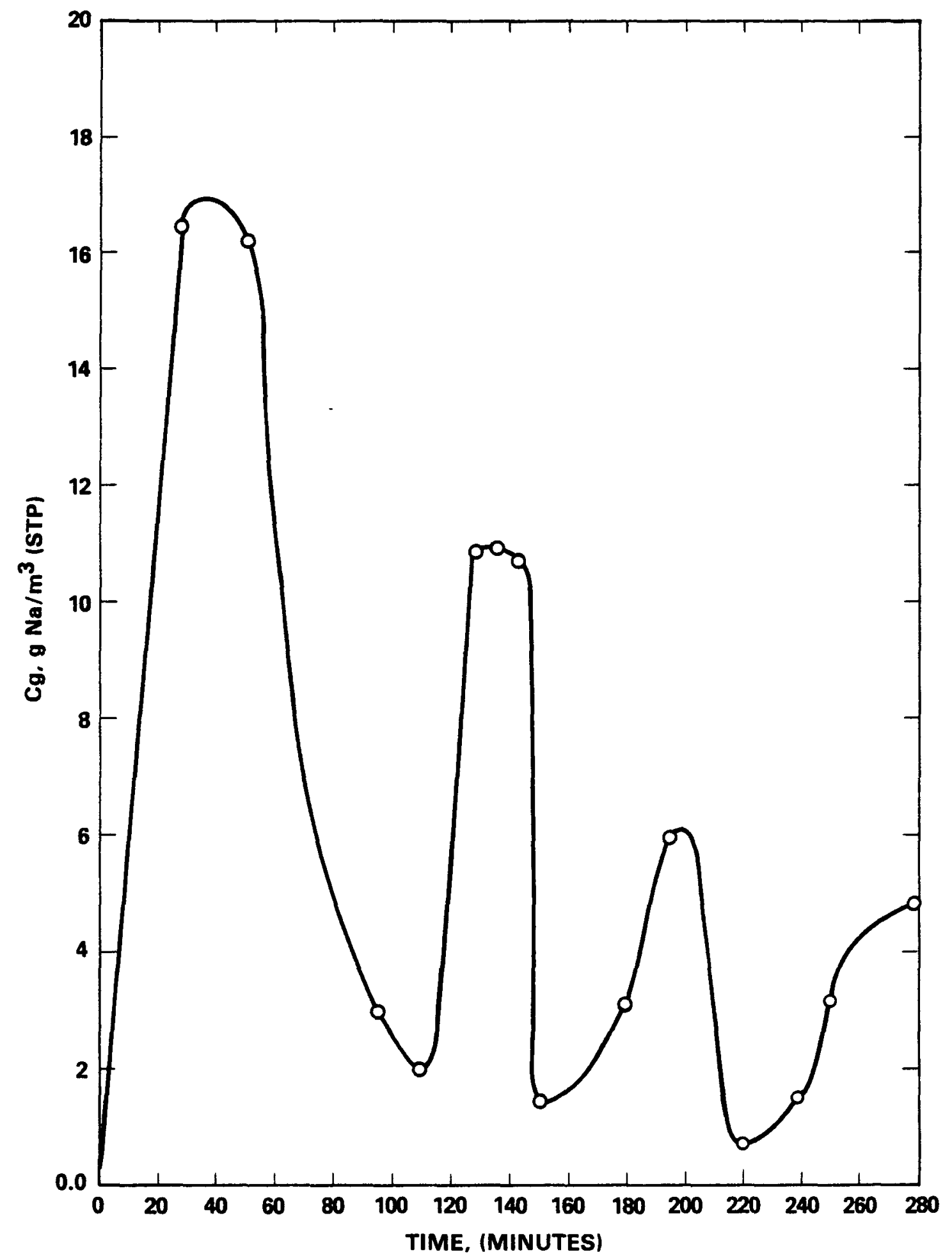

HEDL 8010-137.5

FIGURE 33. Source Aerosol Concentration, Test SGS-E3.

8011937-5 


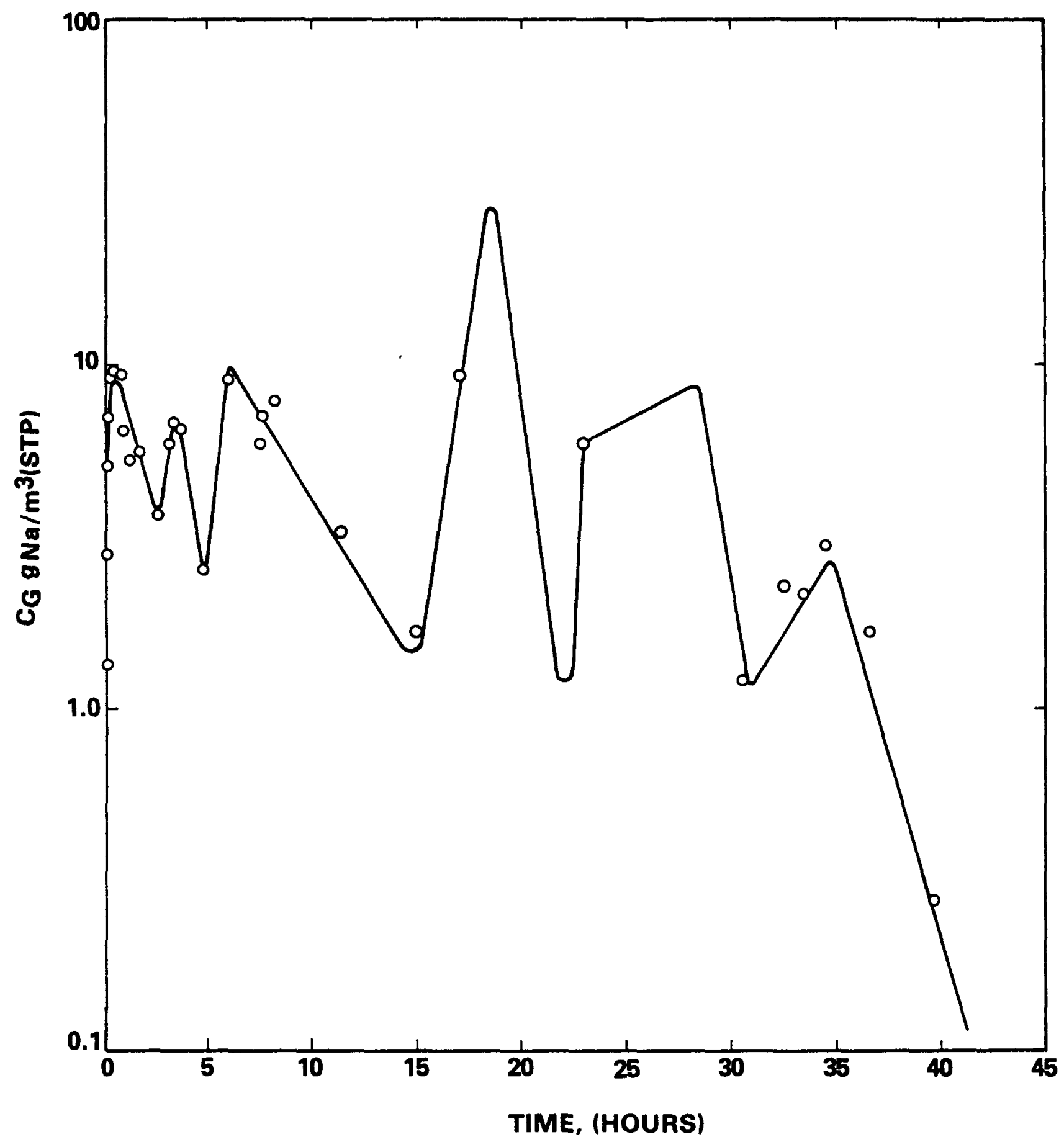

FIGURE 34. Source Aerosol Concentration, Test SGS-AC4. $8010974-2$ 


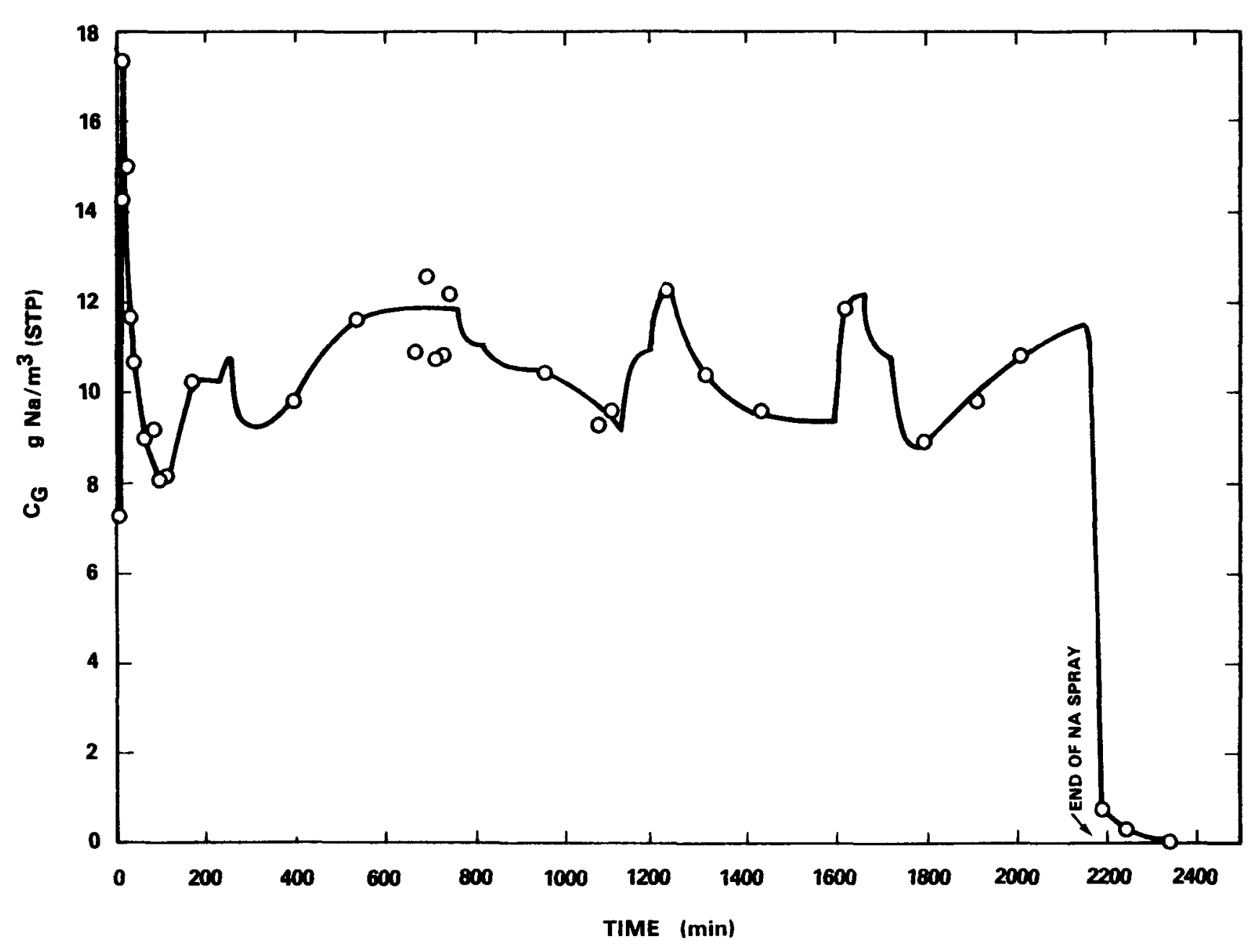

HEOL $\$ 007.031 .23$

FIGURE 35. Source Aerosol Concentration, Test SGS-AC5. 


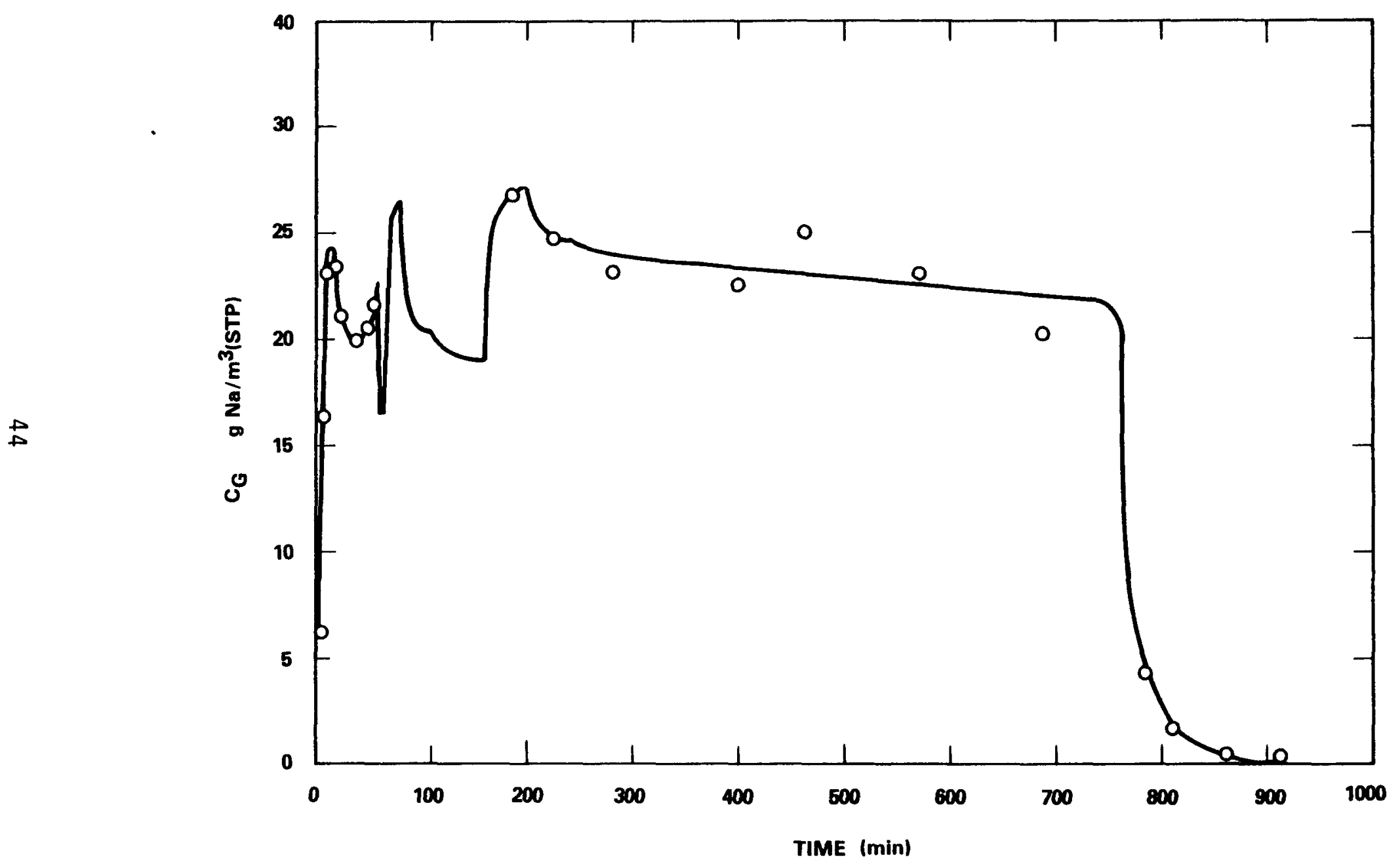

HELL $007-031.24$

FIGURE 36. Source Aerosol Concentration, Test SGS-AC6. 


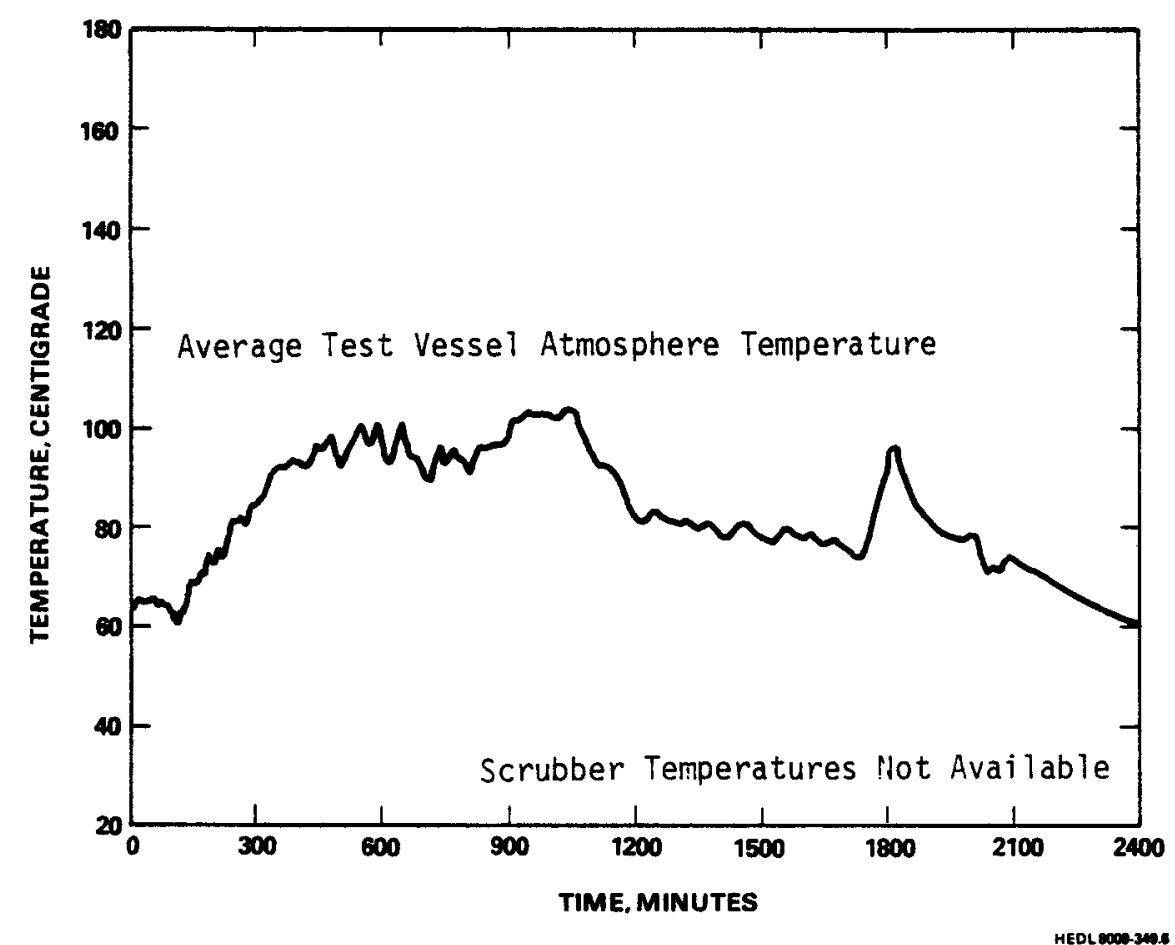

FIGURE 37. Scrubber Temperatures, Test SGS-AC3.

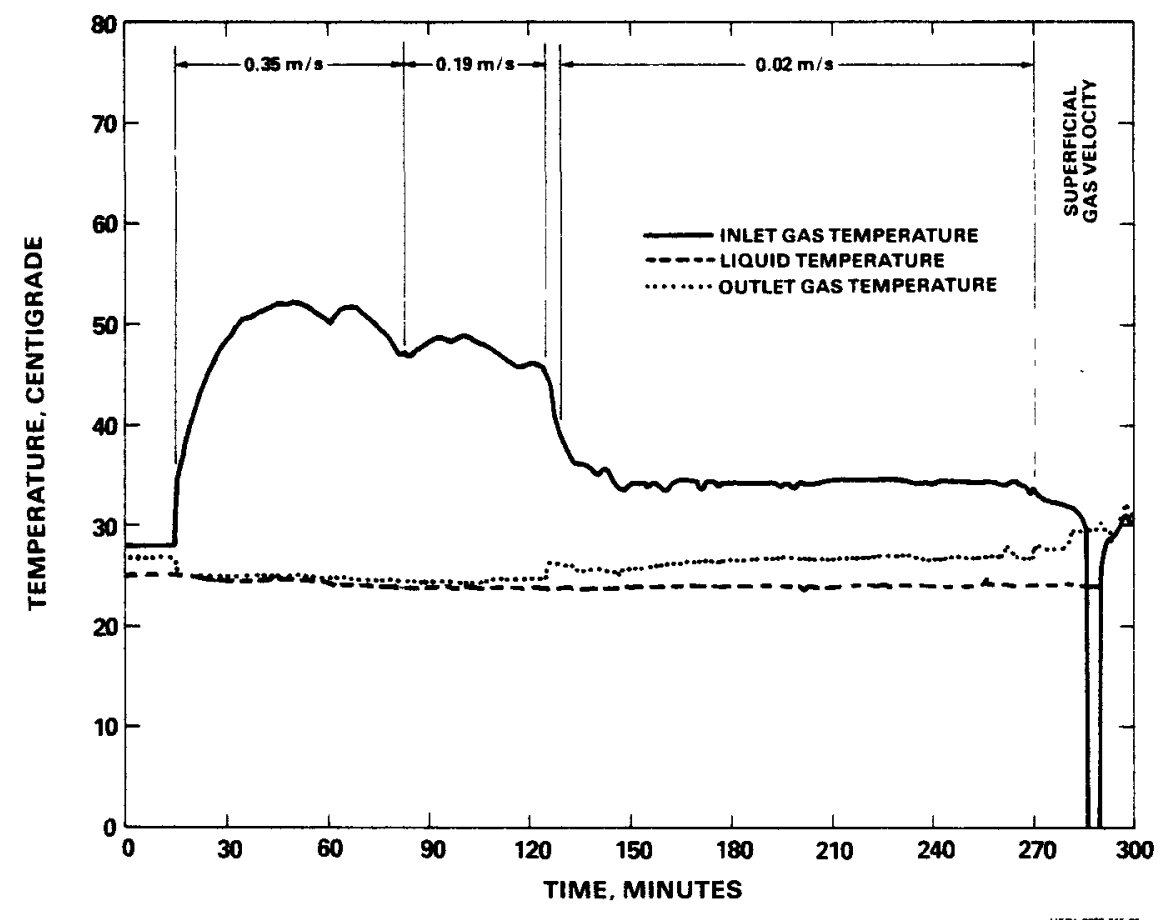

FIGURE 38. Scrubber Temperatures, Test SGS-ET. 


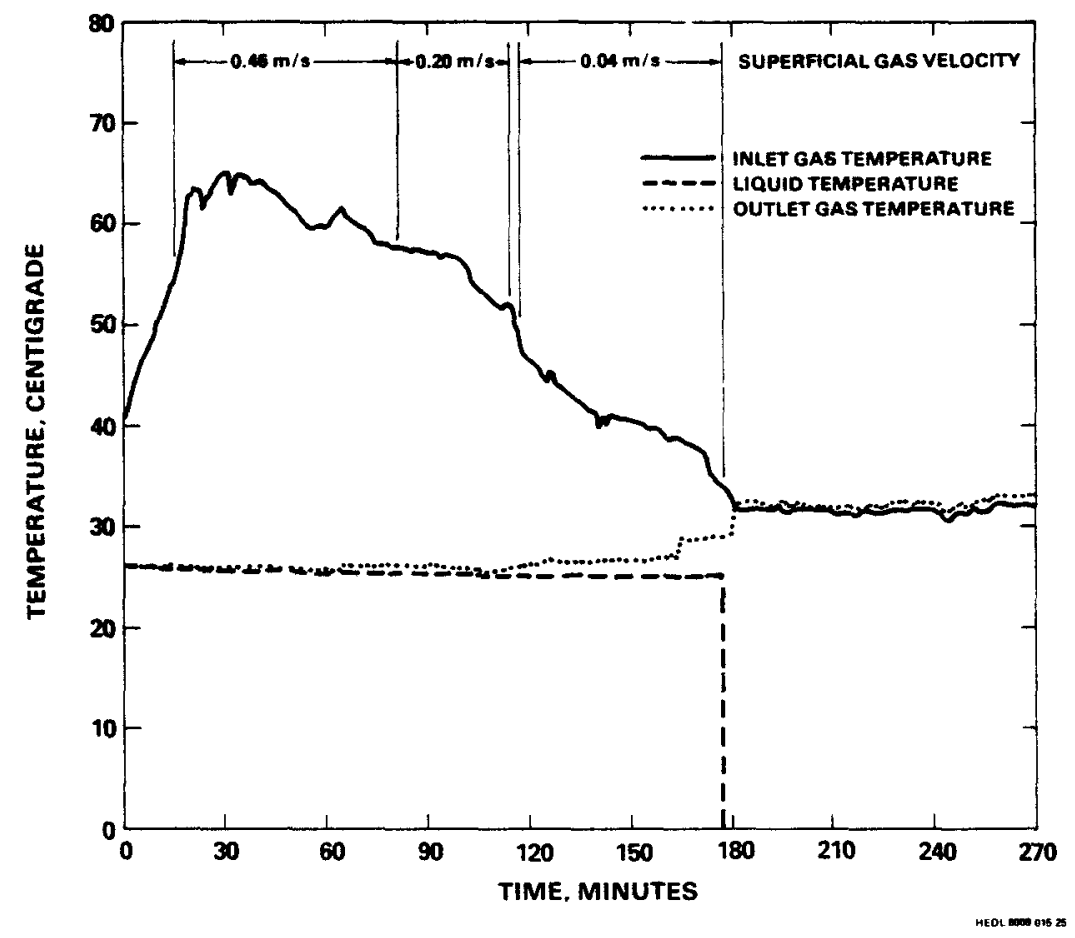

FIGURE 39. Scrubber Temperatures, Test SGS-E2. 8010211-21

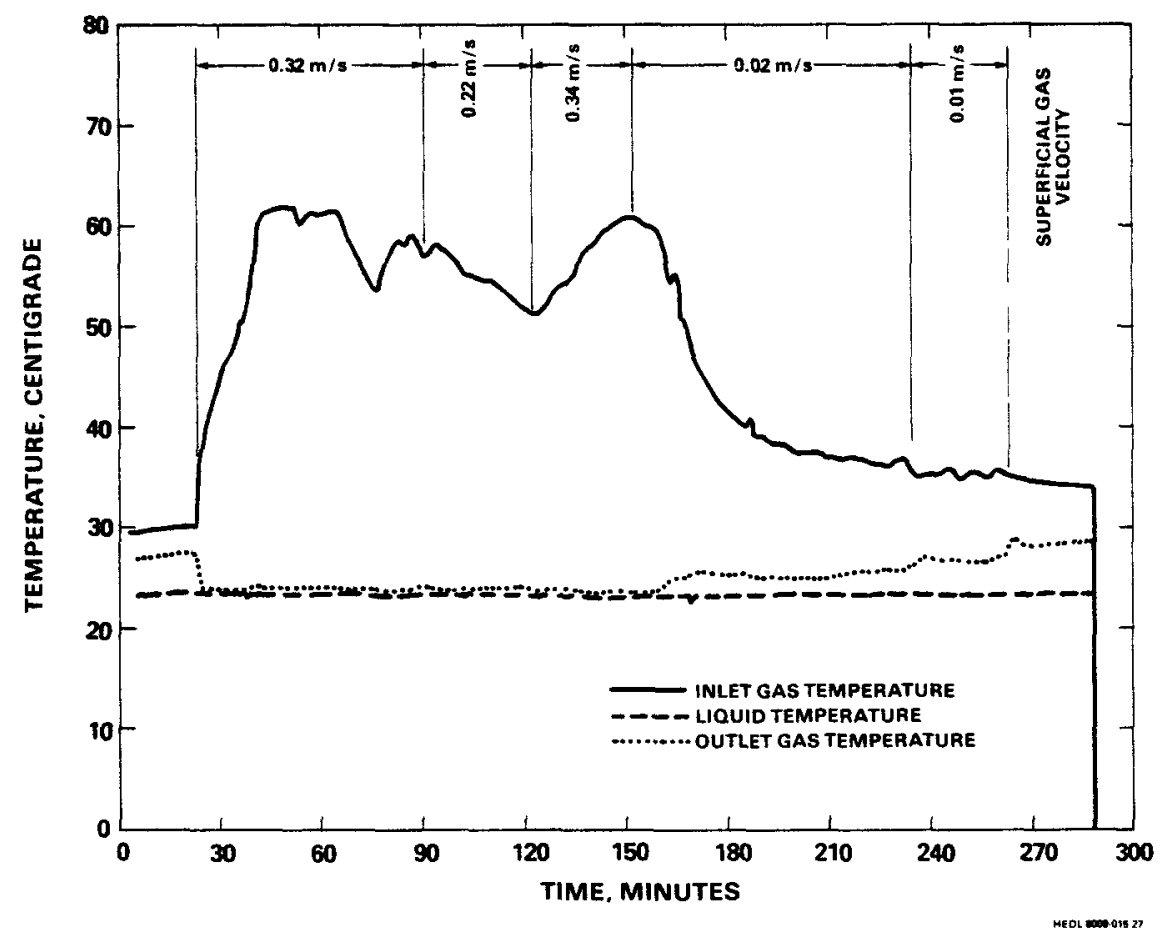

FIGURE 40. Scrubber Temperatures, Test SGS-E3. 8010211-19 


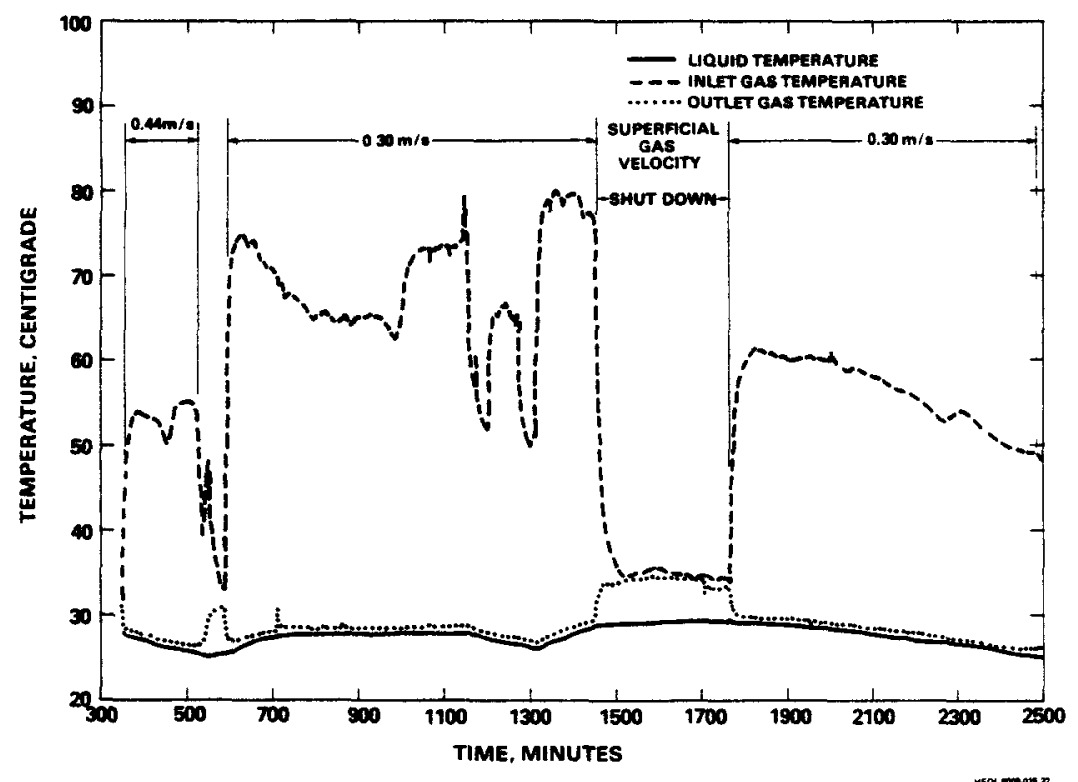

FIGURE 41. Scrubber Temperature, Test SGS-AC4. 809685-j

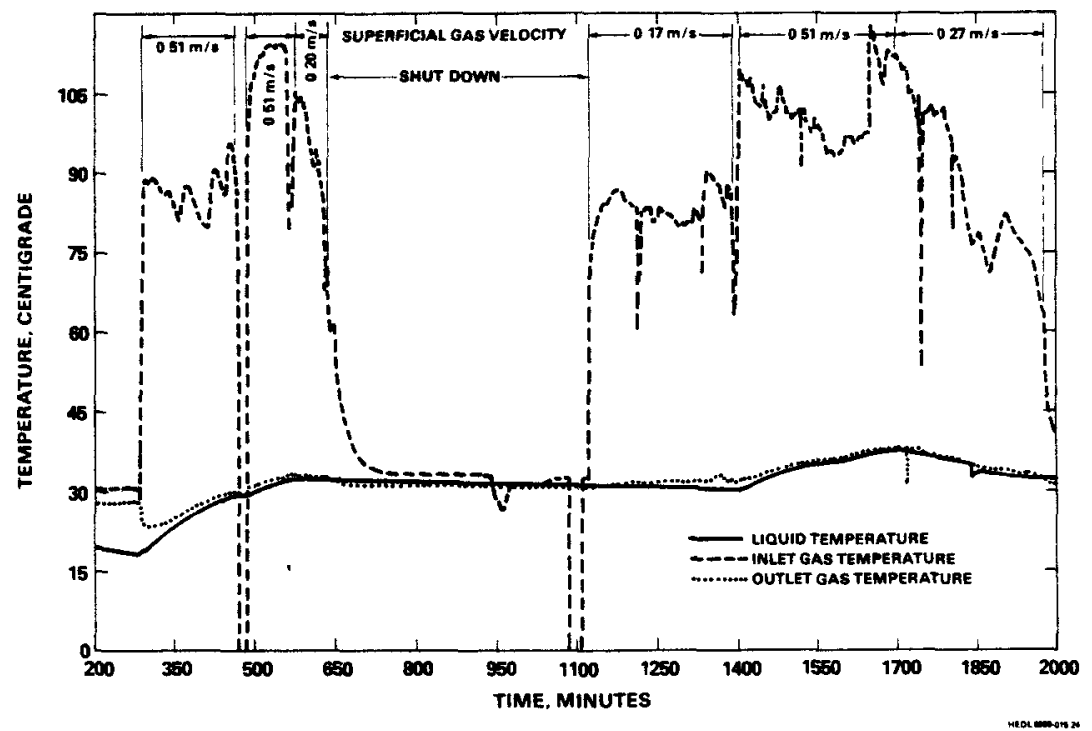

FIGURE 42. Scrubber Temperatures, Test SGS-AC5. 809685-4 


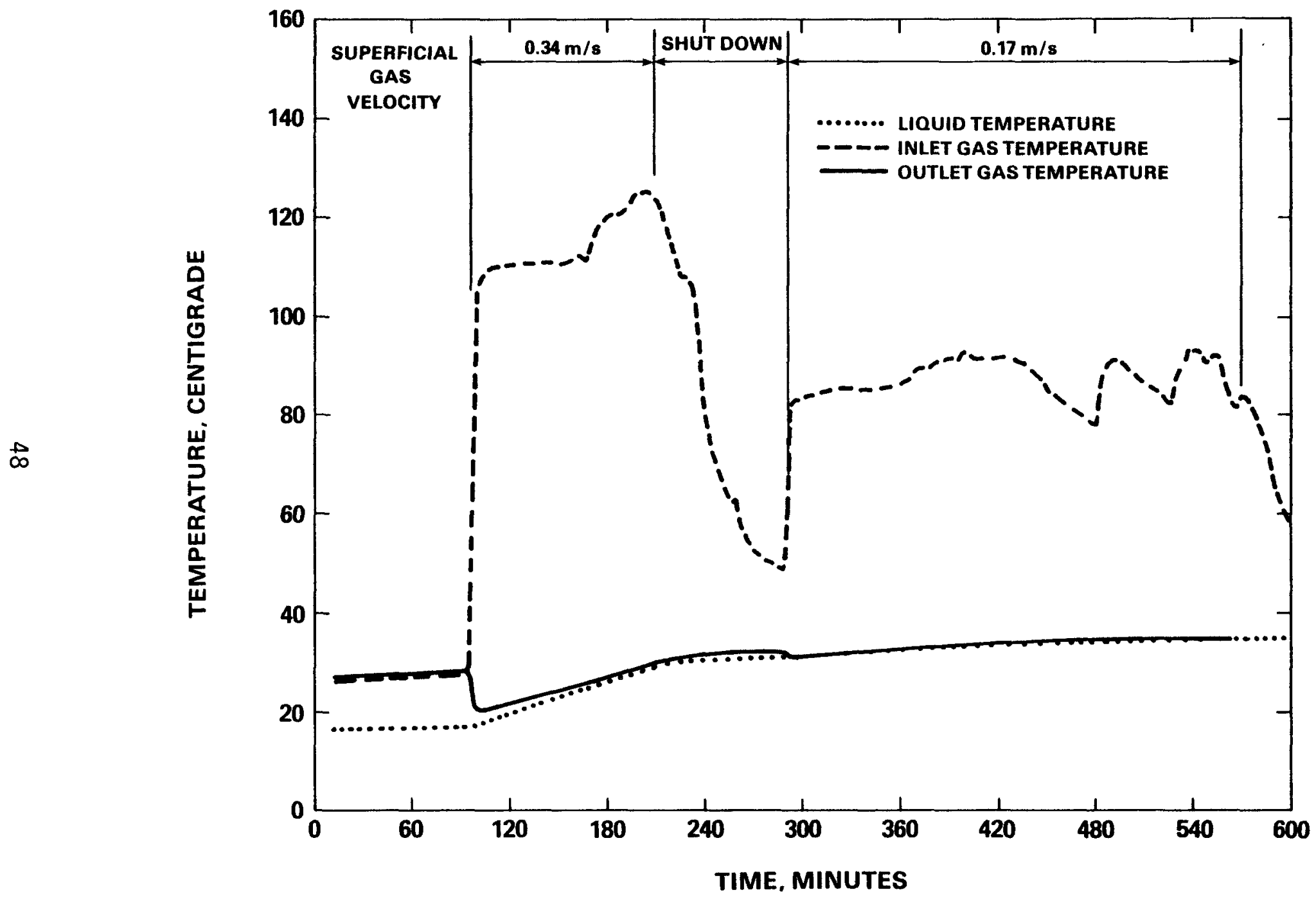

FIGURE 43. Scrubber Temperatures, Test SGS-AC6. 
The aerosol removal efficiency, E, was determined from the aerosol sampling data by:

$$
E(\%)=\left[1-\left(\frac{\text { Out let aerosol mass concentration }}{\text { Inlet aerosol mass concentration }}\right)\right] \times 100 \%
$$

Although this is the most commonly shown performance variable, the scrubber penetration, Pt, is a more useful number. The efficiency and penetration are related by:

$$
P t=1-\frac{E}{100} \%
$$

The scrubber penetration was calculated as a function of time for each of the tests. The results are given in Tables 3 through 9 . Variations in the scrubber penetration could be due to varying gas velocity, changing aerosol concentration and particle size, and sampling errors. Gas superficial velocities as a function of run time are shown in Figures 44 through 50 .

Penetrations of aerosol as a function of gas velocity are given in Figures 51 through 57. The graphs indicate that aerosol penetration may not be a strong function of gas velocity. The aerosol concentration and particle size are interrelated. Higher aerosol concentrations result in larger particle sizes due to the increased agglomeration of the aerosol particles in the source chamber. Figures 58 through 63 are plots of the scrubber penetration versus the scrubber in let aerosol concentration. In each case, the penetration is shown to be a function of the aerosol concentration, with lower concentrations resulting in increased penetration. Due to non-isokinetic sampling from the in let stream in test SGS-AC5, the scrubber in let concentrations were unrealistically high; therefore, penetration could not be plotted vs scrubber in let concentration for this test. Aerosol particle size measurements were limited in number and a plot of aerosol penetration vs particle size could not be made. The impactor results obtained are shown in Appendix B. A log-normal distribution was assumed and the mass of aerosol less than a given particle aerodynamic mass diameter was plotted on lognormal paper. The impactor results indicate that the aerosol particles grew in passing through the scrubber. 
The results of the first four tests are sumarized in Table 10. The overall efficiency, based on the integrated aerosol mass collected in the scrubber liquid and the backup filter, is consistent among tests of similar bed configurations. The average efficiencies, determined by averaging the penetrations measured by aerosol sampling, deviate from the overall efficiency due to errors in non-isokenistic sampling of the aerosol, liquid mist entrainment in the outlet gas, and the uneven time distribution of aerosol samples during each test. An example of the latter is test AC3. A disproportionate number of samples were taken when the aerosol particle concentration was very low, hence the particles were relatively small. Since

TABLE 3

\section{SGS PENETRATION, TEST SGS-AC3}

\section{Run Time (min.)}

490

498

512

530

540

552

562

570

1380

1398

1430

1462

1482

1574

1585

1623

1868

1880

1890

1920

1940

1958

1980

Overall Penetration (based on aerosol collected in scrubber and back-up HEPA filter)

SGS Penetration

$4.6 \times 10^{-3}$

$2.8 \times 10^{-3}$

$2.0 \times 10^{-3}$

$1.7 \times 10^{-3}$

$2.1 \times 10^{-3}$

$1.9 \times 10^{-3}$

$8.8 \times 10^{-4}$

$1.2 \times 10^{-5}$

$8.4 \times 10^{-4}$

$1.4 \times 10^{-2}$

$1.2 \times 10^{-2}$

$8.0 \times 10^{-3}$

$2.6 \times 10^{-3}$

$2.7 \times 10^{-3}$

$3.6 \times 10^{-3}$

$8.1 \times 10^{-4}$

$3.8 \times 10^{-3}$

$2.4 \times 10^{-2}$

$1.9 \times 10^{-2}$

$3.0 \times 10^{-2}$

$1.3 \times 10^{-2}$

$9.9 \times 10^{-3}$

$2.8 \times 10^{-2}$

$1.6 \times 10^{-3}$ 
TABLE 4

SGS PENETRATION, TEST SGS-E1

Run Time (min.)

30
48
76
92
106
122
140
157
198
228
264

Overall Penetration (based on aerosol collected in scrubber and back-up HEPA filter)
SGS Penetration

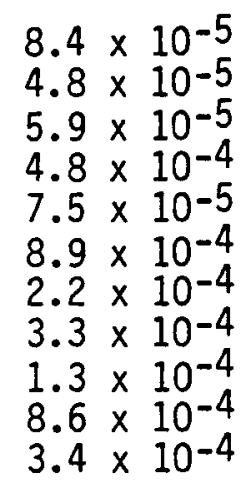

$1.6 \times 10^{-3}$

\section{TABLE 5}

SGS PENETRATION, TEST SGS-E2

\section{Run Time (min.)}

32

40

55

75

91

106

122

141

159

Overall Penetration (based

on aerosol collected in scrubber and back-up HEPA filter)
SGS Penetration

$5.0 \times 10^{-3}$

$7.2 \times 10^{-3}$

$2.1 \times 10^{-2}$

$3.6 \times 10^{-2}$

$1.6 \times 10^{-2}$

$3.0 \times 10^{-3}$

$4.1 \times 10^{-4}$

$6.5 \times 10^{-3}$

$1.4 \times 10^{-2}$

$1.4 \times 10^{-2}$ 
TABLE 6

SGS PENETRATION, TEST SGS-E3

Run Time (min.)

28

48

79

95

108

124

134

143

150

178

194

220

239

250

Overa 11 Penetration (based

on aerosol collected in scrubber and back-up HEPA

filter)
SGS Penetration

$6.2 \times 10^{-4}$

$3.0 \times 10^{-4}$

$1.5 \times 10^{-4}$

$3.6 \times 10^{-4}$

$5.4 \times 10^{-4}$

$2.8 \times 10^{-4}$

$2.0 \times 10^{-4}$

$2.3 \times 10^{-4}$

$7.9 \times 10^{-4}$

$3.6 \times 10^{-4}$

$9.1 \times 10^{-5}$

$3.8 \times 10^{-4}$

$5.0 \times 10^{-4}$

$1.1 \times 10^{-4}$

$2.0 \times 10^{-3}$

TABLE 7

SGS PENETRATION, TEST SGS-AC4

Run Time (min.)

$$
\begin{array}{r}
375 \\
392 \\
432 \\
442 \\
480 \\
500 \\
716 \\
868 \\
1098 \\
1390 \\
1398 \\
2046
\end{array}
$$

SGS Penetration

$4.3 \times 10^{-3}$

$4.3 \times 10^{-3}$

$1.5 \times 10^{-3}$

$2.5 \times 10^{-3}$

$6.8 \times 10^{-3}$

$1.8 \times 10^{-4}$

$3.8 \times 10^{-3}$

$4.3 \times 10^{-3}$

$5.4 \times 10^{-4}$

$2.4 \times 10^{-3}$

$2.1 \times 10^{-3}$

$3.4 \times 10^{-3}$ 
TABLE 8

SGS PENETRATION, TEST SGS-AC5

Run Time (min.)

323

383

443

523

605

1162

1272

1358

1425

1498

1534

1666

1716
SGS Penetration

$1.1 \times 10^{-3}$

$1.3 \times 10^{-3}$

$1.6 \times 10^{-3}$

$2.4 \times 10^{-3}$

$3.8 \times 10-3$

$3.6 \times 10^{-3}$

$8.0 \times 10^{-4}$

$3.0 \times 10^{-4}$

$3.4 \times 10^{-3}$

$3.4 \times 10^{-3}$

$3.5 \times 10^{-3}$

$4.4 \times 10^{-3}$

$4.5 \times 10^{-3}$

(a) Due to non-isokinetic sampling, scrubber inlet aerosol concentration samples showed unrealistically high concentrations. Therefore, based on the source chamber aerosol concentration, a constant inlet aerosol concentration of $5 \mathrm{~g} \mathrm{Na} / \mathrm{STO} \mathrm{m}^{3}$ was assumed.

TABLE 9

SGS PENETRATION, TEST SGS-AC6

Run Time (min.)

102

123

139

284

302

362

517
SGS Penetration

$3.1 \times 10^{-3}$

$3.3 \times 10^{-3}$

$5.7 \times 10^{-3}$

$9.2 \times 10^{-4}$

$1.5 \times 10^{-3}$

$1.6 \times 10^{-3}$

$8.9 \times 10^{-4}$ 


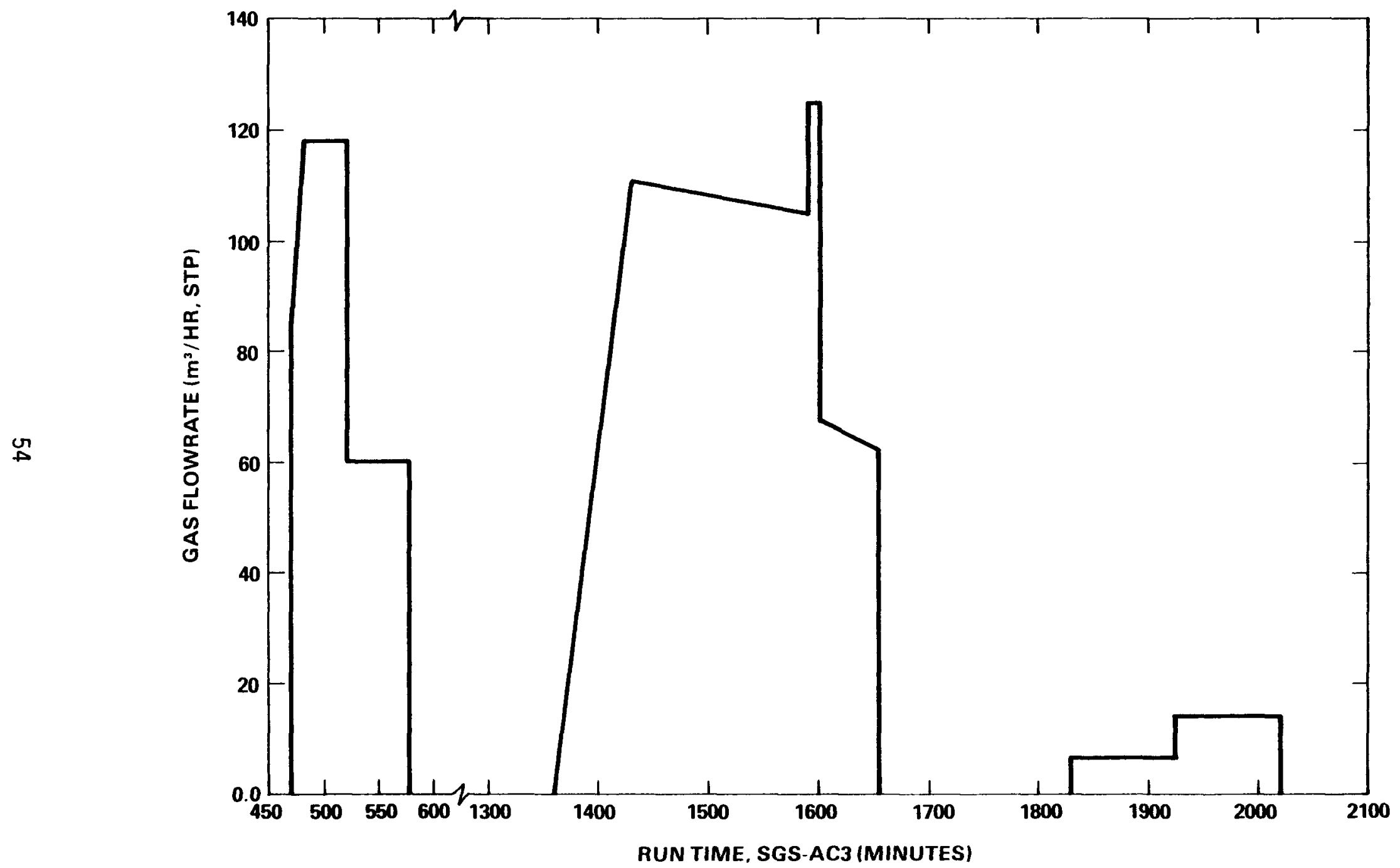

HELL 80090154

FIGURE 44. Gas Superficial Velocity, Test SGS-AC3. 


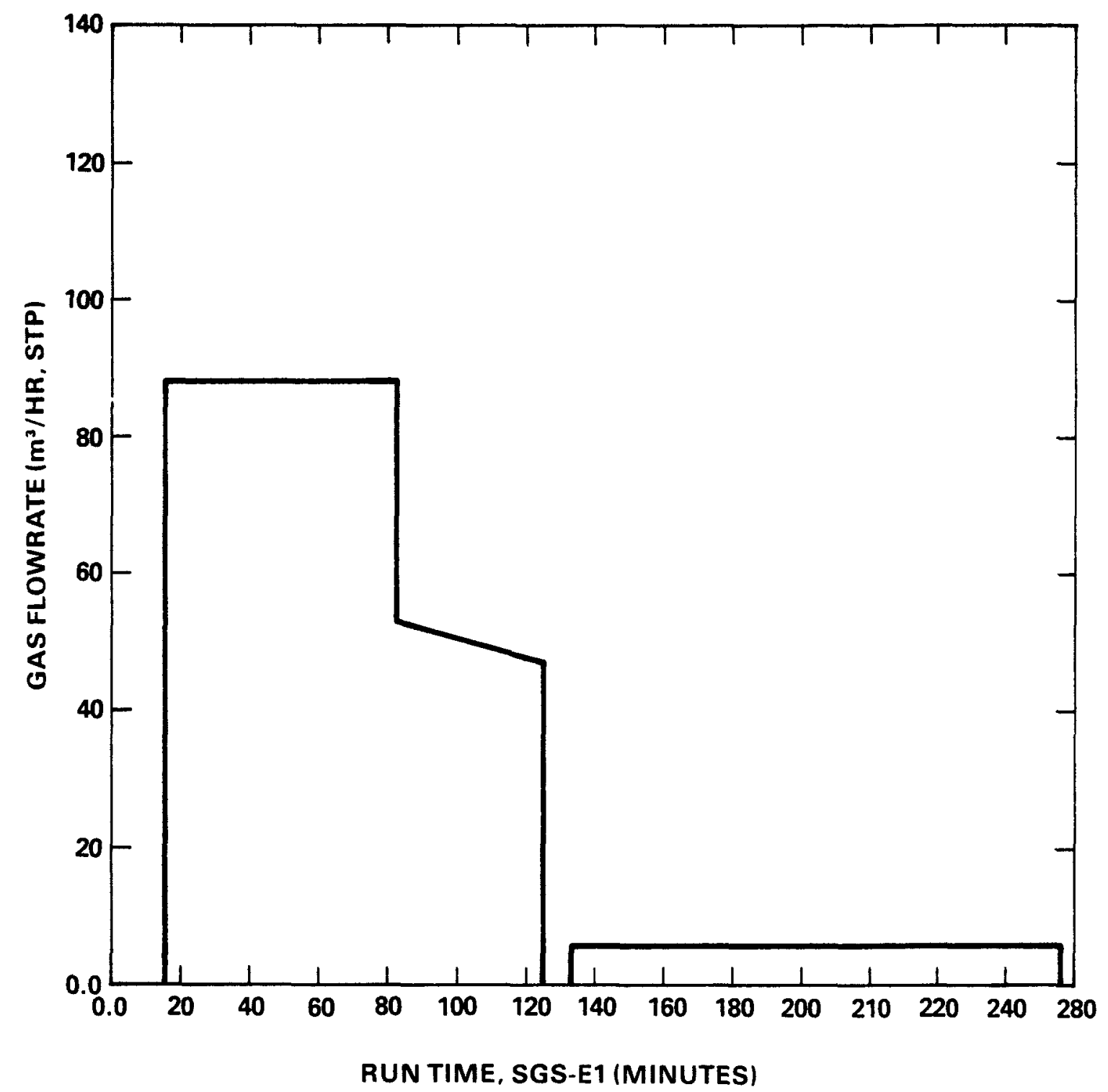

HEDL 8009-015 6

FIGURE 45. Gas Superficial Velocity, Test SGS-E1. 


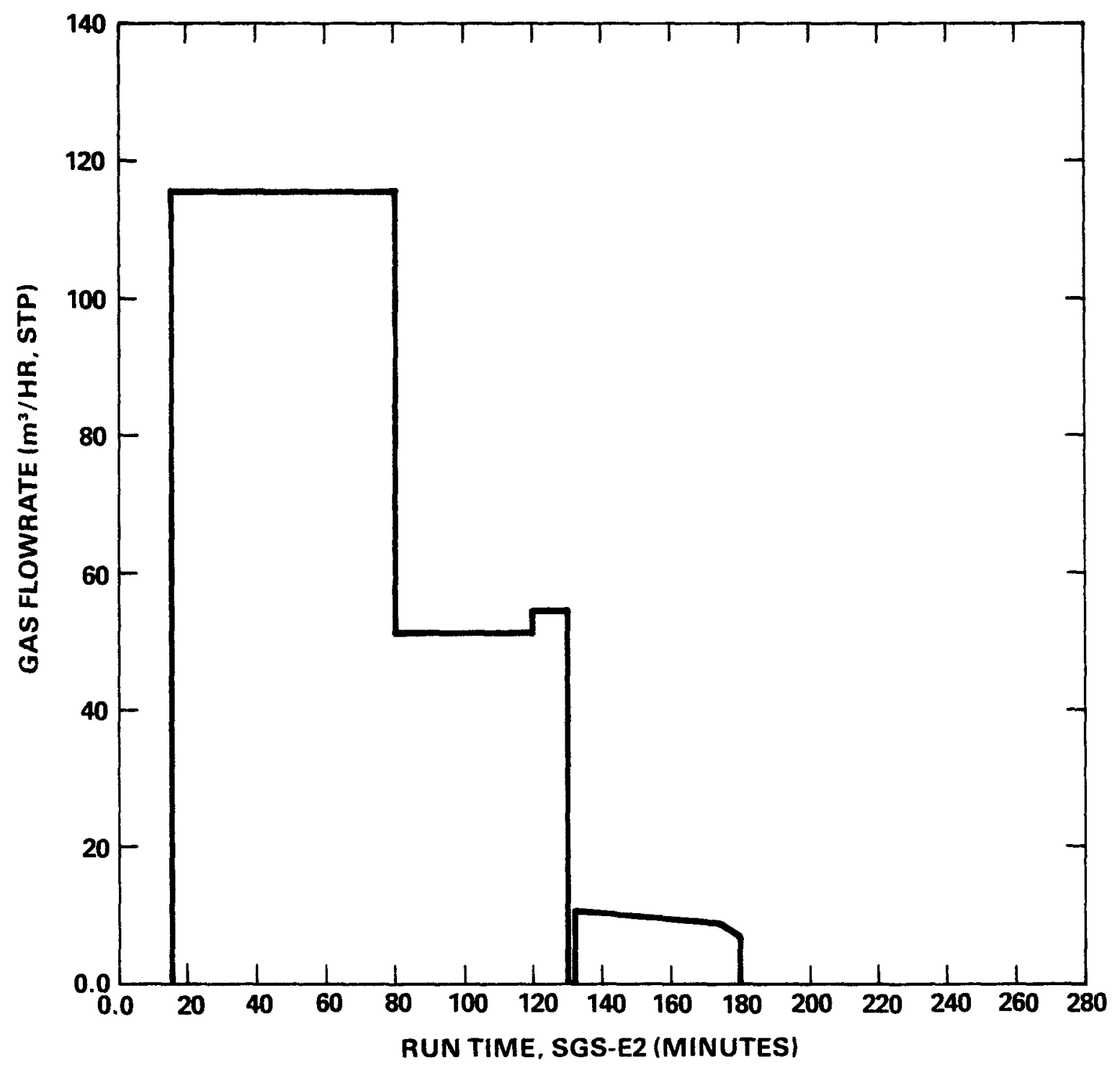

HEDL 8009-015.5

FIGURE 46. Gas Superficial Velocity, Test SGS-E2. 


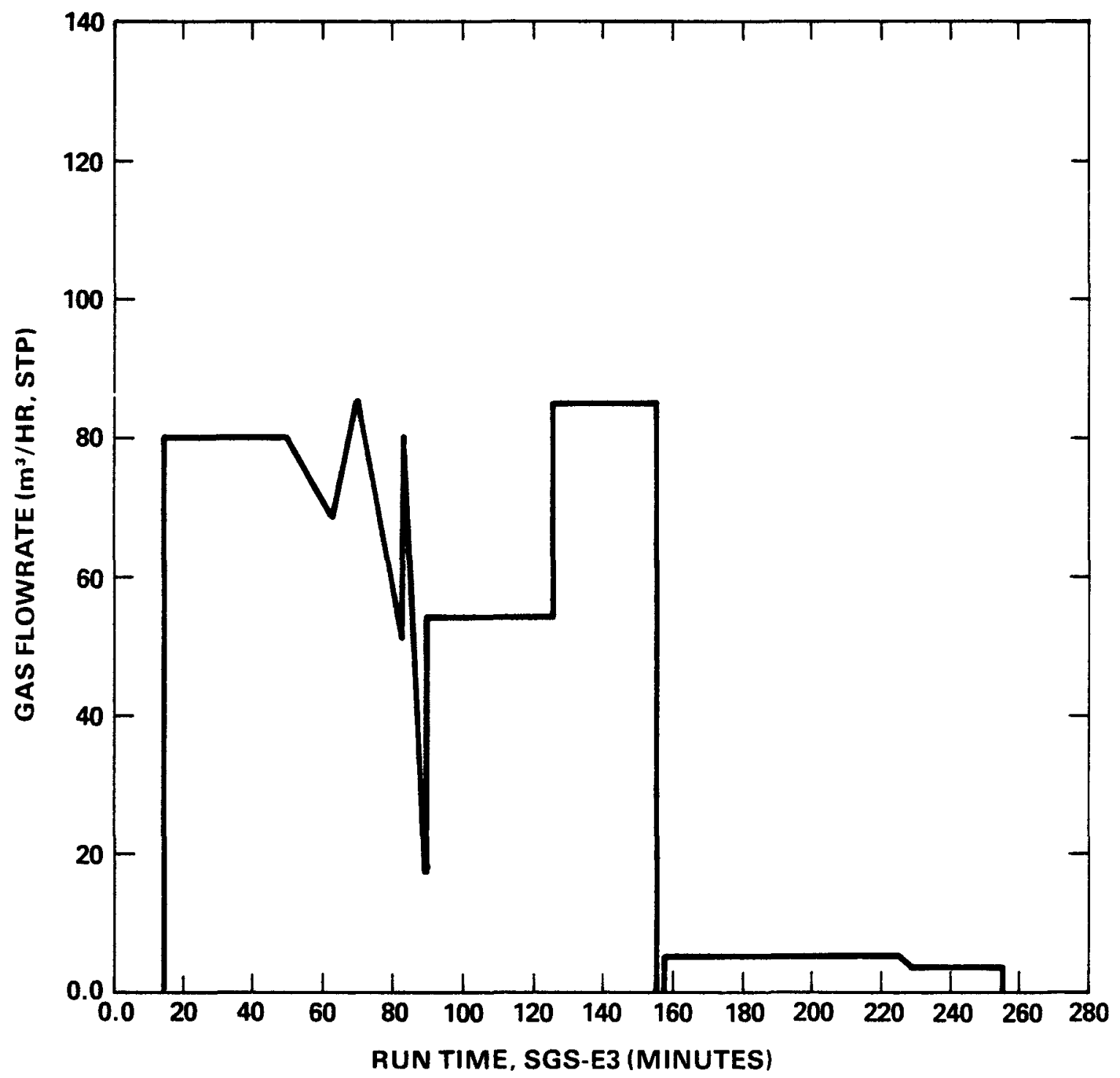

HEDL 8009-015 7

FIGURE 47. Gas Superficial Velocity, Test SGS-E3. 


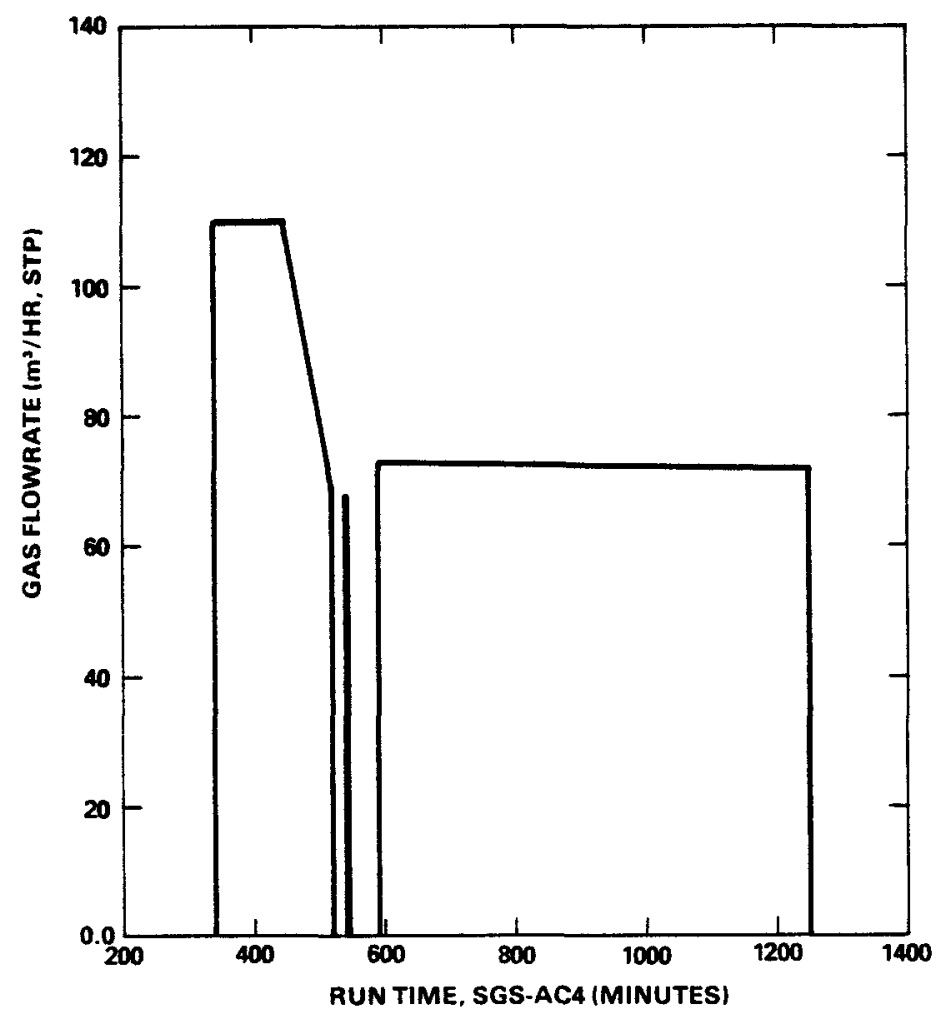

HEOL 80090151

FIGURE 48a. Gas Superficial Velocity, Test SGS-AC4.

8010211-3

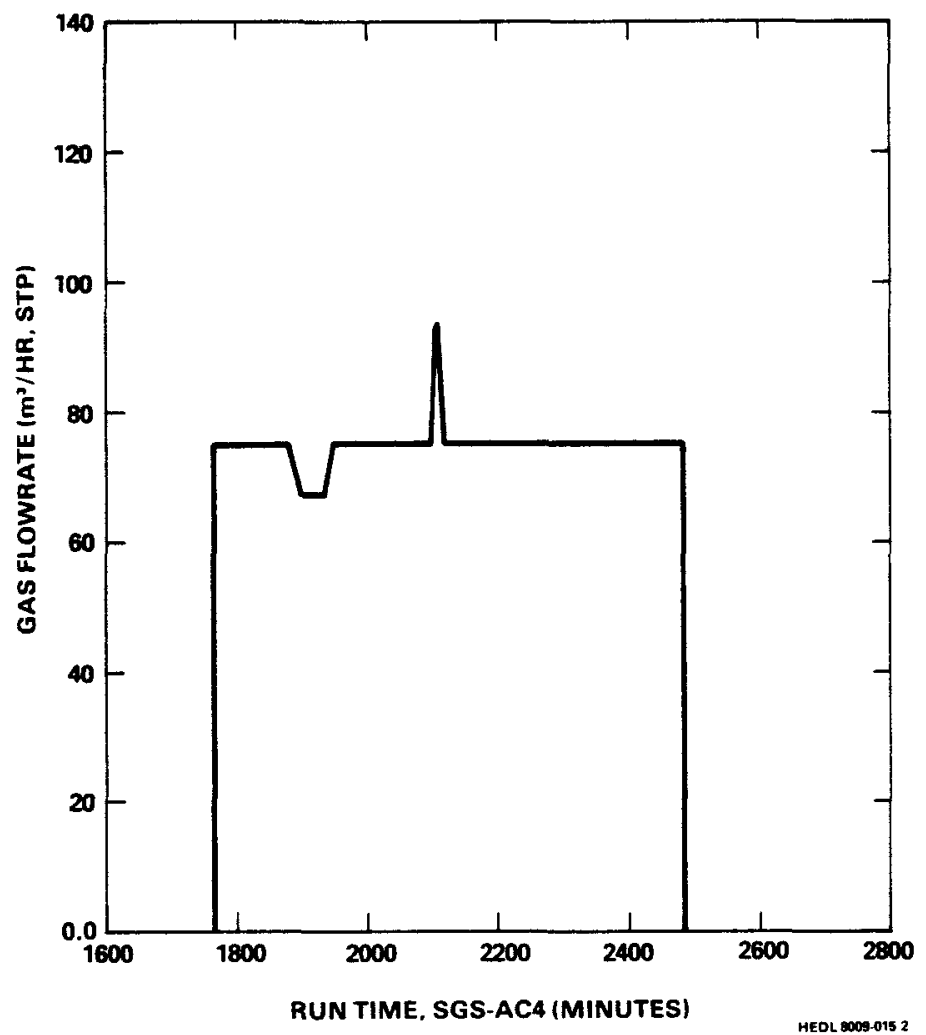

FIGURE 48b. Gas Superficial Velocity, Test SGS-AC4 (Cont'd). 8010211-2 


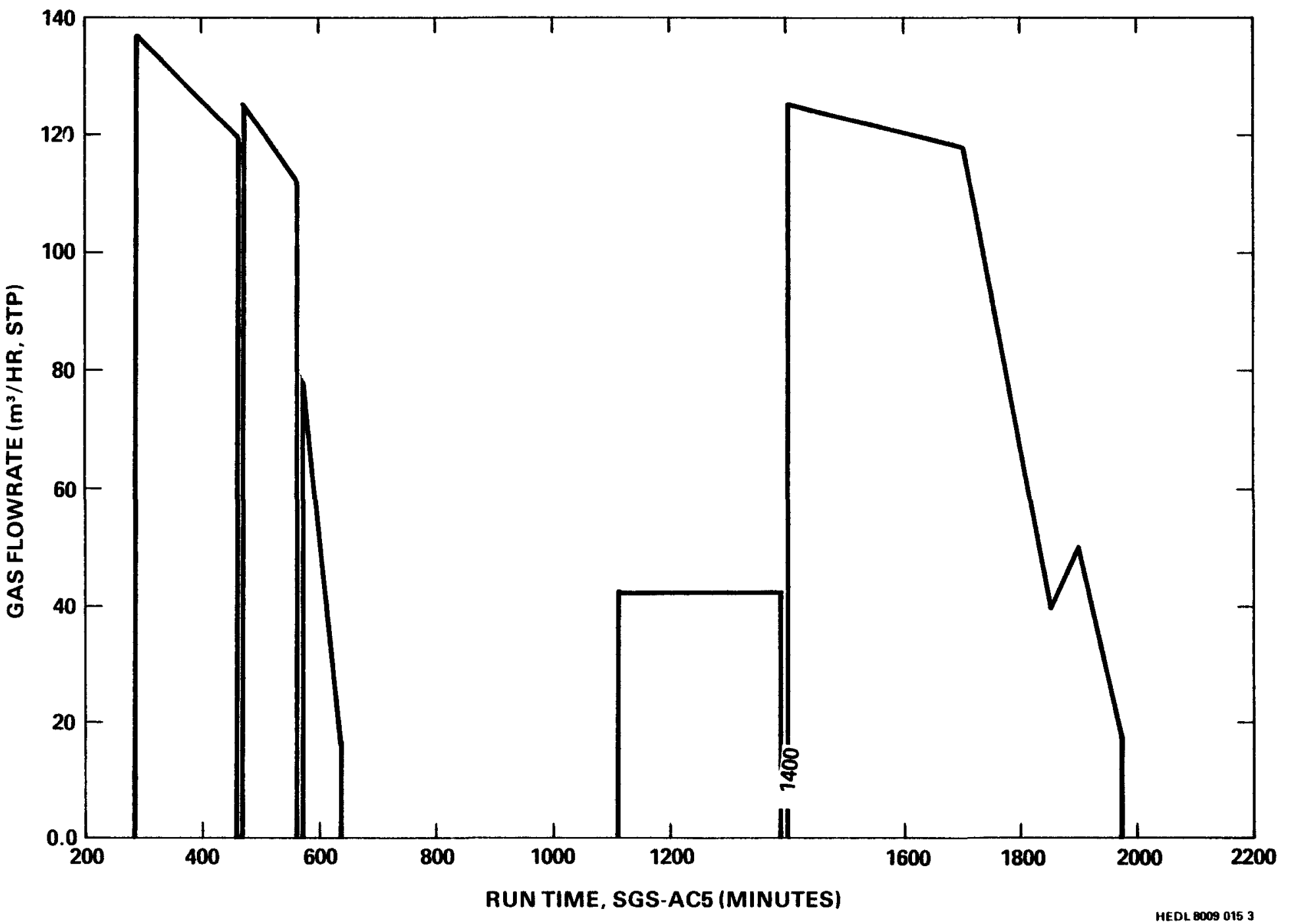

FIGURE 49. Gas Superficial Velocity, Test SGS-AC5. 


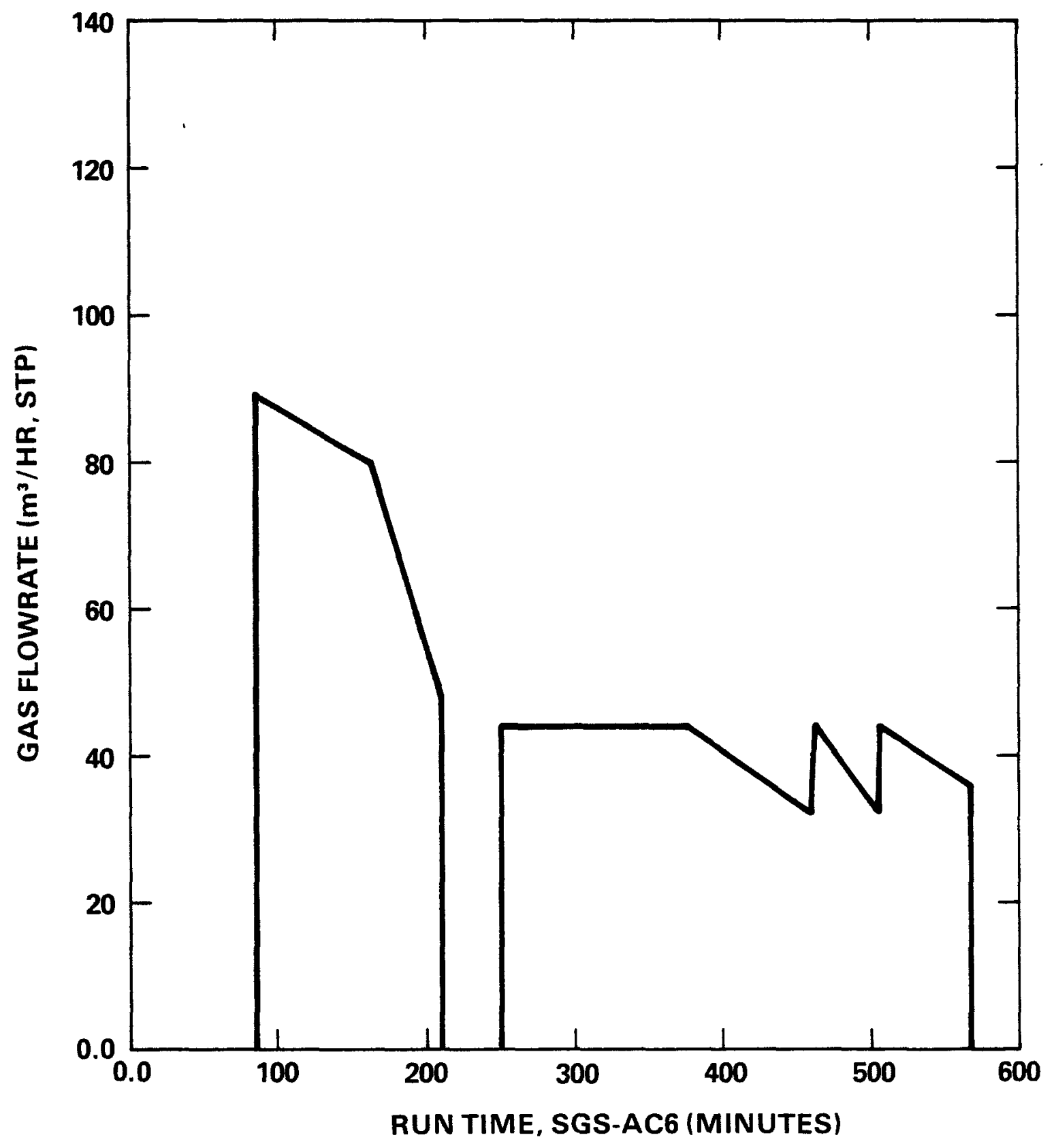

HEDL 8009-015.8

FIGURE 50. Gas Superficial Velocity, Test SGS-AC6. 


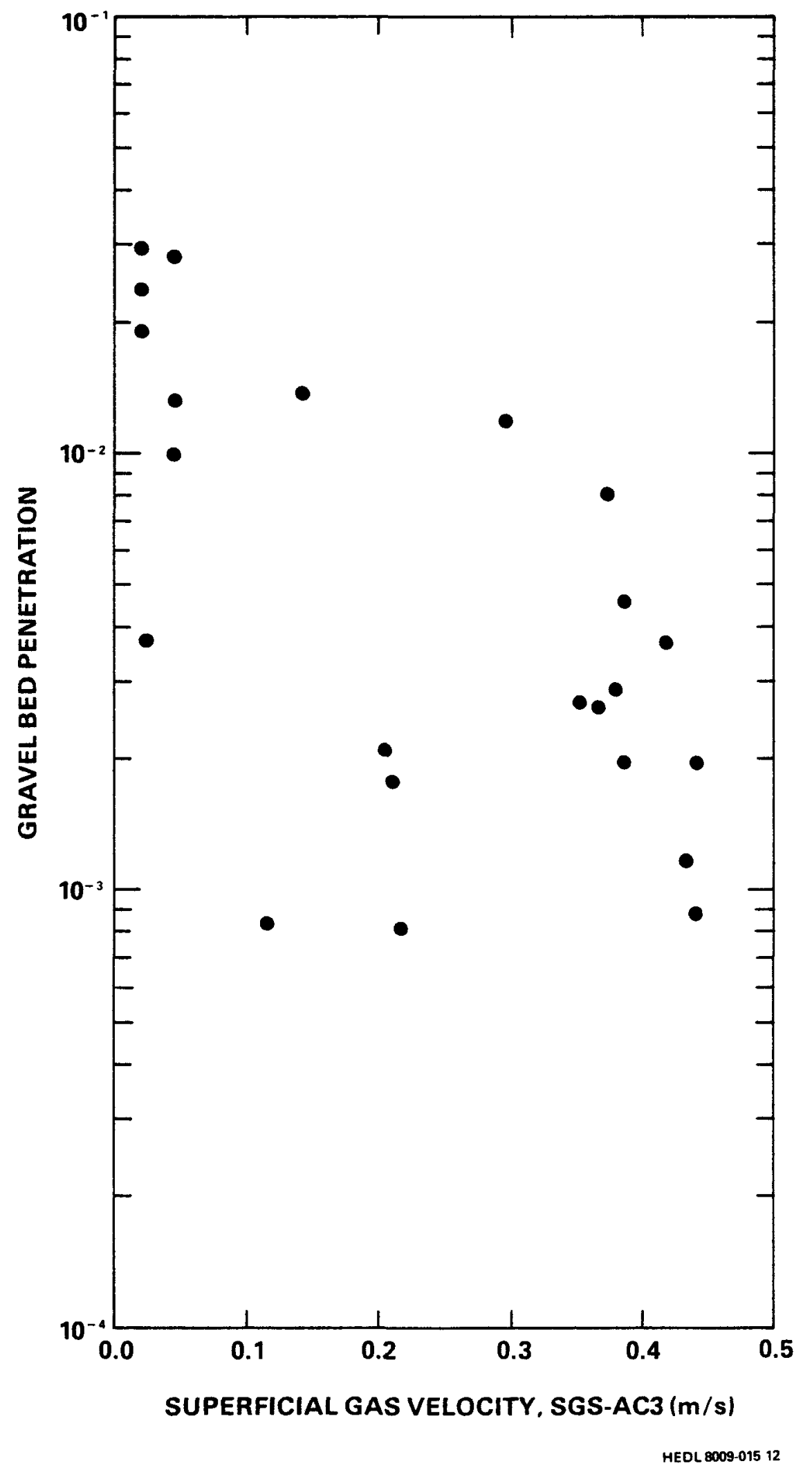

FIGURE 51. Bed Penetration vs Gas Velocity, Test SGS-AC3. 8010211-27 


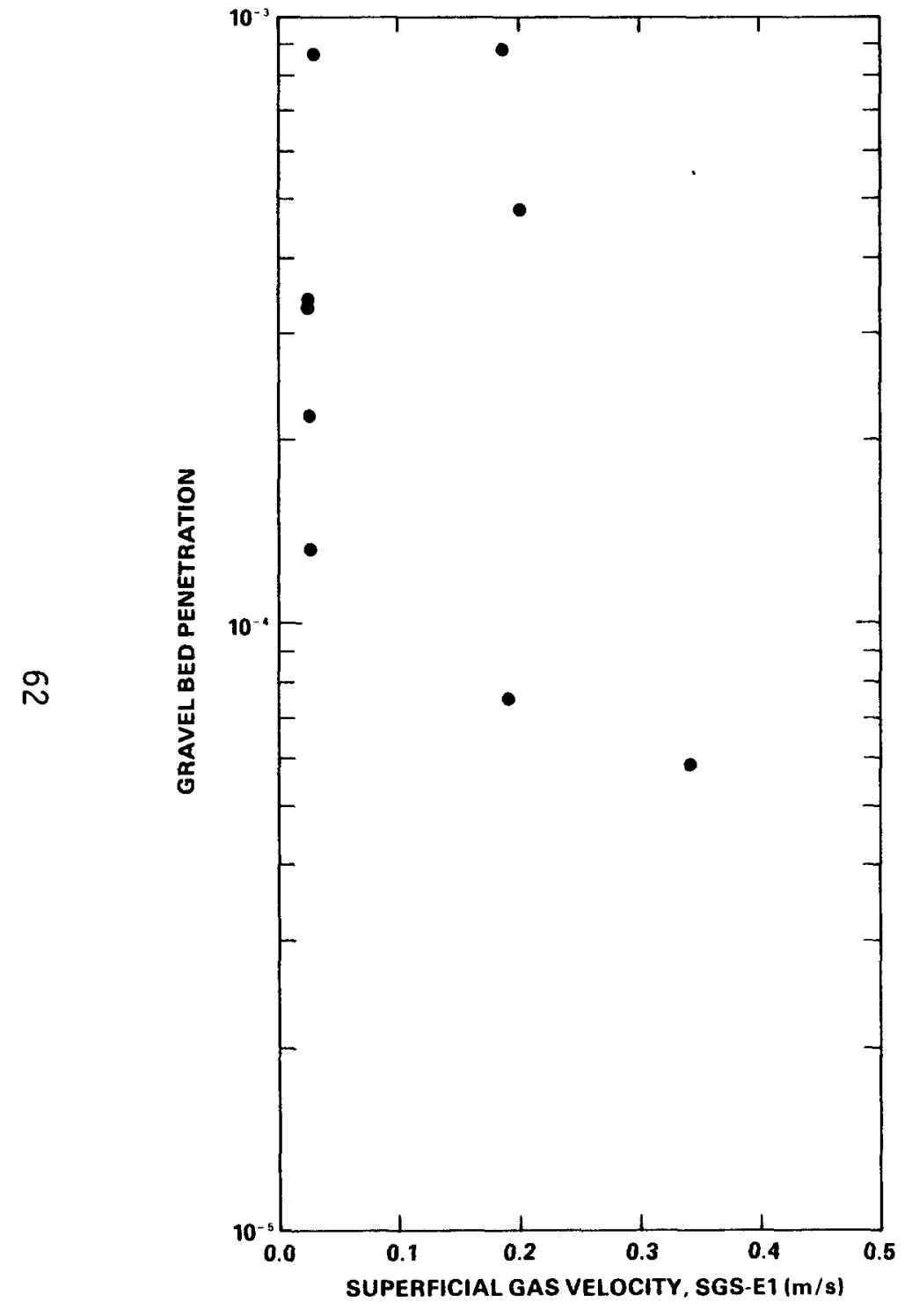

HEDL 800901514

FIGURE 52. Bed Penetration vs Gas Velocity, Test SGS-EI. 8010211-9

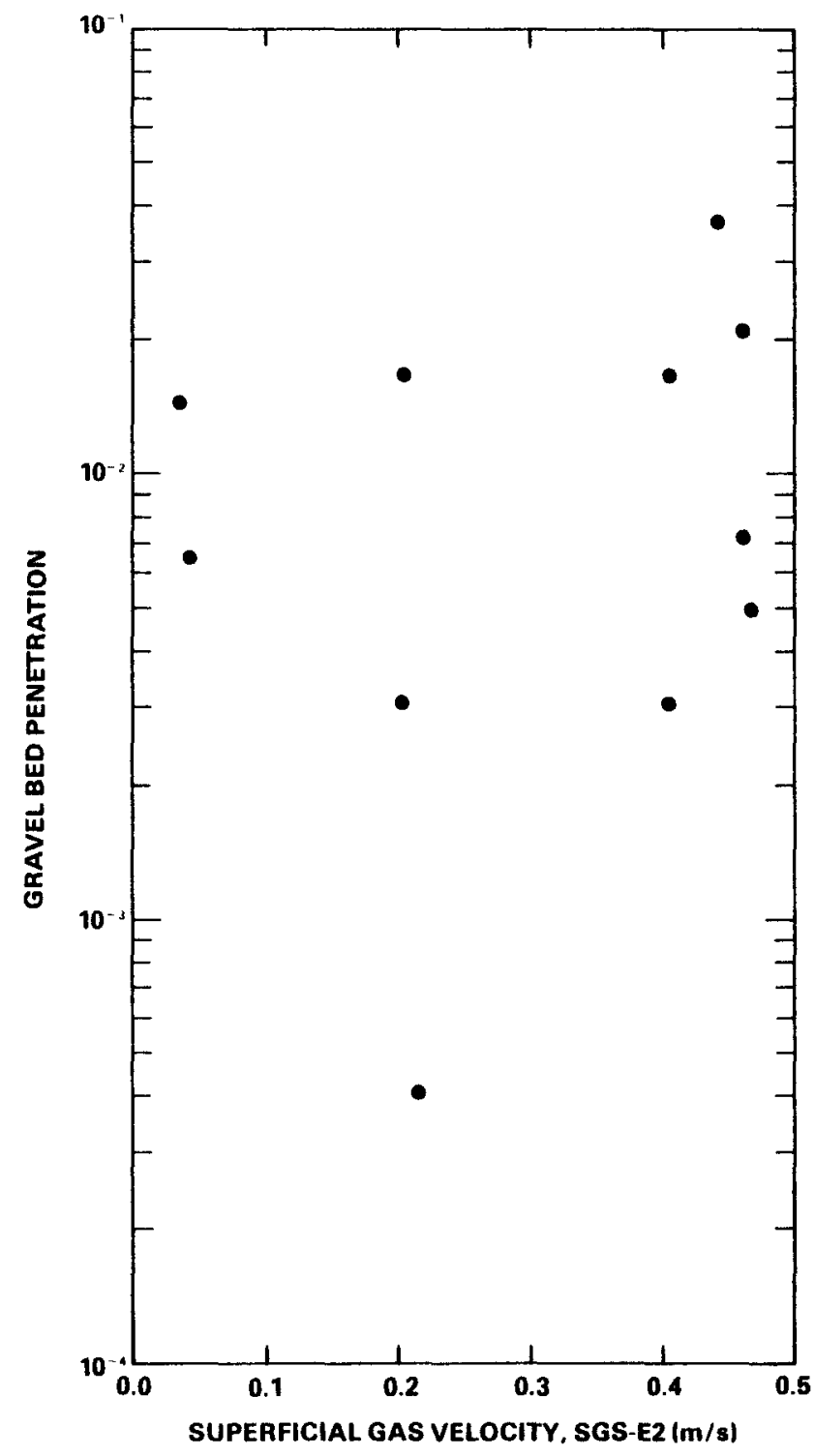

FIGURE 53. Bed Penetration vs Gas Velocity, Test SGS-E2. 8010211-14 


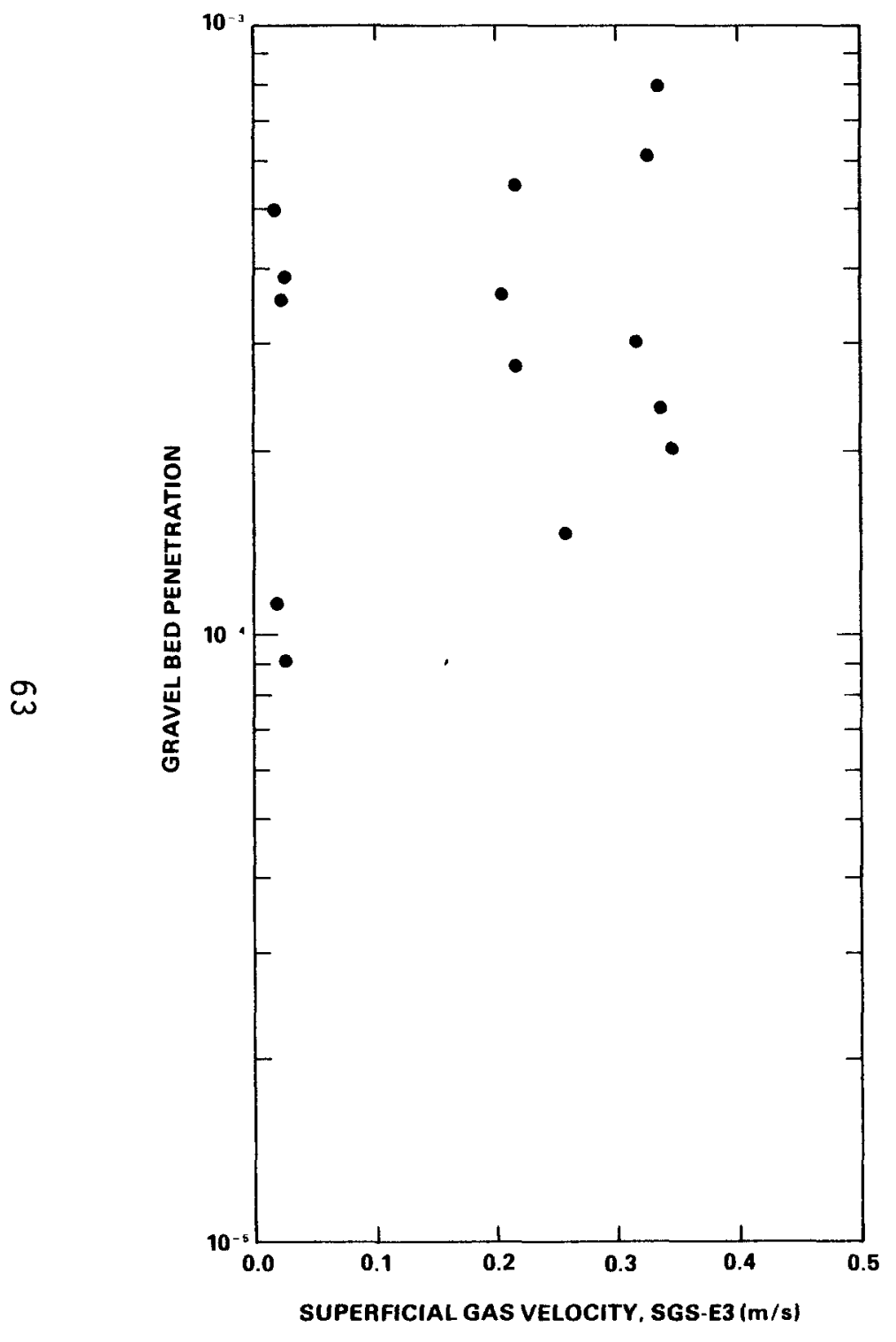

MEDL 200901515

FIGURE 54. Bed Penetration vs Gas Velocity, Test SGS-E3. 8010211-24

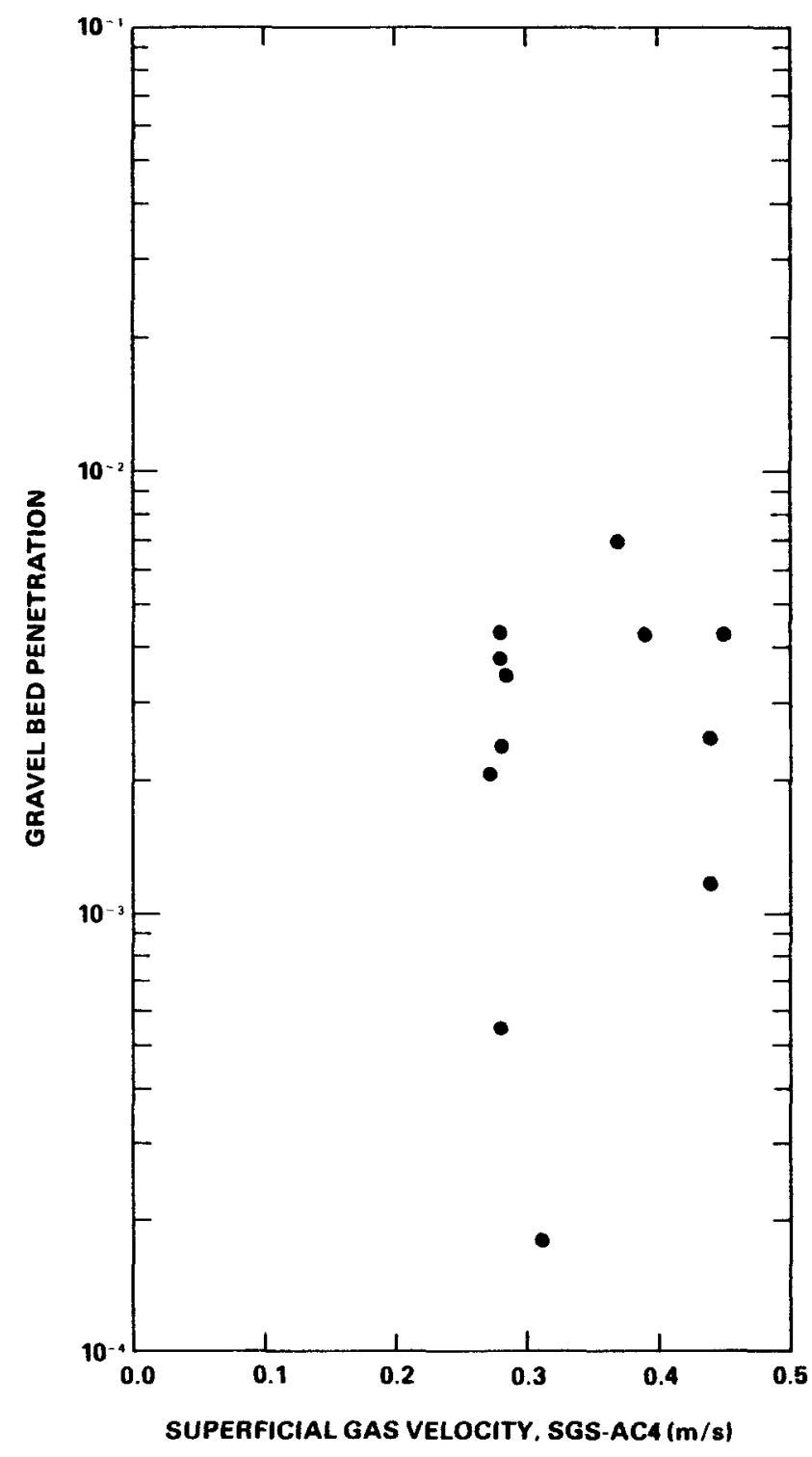

MEDL 800001517

FIGURE 55. Bed Penetration vs Gas Velocity, Test SGS-AC4.

8010211-13 


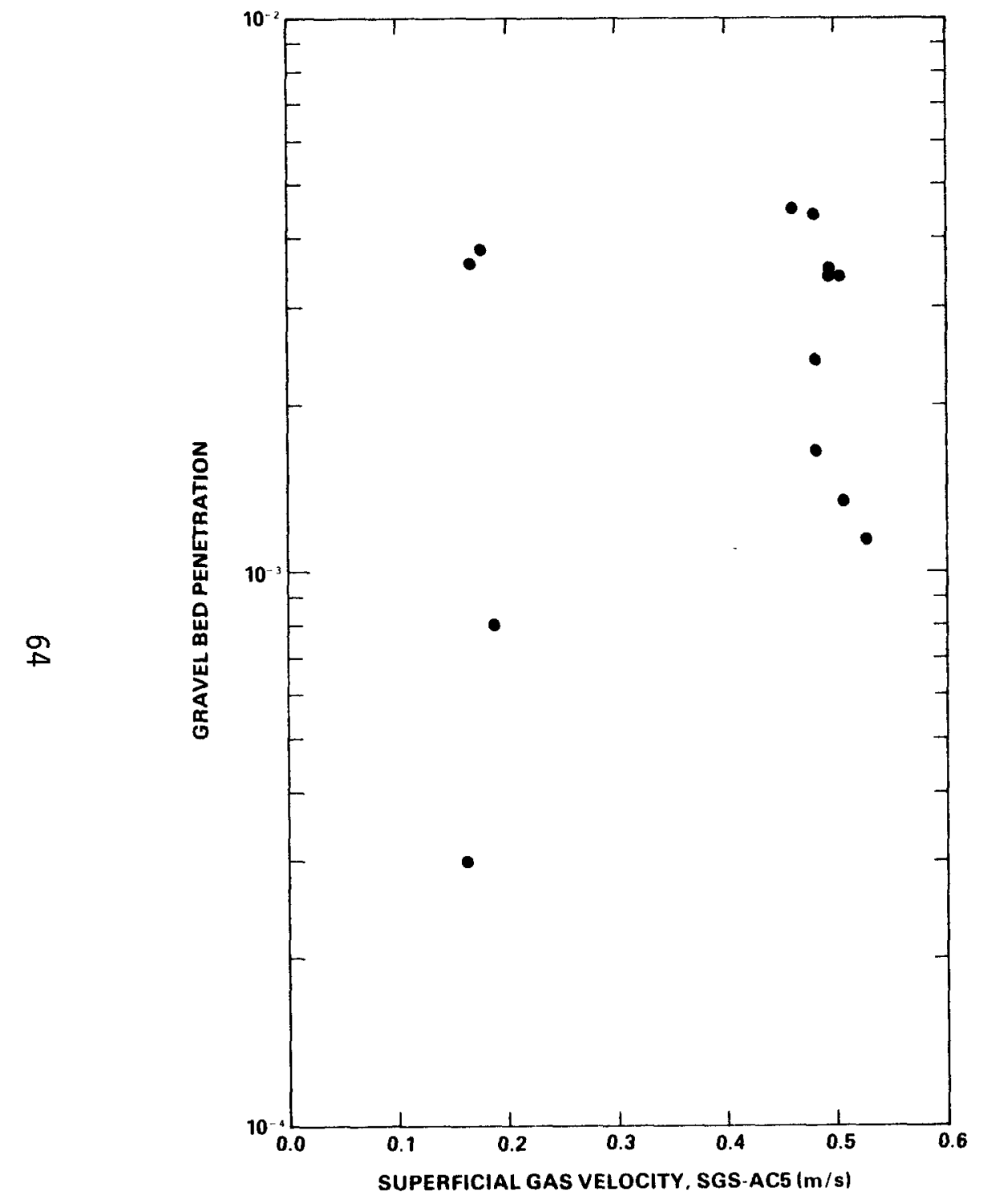

HED1 800901519

FIGURE 56. Bed Penetration vs Gas Velocity, Test SGS-AC5.

8010211-18

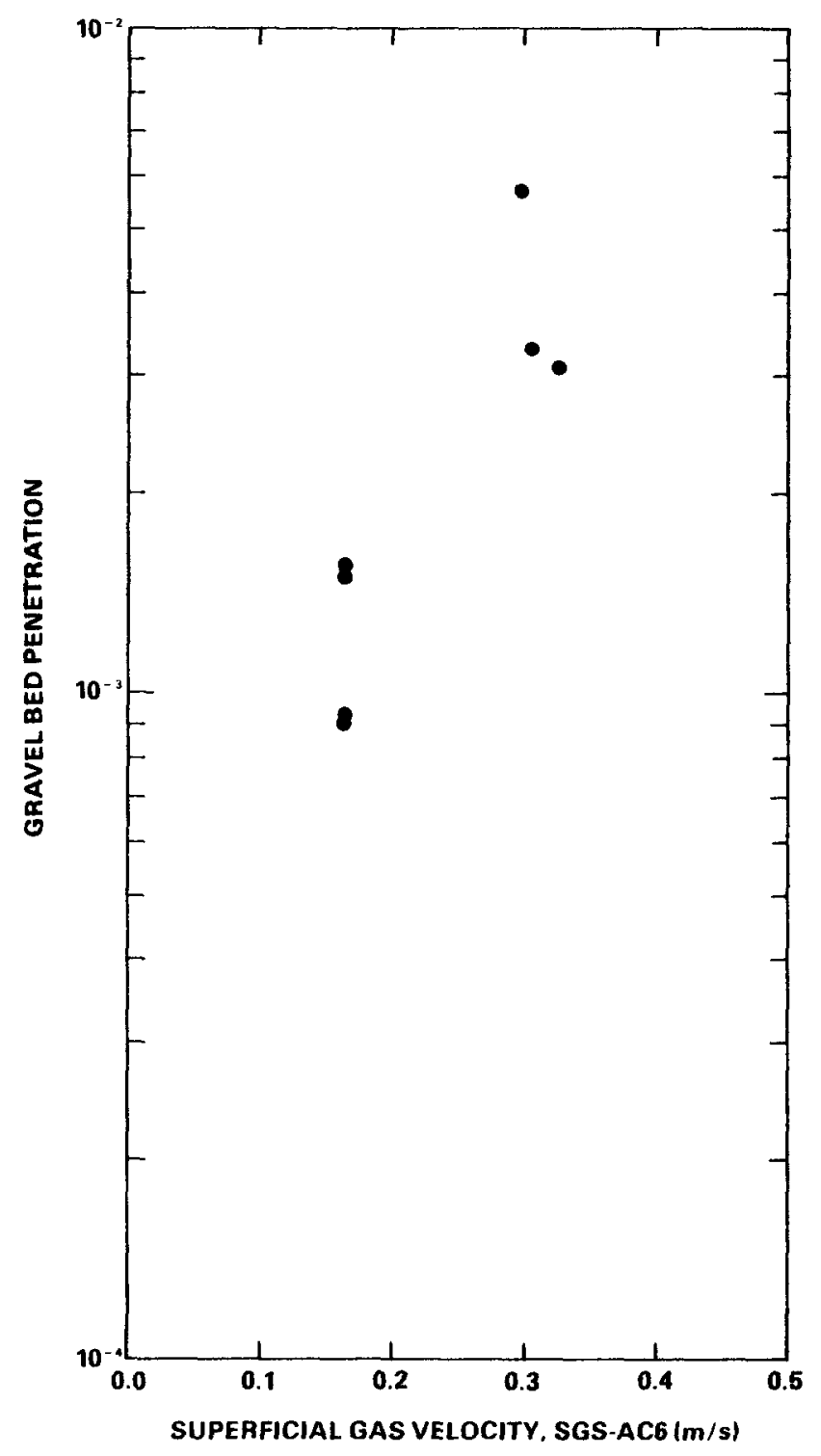

FIGURE 57. Bed Penetration vs Gaș Velocity, Test SGS-AC6. 


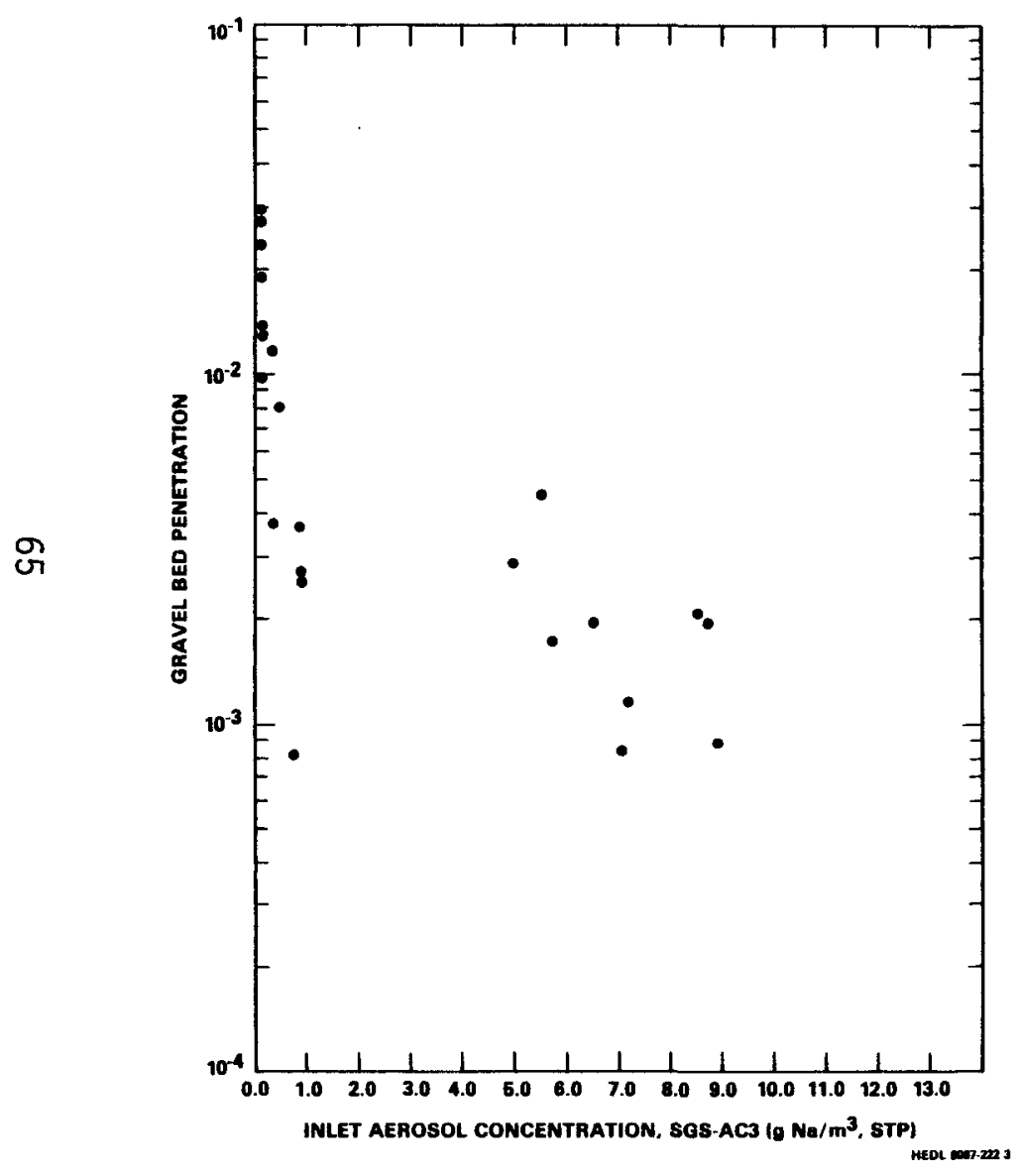

$808941-8$

FIGURE 58. Bed Penetration vs In let Concentration, Test SGS-AC3.

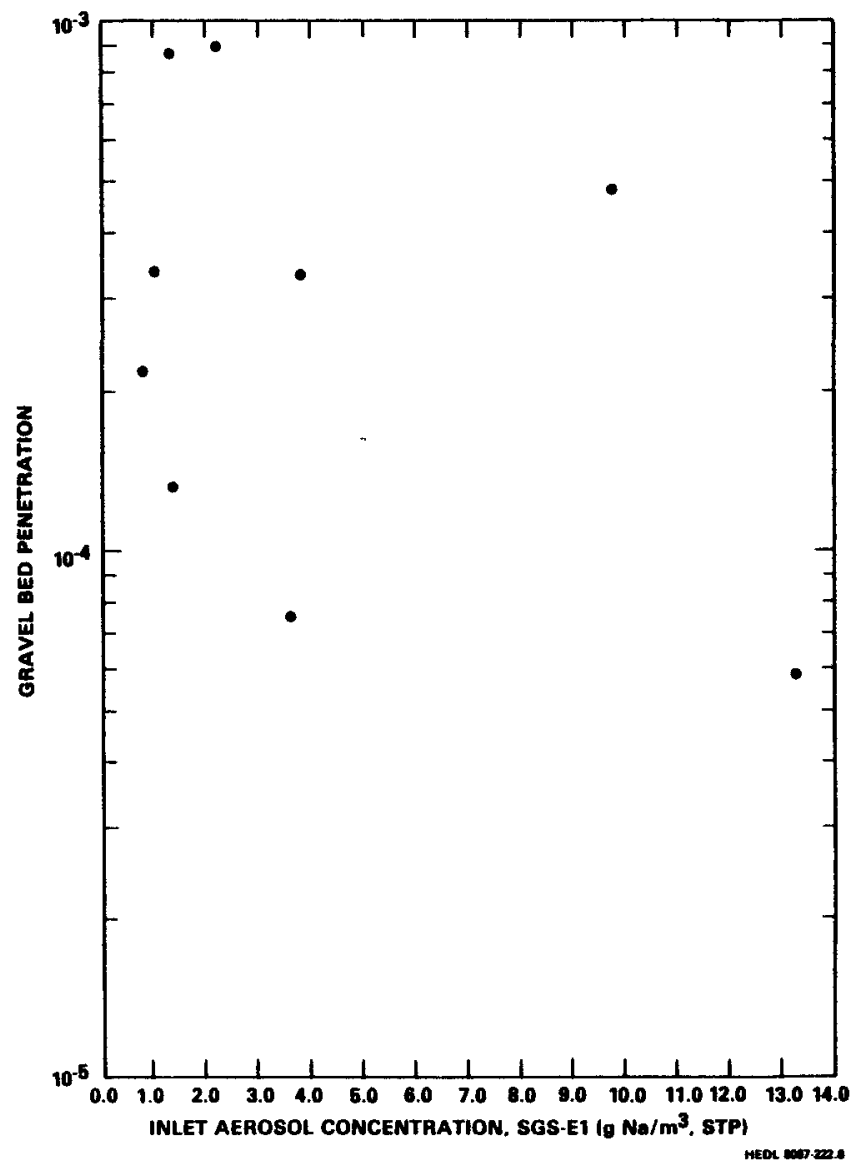

$808941-7$

FIGURE 59. Bed Penetration vs In let Concentration, Test SGS-E1. 


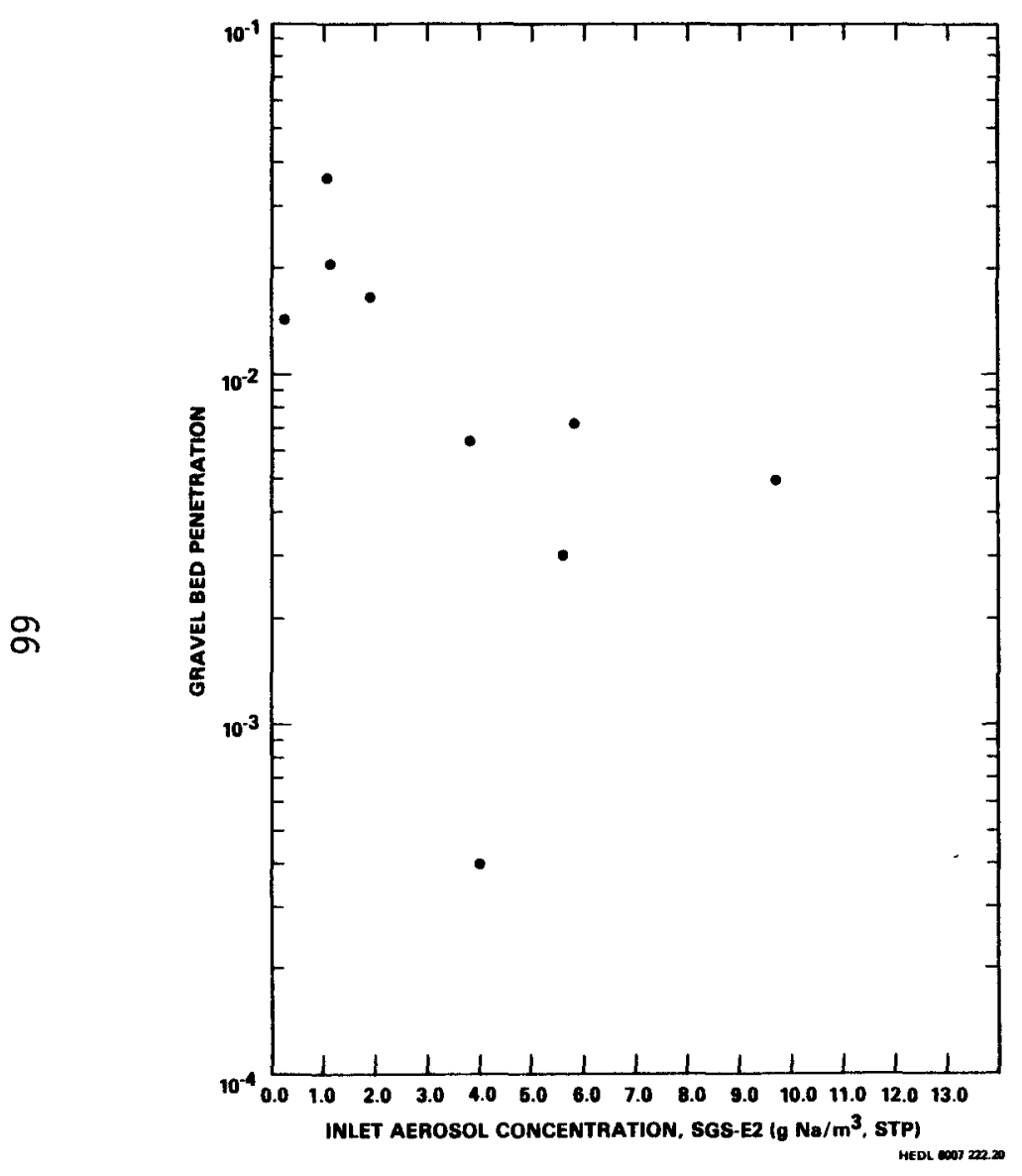

$808941-4$

FIGURE 60. Bed Penetration vs In let Concentration, Test SGS-E2.

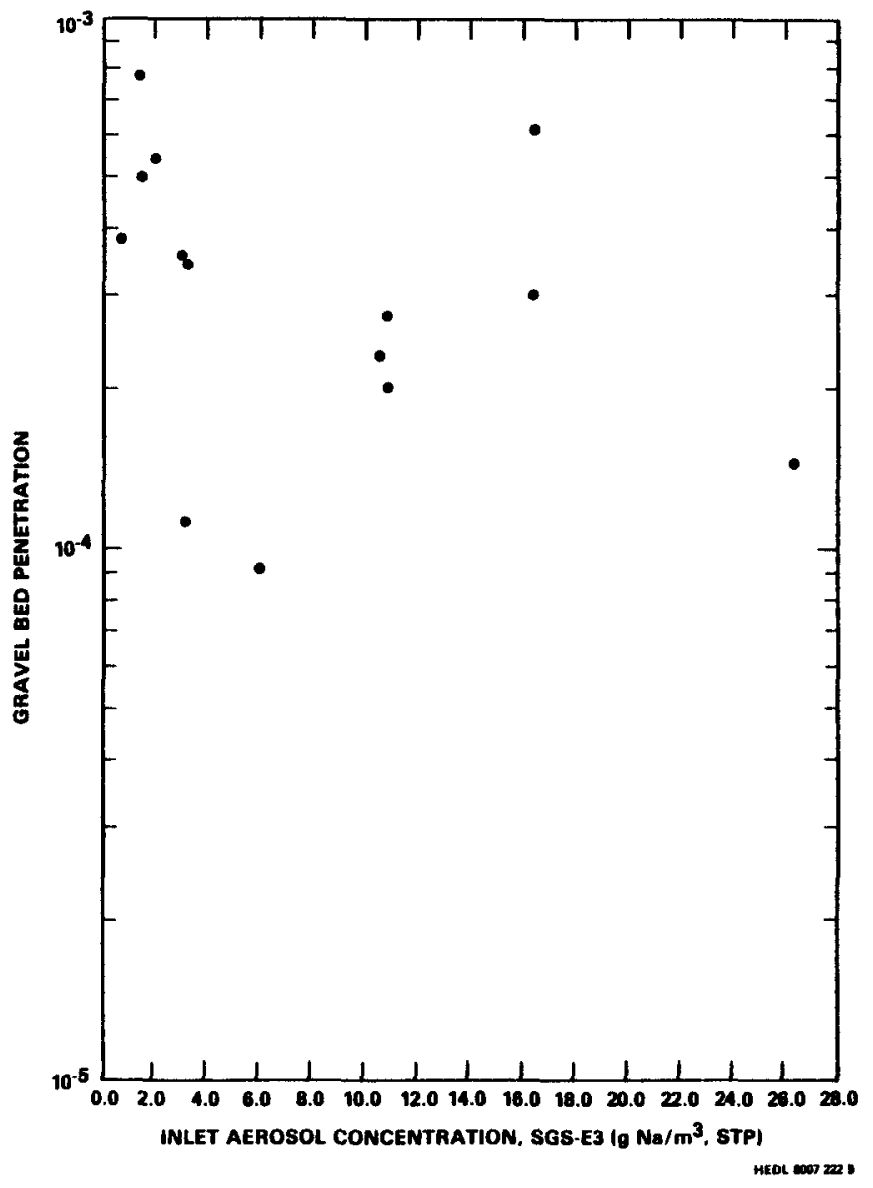

$808941-6$

FIGURE 61. Bed Penetration vs Inlet Concentration, Test SGS-E3. 


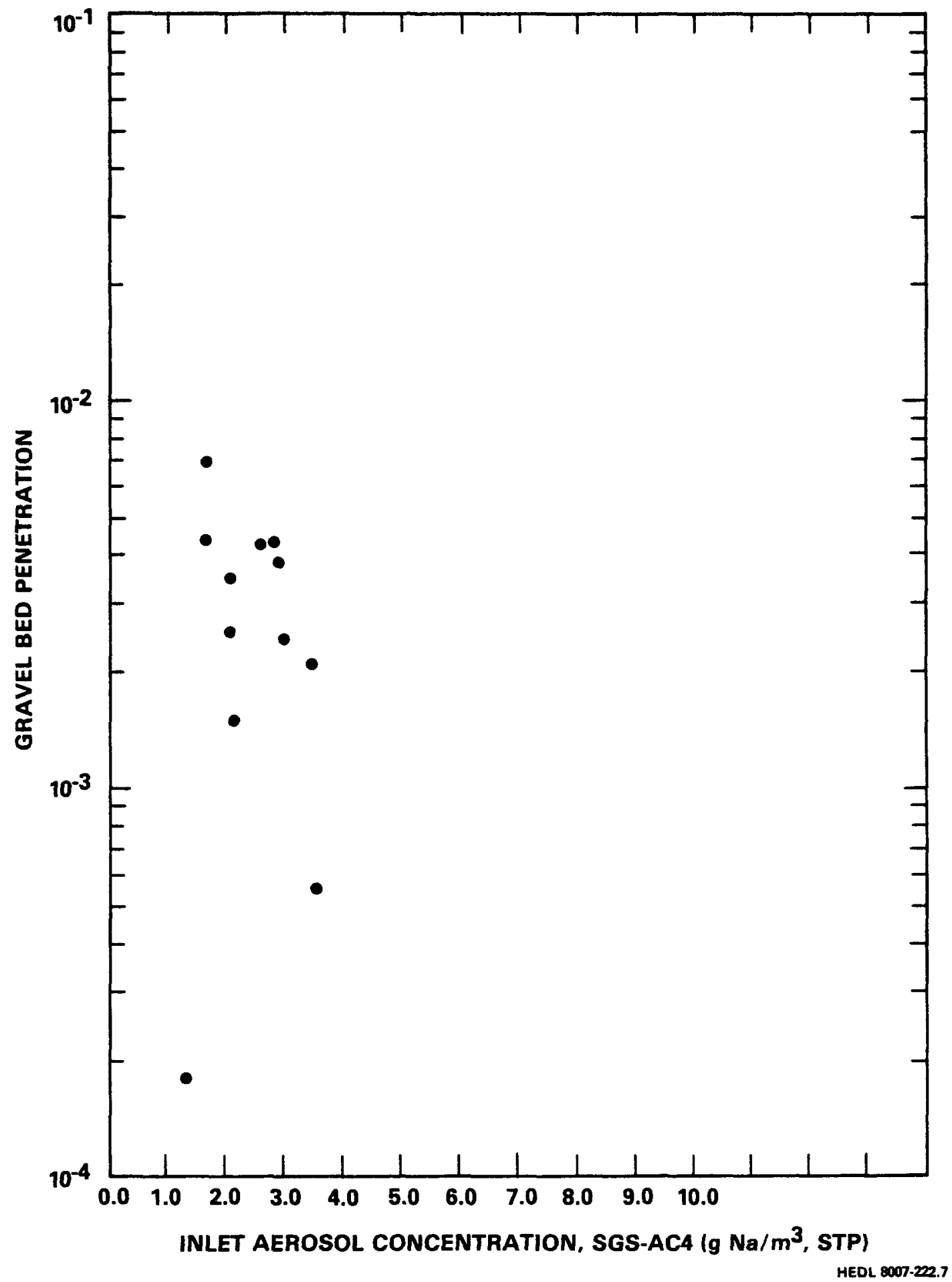

FIGURE 62. Bed Penetration vs Inlet Concentration, Test SGS-AC4. 808941-19 


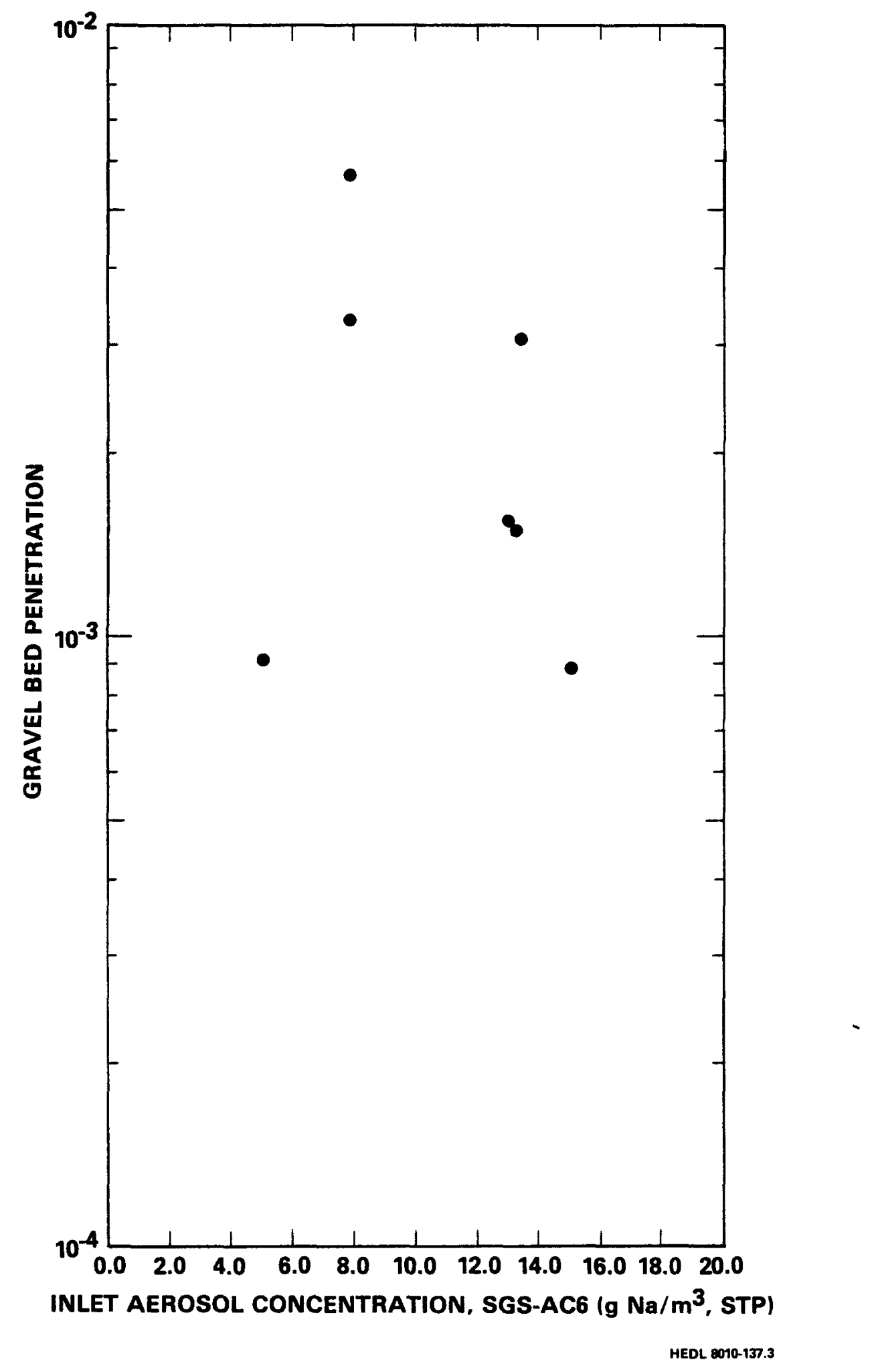

FIGURE 63. Bed Penetration vs Inlet Concentrations, Test SGS-AC6. 
TABLE 10

\section{SGS AEROSOL TEST RESULTS}

\begin{tabular}{|c|c|c|c|c|}
\hline Test & $\begin{array}{c}\text { Overal1 } \\
\text { Efficiency (a) } \\
\end{array}$ & $\begin{array}{c}\text { Average } \\
\text { Efficiency (b) }\end{array}$ & $\begin{array}{c}\text { Na Mass Collected, } \\
\text { grams }\end{array}$ & $\begin{array}{l}\text { Parameter } \\
\text { Tested (c) }\end{array}$ \\
\hline SGS-AC3 & 99.8 & 99.18 & 748 & Type of aerosol \\
\hline SGS-E1 & 99.8 & 99.97 & 590 & Type of aerosol \\
\hline SGS-E2 & 98.6 & 98.78 & 401 & Reduced bed height $(0.305 \mathrm{~m})$ \\
\hline SGS-E3 & 99.8 & 99.97 & 566 & $\begin{array}{l}\text { Reduced size of packing } \\
(0.64-0.95 \mathrm{~cm})\end{array}$ \\
\hline
\end{tabular}

(a) Determined by mass collected in scrubber solution and on a final HEPA filter, assuming HEPA efficiency $100 \%$.

(b) Determined by averaging the efficiencies calculated from aerosol samples from the inlet and out let ducts.

(c) The base bed design was a bed, $0.305 \mathrm{~m}$ in diameter and $0.610 \mathrm{~m}$ in height, consisting of crushed $(+0.95 \mathrm{~cm}$ to $-1.27 \mathrm{~cm})$ basalt rock. 
the scrubber removal efficiency for smaller particles should be reduced, point sampling gave lower efficiencies than the overall values.

In test $E-2$, the bed height was decreased by a factor of two. Based on overall efficiencies, the scrubber aerosol penetration increased by a factor of seven, or an exponential increase, over the deeper bed test. Reducing the size of the rocks to between $(+) 0.64$ to $(-) 0.95 \mathrm{~cm}$ for test $E-3$ had no apparent effect on the overall aerosol penetration of the scrubber.

For the next two tests, the scrubber was modified to include a demisting element, whose purpose was to capture the smaller sized particles and to eliminate liquid mist carry-over. The element chosen was a polypropylene H-E series Brink Mist Eliminator, manufactured by Monsanto*. The element, shown in Figure 64, was a Type 2424 RFUSD flow, hollow cylinder $0.61 \mathrm{~m}$ long by $0.61 \mathrm{~m} 00$. Fibers were packed between two galvanized carbon stee 1 screens to form the $7.6-\mathrm{cm}$ thick wall of the cylinder.

The demister was operated such that gas traveled up through the center of the element and radially outward through the fibers. Aerosol was removed by interception, Brownian diffusion, and inertia forces. Mist carried by the gas collected on the fibers and washed the element clean of soluble and insoluble material. The fiber size was measured as $20 \mu \mathrm{m}$ in diameter and the void fraction was calculated to be $85 \%$.

*Monsanto Enviro-Chem Systems, Inc., St. Louis, Missouri 63141 


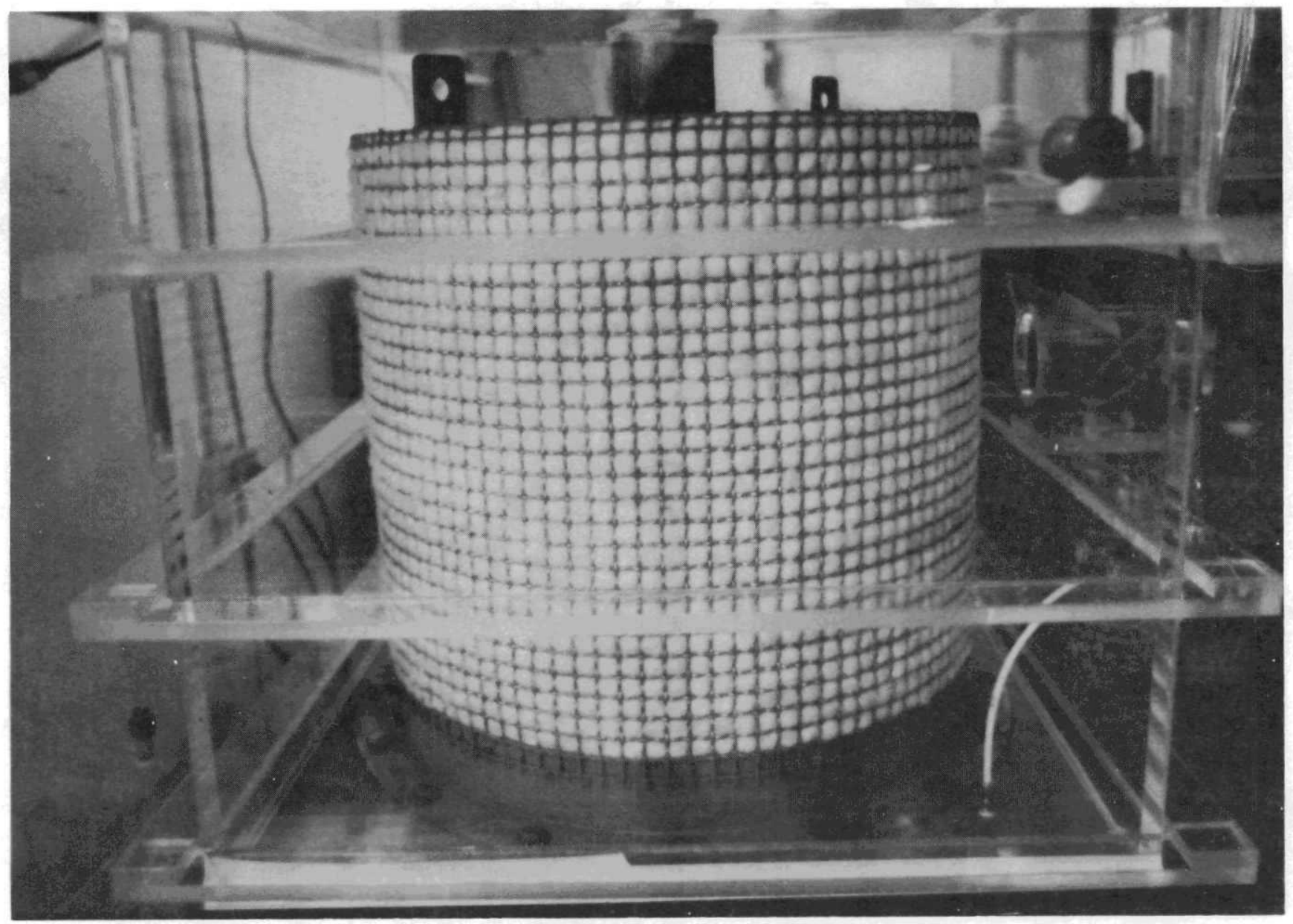

FIGURE 64. Demister Element. Neg 800152-10cn 
The element was bolted to a tube sheet fabricated from a $1 \mathrm{~m}$ by $1 \mathrm{~m}$ by $6 \mathrm{~mm}$ thick plate of 304 S.S. A $0.61-m$ diameter hole was cut in the center, and the element was bolted over the hole. The tube sheet was set on the top edge of the tank and was sealed with tape. The gas inlet duct passed through a 7.6-cm pipe union welded to the top plate of the element. A new lid, $0.76 \mathrm{~m}$ high, was constructed to cover the fiber element. The assembled unit is shown in Figure 65 .

Tests AC4 and AC5 were performed using the fiber element. Aerosol concentrations were measured at the gas inlet and outlet, and additionally in the gas space between the top of the submerged bed and the inside of the fiber element. The scrubber aerosol penetrations given previously for these tests were based on the gas aerosol concentration leaving the submerged gravel bed. Overall scrubber penetration versus time for tests AC4 and AC5 are given in Tables 11 and 12. A plot of aerosol penetration as a function of scrubber inlet aerosol concentration for test AC4 is given in Figure 66. As pointed out earlier, a constant inlet aerosol concentration was assumed for test AC5.

A stainless steel demister pad, manufactured by York*, was evaluated in test AC6 for aerosol collection and entrainment removal. The pad, part no. GWGL8TK-304-QRW304, was $15.2 \mathrm{~cm}$ square by $20.3 \mathrm{~cm}$ deep and was rated by the manufacturer as removing $99 \%$ of $1 \mu \mathrm{m}$ droplets entering the element. A plate and lid were fabricated to hold the demister and are shown in Figure 67. The overall scrubber penetration was calculated and is presented in Table 13. During the test, aerosol or mist was visible in the aerosol stream leaving the demister. The demister pad apparently was not effective in capturing entrained liquid mist or aerosols penetrating the SGS. As the impactor results in Appendix B show, the particles exiting the pad were predominantly submicron in diameter.

*0tto H. York Co., Inc., Fairfield, New Jersey 07006 

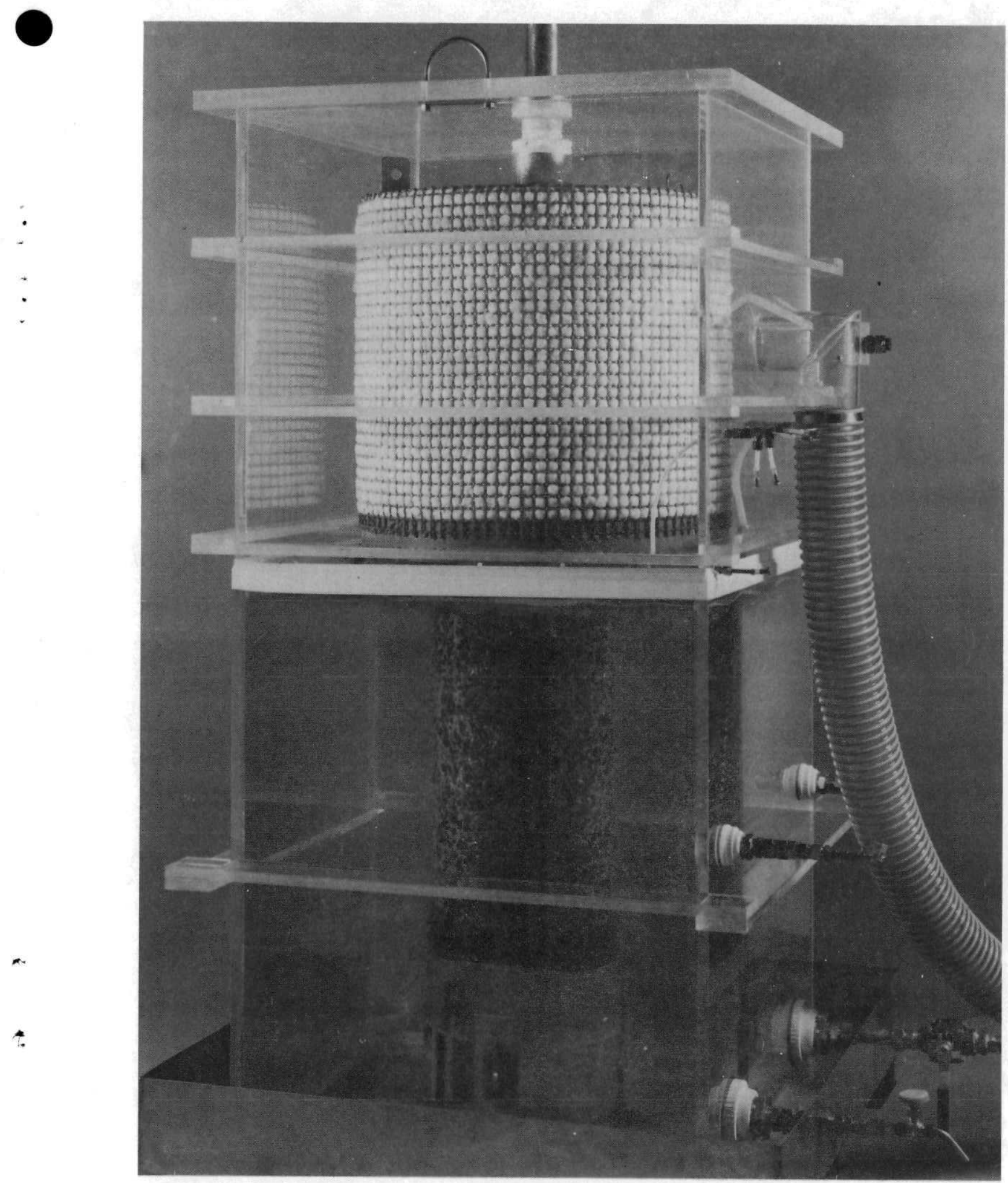

FIGURE 65. SGS/HEFD Unit. Neg 7908846-4cn 


\section{SGS/HEFD PENETRATION, TEST SGS-AC4}

Run Time (min.)

$$
\begin{array}{r}
391 \\
441 \\
492 \\
689 \\
840 \\
1399 \\
1442 \\
1800 \\
1846 \\
1902 \\
1963 \\
2014 \\
2079 \\
2210 \\
2314
\end{array}
$$

Overall Penetration (based on aerosol collected in scrubber and back-up HEPA filter)
SGS/HEFD Penetration

$5.0 \times 10-6$

$6.2 \times 10^{-6}$

$9.1 \times 10^{-6}$

$5.4 \times 10^{-6}$

$8.2 \times 10^{-5}$

$3.4 \times 10^{-6}$

$1.1 \times 10^{-5}$

$1.3 \times 10^{-5}$

$1.1 \times 10^{-5}$

$6.3 \times 10^{-6}$

$5.2 \times 10^{-6}$

$1.7 \times 10^{-5}$

$1.5 \times 10^{-5}$

$2.8 \times 10^{-5}$

$5.1 \times 10^{-5}$

$1.4 \times 10^{-4}$ 
TABLE 12

SGS/HEFD PENETRATION, TEST SGS-AC5

Run Time (min.)

323

383

443

523

605

1162

1272

1358

1425

1498

1534

1666

1716

Overa 71 Penetration (based

on aerosol collected in

scrubber and back-up HEPA
SGS/HEFD Penetration (a)

$4.0 \times 10^{-5}$

$5.6 \times 10^{-5}$

$1.9 \times 10-5$

$7.7 \times 10^{-5}$

$1.2 \times 10^{-4}$

$2.8 \times 10^{-4}$

$1.0 \times 10^{-4}$

$3.0 \times 10^{-4}$

$1.6 \times 10^{-3}$

$5.0 \times 10^{-4}$

$6.0 \times 10^{-4}$

$4.3 \times 10^{-4}$

$2.6 \times 10^{-4}$

$3.2 \times 10^{-4}$

(a) Due to non-isokinetic sampling, scrubber in let aerosol concentration samples showed unrealistically high concentrations. Therefore, based on the source chamber aerosol concentration, a constant inlet aerosol concentration of $5 \mathrm{~g} \mathrm{Na} / \mathrm{STD} \mathrm{m}^{3}$ was assumed. 


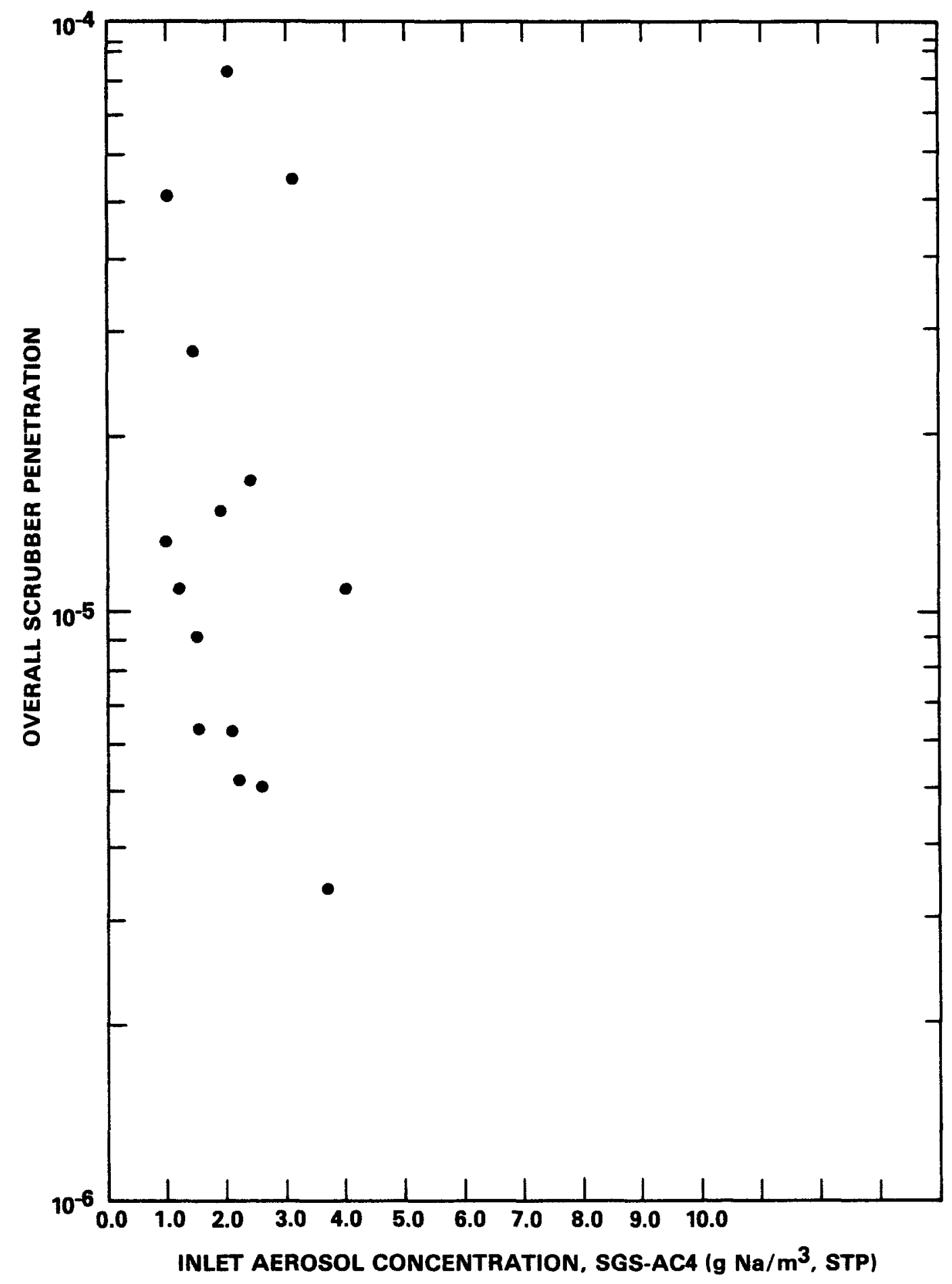

HEDL $8007-222.10$

FIGURE 66. SGS/HEFD Penetration vs In let Concentration, Test SGS-AC4. 

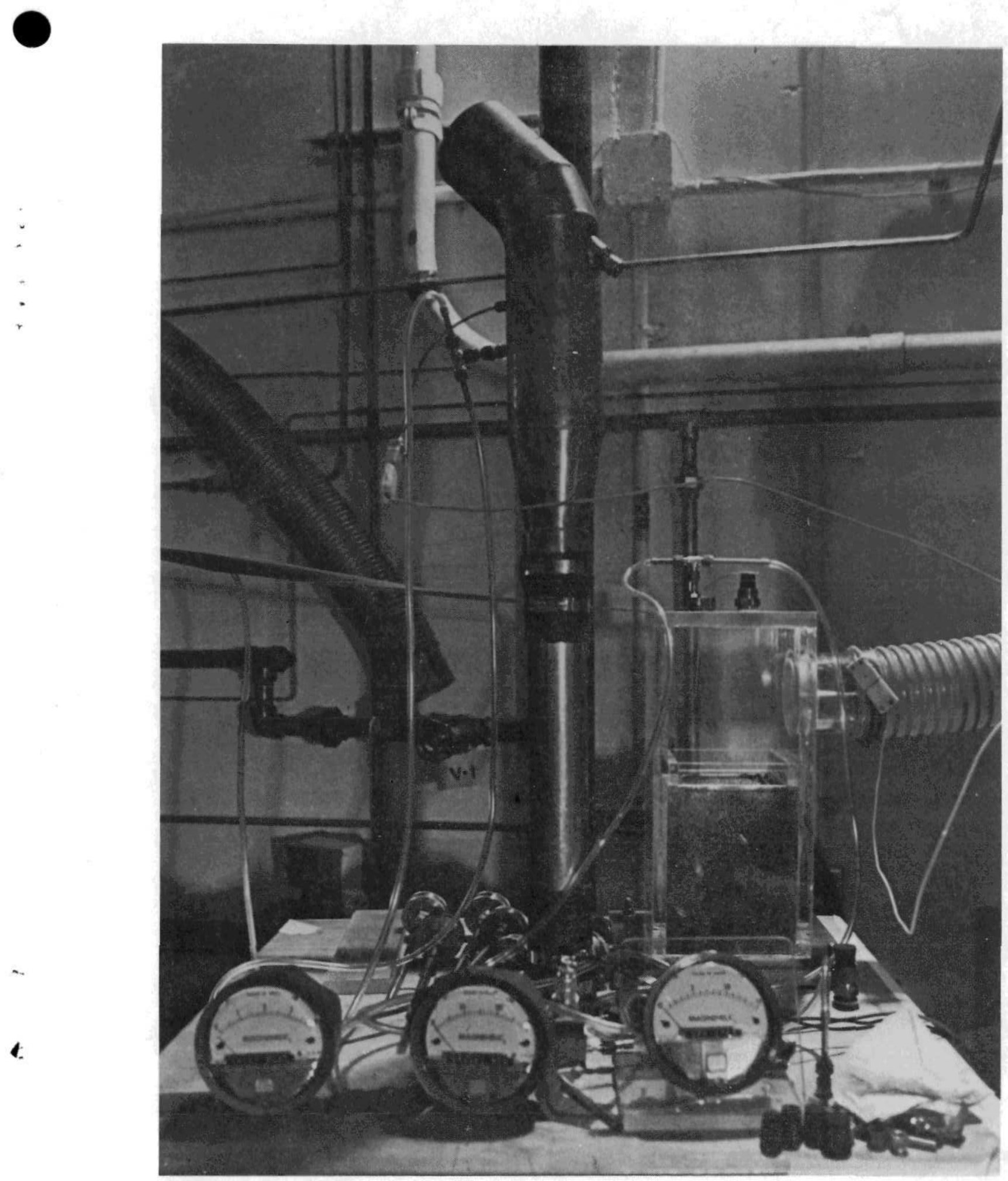

FIGURE 67. Demister Pad. Neg 8003456-4 
TABLE 13

SGS/DEMISTER PAD PENETRATION, TEST SGS-AC6

Run Time (min.) SGS/Demister Pad Penetration

102

123

139

284

302

362

517

Overall Penetration (based on aerosol collected in scrubber and back-up HEPA filter)
$2.4 \times 10^{-3}$

$3.9 \times 10^{-3}$

$3.9 \times 10^{-3}$

$1.5 \times 10^{-3}$

$1.2 \times 10-3$

$1.6 \times 10^{-3}$

$2.1 \times 10^{-3}$

$4.5 \times 10^{-3}$ 
The results of these tests are summarized in Table 14. The overall efficiencies are for the submerged bed/fiber element combinations. The average efficiencies were calculated, based on aerosol sampling, for the submerged bed and the fiber elements separately. The overall penetrations were at least an order of magnitude less for the Brink element tests than the previous tests, due to the fiber bed eliminating the carryover mist and capturing the smaller aerosol particles. The lower efficiencies for test SGS-AC5 were attributed to a leaking seal between the SGS and HEFD. However, the system performance was still acceptable.

The total experience on removing sodium aerosols sums to $5330 \mathrm{~m}^{3}$ of gas processed, removing $32.7 \mathrm{~kg}$ of aerosol, while operating for a total of 78 hours. During the tests, the superficial gas velocity was varied from 0.25 to 0.508 meters per second. The inlet gas temperature varied from room temperature to $125^{\circ} \mathrm{C}$, and the gas was cooled essentially to the scrubber liquid temperature in a 11 cases.

\subsection{DOP TESTS}

To evaluate the scrubber performance on small particles, a DOP test was performed. Dioetylphthalate (DOP) is a saturated paraffin oil with a boiling point of $230^{\circ} \mathrm{C}$. The oil was aspirated into a gas stream by using air pressure, thereby creating an hydrophobic aerosol with a 0.2 to 0.8 mass median diameter. This size of particle has been shown to be the most difficult to remove from a gas stream $(7)$. The DOP test is commonly used to evaluate aerosol penetration through high efficiency particulate (HEPA) filters used in the nuclear industry ${ }^{(8)}$.

* The generator used was a Model TDA-4A manuf actured by ATI*. The aerosol concentration was measured by photometric analysis using a photometric instrument, Model TDA-2DN. A test was performed at four gas flowrates for the following bed configurations: no packing; packing without water; and a

*Air Techniques, Inc., Baltimore, Maryland 21207 
TABLE 14

SGS SYSTEM AEROSOL TEST RESULTS

\begin{tabular}{|c|c|c|c|c|}
\hline Test & $\begin{array}{c}\text { Overal1 } \\
\text { Efficiency (a) }\end{array}$ & $\begin{array}{c}\text { Average } \\
\text { Efficiency (b) }\end{array}$ & $\begin{array}{c}\text { Na Mass Collected, } \\
\text { grams }\end{array}$ & $\begin{array}{l}\text { Parameter } \\
\text { Tested (c) }\end{array}$ \\
\hline SGS-AC4 & $(99.996)$ & $99.70(99.998)$ & 4517 & Fiber element added (d) \\
\hline SGS-AC5 & $(99.97)$ & $99.74(99.97)$ & 8983 & $\begin{array}{l}\text { Fiber element added, packing } \\
\text { size }(1.11-1.59 \mathrm{~cm})\end{array}$ \\
\hline SGS-AC6 & $(99.55)$ & $99.76(99.96)$ & 3007 & S.S. demister pad (e) \\
\hline
\end{tabular}

(a) Determined by mass collected in scrubber solution and on a final HEPA filter, assuming HEPA efficiency $100 \%$.

(b) Determined by averaging the efficiencies calculated from aerosol samples from the inlet and out let ducts.

(c) The base bed design was a bed, $0.305 \mathrm{~m}$ in diameter and $0.610 \mathrm{~m}$ in height, consisting of crushed $(+.95 \mathrm{~cm}$ to $-1.27 \mathrm{~cm})$ basalt rock.

(d) Values in parentheses are for the scrubber and fiber element combination.

(e) Value in parentheses is for the scrubber and demister pad combination. 
submerged bed. The results are given in Table 15. The SGS removal efficiency for this size of aerosol was low, as would be expected. The gas flowrate did not affect the scrubber penetration of the particles.

TABLE 15

DOP PENETRATION

Bed Configuration

Water Pool (no packing)

Dry Bed (no liquid)

Submerged Gravel Bed
Penetration (superficial gas velocity, STD $\mathrm{m}^{3} / \mathrm{s}$ )

$0.80(0.16)$

$1.00(0.03)$

$0.92(0.43)$

$0.90(0.54)$

$0.82(0.07)$

$0.80(0.36)$

$0.82(0.62)$ 


\subsection{SCALEUP TESTS}

A major uncertainty in scaling the engineering model results to a larger unit lies in whether the gas would distribute evenly across the bottom of the bed. A "pie"-shaped bed element was built which represented a 24-deg segment of a circular bed $1.9 \mathrm{~m}$ in diameter. The segment was $0.15 \mathrm{~m}^{2}$ in area and held a $0.61-m$ deep bed of rock. Air was pulled through the bed by using a blower on an auxiliary system within the test facility. The test apparatus is pictured in Figure 68.

The air distribution was relatively even across the bed. At low gas velocities, gas predominantly occupied the portion of the bed towards the inlet duct. At a gas velocity of 0.51 meters per second, the gas distributed completely across the bed. The gas pulsing caused a layer of gas to form across the bottom of the bed, just as in the smaller scale tests, and this layer distributed the gas equally across the bed. In addition, the pulsing created a liquid wave across the bottom of the gas layer which was judged to enhance the liquid washing of the bed.

Scaleup of the bed with respect to aerosol removal is not necessary, because the test apparatus was already at a macro-scale with respect to the collection mechanisms. The scaleup test demonstrated that a unit scaled up to process $0.50 \mathrm{~m}^{3}$ (STP)/s would function satisfactorily.

\subsection{THEORETICAL CONS IDERATIONS}

Concurrent liquid-gas flow through a packed bed has been used infrequently in industry, with the exception of certain concurrent gas absorption schemes. Consequently, little theoretical work has been published on the predictions of pressure drop and particle removal efficiencies in such devices. Whereas 


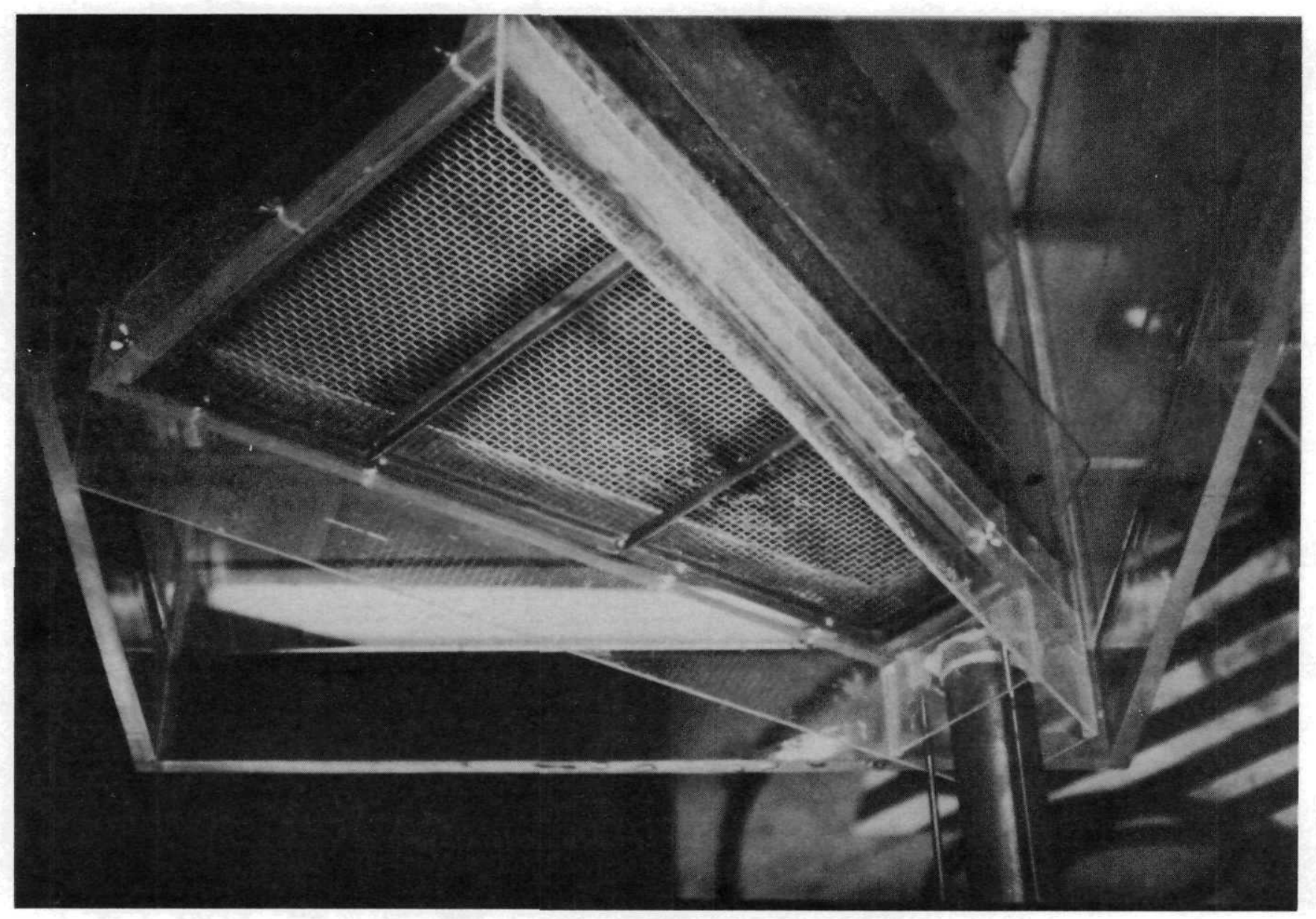


a theoretical model development is outside the scope of this project, comparisons will be made with those empirical models identified as applicable.

\subsection{HYDRAULICS}

A study was made by J.L. Turbin and R.L. Huntington ${ }^{(9)}$ on two-phase concurrent flow in a vertical packed tube using air and water. The liquid holdup and pressure drops were measured as a function of gas flowrate, fluid temperature, and liquid flowrate. The authors noted three distinct flow patterns and termed them bubble flow, slug flow, and spray flow. Figure 69, taken from Ref. 9, shows the flow regimes as a function of gas and liquid mass velocities. The circles have been added to indicate points that pertain to the SGS. The authors noted that the slug flow was characterized by alternating flows of predominatly gas and liquid phases. This description is equivalent to that given for the SGS, and lends credence to the belief that the flow patterns through the bed are not characteristic of the blower and ducting arrangement, but are fundamentally linked to the design concept.

The liquid holdup in the bed, termed liquid saturation (Rv) in Ref. 9, was measured and empirical data ${ }^{(10)}$ were analyzed by Turbin and Huntington to give the following correlation for upward flow:

$$
\begin{aligned}
R v= & -0.035+0.182\left(G_{1} / G_{g}\right) 0.24 \\
& \left(1.0 \leq\left(G_{7} / G_{g}\right)^{0.24} \leq 6.0\right)
\end{aligned}
$$

where; Rv = liquid saturation, the fraction of the total bed volume occupied of liquid, dimensionless

$G_{1}=1$ liquid mass flowrate, $1 \mathrm{bm} / \mathrm{min}_{-} \mathrm{ft}^{2}$

$G_{g}=$ gas mass flowrate, $1 \mathrm{bm} / \mathrm{min}-\mathrm{ft}^{2}$

The liquid saturation was noted to be a weak function of the bed porosity and did not vary abruptly from one flow regime to another. Using this correlation, the liquid holdup of the SGS would range from 0.12 to 0.20 :

The pressure drop development in the paper is not pertinent to this application, because the arrangement of the apparatus did not allow a layer 


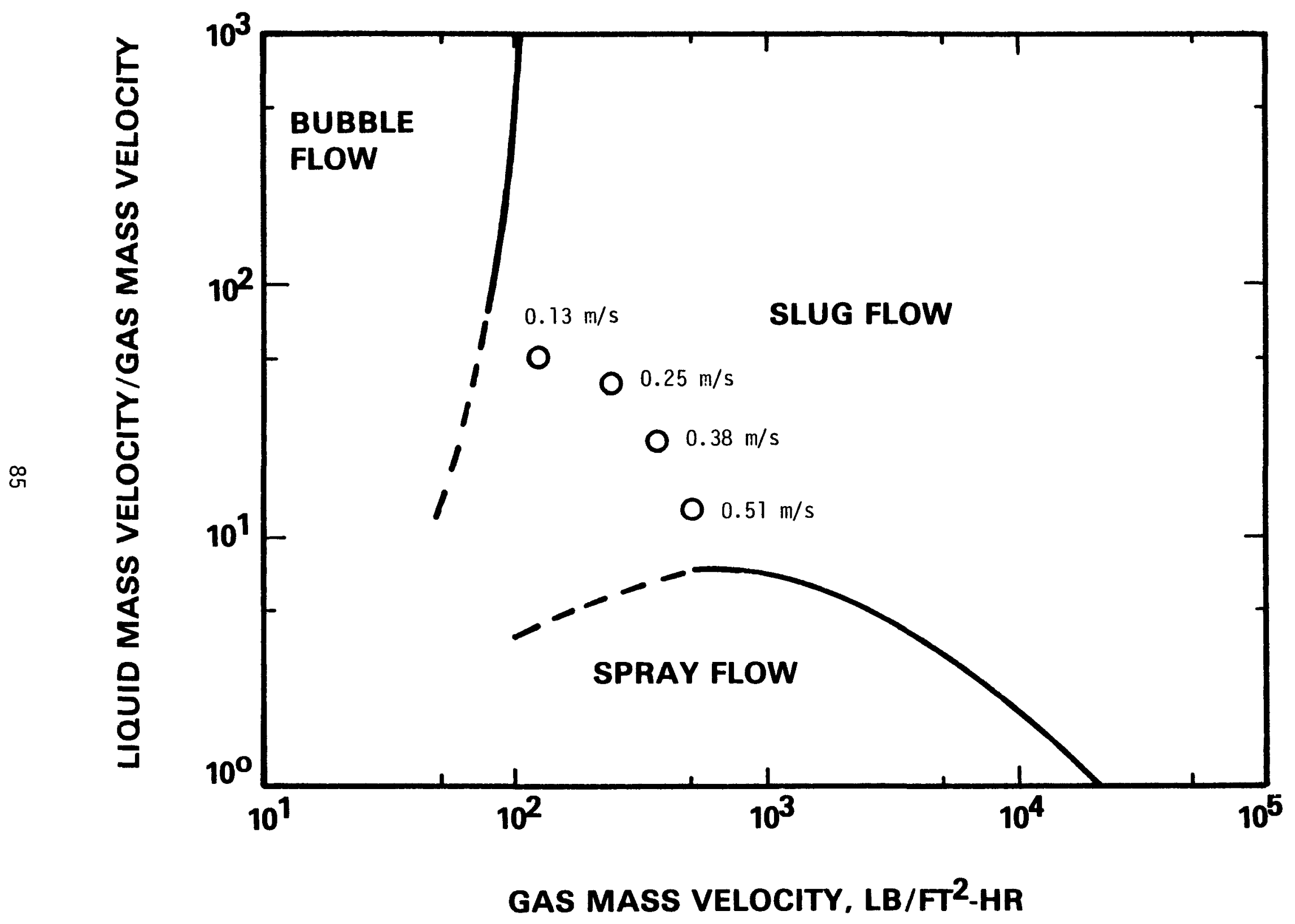

FIGURE 69. Submerged Packing Flow Patterns. 
of gas to build up below the packing. As noted earlier, the pressure drop across the submerged bed is the sum of the static head and the thickness of the layer of gas below the bed. In addition, as the layer of gas is pulsating in thickness, the total pressure drop pulsates. At higher gas flowrates, the bed enters into the spray regime, and predictions are available for pressure drop across the wetted bed. However, since the SGS is always operated below this regime, these are not applicable. Additional experimental work would be useful in defining the hydrodynamics of this pulsating flow.

\subsection{AEROSOL COLLECTION}

Aerosols generated by condensation are generally considered to have lognormal distribution of particle size. Experimental results have verified this in the case of sodium fire aerosols (11). The log-normal particle distribution density is given by:

$$
\begin{aligned}
\frac{1}{W_{c}} \quad \frac{d W_{c}}{d\left(\ln d_{p}\right)} & =\frac{1}{\sqrt{2} \pi \ln \sigma_{g}} \exp \left[-\frac{\left(\ln d_{p}-\ln d_{p g}\right)}{\sqrt{2} \ln \sigma_{g}}\right] \\
\text { where: } W_{c} & =\text { total weight of particles, grams } \\
d_{p} & =\text { diameter of particle, microns } \\
d_{p g} & =\text { mass median diameter, microns } \\
g & =\text { geometric standard deviation, dimensioniess }
\end{aligned}
$$

When the distribution is ploted on log-normal paper, with the particle size on the $\log$ axis and the associated cumulative mass fraction less than a given size on the normal axis, the particle size data plots as a straight line. The mass median diameter $\left(d_{p g}\right)$ is the diameter at which $50 \%$ of the aerosol mass is smaller than; the geometric mean $\left(\sigma_{g}\right)$ is given by the diameter at $84.3 \%$ cumulative mass divided by $\mathrm{d}_{\mathrm{pg}}$ : The two parameters, $d_{p g}$ and $\sigma_{g}$, define the distribution.

The overall penetration of an aerosol distribution of particles through a scrubber is determined by integrating the penetration of a given size of 
particle over all particle diameters. To determine the penetration based on mass, the mass fraction of each particle is used to weigh the penetration: $\bar{P}_{t}=\int_{0}^{\infty} P_{t}(d p) d[d p]$

Given the distribution parameters of the aerosol, $d_{p g}$ and $\sigma_{g}$, and the penetration of aerosol through the device as a function of particle diameter, the overall mass penetration could be calculated. Therefore, it is necessary to be able to predict the scrubber penetrations as a function of the particle diameter.

The basic mechanisms of aerosol separation from a gas stream are:

- Inertial impaction

- Direct interception

- Brownian diffusion

- Thermophoresis

- Particle growth by condensation

- Diffusiophoresis

- Gravitational settiing

- Centrifugal forces

- Eddy diffusion

- Electrostatic separation

- Agglomeration

The primary mechanisms in the SGS would be inertial impaction, direct interception, and Brownian diffusion. In addition, thermophoresis, diffusiophoresis, and particle growth may occur simultaneously under conditions of water condensation in the scrubber, and this combination is designated as flux force/condensation $(F / C)^{(12)}$ scrubbing.

As gas flows through the bed of packing, the gas streamlines approaching an obstacle diverge and flow around the object without touching it. The distance upstream the flow is perturbated is dependent on the local gas velocity. At higher gas velocities, the streamlines diverge more rapidly and closer to the body. A particle flowing along a gas streamline will tend to 
continue traveling along a straight line due to its momentum as the streamline diverges. Larger particles have greater inertia and thus are more likely to deviate from streamlines than smaller particles and be collected. Typically, inertial effects are insignificant on particles less than $0.5 \mathrm{~m}$ in diameter, and impaction is the primary collecting mechanisn for particles greater than $1 \mathrm{~m}$ in diameter.

The parameter characterizing impaction is the Stokes number, or impaction parameter:

$$
\text { Stk }=\psi=\frac{C_{c}{ }_{p} d_{p}^{2} v_{p}}{18 \mu_{f} d_{c} 10^{4}}
$$

where: $\psi=$ impaction parameter, dimensionless

$\rho_{p}=$ density of the paticle, $\mathrm{g} / \mathrm{cm}^{3}$

$d_{p}=$ diameter of the particle, $m$

$v_{p}=$ velocity of the particle, $\mathrm{cm} / \mathrm{sec}$

$\mu_{f}=V$ iscosity of the fluid, $\mathrm{gm} / \mathrm{cm}-\mathrm{sec}$

$d_{c}=$ diameter characteristic of the obstacle, $\mathrm{cm}$

$c_{c}=$ Cunningham slip correction factor, dimension less

$C_{C}$ is given by:

$$
c_{c}=1+A \frac{2 \lambda}{d_{p}}+Q \frac{2 \lambda}{d_{p}} \exp \left(-\frac{b d_{p}}{2 \lambda}\right)
$$

where: = mean free path of gas molecules, $\mathrm{cm}$

$$
\begin{aligned}
= & 6.4955 \times 10^{-9}\left(T^{\mathrm{OK}}\right)^{1.24} \mathrm{P} \text { atm, as determined from the } \\
& \text { data of Dushman }(13) \\
A= & \text { empirical constant } \\
Q= & \text { empirical constant } \\
\mathrm{b}= & \text { empirical constant }
\end{aligned}
$$

The impaction parameter is defined as the ratio of the force necessary to stop a particle initially at the gas superficial velocity, $v_{s}$, in a distance of $\frac{1}{2} d p$, to the fluid resistance at the particle velocity, $v_{p}$. It can also be defined as the ratio of the distance a particle will penetrate 
- into still air when moving at its initial velocity to the diameter of the collector.

The efficiency of a particle colliding with a single obstacle by impaction, $n_{I}:$

$$
{ }^{n} I=\frac{S t k^{2}}{(S t k+.5)^{2}}
$$

is a function of both the Stokes number and the Reynolds number. The collection efficiencies of a single sphere are reported $(14)$ to be neglibible for $\sqrt{\psi<0.2}$. The collection efficiencies of spheres in a bed would be higher, since the local gas velocities would be higher than the superficial gas velocity. The effect of interstitial water in the bed is to further increase the local gas velocities (by decreasing the bed void volume) while at the same time possibly reducing the irregularity of the rock surfaces.

For direct or flow interception, the center of the particle is assumed to follow the streamlines around the obstacle. Particles in certain streamlines, due to finite particle size and compression of the streamlines around the obstacle, will approach close enough to the collector surface such that the distance between the center of the particle and the surface is less than the radius of the particle. These particles will touch the collector and be captured. This mechanism is called interception and is characterized by the interception parameter, $R$. The parameter is defined as:

$$
\begin{aligned}
& R=d_{p} / d_{c} 10^{4} \\
& R=\text { interception parameter, dimensionless }
\end{aligned}
$$

Note that the parameter is independent of gas velocity. However, the particle collection efficiency by direct interception $n_{D I}$,

$$
{ }^{n} D I=\frac{3 d p}{d_{c} 10^{4}}
$$


depends on the Reynolds number, as this reflects the extent to which the streamlines are disturbed.

Brownian motion describes the diffusion of aerosol particles in a gas stream. Due to the bombardment of gas molecules, the trajectories of particles do not follow the streamlines of the gas and the particles diffuse from the gas stream to the collecting surface. As the intensity of Brownian diffusion increases with smaller particles, Brownian diffusion is the only mechanism which becomes more effective the smaller the aerosol size, and is the dominant mechanism for particles less than $0.1 \mathrm{~m}$ diameter. Brownian diffusion is a function of the Peclet number:

$$
\begin{aligned}
& P e=\frac{{ }_{c} V_{p}}{d_{v}} \\
& P e=P e c l e t \text { number, dimensionless } \\
& \hat{Q}_{v}=\text { Diffusion coefficient of aerosol particle in air, } \\
& \mathrm{cm}^{2} / \mathrm{sec} \\
& \mathbb{A}_{v}=\frac{R T c_{c}}{\operatorname{Na} 3 \pi \mu_{f} d_{p}} \\
& R=\text { Gas constant, } 8.315 \times 10^{7} \mathrm{ergs} / \mathrm{mo} \mathrm{e} /{ }^{\circ} \mathrm{C} \\
& \mathrm{Na}=\text { Avogadro's number, } 6.02 \times 10^{23} \\
& T=\text { Gas temperature, }{ }^{\circ} \mathrm{C}
\end{aligned}
$$

The Brownian diffusion collection efficiency for a single sphere, $B D$, is given (16) as:

$$
n_{B D}=\frac{1}{\mathrm{Pe}}+1.727 \mathrm{Re}^{1 / 6} \mathrm{Pe}^{-2 / 3}
$$

The flux force/condensation mechanism is pertinent to a scrubber which would operate in a manner such that condensation takes place. Flux force condensation is a combination of particle growth, diffusiophoresis, thermophoresis and Stephan flow. Under the predicted conditions that the scrubber would operate, the gas entering the scrubber would be at a high temperature and would have a variable water vapor content. While passing through the scrubber, the gas cools by evaporation of water, undergoes expansion, and performs work on the water in the bed. The gas may become supersaturated with water vapor and condensation may take place. During evaporation and 
condensation of water onto the surface of the bed channels, particles are swept away from or towards, respectively, the liquid surface by the flux of water molecules. This is called Stephan flow.

The associated temperature gradient drives particles down the gradient, because the particle is bombarded with gas molecules of higher average energy on the hot side of the particles relative to the gas molecules on the cooler side. This phenomenon is called thermophoresis.

If the gas is saturated and is cooled, the liquid vapor will condense. Since sodium aerosols are hygroscopic, the supersaturation required to cause condensation is very small. Water condensing on a particle causes particle growth and makes the particle subsequently easier to collect by inertial mechanisms. Diffusiophoresis induces particle motion in a concentration gradient of water vapor because the average molecular weight of the gas, and therefore the average energy, is higher on one side of the particle than the other. Although the flux/force condensation mechanisms may have a large effect on particle collection, the changes that occur in the gas stream as it flows through the bed are presently unknown. Thus, the effect of $F / C$ on SGS collection efficiency could not be estimated. This would be an excellent area for further study.

There are several approaches in determining the efficiency of a device with more than one collection mechanism taking place. One approach is to assume particles not collected by one mechanism are available to be collected by another. The overall efficiency is then given by $(15)$ :

$$
\begin{aligned}
& E_{t}=1-\pi\left(1-E_{j}\right) \\
& E_{t}=\text { overall efficiency } \\
& E_{i}=\text { efficiency of each mechanism }
\end{aligned}
$$

Another approach is to assume that the collection mechanisms are independent of each other. The collection efficiencies of each mechanism can then be added to give the overall efficiency:

$$
E_{t}=\Sigma E_{i}
$$


This is a simplified overview of some basic aerosol science background pertinent to the SGS. For a more in-depth study, see References (17-21) for theoretical aspects of aerosols and their collection and References for information about industrial application.

To predict the SGS performance on aerosol collection, two models were used. The first model assumes that Brownian diffusion, direct interception, and impaction are the collection mechanisms. The derivation is given in Appendix $C$. The predicted particle penetration is shown in Figure 70 as a function of the aerodynamic particle diameter. The model predicts a maximum penetration for a particle diameter of $0.3 \mathrm{\mu}$. Larger particles are collected progressively better by inertial forces, and smaller particles are collected increasingly more effectively by diffusion. The shape of the curve is typical of air cleaning devices $(26)$. The model is given as:

$$
\bar{P} t=\operatorname{EXP}\left[\frac{-3(1-\varepsilon) Z}{2 \varepsilon d_{R}}\right] E_{f}
$$

where: $E_{f}=$ sum of the individual collection efficiencies (Brownian diffusion, interception, inertia) for a single sphere

$Z=$ Bed height, $\mathrm{cm}$

$\varepsilon=$ Bed void fraction

$d_{R}=$ Diameter of packing, cm 


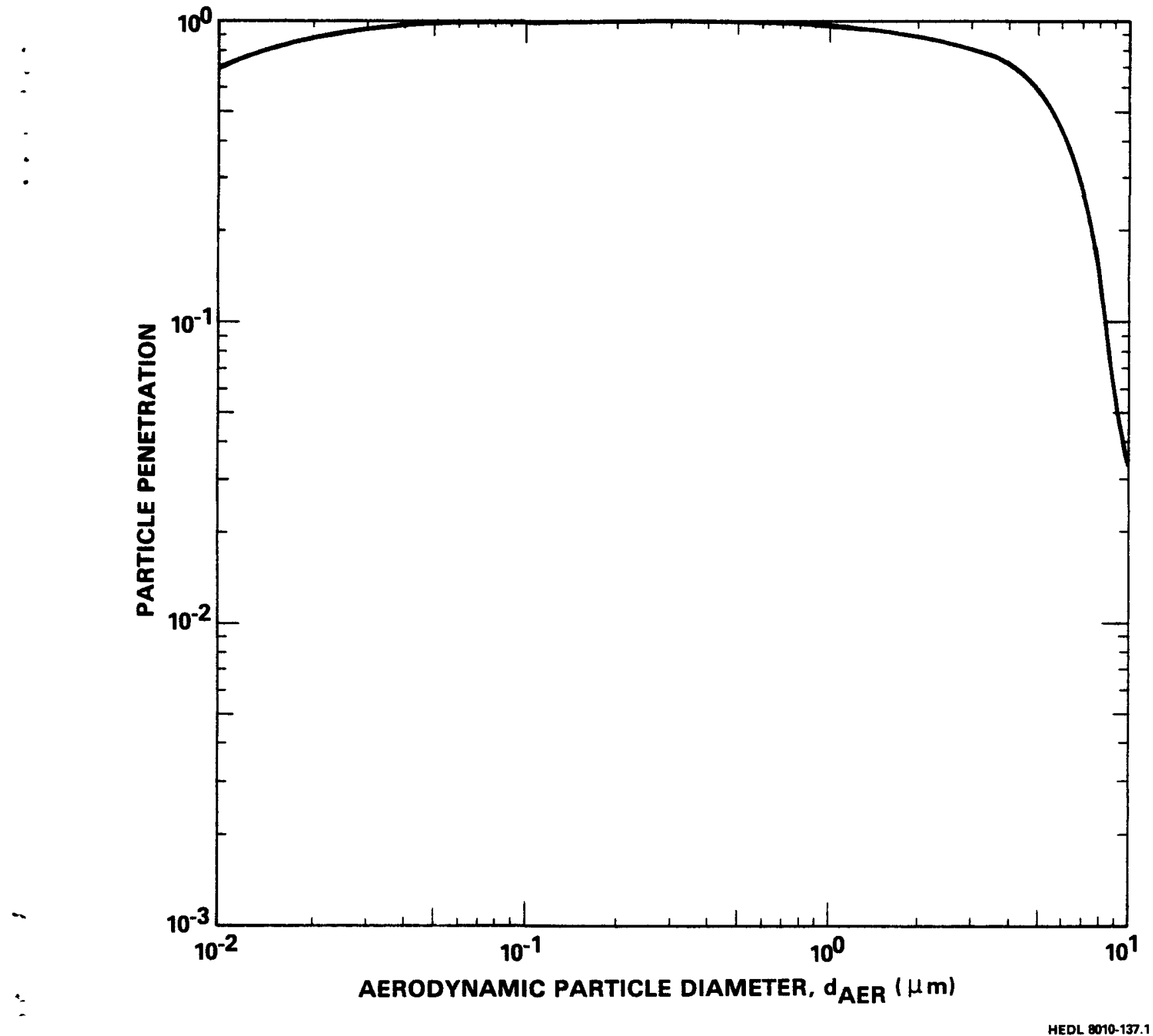

FIGURE 70. Sphere Model Penetration Prediction. 
A semi-empirical correlation was given by Calvert(27) for a packed bed irrigated with water. The model assumes that the bed is composed of a set of semi-circular bends of unit width and ' $b$ ' thickness. The thickness is related to the packing size. Aerosol particles are collected solely by impaction on walls of the channels. The model assumes that the particle concentration is uniform throughout the channel. Appendix $D$ gives the development of the equation:

$$
\begin{aligned}
& P t=\operatorname{EXP}\left[-\frac{\pi Z K_{p}}{2\left(j+j^{2}\right)(\varepsilon-H d) d_{R}}\right] \\
& \text { where: } j=\text { empirical constant relating channel width to } \\
& \text { packing diameter } \\
& H d \text { = fraction of bed occupied by liquid } \\
& d_{R}=\text { diameter of packing, } \mathrm{cm} \\
& K_{p}=\text { inertial parameter } \\
& K_{p}=\frac{V s d p^{2} \rho_{p}}{9 \mu_{f} d_{R} 10^{4}}
\end{aligned}
$$

The predicted penetration of aerosol as a function of particle size is shown in Figure 71 .

Because a mono-dispersed aerosol was not available for experimentally determining the scrubber penetration as a function of particle size, the bed penetration had to be calculated from the poly-dispersed test aerosol. Impactor data was used to determine the test aerosol particle size distribution. The distribution was broken into 10 groups, each representing a fraction of the total mass. The average particle diameter for each increment was used in the theoretical models to predict the penetration of that mass increment. By summing the penetration of the increments, the total predicted penetration was calculated. For a distribution with an aerodynamic mass median diameter of 5.5 and a geometric deviation of 2.5 , the sphere model predicts a scrubber efficiency of $54 \%$ and the channel model predicts an aerosol collection of $90 \%$. Test SGS-AC6 results showed the actual scrubber performance to be 


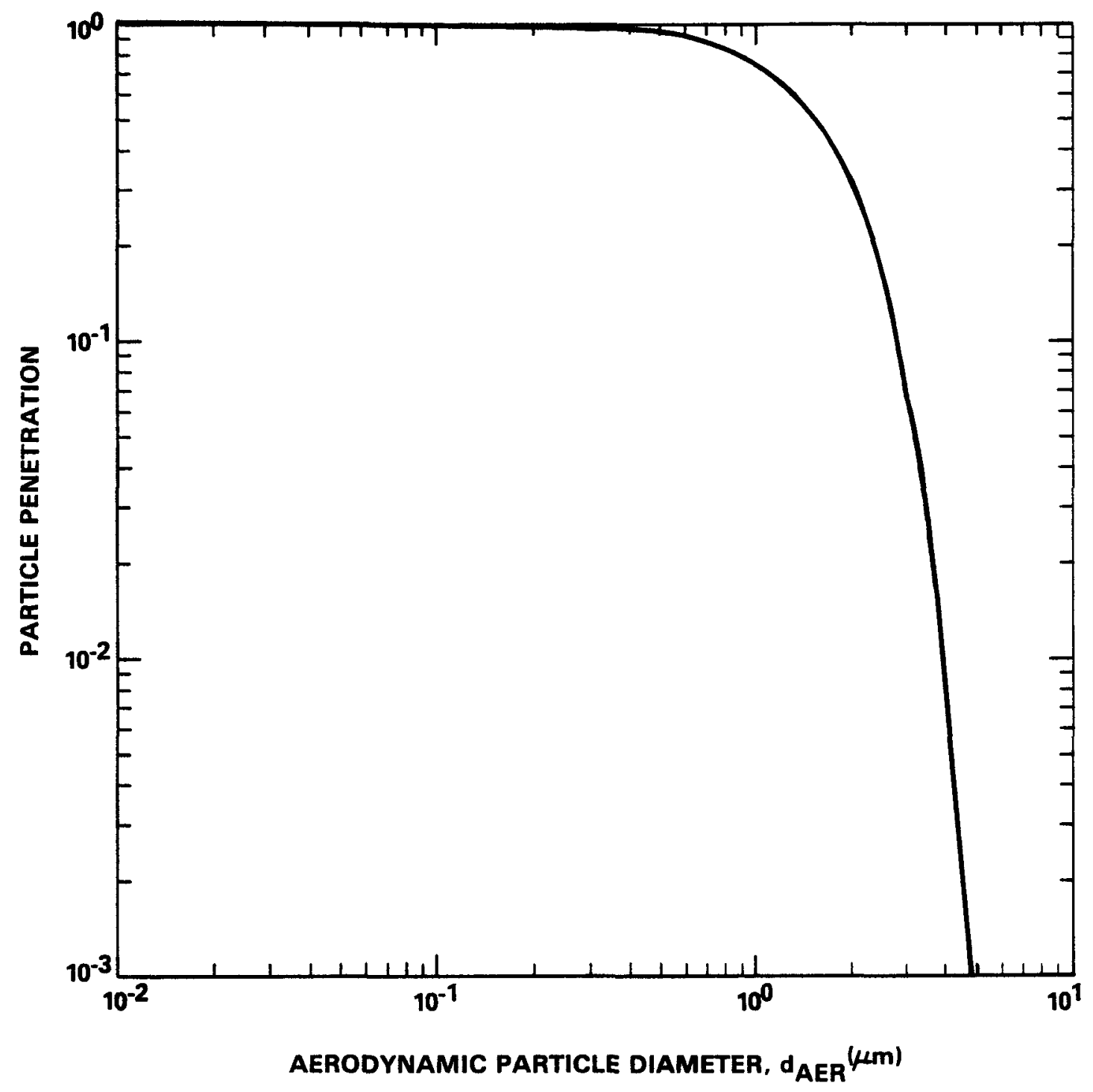

HEDL 6010-174.1

FIGURE 71. Channel Model Penetration Prediction. 
99.55\%. Both models underpredict the scrubber performance. This is probably due to additional collection mechanisms, such as flux/force condensation, making an unaccounted for, but important, contribution to aerosol removal.

A comparison can be made between the SGS performance and conventional scrubbers. The performance cut diameter of a scrubber, $d_{p c}$, is defined as the particle aerodynamic diameter that the scrubber collects with $50 \%$ efficiency. Since the curve of collection efficiency versus particle diameter for collection by inertial impaction is relatively steep, a rough approximation can be made that the scrubber collects everything larger than the cut diameter and passes all smaller particles. Based on the data of test SGS- AC6, the SGS would have a cut diameter of $0.4 \mathrm{~m}$. Calvert(28) gives a curve of cut diameter versus gas-phase pressure drop, shown in Figure 72 . The SGS is plotted as a single point. The SGS performance is comparable to a fibrous packed bed.

\subsection{ACCIDENT CONDITIONS AND SYSTEM CR ITER IA}

The function of an emergency air cleaning system is to limit the release of sodium compounds and radioactive matter to the atmosphere within acceptable limits if a reactor containment building (RCB) is vented or purged during a hypothetical core disruptive accident (HCDA). Although a mechanism has not been identified that would cause such a sequence of events to occur, it is hypothetically possible. The accident is conservatively based on the downward displacement of $100 \%$ of the core material and coolant which penetrate both the reactor vesse 1 and the reactor guard vessel after 1000 seconds following neutronic shutdown of the core.

The sodium, fuel, and fission products could drain into the nitrogen-inerted lower cavity region, where the cavity steel liners are assumed to fail. The sodium then attacks and heats the underlying concrete, driving off 1 arge quantities of water. The water, as steam, is vented to the containment building. In addition, the water may react with sodium to form hydrogen, which is also vented to the containment. The exothermic reactions and the 
GAS-PHASE PRESSURE DROP $\left(\mathrm{cm}, \mathrm{H}_{2} \mathrm{O}\right)$

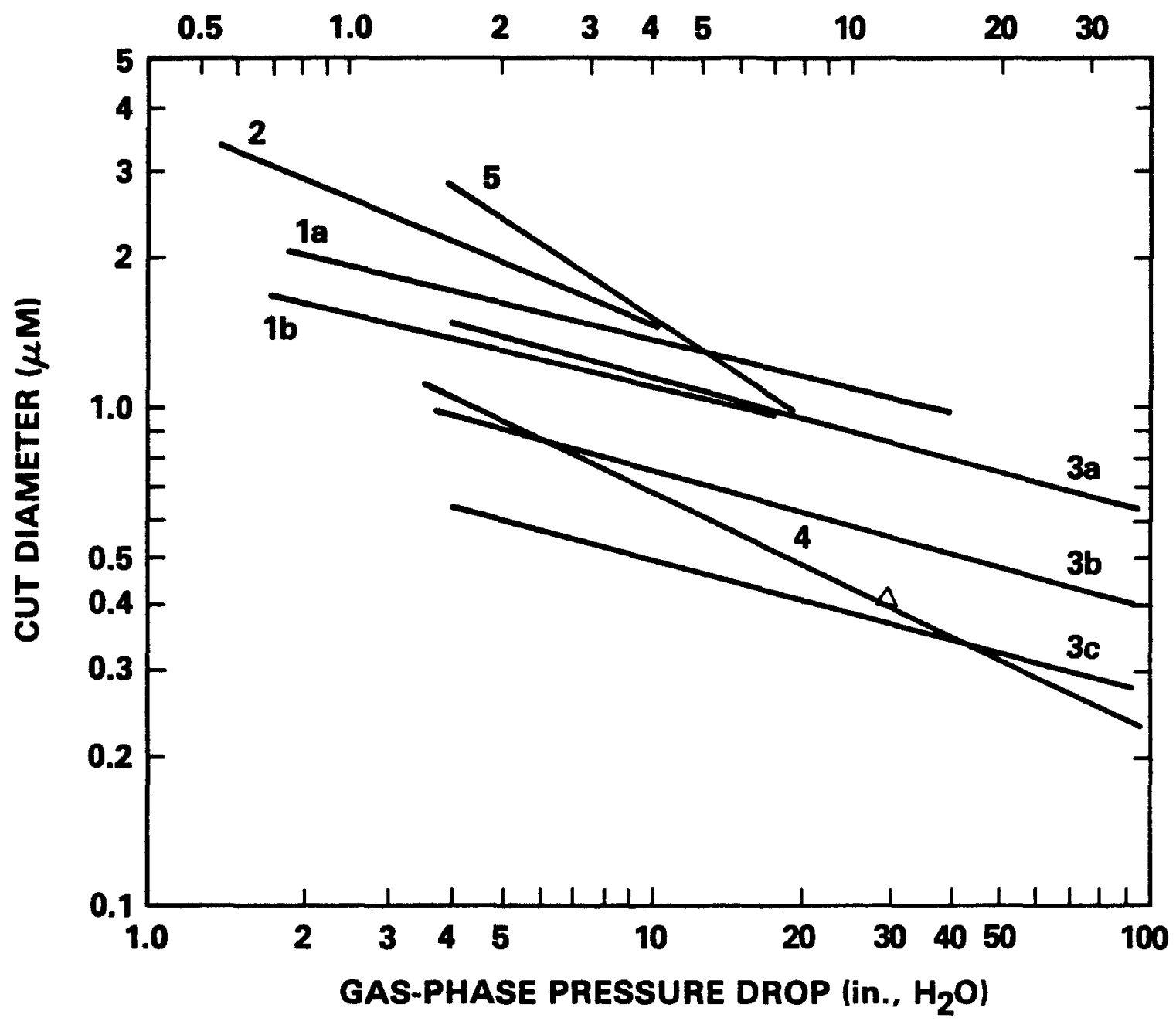

1a. SIEVE-PLATE COLUMN, 0.2-in. HOLE DIAMETER

1b. SIEVE-PLATE COLUMN, 0.125-in. HOLE DIAMETER

2 PACKED COLUMN, 1-in. RINGS OR SADDLES

3a. FIBROUS PACKED BED, 0.012-in. DIAMETER FIBERS

3b. FIBROUS PACKED BED, 0.004-in. DIAMETER FIBERS

3c. FIBROUS PACKED BED, 0.002-in. DIAMETER FIBERS

4 GAS-ATOMIZED SPRAY

5 MOBILE BED, 1 TO 3 STAGES, HOLLOW SPHERES

$\triangle$ SUBMERGED GRAVEL SCRUBBER

FIGURE 72. Scrubber Performance Correlation(27). 
vented steam increase the temperature and the pressure of the containment atmosphere. Sodium entering the containment will burn to form sodium oxides, releasing energy and further increasing the pressure. To prevent containment overpressurization, the building would be vented to relieve excess pressure.

If hydrogen is generated and accummulates in the containment, it might form a flammable mixture. To prevent a hydrogen deflagration or detonation from threatening containment integrity, the RCB could be purged with either air or an inerting gas, such as nitrogen, to reduce the hydrogen concentration. In venting or purging, the thermally hot gas leaving the containment building could contain fission product gases, large amounts of sodium aerosols, and fuel aerosols. The exact gas composition and flowrate would depend on the accident sequence.

To design an air cleaning system for the released gas, the worst-case conditions are conservatively used. These accident conditions have been predicted for the Clinch River Breeder Reactor Project (29) and are termed the Thermal Margins Beyond the Design Base (TMBDB) requirements. An indepth evaluation of the accident scenario to obtain accident conditions is beyond the scope of this project; therefore the TMBDB conditions will be used in part for the scoping design.

The conditions that need to be addressed in designing an air cleaning system are as follows:

- Thermal conditions of gas entering the system

- Chemical forms of aerosols and gases

- Aerosol particle physical properties

- Gas flow rate through the system

- Aerosol mass to be collected, and

- Required removal efficiency.

These parameters are discussed in the following sections. 


\subsection{THERMAL CONDITIONS}

The RCB is heated by the exothermic chemical reactions of the sodium, steam and hydrogen release from the reactor cavity and its liner system, as well as the decay heat of fission products released to the RCB. If the heat losses in the duct connecting the RCB to the scrubber are neglected, the temperature of the gas entering the scrubber is the same as that of the containment atmosphere. A predicted temperature history of the RCB atmosphere is shown in Figure 73. A maximum temperature of $620^{\circ} \mathrm{C}$ is attained at about 40 hours. The temperature then gradually decreases until at 160 hours it is $400^{\circ} \mathrm{C}$.

\subsection{CHEMICAL FORMS OF AEROSOL AND GASES}

The RCB atmosphere is normally air. As sodium vapor, sodium aerosol particles, hydrogen, and possibly carbon dioxide are released from the reactor cavity and the liner system, oxygen is consumed. Hydrogen will combine with oxygen as long as the oxygen concentration remains above $10 \%(30)$. After the oxygen concentration drops below $10 \%$, hydrogen accumulates in the RCB until venting or purging is started.

The sodium reacts to form sodium oxide and sodium hydroxide particles. As the accident proceeds, a large quantity of $\mathrm{CO}_{2}$ could be released from heated concrete aggregate in a reactor built with limestone concrete. In that case, sufficient $\mathrm{CO}_{2}$ could be released to convert $35 \%$ of the sodium to $\mathrm{Na}_{2} \mathrm{CO}_{3}$ on a stoichiometric basis ${ }^{(3)}$. Sufficient water vapor would be present to convert all the sodium inventory to $\mathrm{NaOH}$. Since $\mathrm{Na}_{2} \mathrm{CO}_{3}$ is appreciably less soluble in water than $\mathrm{NaOH}$, its presence is important to the sizing of an aqueous scrubber.

If unreacted metallic sodium is present in the aerosol particles which are removed in the aqueous scrubber, additional hydrogen gas would be formed. Based on an aerosol concentration of $50 \mathrm{~g} / \mathrm{m}^{3}$ in the containment atmosphere, the increase in hydrogen concentration in the scrubber is given 


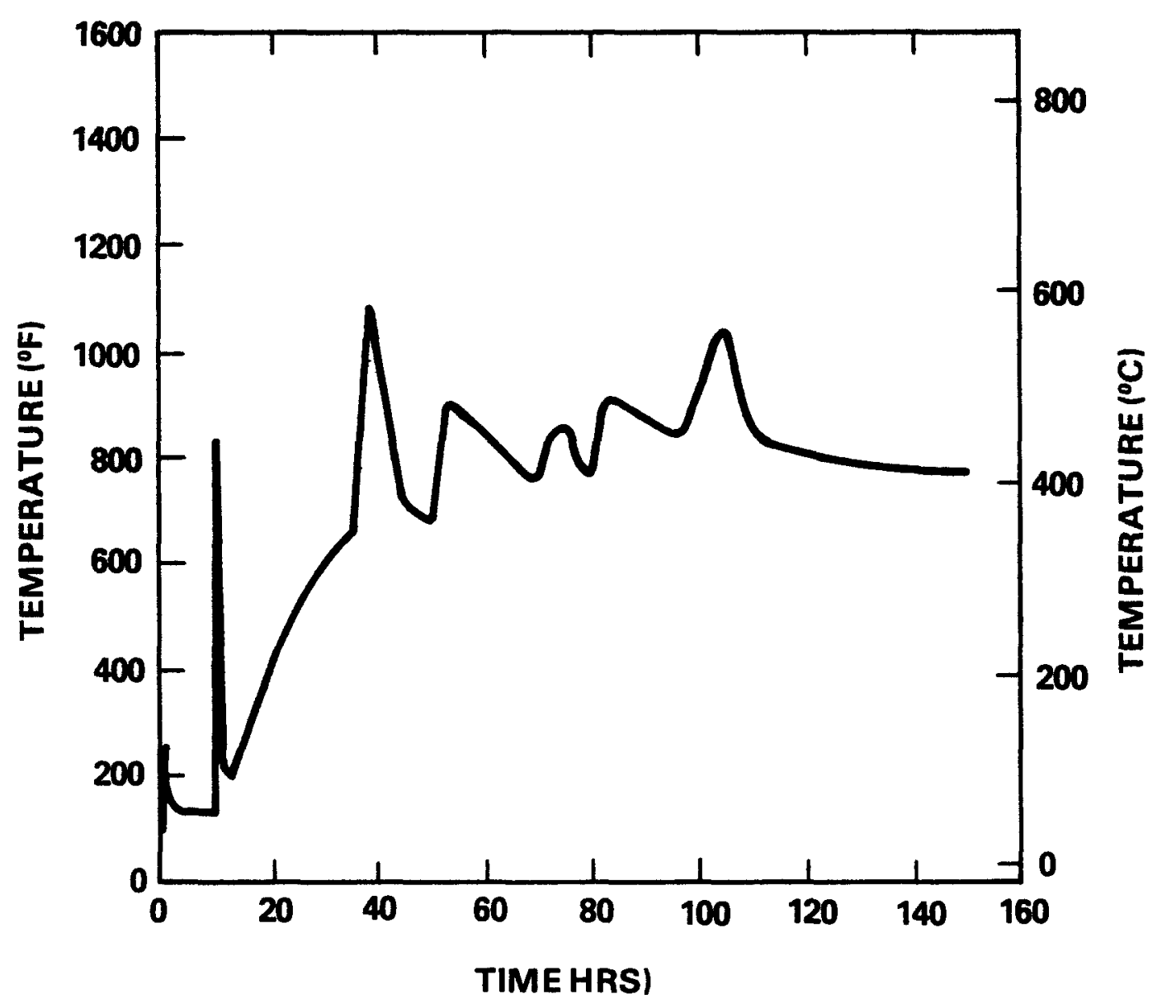

HEDL $8009-349.4$

FIGURE 73. Postulated RCB Atmosphere Temperature. 
by (3).

$$
\Delta \mathrm{H}_{2}=0.028 \mathrm{f}
$$

where $\Delta \mathrm{H}_{2}$ is the increase in hydrogen concentration, volume fraction, and $f$ is the fraction of aerosol mass that is metallic sodium.

\subsection{AEROSOL PROPERTIES}

The aerosol concentration and particle distribution have been predicted by appropriate aerosol codes ${ }^{(3)}$ and defined by design criteria ${ }^{(29)}$. Figure 74 shows the aerosol mass concentration in the RCB atmosphere for the first 160 hours of the accident. The peak aerosol concentration is $70 \mu \mathrm{g} / \mathrm{m}^{3}$ at 41 hours, and gradually declines to $14 \mathrm{~g} / \mathrm{m}^{3}$ over the next 120 hours. A particle aerodynamic mass median diameter (AMMD) of $5.0 \mathrm{um}$, a geometric standard deviation of 3.3 and a material density of $2.30 \mathrm{~g} / \mathrm{cm}^{3}$ were assumed. The particle size distribution based on these parameters is plotted on log-normal coordinates in Figure 75, which shows that approximately $9 \%$ of aerosol mass is associated with particles smaller than $1 \mu \mathrm{m}$ aerodynamic equivalent diameter.

\subsection{GAS FLOW RATE}

The gas flow rate entering the scrubber varies with time because the containment pressure is used to initially vent the RCB; then a blower, producing a smaller driving force, is used to purge the RCB. The purge rate is adjusted with time to control the hydrogen concentration to a specified maximum value, thereby minimizing the gas released.

The projected scrubber gas inlet rate is presented in Figure 76 . The maximum flow rate is about $12.5 \mathrm{~m}^{3}$ (actua 1)/s, which occurs at about 38 hours after the accident initiation. The flow rate at standard conditions $\left(1 \mathrm{~atm}, 0^{\circ} \mathrm{C}\right)$ is shown in Figure 77 . The actual flow rates are approximately twice the flowrates at standard conditions. For times between 160 hours and 1000 hours, it is assumed that the flow rate remains constant at $3.0 \mathrm{~m}^{3}$ (STD)/s. Venting beyond 1000 hours is not required. 


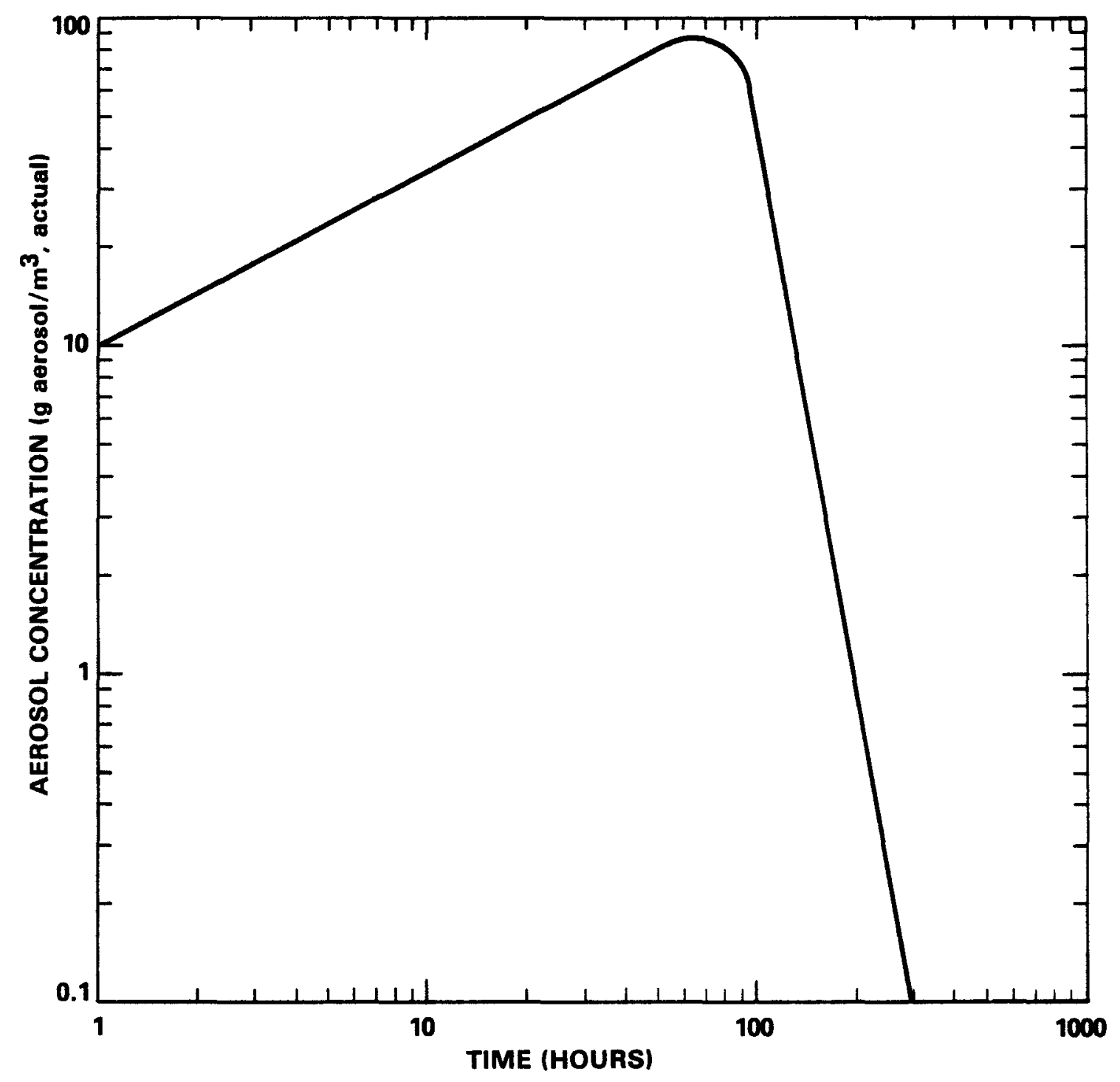

HEDL ENO-174.3

FIGURE 74. Postulated RCB Aerosol Concentration. 


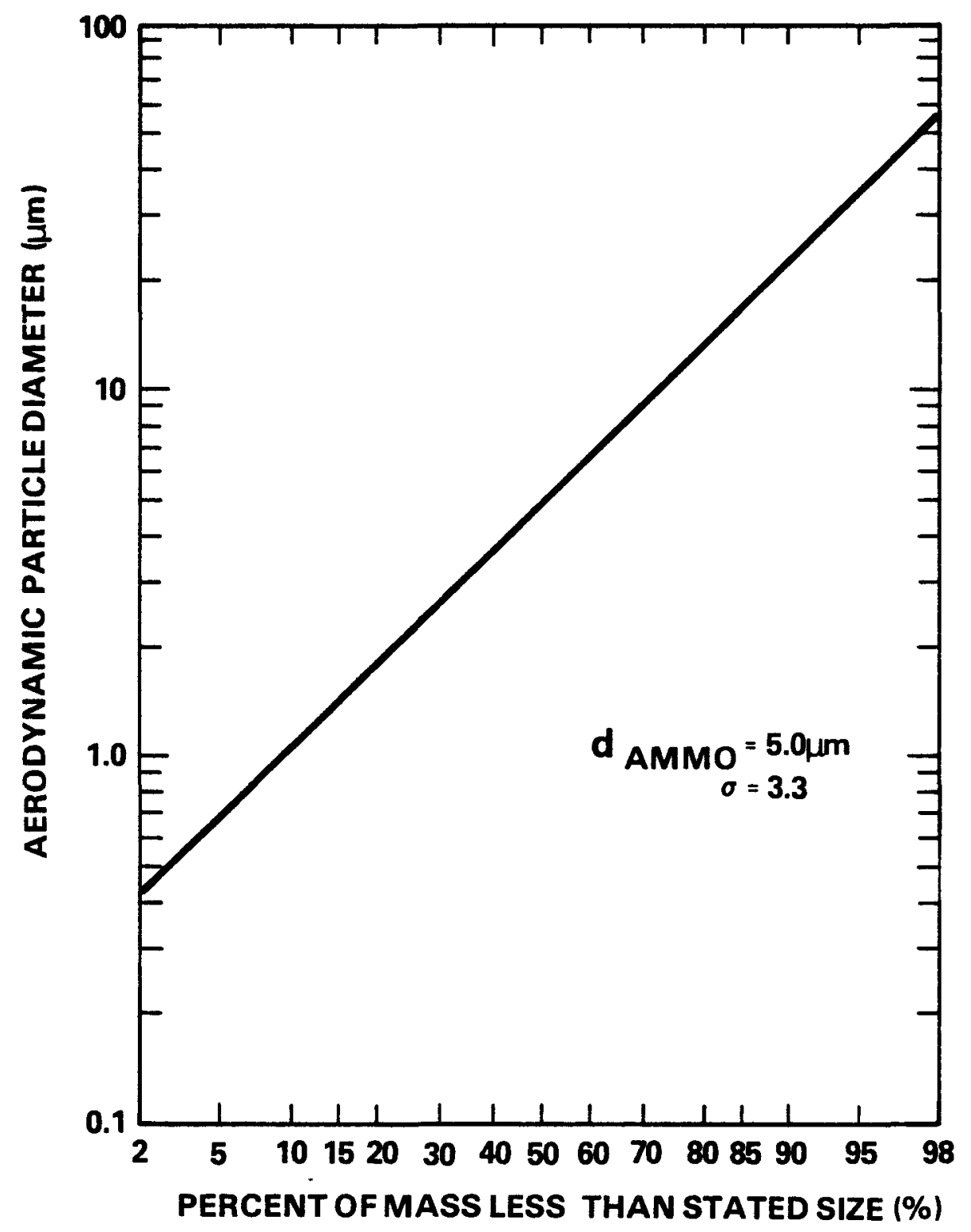

HEDL 8009-349.5

FIGURE 75. Postulated Aerosol Distribution. 
PAGE 104 IS BLANK 


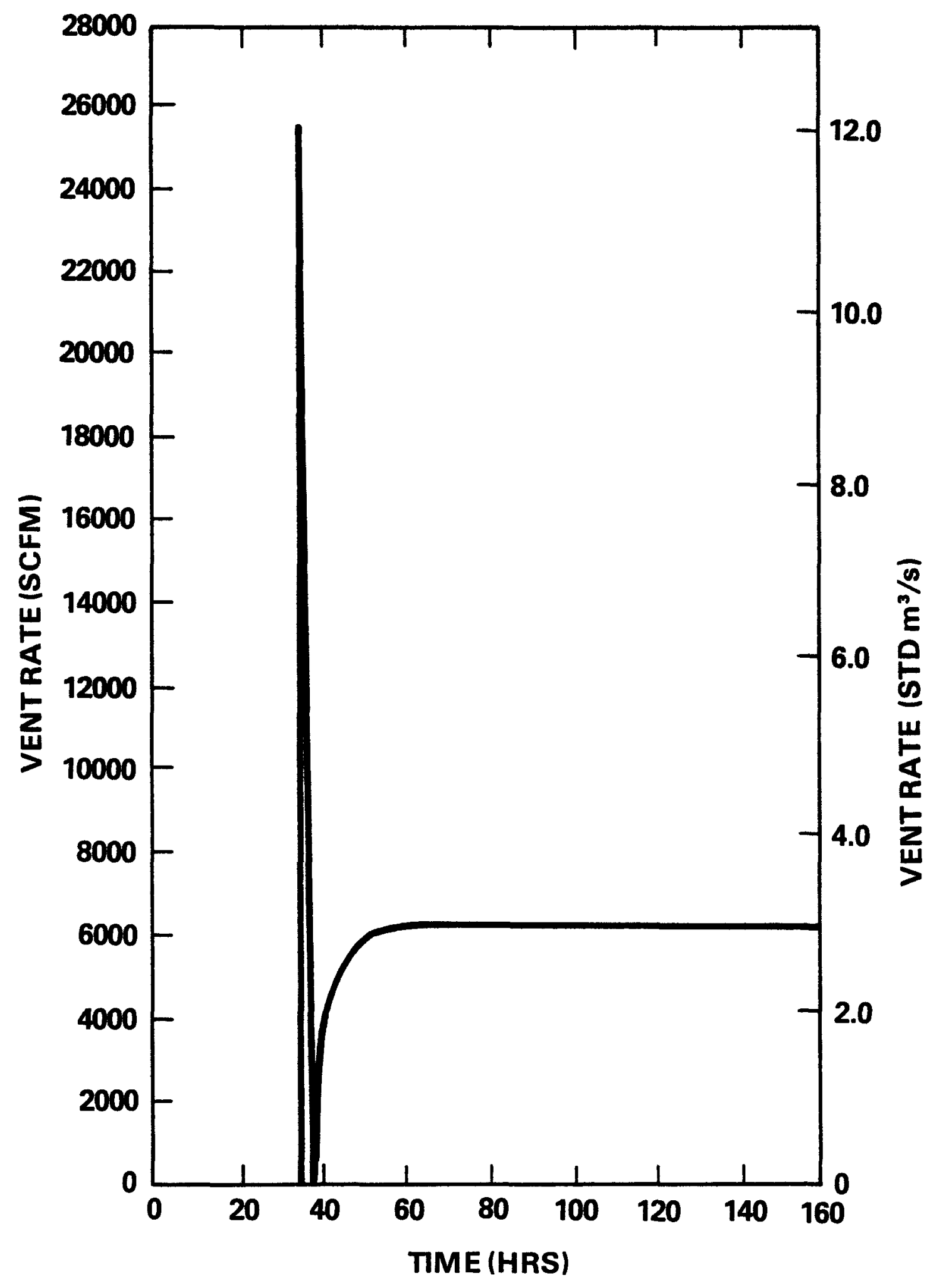

HEDL 8009-349.3

FIGURE 77. Postulated Vent/Purge Flow Rate, Standard Conditions. 


\subsection{AEROSOL MASS COLLECTED}

The amount of aerosol mass that would be carried by the gas entering the scrubber can be obtained by integrating over time the product of the mass concentration and the containment vent rate (actual conditions). The result is shown in Figure 78. A total of $136 \mathrm{MT}$ of aerosol, as $\mathrm{NaOH}$, would enter the scrubber. The maximum rate would be $42 \mathrm{~kg} / \mathrm{min}$.

\subsection{REQUIRED REMOVAL EFFICIENCY}

The required aerosol removal efficiency is $99 \%$, by mass, for the solid or liquid vented materials, 97\% for vapors ( $\mathrm{NaI}, \mathrm{SeO}_{2}$, and $\mathrm{Sb}_{2} \mathrm{O}_{3}$ ) that will condense in the scrubber, and $0 \%$ for the noble gases $(29)^{3}$.

\subsection{OTHER CONSIDERATIONS}

Additional criteria, while not necessary for a scoping design, are worth considering in integrating the scrubber system into the plant. Some of these considerations are as follows ${ }^{(29)}$ :

- The scrubber must be compatible with $\mathrm{Ar}, \mathrm{N}_{2}, \mathrm{H}_{2}, \mathrm{H}_{2} \mathrm{O}$, $\mathrm{CO}, \mathrm{CO}_{2}, \mathrm{O}_{2}, \mathrm{Na}_{2} \mathrm{O}, \mathrm{NaOH}, \mathrm{Na}_{2} \mathrm{CO}_{3}$, and fission products.

- The scrubber vent and purge operations will be solely by remote manual actuation from the reactor control room.

- The maximum fission product power levels in the collected aerosol are predicted as: 


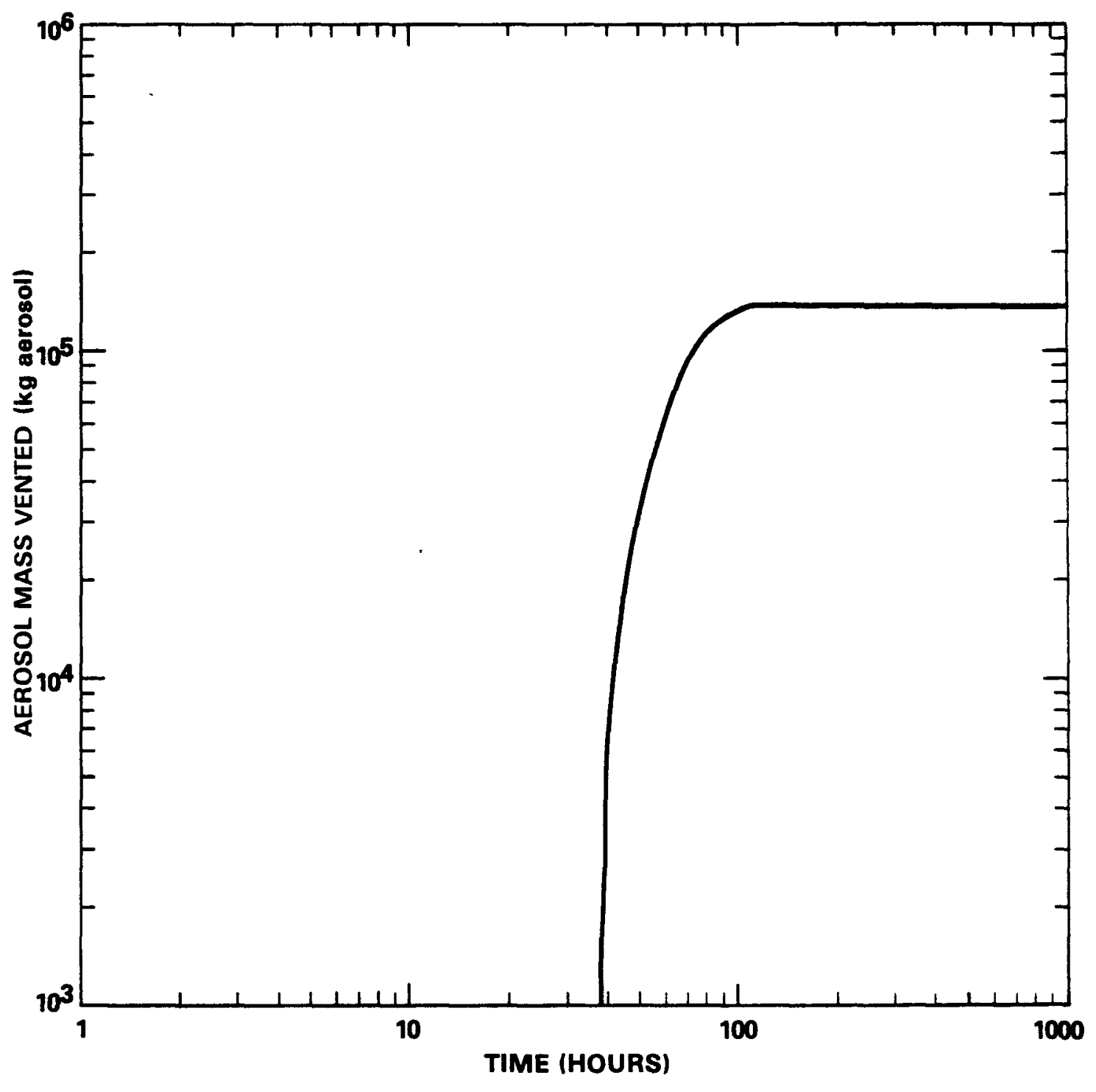

HEDL ENQ-174.2

FIGURE 78. Integrated Mass Loading. 


\begin{tabular}{rc} 
Time & Fission Product Power (MW) \\
\cline { 2 - 2 } 0 & 0 \\
24 & $3.1 \times 10^{-5}$ \\
48 & 0.16 \\
96 & 0.16 \\
240 & 0.11 \\
720 & 0.05
\end{tabular}

- A thermal evaluation of the vented/purged gas must be made to ascertain the maximum water condensation and evaporation rates. Provisions will have to be made for this water.

- Inadvertant operation of the system must not result in defeating the plant Engineered Safety Features (ESF), endanger the RCB, nor reduce the overall safety of the plant.

- The system will be designed to be on standby for 20 years. The unit must reliably function on demand. A passive unit is preferred.

- The radioactivity through the building may be substantial following an accident. Shielding may be required for meters, valves, and instrumentation.

- The unit's performance must be verifiable through periodic testing.

- Whereas the system is designed for an extremely low probability event, the unit is not an ESF.

\subsection{SCRUBBER CONCEPTUAL DESIGN}

The overall objective of this project is to present, based on experimental results, a scoping design for a scrubber that will function under the 
predicted accident conditions and meet the design criteria. Based on the experimental results given in this report, such a design was made for a 975 Mwt plant. The various parameters for the design shown in Figures 79 and 80 are considered in the following discussions.

\subsection{BED DIMENSIONS}

The bed dimensions are based on the desire to minimize the size of the unit and the need to have a reasonable flow of water through the bed to wash the collected aerosol from the bed voids. The experimental resuits indicated that a superficial gas velocity of $0.51 \mathrm{~m}^{3} / \mathrm{s}$, based on actual conditions, was acceptable. At this gas velocity, water was purged through the bed at a rate equivalent to $9.7 \mathrm{l} / \mathrm{m}^{2}-\mathrm{s}$. The bed could be designed using gas conditions between the inlet gas conditions and the outlet gas conditions, since the gas cools rapidly in passing through the packing. However, for conservative purposes, the gas inlet conditions were used. The maximum gas flow rate was $12.5 \mathrm{~m}^{3}$ (actua 1 )/s, thereby dictating a bed area of $24.2 \mathrm{~m}^{2}$.

The bed depth would be 0.61 meters. The experimental results indicated that decreasing the bed thickness by a factor of two increased the aerosol penetration by a factor of seven, an exponential change. This is consistent with the theories presented. Although the aerosol removal efficiency during the tests exceeded the design criteria of $99 \%$, the bed depth of 0.61 meters provides additional margin in the event of a lesser accident, which could generate smaller particles.

\subsection{PACKING}

It is known that sodium hydroxide will attack basalt, albeit slowly. Tests were made in which basalt rock was soaked in hot $\left(80\right.$ to $\left.90^{\circ} \mathrm{C}\right) 4 \overline{\mathrm{M}}$ sodium hydroxide for 80 days. The rock showed little erosion (less than $10 \%$ weight change). In considering the large size of the packing particles and the 


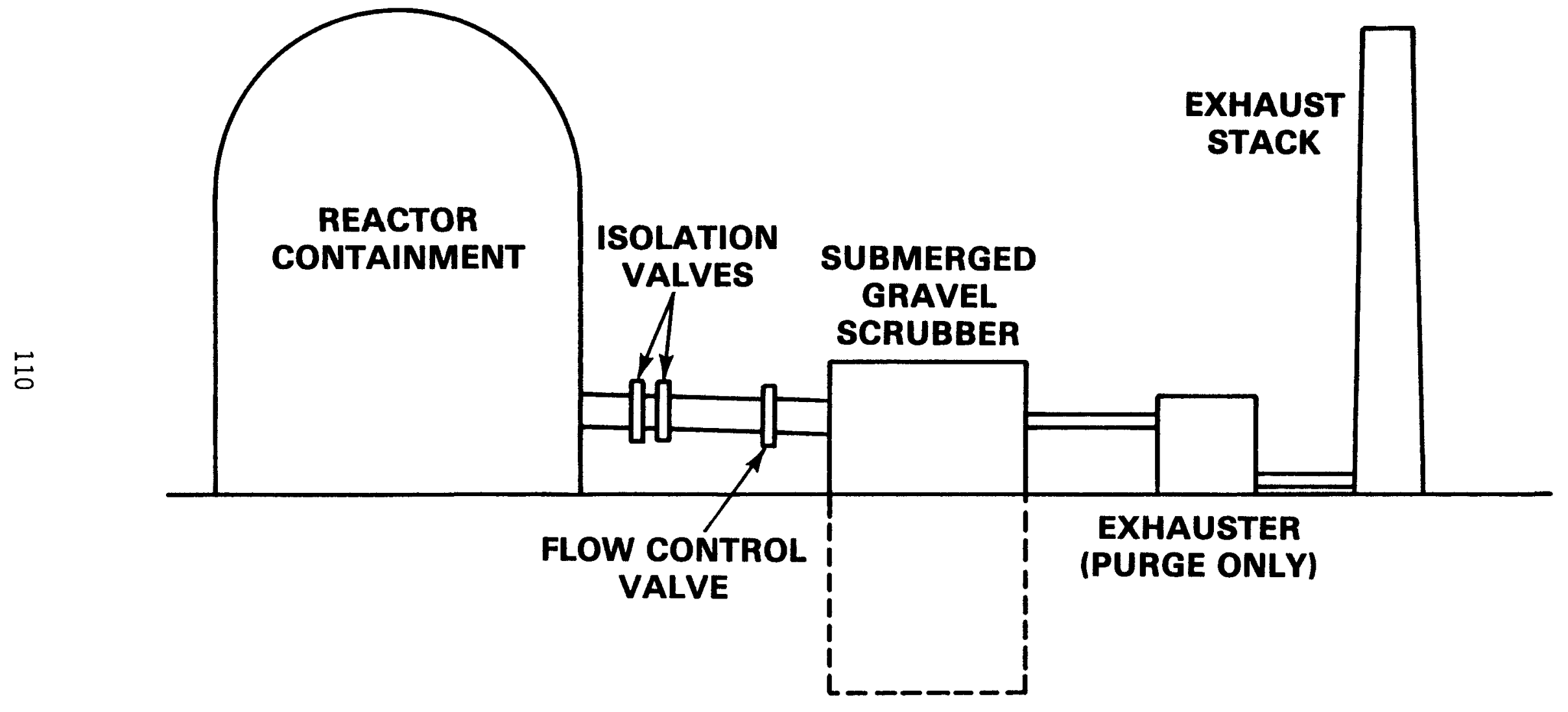

HEDL B010-311.2 

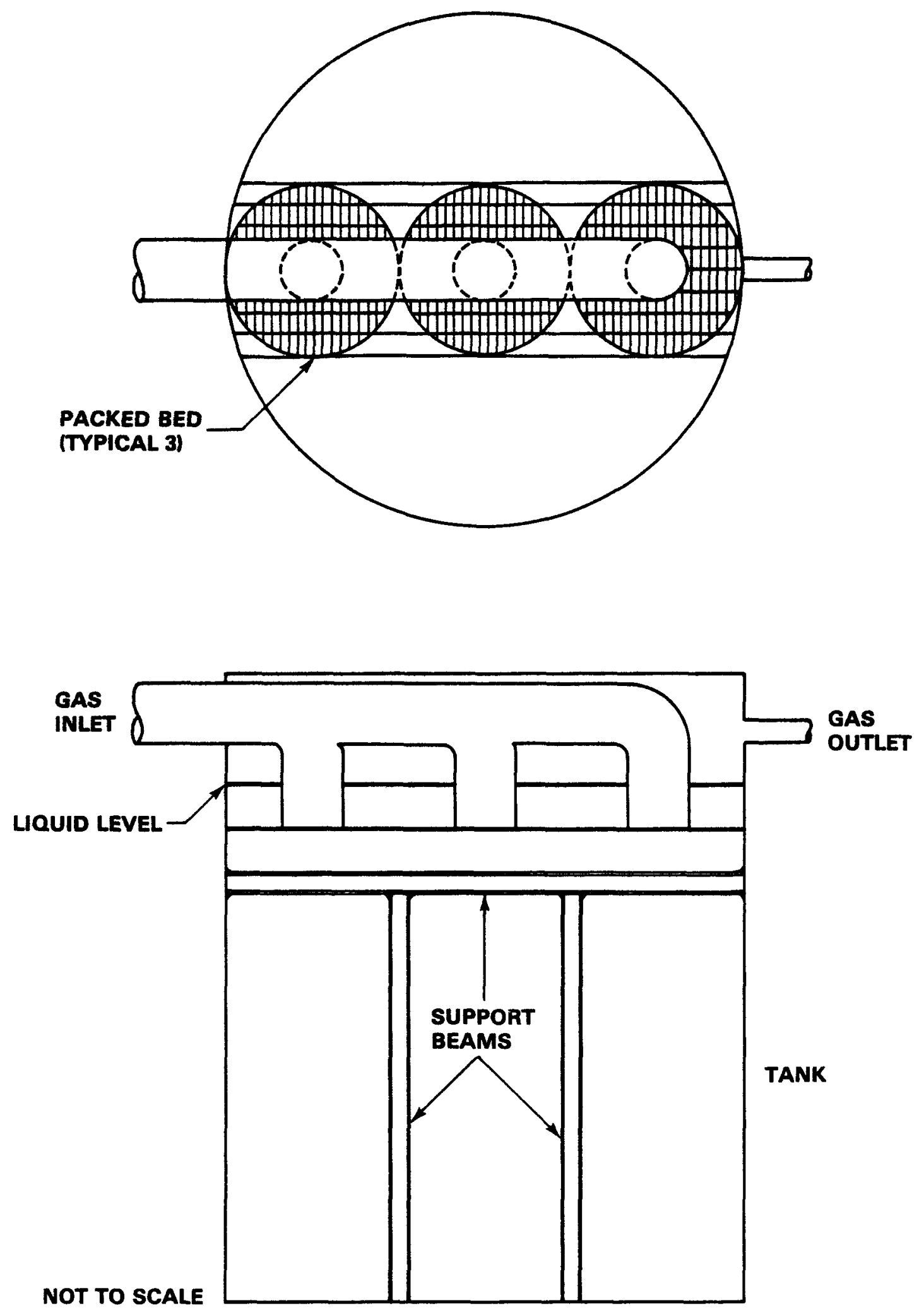

HEDL

FIGURE 80. Scrubber Conceptual Design.

8012707-8 
short term that the scrubber might be utilized, it was concluded that basalt was an acceptable packing material.

The basalt rock could be obtained by crushing larger pieces of rock that are obtainable from commercial sources. The rock could be sieved to $(+) 0.95 \mathrm{~cm}$ to $(-) 1.3 \mathrm{~cm}$ with screens typically used by paving and concrete mix firms. The quantity of rock required would be $14.8 \mathrm{~m}^{3}$.

\subsection{INLET DUCT}

The scrubber inlet duct must be sized to prevent aerosol plugging. An experimental correlation (31) was developed for the amount of mass entering a duct necessary to plug it. The correlation is expressed by:

$$
G=40 D^{3}
$$

Where $G=$ mass of aerosol entering duct, (grams)

$$
0=\text { diameter of duct, }(\mathrm{cm})
$$

For the reactor considered, a duct $1.5 \mathrm{~m}$ in diameter would be required. The duct would be constructed of a 300 series stainless steel to minimize the corrosive attack of the hot aerosols. The duct would be installed through the top of the RCB and would contain a minimum of bends. The duct would slant downwards with a slope of $1 \mathrm{~cm}$ per meter towards the scrubber, and would be equipped with duplicate coded isolation valves and designed for seismic qualifications. Stainless steel expansion joints would be used, one inside the scrubber, to account for duct expansion.

\subsection{BED SKIRT}

Using the inlet duct size of $1.5 \mathrm{~m}$ and a bed area of $24.2 \mathrm{~m}^{2}$ for gas flow, a skirt radius of $2.9 \mathrm{~m}$ was calculated. The maximum distance the gas would have to transverse from the outside edge of the inlet duct would be 2.1 meters. Whereas the gas distribution on scaleup is the largest uncertainty, th is distance was judged unacceptable. Therefore, three units, $3.66 \mathrm{~m}$ in diameter, were designed. A 1.5-m downcomer was used in each bed to 
minimize aerosol plugging problems. A single unit with multiple downcomers was avoided, as the effect on bed gas distribution by multiple gas layers is unknown. A tank $11 \mathrm{~m}$ in diameter would be required if the units were lineally placed. The maximum distance the gas would have to travel from the outside of an inlet duct would then be $1.1 \mathrm{~m}$ to the outside of the skirt.

The top edge of each skirt would project $1.3 \mathrm{~cm}$ above the bed for attachment of the top screen support. The air layer across the bed bottom was observed in the scaleup tests to increase in depth as the bed radius increased. Therefore, a $60-\mathrm{cm}$ space was allowed for the air layer. The total height of each skirt would be $1.23 \mathrm{~m}$. A strip of $6.4 \mathrm{~mm}$ thick carbon steel could be rolled and welded to form each skirt.

\subsection{BED SCREENS}

The upper and lower gravel supports, shown in Figure 81, would consist of carbon steel grating and stainless steel screen. The grating provides the support and the finer screen constrains the grave1. Four radial I-beams under the bottom grate provide the support needed for the estimated 9.1 MT of rock in each bed. The gas distribution ring would be installed below the bottom screen to enhance even gas distribution. The plate, constructed of $0.64 \mathrm{~cm}$ carbon steel, would be $30 \mathrm{~cm}$ wide and would fit over the inlet duct. The screens, grating, beams, and plate would all be welded in place.

\subsection{TANK}

The tank must be sized to hold enough water so that the liquid does not become saturated with aerosol nor become excessively viscous. The solubility of sodium carbonate at $0^{\circ} \mathrm{C}$ is $1.9 \mathrm{~g}$-moles/1(32), as shown in Figure 82. Sodium carbonate is less soluble than sodium hydroxide; therefore, this is a conservative number. The viscosity of sodium hydroxide solutions as a function of concentration for various temperatures is plotted in Figure 83. From this plot, a value of $5.0 \bar{M}$ was chosen as a reasonable concentration with a reasonable viscosity. For 136 MT of aerosol, a tank 

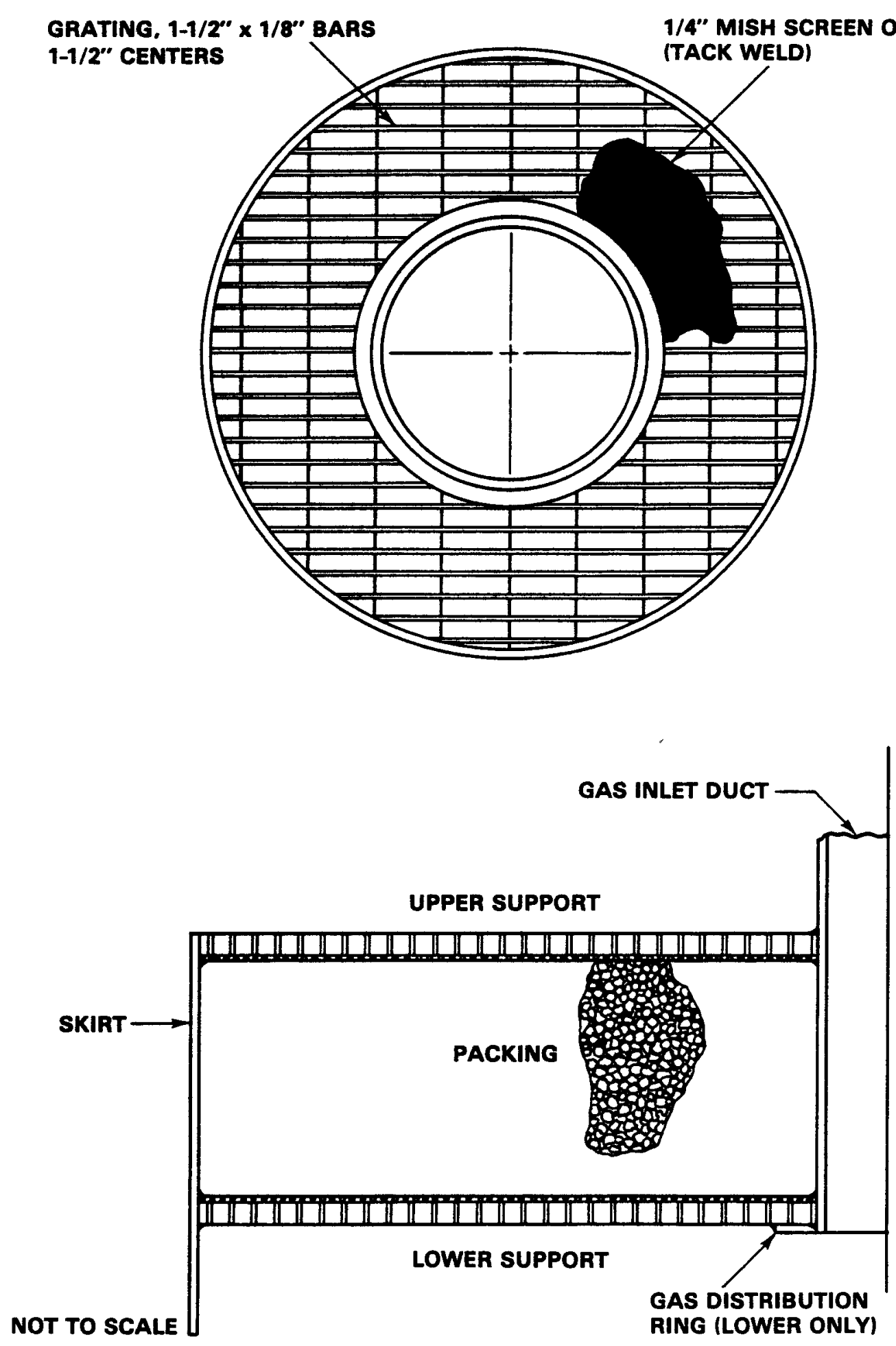

FIGURE 81. Conceptual Bed Supports. 


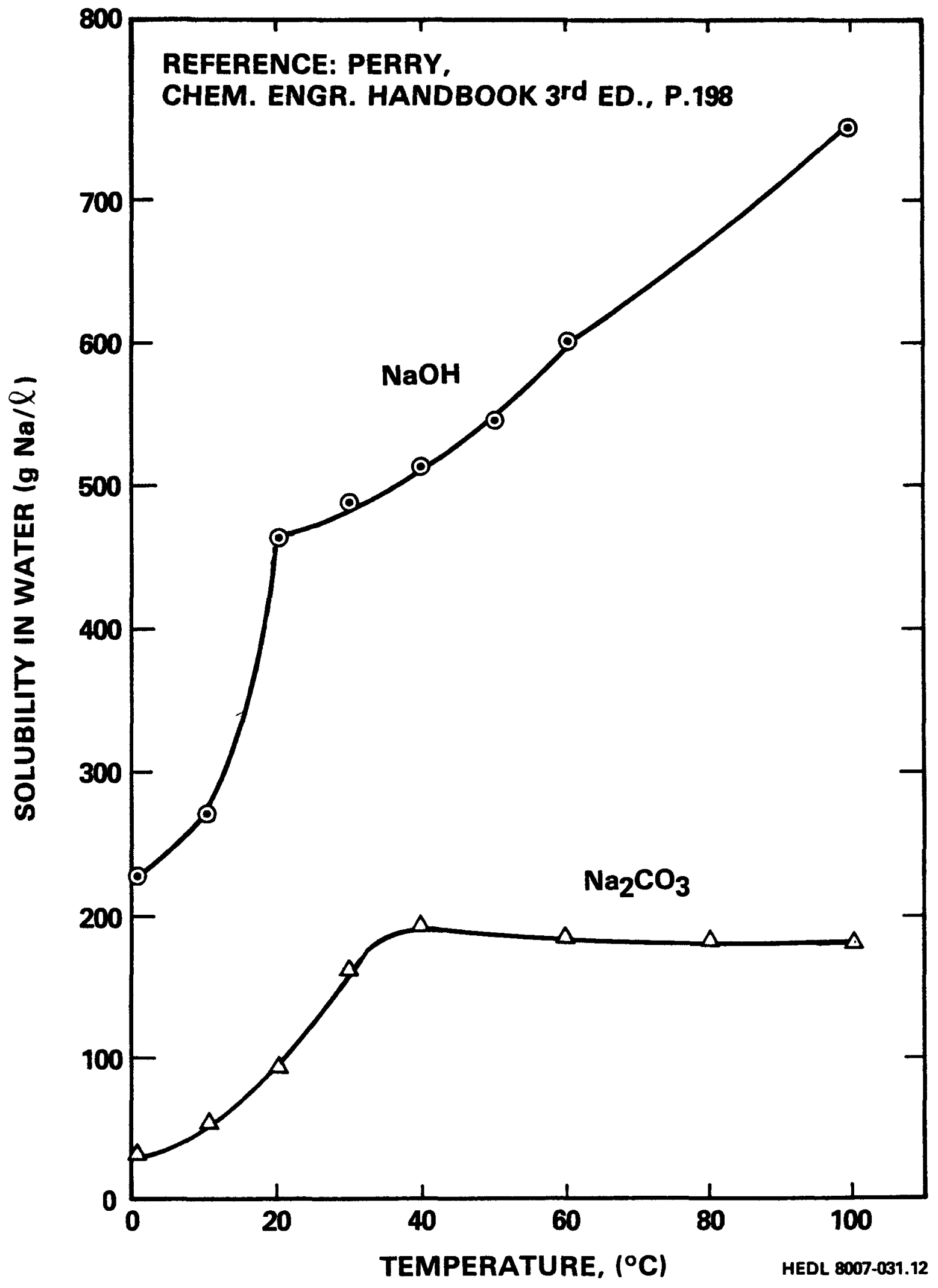

FIGURE 82. Solubilities of $\mathrm{NaOH}$ and $\mathrm{Na}_{2} \mathrm{CO}_{3}$. 


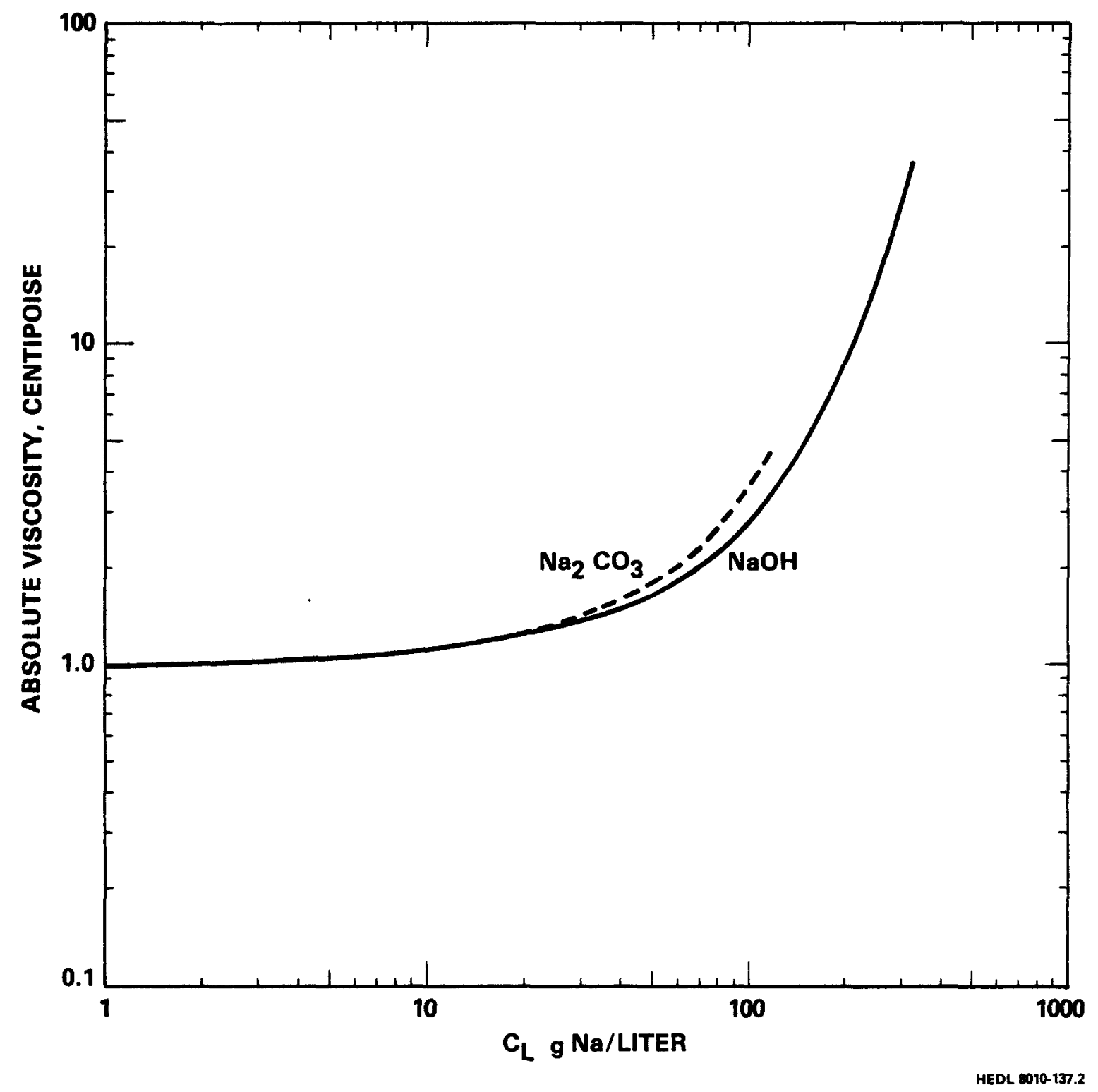

FIGURE 83. Viscosities of $\mathrm{NaOH}$ and $\mathrm{Na}_{2} \mathrm{CO}_{3}$.

$8011937-2$ 
volume of 680 kiloliters is required, based on the limiting viscosity concentration. Allowing $0.61 \mathrm{~m}$ of head space above the liquid surface results in a $9.1 \mathrm{~m}$ diameter tank $12 \mathrm{~m}$ high. To suspend the beds in the tank such that the top of the beds would be at the operating water level would require a support structure of I-beams installed across the tank as shown. Additional vertical beams would be used to hold the cross-beams up. The total static load of the beds is estimated at 27 MT. A dynamic load would include both horizontal and vertical loads, because of the oscillatory nature of the bed operation. The supporting structure would not interfere with the bed operation as long as free access is provided for water flowing into the bed bottom.

The tank would rest on a concrete pad poured below the ground level such that the top of the tank would be just above grade. The location would be downwind from the control room air intakes. The outside of the carbon stee 1 tank would be prepared and coated with an asphalt compound for rust protection. After the tank is assembled on the pad and the water supply and drain lines connected, the hole would be backfilled. The subgrade location minimizes tank maintainance and provides easy access for inspection. The tank would be constructed of mild stee 1 rolled and welded per ASTME code. The tank would be built to withstand a $10 \mathrm{KPa}$ vacuum and a gauge pressure of $69 \mathrm{KPa}$. The material thickness is estimated to be $1.3 \mathrm{~cm}$. The bottom head would be flat and the top head would be ellipsoid and reinforced. Tank penetrations would be required for the inlet duct, the outlet duct, a water supply line, a drain, instrumentation, and a manway access port.

\subsection{BLOWER}

A blower will be required to purge the containment building after the pressure in the RCB has been vented. The criteria of a $5.7 \mathrm{~m}^{3}($ STP $) / \mathrm{s}$ purge rate and the high pressure drop of $6.7 \mathrm{KPa}$ through the scrubber requires a relatively large blower. Design requirements were discussed with a blower manufacturer, who indicated that a skid-mounted blower with motor could be provided. The blower would be operated as an exhauster, 
pulling gas from the RCB through the scrubber and then exhausting it to the atmosphere through a short stack. The stack would have to be located such that hydrogen released would not accumulate and if the hydrogen burned as it left the stack, the flames could not damage any equipment. The blower would require approximately 470 amps at 460 VAC. Passing gas through the blower while passively venting the RCB would present no problem. Positioning the blower downstream of the scrubber results in only cleaned gas passing through the olower, thereby avoiding a clogged impeller.

\subsection{FLOW CONTROL}

A control valve will be required to adjust the flowrate of gas through the scrubber. If the valve were placed downstream of the scrubber, it could result in pressurizing the tank to the containment maximum absolute pressure, $220 \mathrm{KPa}$, which would increase the tank structural requirements. Tests have shown ${ }^{(33)}$ that a butterfly valve in the inlet duct will function reliably in an aerosol environment. Therefore, a $1.5 \mathrm{~m}$ butterfly valve would be installed just prior to the scrubber. The valve would be designed for one short-time use and would have to be built with seals that would withstand the high temperatures such that the valve would open. The valve would not necessarily be required to seal completely thereafter. The valve would include a remote position indicator and would be motor driven. The valve controls would be located in the control room. Correlations could be provided by the valve manufacturer to give the flowrate based on the valve position and the RCB pressure.

\subsection{INSTRUMENTATION}

Instrumentation requirements would be minimal. Valve and blower operator switches are the only essential elements. A valve position indicator, as mentioned above, would provide information useful to the operator during venting of the RCB. A pressure transducer located on the scrubber outlet duct upstream of the blower would provide an indicator of the system operation. A thermocouple in the outlet gas would give an indication that 
water was in the tank and that gas was not bypassing the scrubber, but was in fact flowing through the submerged bed and being cooled by water evaporation. A radiation monitor at the gas outlet would measure and record the actual radiation released to the environment.

\subsection{ASSEMBLY}

First, the hole for the tank would be excavated, a concrete pad poured, and tank bottom and sides assembled. Then, for each unit, the bed skirt would be welded in place, followed by the lower bed screens and supports. The inlet ducts would be centered in the lower screen-supports and welded. The sized rock would be poured into the beds and loosely tamped into place.

The top screen supports would be then welded into place; the tank top assembled over the inlet ducts, and ducts would be connected to the common header and the RCB. The blower would be installed on a pad next to the tank and the outlet ducting assembled. The tank would be filled with water to the top of the gravel beds and then the tank would be pressure tested.

\subsection{ACCEPTANCE TESTING}

After construction, the unit would be tested. A convenient and accepted method of testing air cleaning devices is a DOP test, as discussed earlier (section 3.4). The blower would pull air through the scrubber and DOP. aerosol would be injected in the inlet duct. The aerosol concentration would be measured upstream and downstream of the scrubber to determine the aerosol penetration. Based on small-scale tests, a penetration of $80 \%$ would be acceptable. Higher leakage would indicate that gas was bypassing the submerged bed or that the gas was mal-distributed in the bed. After successful testing, the scrubber beds should be inspected to insure that the beds are intact. 


\subsection{MAINTENANCE}

The submerged gravel scrubber should require little maintenance. The water would have to be periodically checked for algae growth. The blower and valves would have typical preventative maintanance schedules. The scrubber beds should be inspected once every two years to verify that the supports are still functional. The scrubber should be aerosol tested once every five years. The instrumentation would be calibrated periodically as called for. Upkeep of the tank top would involve weather proofing every ten years.

\subsection{OPTIONAL FIBER ELEMENTS}

When the reactor design is reviewed for licensing approval, it may be argued that while the most severe accident has been accounted for, minor accidents might result in compromising the radioactive release criteria. If an accident of less magnitude occurred, it could be possible to produce an aerosol of lower concentration in the containment. The aerosol size distribution would therefore have a smaller average particle size. Since the SGS aerosol removal efficiency may decrease with particle size, the removal criteria might possibly not be met. Although it can be argued that an accident of this reduced magnitude would not require the containment to be vented or purged, this is outside the scope of this project. Rather, as a back-up position, the scoping design includes an optional set of fiber elements to remove the smallest particles. The fiber element addition results in a system which will remove at least $99.99 \%$ of the aeroso 1 mass.

The fiber elements are constructed of polypropylene fibers, $20 \mathrm{um}$ in diameter, packed in a bed to a void density of approximately $85 \%$. The fibers are held between two galvanized wire support screens and form the wall of a hollow cylinder, 3 meters long and $0.61 \mathrm{~m}$ outside diameter. The annulus diameter is $0.46 \mathrm{~m}$. Each cylinder can handle $0.47 \mathrm{~m}^{3}$ (actual)/s; 
therefore, based on the bed outlet conditions, 24 elements would be required for the scoping design. The elements are commercially sold as Brink* High Efficiency (HE) demister elements.

The elements were designed to collect small particles by Brownian diffusion; therefore, their removal efficiency is not strongly flow-dependent. The collection of the most penetrating sized particle typically exceeds $99 \%$.

A 0.61-meter section of a fiber element was tested in series with the SGS in tests SGS-AC4 and SGS-AC5. In test AC4, the aerosol removal efficiency was measured as $99.996 \%$. Sealing problems developed during SGS-AC5, resulting in aerosol bypassing the fiber element; thus, the measured efficiency was not representative of the system. Sodium aerosol tests have been made on large-scale air cleaning systems using a $0.47 \mathrm{~m}^{3}($ STP $) / \mathrm{s}, 3$ meter long element $(33)$. The test results indicate that fiber scrubber performance is acceptable, as long as the aerosol concentration is suitably reduced by a prescrubber and the fiber bed is suitably irrigated to wash collected aerosol from the fibers. The submerged scrubber would perform very well as a prescrubber, as evidenced by the development tests. The mist generated and carried by the gas should be sufficient to remove the collected aerosol from the fiber elements. Although test SGS-AC4 demonstrated that the collected aerosol was removed, a large-scale proof test should be made to evaluate the amount of liquid carried into a longer element placed higher above the liquid surface.

The scoping design would be changed as shown in Figure 84. A second chamber, $3.7 \mathrm{~m} \mathrm{high}$, would be assembled on top of the tank vessel. A tube sheet would be welded between the two vessels. The elements would be bolted over holes in the tubesheet. Gas leaving the submerged bed would travel upwards into each element annulus and then transverse through the element walls. The tubesheet would be designed to withstand the weight of the elements containing holdup liquid, estimated at a total of 5.8 MT, and a

* Manufactured by the Monsanto Chemical Co., St. Louis, Missouri. 

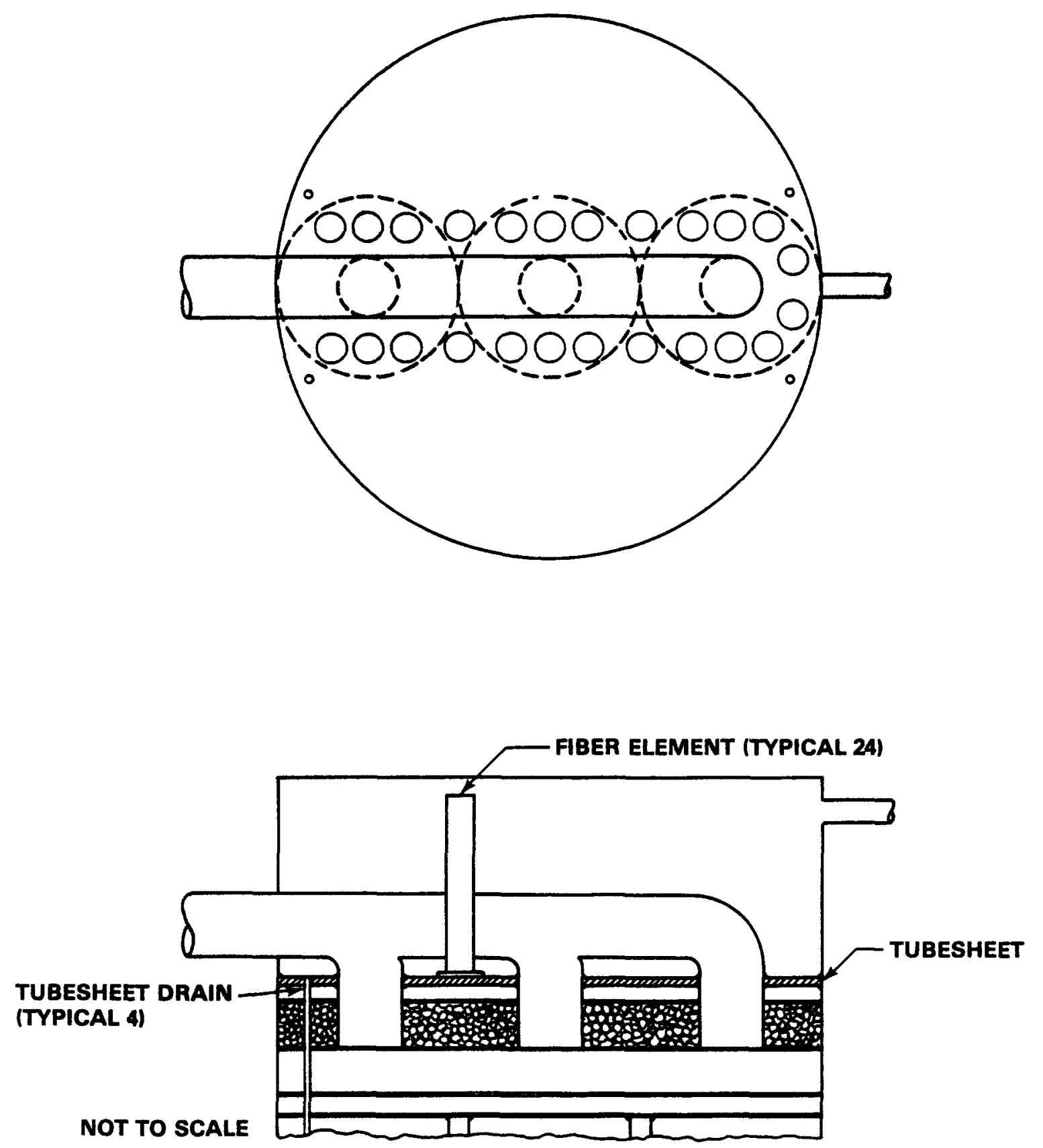

FIGURE 84. SGS/HEFD System Conceptual Design. 
pressure drop of $2.5 \mathrm{KPa}$ across the elements. A $5-\mathrm{cm}$ pipe would be welded to the tubesheet and project down into the tank to $30 \mathrm{~cm}$ above the tank bottom. The pipe would serve as a liquid return for the mist carried by the gas. In assembling the scrubber, the sequence would be as before, except that the tubesheet and the fiber elements would be installed before the lid was assembled. The pressure drop across the elements under normal conditions is about $1.5 \mathrm{KPa}$. The blower would be sized for an additional 2.5 $\mathrm{KPa}$, or a net $12.5 \mathrm{KPa}$ suction pressure. Maintenance would be essentially the same as the SGS unit. An additional sample port would be required in the gas space between the liquid surface and the tubesheet for DOP testing. The overall removal efficiency for DOP aerosol would exceed $99 \%$.

\subsection{SUGGESTED AREAS FOR FURTHER STUDY}

The development program proved that the concept is viable and provided values for design parameters. Additional development is warranted in the areas of scaleup, bed optimization, and theoretical modeling.

The major uncertainty in scaling the test results is the hydraulic performance, in particular, gas distribution. The complexity of modeling the bed pulsing and subsequent gas flow prevents predicting the gas distribution in larger diameter beds. The results indicate that there is a limiting bed diameter on scaling-up the scrubber unit. A full scale unit should be built and tested to define the limit. The aerosol removal efficiency should not change on scale-up, since the development tests were macro in scale with regard to the collection mechanisms.

There is a strong incentive to reduce the bed depth, and hence the pressure drop across the scrubber. Decreasing the pressure drop reduces the blower size, the scrubber tank structural requirements, and the operating 
requirements. Energy consumption is not a concern because of operating costs, but is a consideration from the standpoint of supply. The reactor emergency power supply would be required to handle all the reactor systems, including the scrubber blower. Reducing the power requirement reduces the required capacity of this expensive source. The bed depth can be reduced, but with a loss of aerosol collection efficiency. By optimizing the packing shape, size, and material, a shorter bed may be developed which maintains the same removal efficiency.

As shown by the development tests, the scrubber performance exceeds the performance predicted by models based on inertia collection mechanisms. Undoubtediy, some other mechanism is contributing to the aerosol removal, probably particle growth. An effort should be made to identify and quantify the collection mechanisms at work in the SGS. This would facilitate predicting the submerged gravel scrubber performance for various design configurations and for other air cleaning applications. 


\subsection{SUMMARY AND CONCLUSIONS}

A series of hydraulic and aerosol tests was performed on an engineering scale model of a novel air cleaning concept, the submerged gravel scrubber (SGS). The SGS consisted of a packed bed of gravel suspended in a pool of liquid. A high efficiency fibrous demister (HEFD) was tested in conjunction with the submerged bed as a means of enhancing the efficiency of collecting smaller particles.

Hydraulic tests were made to evaluate the gravel scrubber pressure drop and the liquid circulation rate through the bed for various bed configurations and operating conditions. Aerosol tests were performed with different bed arrangements using sodium aerosols generated by burning sodium in air atmos pheres.

The aerosol test experience sums to 78 hours of operation, approximately $5300 \mathrm{std} \mathrm{m}^{3}$ of cleaned gas at in let gas temperatures up to $125^{\circ} \mathrm{C}$, and $33 \mathrm{~kg}$ of collected aerosol.

The tests demonstrated that the submerged gravel scrubber concept is viable and provided information on scrubber performance for various bed arrangements. Based on these tests, design parameters were chosen. The tests also demonstrated that the addition of a high efficiency fibrous demister element to the submerged gravel bed resulted in a system with significantly enhanced aerosol removal efficiency.

An air cleaning system conceptual design was made for venting a 975 MWth liquid metal fast breeder reactor using the design parameters obtained from the development tests. The conceptual design demonstrates application of the submerged gravel scrubber concept to large-scale reactors. 
Specific conclusions from this work are:

- An acceptable bed design configuration is a $0.61-\mathrm{m}$ deep bed composed of $0.95 \mathrm{~cm}$ to $1.27 \mathrm{~cm}$ diameter crushed rock.

- An appropriate design gas superficial velocity is $0.5-\mathrm{m} / \mathrm{s}$. Scrubber performance is maintained for gas velocities from 0 to $0.5-\mathrm{m} / \mathrm{s}$.

- A novel feature of the SGS is the gas-induced liquid circulation through the bed. The liquid circulates at a nominal superficial veloc ity of $50 \mathrm{~m} / \mathrm{hr}$.

- The scrubber pressure drop is essentially equivalent to the static head of water, or $6.7 \mathrm{kPa}$ for a 0.61 deep bed.

- The aerosol mass removal efficiency for sodium aerosols was $99.8 \%$ for the SGS. The SGS/HEFD system mass removal efficiency exceeded $99.99 \%$.

- Aerosol removal efficiency was essentially the same for the three chemical forms of sodium aerosol tested; $\mathrm{Na}_{2} \mathrm{CO}_{3}, \mathrm{Na}_{2} \mathrm{O}_{2}, \mathrm{NaOH}$.

- The total mass loading of the system is dependent on the liquid pool volume and a limiting concentration level. A limit of $5 \overrightarrow{\mathrm{M}}-\mathrm{NaOH}$ is recommended based on solubility and viscosity considerations.

- Hydraulic scaleup has been demonstrated for a bed capable of handling 275 actual $\mathrm{m}^{3} / \mathrm{hr}$.

- Cooling of the inlet gas to within $2^{\circ} \mathrm{C}$ of the liquid temperature was demonstrated for inlet gas temperatures up to $120^{\circ} \mathrm{C}$. 
- The major design criteria needed for scaling the SGS to a particular reactor are the total mass of aerosol to be vented, the maximum vent rate at actual temperature and pressure conditions, the required aerosol mass removal efficiency, and the vented aerosol particle size distribution. The mass of vented aerosol and the recommended limiting concentration of $5 \bar{M} \mathrm{NaOH}$ define the pool volume. The vent rate and the design superficial velocity, $0.5-\mathrm{m} / \mathrm{s}$, set the submerged bed area. The particle size distribution and required mass removal efficiency will dictate the need for adding the HEFD units to the SGS.

- Further study is required to identify and then quantify the aerosol collection mechanisms at work in the submerged gravel scrubber. In particular, particle growth by liquid condensation on the particles should be investigated. 


\subsection{REFERENCES}

1. R. K. Hilliard, J. D. McCormack, and A. K. Postma, Evaluation of Air Cleaning System Concepts for Emergency Use in LMFBR PTants, HEDL-TME 76-41, Hanford Engineering Development Laboratory, Richland, Washington, 1976.

2. A. K. Postma, R. K. Hilliard, Evaluation of Air Cleaning Systems for FFTF Containment Margins, HEDL-TME 79-79, Hanford Eng ineering Deve1opment Laboratory, Richland, Washington, 1980.

3. A. K. Postma, R. K. Hilliard, Preliminary Evaluation of Air Cleaning Systems for the CRBRP TLTM Case, HEDL TC-836, Hanford Eng ineering Development Laboratory, Richland, Washington, April 1977.

4. Patent application filed by U.S. Department of Energy, 1980.

5. "Application, Part II of Fluid Meters," Inter im Supplement 19.5 on Instruments and Apparatus, Report of ASME Research Committee on Fluid Meters, Sixth Edition, 1971 .

6. R. K. Hilliard, J. D. McCormack, and A. K. Postma, Aerosol Behavior During Sodium Pool Fires in a Large Vesse 1 - CSTF Tests AB1 and AB2, HEDL-TME 79-28, Hanford Eng ineering Development Laboratory, Richland, Washington, 1979.

7. R. J. Davis, A Nuclear Safety Particle Primer, ORNL-4337, Oak Ridge National Laboratory, January 1969.

8. Testing of Nuclear Air-Cleaning Systems, American National Standard ANSI N510-1975, American Society of Mechanical Engineers.

9. J. L. Turpin, R. L. Huntington, "Prediction of Pressure Drop for TwoPhase, Two-Component Concurrent Flow in Packed Beds," AIChE Journal 13, 1196-1202, November 1967.

10. R. P. Lackins, Ph.D. dissertation, Univ. Michigan, Ann Arbor, 1959.

11. R. S. Hubner et a 1. HAA-3 USER Report, AI-AEC-13088, Atomics Internationa 1, March 30, 1973.

12. S. C. Yung, R. Chmielewski and S. Calvert, Mobile Bed Flux Force/ Condensation Scrubbers, EPA-600/7-79-071, A ir Pollution Technology, Inc., November 1979.

13. S. Dushman, Vacuum Technique, 2nd Edition, August 1949, John Wi ley \& Sons, NY.

14. W. E. Ranz, J. B. Wong, "Impaction of Dust and Smoke Particles on Surface and Body Collectors," Industrial and Engineering Chemistry, June 1952. 


\subsection{REFERENCES (Cont'd)}

15. S. C. Saxena and W. M. Swift, Dust Removal from Hot and Compressed Gas Streams by Fibrous-and Granular-Bed Filters: A State of the Art Review, ANL/CEN/FE-77-9, Argonne Nationa 7 Laboratory, May 1978.

16. A. K. Postma, R. L. Riteman, J. A. Gieseke, and E. W. Schmidt, Models for Predicting the Removal of Airborne Contaminants by Reactor Containment Sprays, BNWL-B-417, Batte 17e Pacific Northwest Laboratory, Richland, WA, June 1975.

17. N. A. Fuchs, The Mechanics of Aerosols, MacMillan Co., New York, 1964.

18. C. N. Davies, Air Filtration, Academic Press, London, 1973.

19. L. C. Schwendiman, et a 1., Radioactive Particle Retention in Aerosol Transport Systems, HW-SA-3210, Hanford Atomic Products Operation, Richland, Washington, October 1963.

20. Richard Dennis, ed., Handbook on Aerosols, TID-26608, Technical Information Center, Office of Public Affairs, U.S. Energy Research and Development Administration, 1976.

21. C. N. Davies, "The Separation of Airborne Dust and Particles," Proceedings of Instn. Mech. Engrs., Vo 1. 1B, 1952.

22. C. E. Lapple, H. J. Kammack, "Performance of Wet Dust Scrubbers," Chemical Engineering Progress, p. 110, March 1955.

23. S. Calvert, et al., "Scrubber Performance for Particle Collection," AIChE Symposium Series, No. 137, Vol. 70.

24. C. E. Lapple, "Processes Use Many Collector Types," Chemical Engineering, May 1951.

25. C. J. Stairmond, "Dust Collection by Impingment and Diffusion," Instn. Chem. Eng. Trans., Vo 1. 28, 1950.

26. S. Calvert, "How to Choose a Particulate Scrubber," Chemical Engineering, August 29, 1977.

27. S. Jackson and S. Calvert, "Entrained Particle Collection in Packed Beds," AIChE Journal 12, 1075-1078, November 1966.

28. S. Calvert, et al., Wet Scrubber System Study, Volume I, Scrubber Handbook, PB-213 016, APT, Inc., Riverside, California, July 1972.

29. Hypothetical Core Disruptive Accident Considerations in CRBRP, Vol 2, Assesment of Thermal Margins Beyond the Design Base, CRBRP-3, $\sqrt{012}$, Rev. 0, March, 1980. 


\subsection{REFERENCES (Cont' $d$ )}

30. R. W. Wierman, Experimental Study of Hydrogen Jet Ignition and Jet Extingu ishment, HEDL-TME 78-80, Hanford Eng ineering Development Laboratory, April 1979.

31. R. K. Hilliard, J. D. McCormack, and A. K. Postma, "Containment Air Cleaning for LMFBRs," in Proc. of the International Meeting on Fast Reactor Safety Technology, Seatt le, Washington, Am. Nucl. Soc., August 19-23, 1979.

32. Handbook of Chemistry and Physics, 60th Edition, CRC Press Inc., Boca Raton. Florida, 1979 .

33. J. D. McCormack, R. K. Hilliard and A. K. Postma, Large-Scale Tests of Aqueous Scrubber systems for LMFBR Vented Conta inments, HEDL-SA-2121 FP Paper 5-4, presented at 16 th DOE Nuclear Air Cleaning Conference, October 20-23, 1980, San Diego, California. 
A P P ENDIX A

TEST FACILITY DESCRIPTION 


\section{APPENDIX A}

\section{TEST FACILITY DESCRIPTION}

\section{Containment Systems Test Facility (CSTF)}

Four of the aerosol tests were performed using sodium aerosols generated in the CSTF containment vessel. The vessel is 7.62-m in diameter and is $20.4-\mathrm{m}$ high, or roughly one-half the projected height of a containment building. The carbon steel vessel was fabricated in accordance with ASME VIII Code (1962) with a design pressure of $0.517 \mathrm{MPa}$ at $160^{\circ} \mathrm{C}$. The top and bottom heads are dished. The vessel external surface is covered with a $25.4-\mathrm{mm}$ layer of fiberglass insulation. The volume of the vessel is $850 \mathrm{~m}^{3}$, the total horizontal surface area is $88 \mathrm{~m}^{2}$, the shell area is $520 \mathrm{~m}^{2}$, and the total internal surface area is $1000 \mathrm{~m}^{2}$. The vesse 1 has a measured leak rate of $2.0 \%$ per day at 10 psig. The vessel is equipped with thermocouples, gas sample points, aerosol sample ports, a ventilation system, and a sodium supply system. Figure A-1 is a schematic of the vessel. The scrubber was connected to a nozzle approximately at the vessel midplane.

The sodium system is capable of delivering up to $1700 \mathrm{~kg}$ of liquid sodium at $550^{\circ} \mathrm{C}$ to the vessel. For the aerosol tests, three nozzles were installed in the vesse1; two nozzles were located on the vessel bottom above a catch pan and one nozzle was installed at about vessel center. Usually, one nozzle was used at a time, spraying sodium at an average rate of $5.3 \mathrm{~g} / \mathrm{s}$. For test SGS-AC6, three nozzles sprayed simultaniously, for a total sodium flowrate of $26.5 \mathrm{~g} / \mathrm{s}$.

The aerosol was generated primarily for proof-testing a large-scale air cleaning system of another configuration. The SGS tests were performed in conjunction with those tests. 


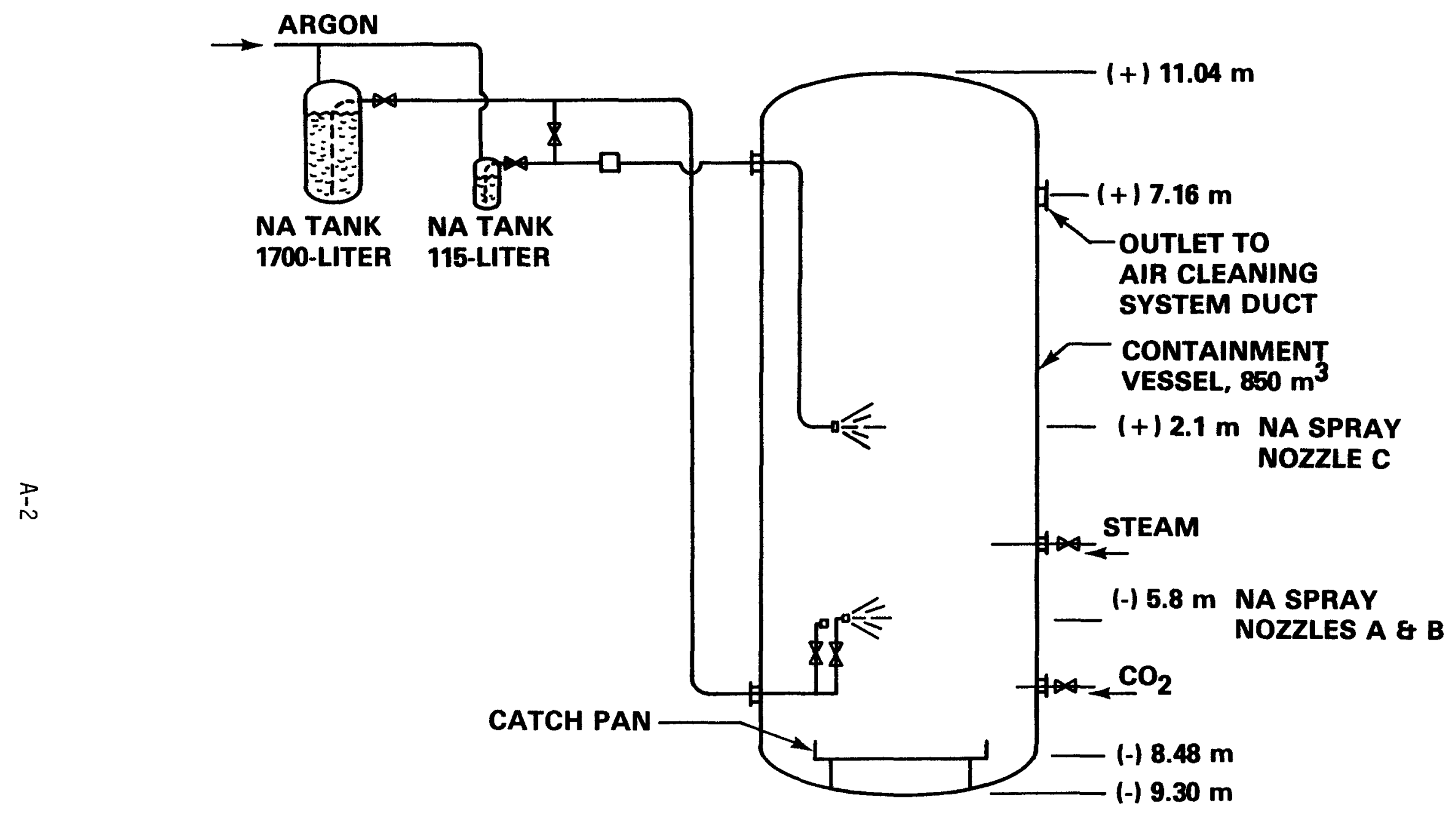

HEDL 8007-031.10

FIGURE A-1. Containment Systems Test Facility. 
Throughout the tests, the vessel oxygen and hydrogen concentrations, and the dewpoint were continuously monitored. Temperatures were automatically logged at 44 locations inside and outside the containment vessel. The pressure was measured periodically by sampling through the thief stations. Impactors were inserted through the ports to obtain particle size information. Deposition coupon samples, electron microscope grids, and fluorocarbon filter samples were used to obtain information on composition, particle shape, and chemical analysis, respectively.

The facility is equipped with process water, sanitary water, distilled water, argon gas, nitrogen gas, plant high pressure air, and a high volume vacuum system. A titration lab is available for sodium analysis.

\section{Large Sodium Fire Facility (LSFF)}

Three tests were performed in the Air Cleaning Room (ACR) located in the Large Sodium Fire Facility. The ACR is a $335-\mathrm{m}^{3}$ room with concrete walls, floor, and ceiling. The room is $6.6-\mathrm{m}$ tall. A ventilation system, rated at $175-\mathrm{m}^{3} / \mathrm{min}$, is connected to the ACR and includes a scrubber, HEPA filters, and discharge through a $61-m$ stack. Figure $A-2$ is a schematic of the facility.

The ACR was equipped with thermocouples, aerosol sampling ports, dewpoint meters, and gas analysis instrumentation. Aerosol for SGS testing was taken from a center wall port located $2.5 \mathrm{~m}$ off the floor. The facility is equipped with a sodium melt station capable of supplying $23 \mathrm{~kg}$ of liquid sodium at up to $550^{\circ} \mathrm{C}$. Water, air, argon, nitrogen, and vacuum systems are also available.

Sodium aerosol was created by spilling approximately $23 \mathrm{~kg}$ of sodium into a $1-m \times 1-m$ burn pan, thereby creating a pool fire. The pan was $0.3 \mathrm{~m}$ deep and was equipped with heaters. As each sodium spill burned out, additional spills were used to maintain the aerosol concentration. Approximately $25 \%$ of the sodium spilled during each test aerosolized. Folowing each test, the burn pan deposits were removed. 


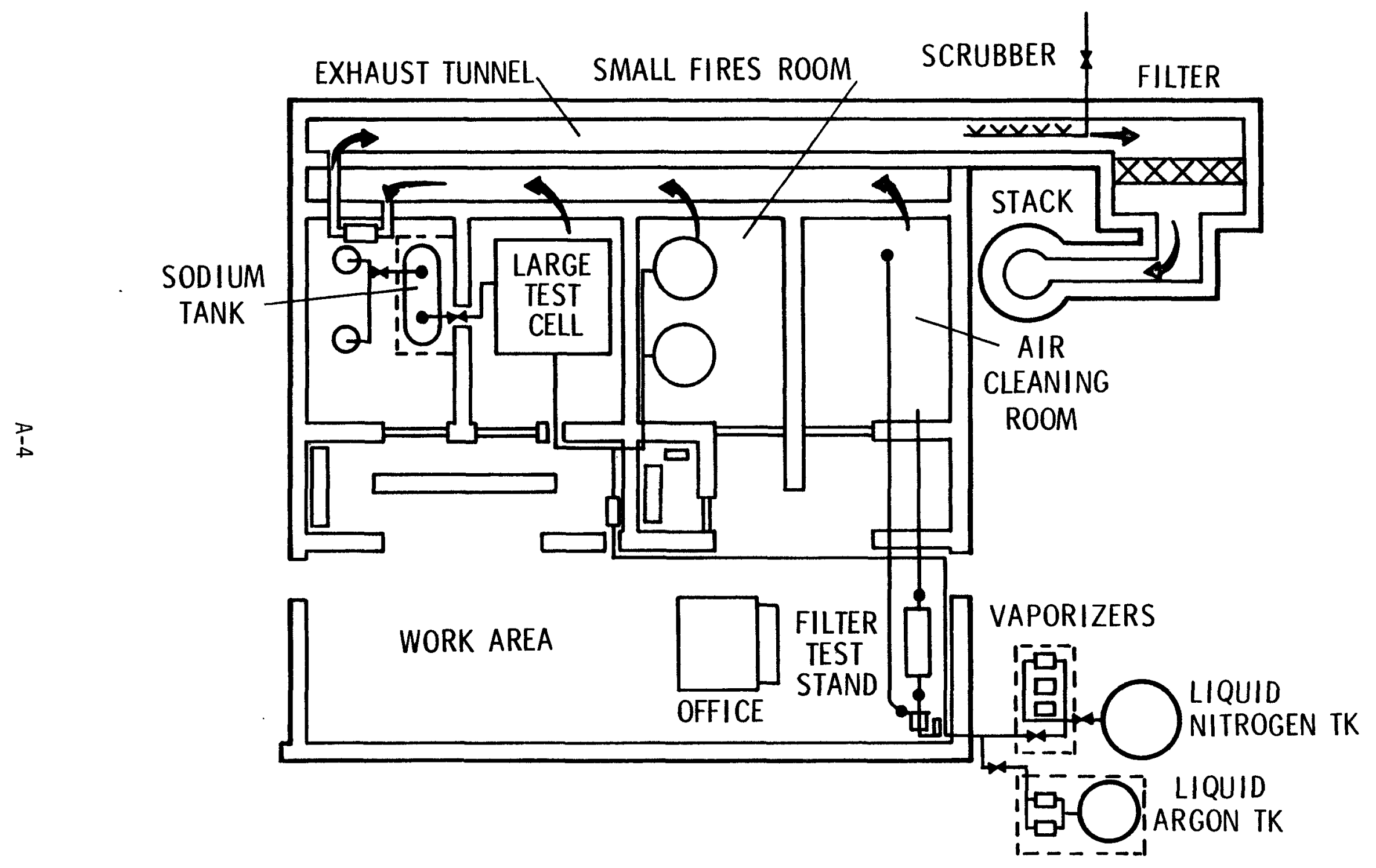

FIGURE A-2. Large Scale Sodium Facility.

HEDL 7904-026.I 


\section{A P PENDIX B}

CALCULATING AEROSOL PARTICLE SIZE

\section{FROM IMPACTOR MEASUREMENTS}




\section{CALCULATING AEROSOL PARTICLE SIZE FROM IMPACTOR MEASUREMENTS}

In this Appendix, the procedures for calculating particle size from impactor measurements is presented. In addition, the individual cascade impactor results are given.

The collection characteristics of an impactor stage were assumed to be dominated by the impaction parameter, $\psi$, given by:

$$
=\frac{\rho u d^{2} C}{180}
$$

Where:

$$
\begin{aligned}
& \psi=\text { Impaction parameter (dimensionless) } \\
& v=\text { Gas velocity }(\mathrm{cm} / \mathrm{s}) \\
& o=\text { Particle density }\left(\mathrm{g} / \mathrm{cm}^{3}\right) \\
& d=\text { Particle diameter }(\mathrm{cm}) \\
& \mu=\text { Gas viscosity }(\mathrm{g} / \mathrm{cm}-\mathrm{s}) \\
& D=\text { Impactor jet diameter }(\mathrm{cm}), \text { and } \\
& C=\text { Cunningham correction factor (dimensionless). }
\end{aligned}
$$

If the collection efficiency of an impactor stage is plotted versus the particle diameter, the diameter at which $50 \%$ of the particles are collected is denoted as $d_{50}$, and the corresponding value of the impaction parameter is labeled as $\psi_{50}$. These values are related through equation (B-1) thus:

$$
d_{50}=\left(\frac{18 \mu D \psi_{50}}{\rho \cup C}\right)^{0.5}
$$


Where:

$$
\begin{aligned}
d_{50}= & \begin{array}{r}
\text { Particle diameter at } 50 \% \text { point on efficiency } \\
\text { versus size curve, }(\mathrm{cm})
\end{array} \\
\psi_{50}= & \text { Impaction parameter for the stage at } 50 \% \\
& \text { efficiency point. }
\end{aligned}
$$

By use of equation (B-2), the $d_{50}$ value can be calculated for each impactor stage at flow conditions different from those used to calibrate the impactor. If $C$ is assumed to be constant, then $d_{50}$ can be expressed as:

$$
d_{50}=d_{50} \text { ref }\left(\frac{\mu}{\mu r e f} \cdot \frac{\text { Qref }}{Q}\right)^{0.5}
$$

Where:

$$
\begin{aligned}
d_{50}= & \text { Aerodynamic diameter at sampling conditions, },(\mathrm{cm}), \\
\mu= & V \text { iscosity of gas at sampling conditions }(\mathrm{g} / \mathrm{cms}), \\
Q= & \text { Gas flow rate at sampling conditions }\left(\mathrm{cm}^{3} / \mathrm{s}\right), \text { and } \\
\text { ref = } & \text { Subscript denoting value of parameter under } \\
& \text { calibration conditions. }
\end{aligned}
$$

Cascade impactors of two designs were used for particle size analysis. The reference cut-size diameters used to interpret data obtained from a circular jet impactor (Anderson* Mark III High Temperature Sampler) are listed in Table B-1.

* Manufactured by Anderson 2000, Inc. Atlanta, GA 30320 
TABLE B-1

STAGE REFERENCE CUT DIAMETERS FOR CIRCULAR JET IMPACTOR

\begin{tabular}{|c|c|c|}
\hline Stage & Number & d $(a)(m)$ \\
\hline & 0 & 13.2 \\
\hline & 1 & 8.3 \\
\hline & 2 & 5.6 \\
\hline & 3 & 3.8 \\
\hline & 4 & 2.4 \\
\hline & 5 & 1.2 \\
\hline & 6 & 0.77 \\
\hline & 7 & 0.52 \\
\hline
\end{tabular}

(a) Size of unit density spheres that are removed with $50 \%$ efficiency at $21{ }^{\circ} \mathrm{C}$, testing pressure, and a flowrate of 0.50 ACFM.

The cut diameters listed in Table B-1 are those recommended by the manufacturer $(B-1)$. These values are in good agreement with calibrations reported by Cushing et ${ }_{a}{ }^{(B-2)}$. The reference stage cut-off diameters for the rectangular jet impactor (Sierra Instrument Co., Mode 1226 Stack Sampler*) are given in Table B-2. The data were obtained from the work of Cushing, et.al ${ }^{(B-2)}$.

*Manufactured by Sierra Instrumental Co., Carmel Valley, CA. 


\section{STAGE REFERENCE CUT DIAMETERS FOR RECTANGULAR JET IMPACTOR}

\begin{tabular}{|c|c|c|}
\hline Stage & Number & $d_{50}(a)(\mu \mathrm{m})$ \\
\hline & 1 & 18.0 \\
\hline & 2 & 11.0 \\
\hline & 3 & 4.4 \\
\hline & 4 & 2.6 \\
\hline & 5 & 1.7 \\
\hline & 6 & 0.95 \\
\hline
\end{tabular}

(a) Size of unit density spheres that are removed with $50 \%$ efficiency at $28^{\circ} \mathrm{C}, 29.5 \mathrm{in}$. $\mathrm{Hg}$ pressure, and 0.25 ACFM.

The cut diameters for each impactor stage were adjusted for sampling conditions using equation ${ }^{(B-3)}$. The particle size distributions were constructed from the impactor data using the cut-off diameter approach described by Mercer $(B-3)$. The stage sodium aerosol mass deposits were obtained by washing each stage collection paper with water and analyzing the water by flame emission spectrometry. Impactor inlet and wall deposits were ignored. A background level was subtracted off each stage to account for sodium in the water and stage papers. The cumulative mass fraction penetrating each state was calculated and the stage cut-diameters were corrected for actual flow conditions. The results of an example calculation are shown in Table B-3.

The particle size distribution was obtained by plotting the last two columns on the right in Table B-3 on log-probability paper as shown in Figure B-1. The aerodynamic mass median diameter, $d_{A M M D}$, and the geometric standard deviation can be obtained from the line drawn through the data points if a log-normal distribution is assumed. The ${ }_{A M M D}$ is the diameter at $50 \%$ cumulative mass and $\sigma_{g}$ is given by:

$$
\sigma_{g}=\frac{\text { Particle Diameter at } 84.16 \%}{\text { Particle Diameter at } 50 \%}
$$


The impactor results are presented in the graphs that follow. Most of the sample data fit a log-normal distribution reasonably we 11. Some of the graphs show a bi-model distribution (e.g. Figure B-7). This is undoubtedly due to entrained liquid and particle growth. 
TABLE B-3

EXAMPLE TREATMENT OF CASCADE IMPACTOR DATA(a)

\begin{tabular}{|c|c|c|c|c|c|}
\hline Stage Number & Sodium $(\mathrm{b})(\mathrm{mg})$ & Mass Fraction & Cumulative Fraction & $\begin{array}{c}\text { One Minus } \\
\text { Cumulative Fraction } \\
\end{array}$ & $\mathrm{dp}_{50}(\mu \mathrm{m})$ \\
\hline 1 & 0.188 & 0.1483 & 0.1483 & 0.852 & 14.998 \\
\hline 2 & 0.188 & 0.1483 & 0.2966 & 0.703 & 9.165 \\
\hline 3 & 0.248 & 0.1956 & 0.4922 & 0.508 & 3.666 \\
\hline 4 & 0.198 & 0.1562 & 0.6484 & 0.352 & 2.208 \\
\hline 5 & 0.208 & 0.1640 & 0.8124 & 0.188 & 1.416 \\
\hline 6 & 0.228 & 0.1798 & 0.9922 & 0.008 & 0.792 \\
\hline 7 & $\underline{0.010}$ & 0.0079 & 1. & 0. & \\
\hline & 1.268 & & & & \\
\hline
\end{tabular}

(a) Sample Number

Impactor: Rectangular Jet Flowrate: 0.3 (scfm) Temperature: $77.0(\mathrm{OF})$ Pressure: 13.5 (psia)

(b) Net mass after correction for stage paper blank. 


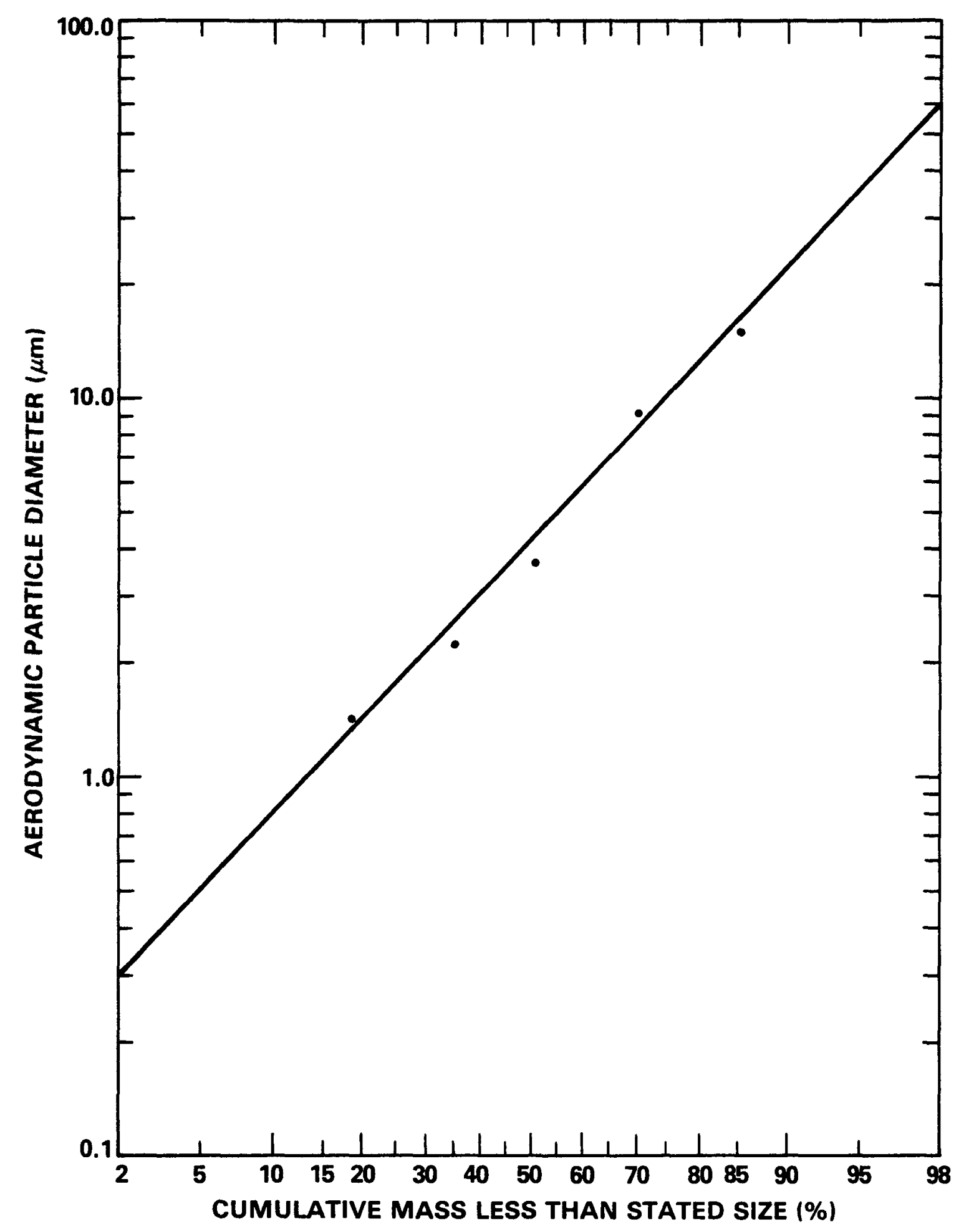

HEDL 8010-174.5

FIGURE B-1. Sample Calculation Particle Size Distribution Plot. 


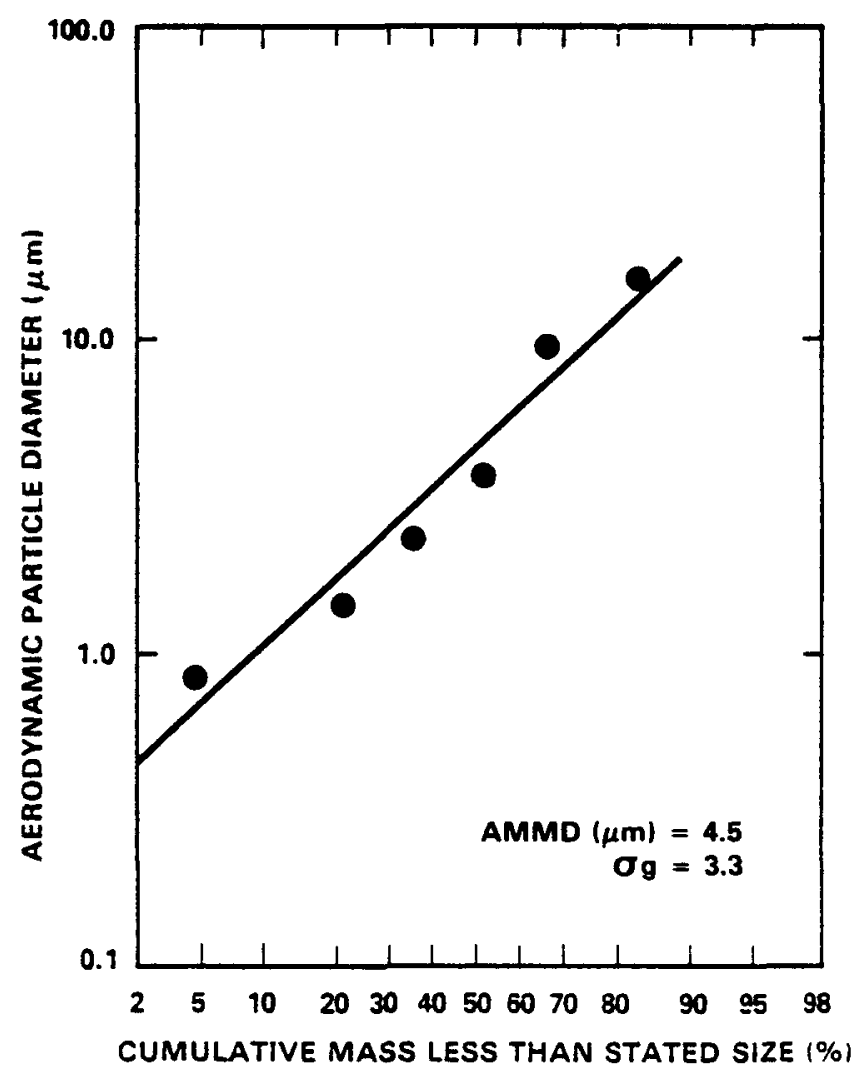

\section{RECTANGULAR JET IMPACTOR}

TEST: SGS-AC3

TIME: 1610

SCRUBBER OUTLET

LAB

mg $\mathrm{Na}$

0.310

0.310

0.310

0.320

0.270

0.340

0.130
CUM. FRACT.

LESS THAN

0.840

0.681

0.521

0.357

0.218

0.043
Dp, 50

MICROMETERS

16.012

9.785

3.914

2.357

1.512

0.845

$\begin{array}{llc}\text { TEMPERATURE } & \left({ }^{\circ} \mathrm{F}\right): & \mathbf{8 0 . 0 0} \\ \text { STAGE BACKGROUND } & (\mathrm{mg}): & \mathbf{0 . 0 1 2 0} \\ \text { B.U. BACKGROUND } & \text { (mg): } & 0.0500 \\ \text { PRESSURE } & \text { (PSIA): } & \mathbf{1 4 . 7 0 0 0} \\ \text { FLOW } & \text { (SCFM): } & \mathbf{0 . 2 8 5 0} \\ \text { VISCOSITY } & (\mu \mathrm{p}): & \mathbf{1 8 3 . 0 0}\end{array}$

HEDL 8007-104.10

FIGURE B-2. Particle Size Distribution Plot, SGS-AC3. 


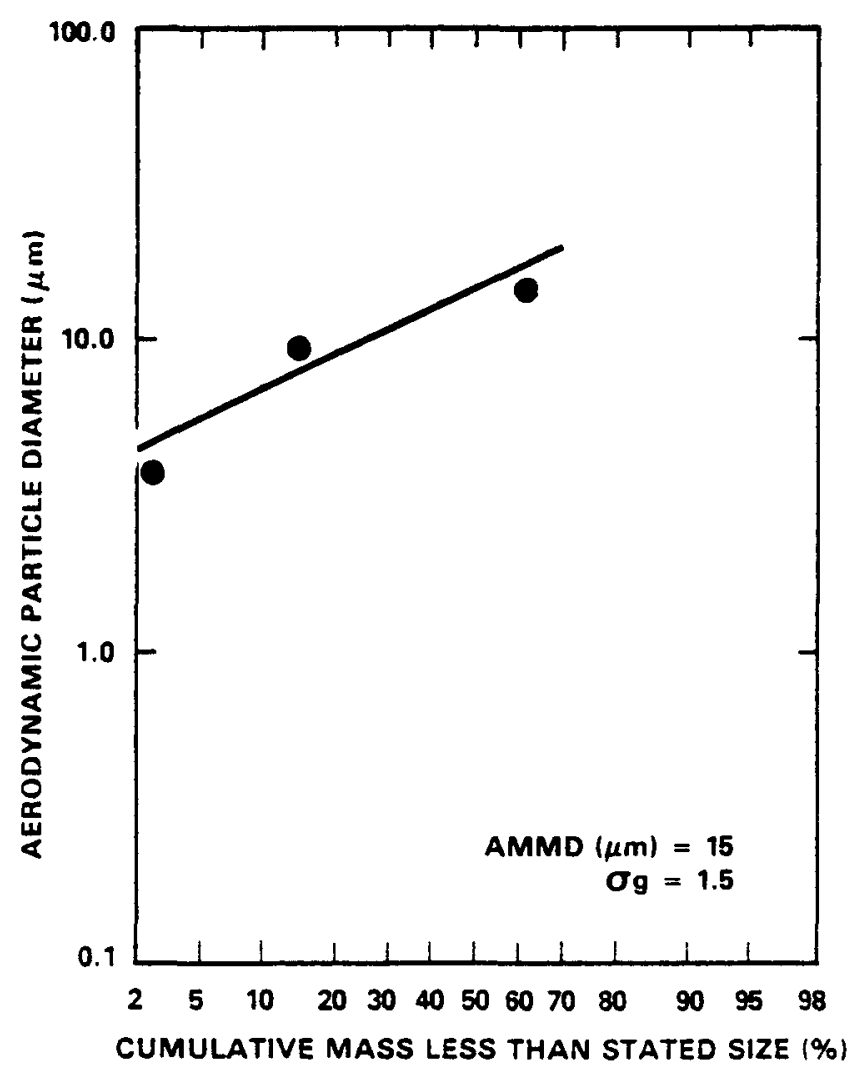

RECTANGULAR JET IMPACTOR TEST: SGS-E1

TIME: 60 MINUTES

SCRUBBER INLET

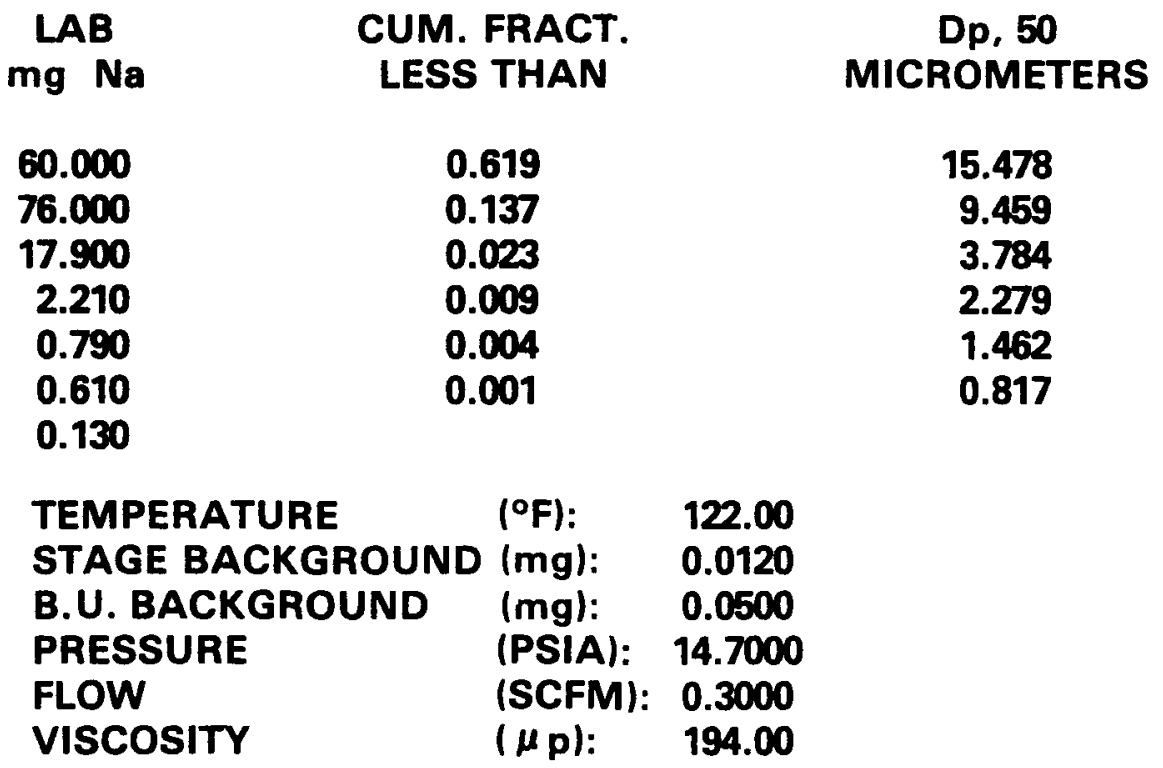

FIGURE B-3. Particle Size Distribution Plot, SGS-El. HEDL 8007-104.11 


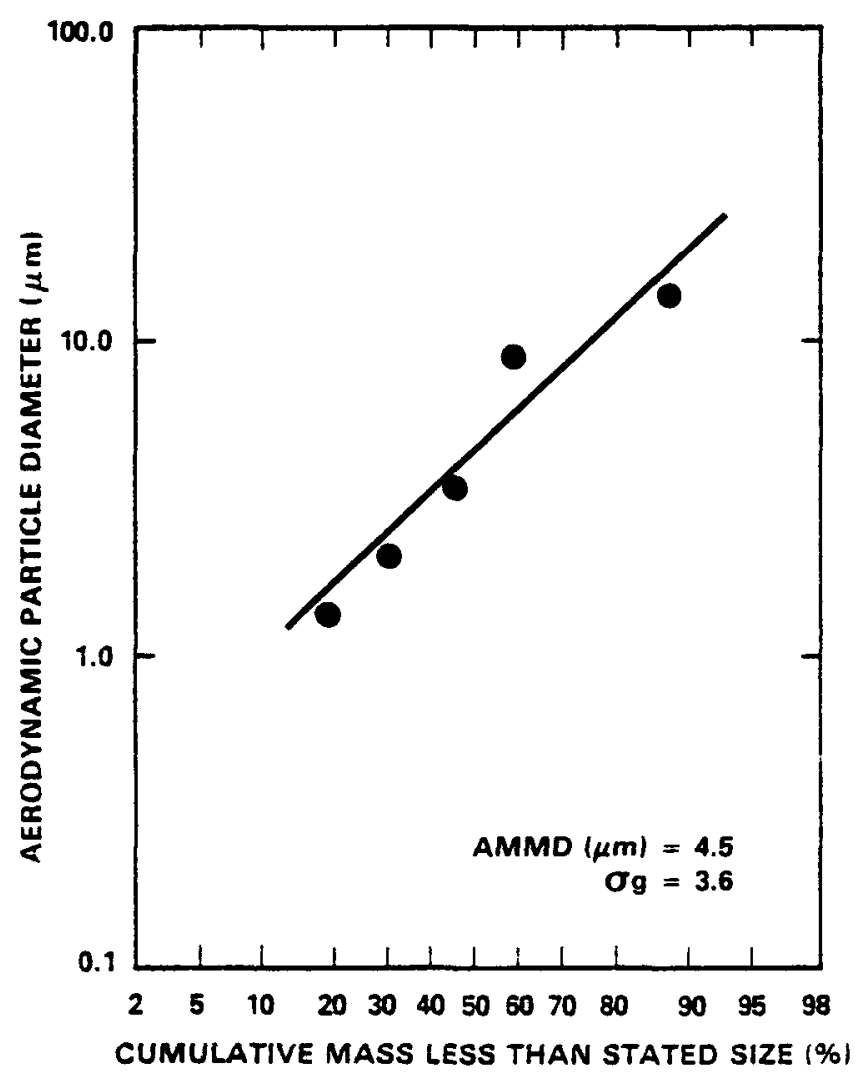

RECTANGULAR JET IMPACTOR

TEST: SGS-E1

TIME: 63 MINUTES

SCRUBBER OUTLET

\begin{tabular}{|c|c|c|c|}
\hline $\begin{array}{l}\text { LAB } \\
m g N a\end{array}$ & \multicolumn{2}{|l|}{$\begin{array}{l}\text { CUM. FRACT. } \\
\text { LESS THAN }\end{array}$} & $\begin{array}{c}\text { Dp, } 50 \\
\text { MICROMETERS }\end{array}$ \\
\hline $\begin{array}{l}0.250 \\
0.480 \\
0.250 \\
0.260 \\
0.250 \\
0.290 \\
0.070\end{array}$ & $\begin{array}{l}0.862 \\
0.591 \\
0.454 \\
0.310 \\
0.172 \\
0.012\end{array}$ & & $\begin{array}{r}15.026 \\
9.183 \\
3.673 \\
2.212 \\
1.419 \\
0.793\end{array}$ \\
\hline $\begin{array}{l}\text { TEMPE } \\
\text { STAGE } \\
\text { B.U. B } \\
\text { PRESS } \\
\text { FLOW } \\
\text { VISCO }\end{array}$ & $\begin{array}{ll} & \text { (') } \\
\text { ROUND } & \text { (mg): } \\
\text { UND } & \text { (mg): } \\
& \text { (PSIA): } \\
& \text { (SCFM): } \\
& (\mu \mathrm{p}):\end{array}$ & $\begin{array}{l}76.00 \\
0.0120 \\
0.0500 \\
13.6000 \\
0.3000 \\
182.00\end{array}$ & \\
\hline
\end{tabular}

FIGURE B-4. Particle Size Distribution Plot, SGS-E1. HEDL 8007-104.23 


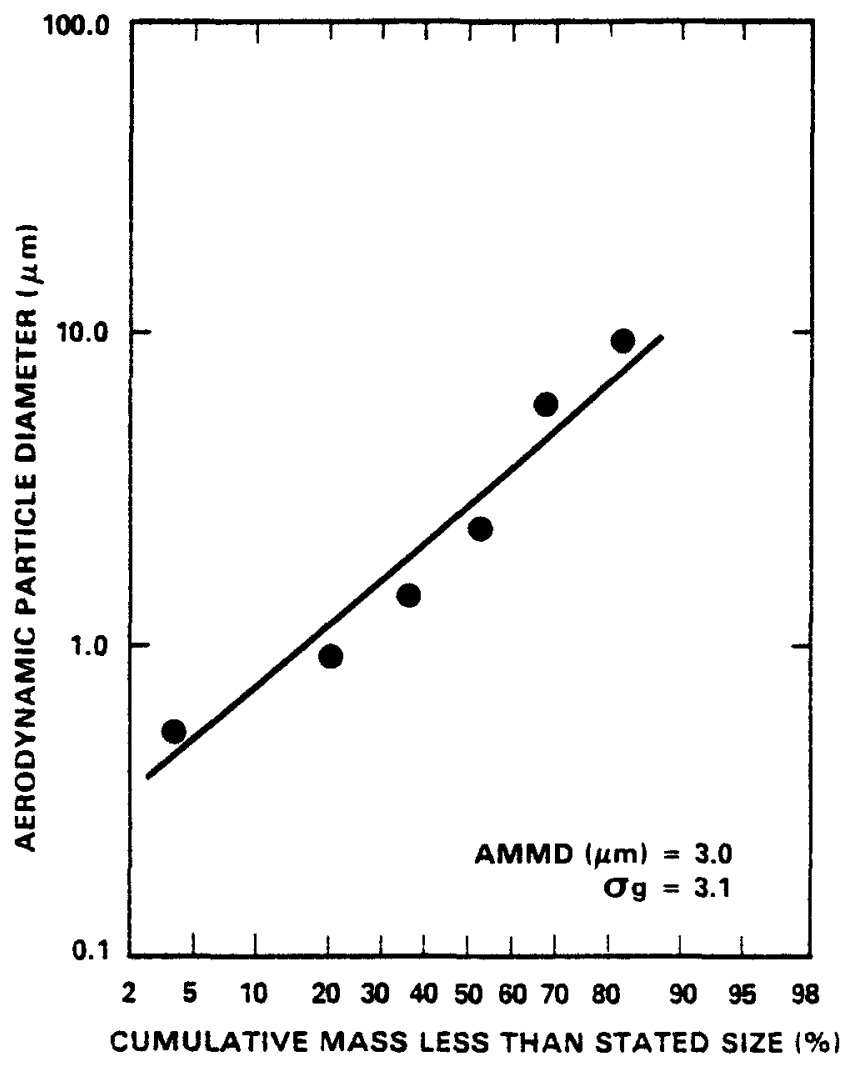

RECTANGULAR JET IMPACTOR

TEST: SGS-E1

TIME: 170 MINUTES

SCRUBBER OUTLET

LAB mg Na

0.260

0.210

0.240

0.260

0.220

0.240

0.100
CUM. FRACT.

LESS THAN

0.824

0.683

0.521

0.345

0.197

0.036
Dp, 50

MICROMETERS

9.980

6.099

2.440

1.469

0.943

0.527

TEMPERATURE $\quad\left({ }^{\circ} \mathrm{F}\right): \quad 79.00$

STAGE BACKGROUND (mg): 0.0120

B.U. BACKGROUND (mg): $\quad 0.0500$

PRESSURE

FLOW

VISCOSITY

(PSIA): 13.6000

(SCFM): 0.6800

( $\mu \mathrm{p}): \quad \mathbf{1 8 3 . 0 0}$

FIGURE B-5. Particle Size Distribution Plot, SGS-E1. HEDL 8007-104.22 


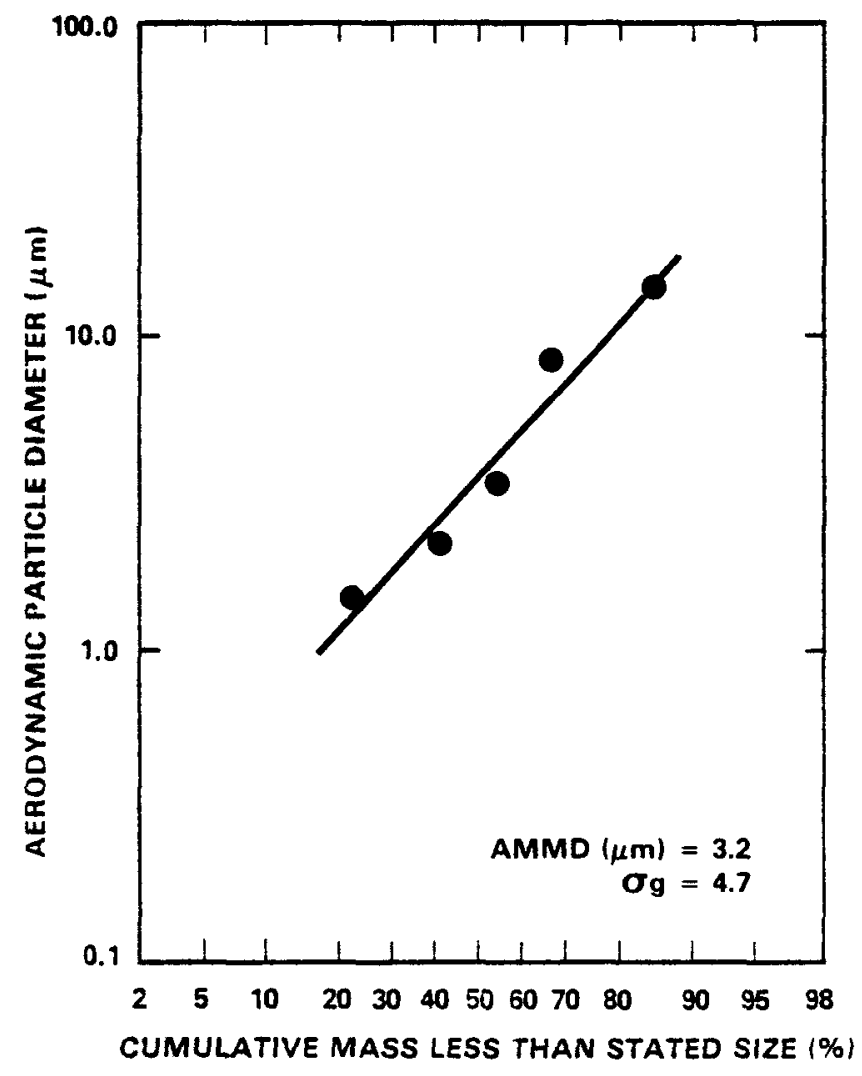

RECTANGULAR JET IMPACTOR TEST: SGS-E2

TIME: 47 MINUTES

SCRUBBER OUTLET

$\begin{array}{ll}\text { LAB } & \text { CUM. FRACT. } \\ \mathrm{mg} \mathrm{Na} & \text { LESS THAN }\end{array}$
0.240
0.290
0.250
0.220
0.280
0.380
0.060

0.857

0.683

0.534

0.404

0.237

0.006
Dp, 50

MICROMETERS

15.272

9.333

3.733

2.248

1.442

0.806

TEMPERATURE

$\left({ }^{\circ} \mathrm{F}\right):$

79.00

STAGE BACKGROUND (mg): $\quad 0.0120$

B.V. BACKGROUND (mg): $\quad 0.0500$

PRESSURE

FLOW

(PSIA): 14.0500

VISCOSITY

(SCFM): 0.3000

( $\mu$ p): $\quad \mathbf{1 8 3 . 0 0}$

FIGURE B-6. Particle Size Distribution Plot, SGS-E2

HEDL 8007-104.14

8007969-13 


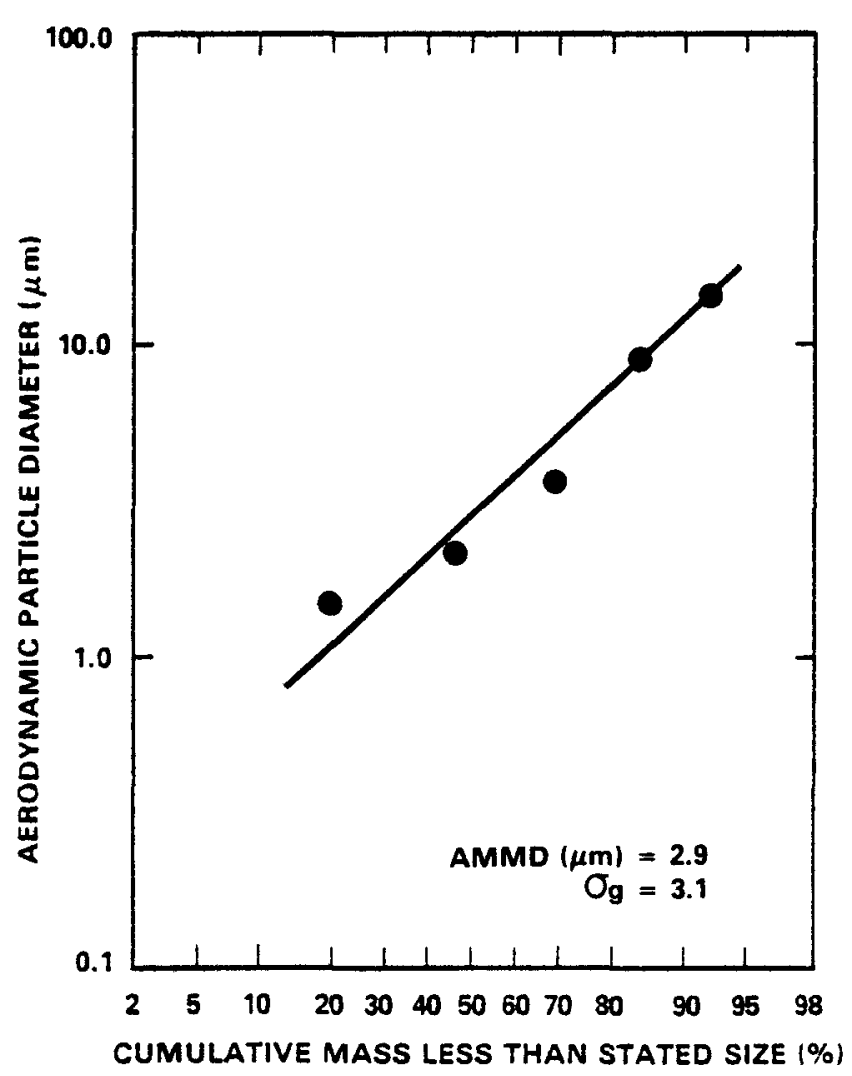

RECTANGULAR JET IMPACTOR

TEST: SGS-E2

TIME: 48 MINUTES

SCRUBBER INLET

LAB

mg Na

0.240

0.260

0.540

0.780

0.810

0.620

0.070
CUM. FRACT.

LESS THAN

0.929

0.851

0.686

0.446

0.196

0.006
Dp, 50

MICROMETERS

15.414

9.420

3.768

2.269

1.456

0.814

TEMPERATURE

$\left({ }^{\circ} \mathrm{F}\right): \quad \mathbf{1 4 5 . 0 0}$

STAGE BACKGROUND (mg): $\quad 0.0120$

B.U. BACKGROUND (mg): $\quad 0.0500$

PRESSURE

FLOW

(PSIA): 14.7000

VISCOSITY

(SCFM): 0.3000

$(\mu \mathrm{p}): \quad 200.00$

FIGURE B-7. Particle Size Distribution Plot, SGS-E2.

HEDL 8007-104.13 


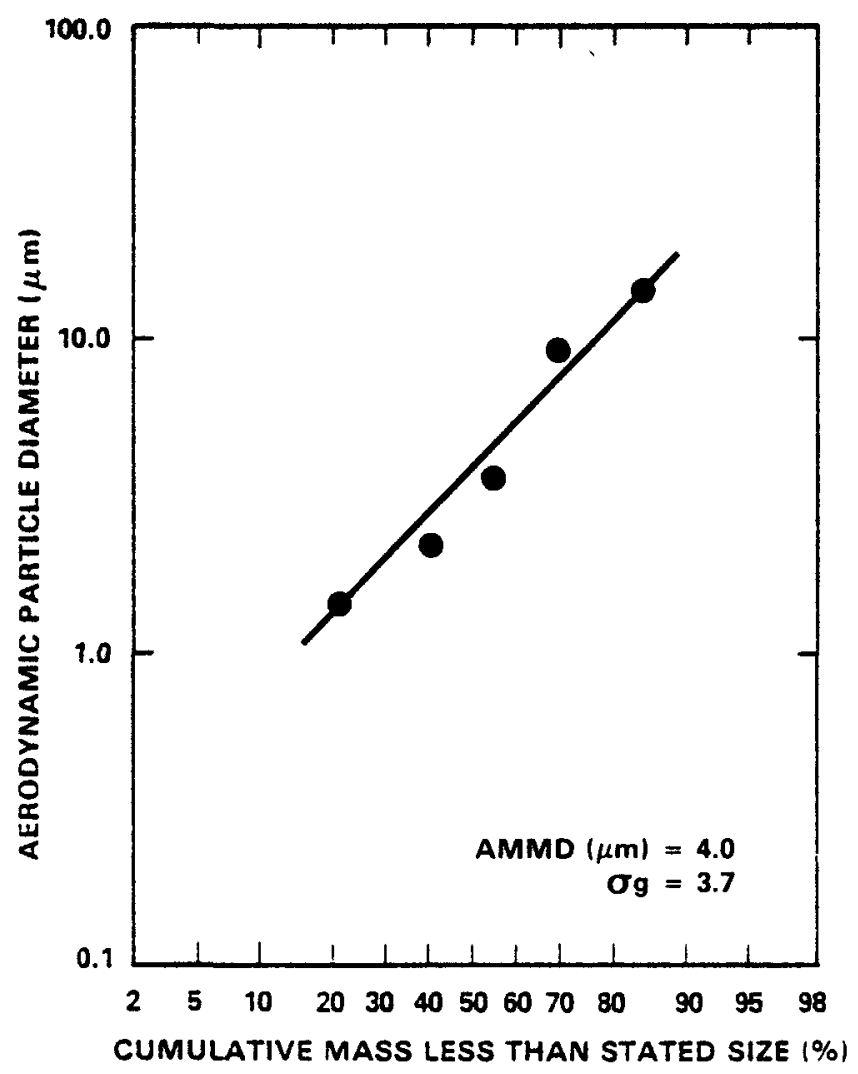

RECTANGULAR JET IMPACTOR TEST: SGS-E2 TIME: 172 MINUTES SCRUBBER OUTLET

LAB mg $\mathrm{Na}$

0.230

0.250

0.270

0.240

0.290

0.320

0.070
CUM. FRACT. LESS THAN

\subsection{9}

0.705

0.539

0.391

0.212

0.013
Dp, 50

MICROMETERS

15.258

9.324

3.730

2.246

1.441

0.805

TEMPERATURE

$\left({ }^{\circ} \mathrm{F}\right): \quad 80.00$

STAGE BACKGROUND (mg): $\quad 0.0120$

B.U. BACKGROUND (mg): $\quad 0.0500$

PRESSURE

FLOW

(PSIA): 14.0500

VISCOSITY

(SCFM): 0.3000

$(\mu \mathrm{p}): \quad \mathbf{1 8 3 . 0 0}$

FIGURE B-8. Particle Size Distribution Plot, SGS-E2.

HEDL 8007-104.15

8007969-14 


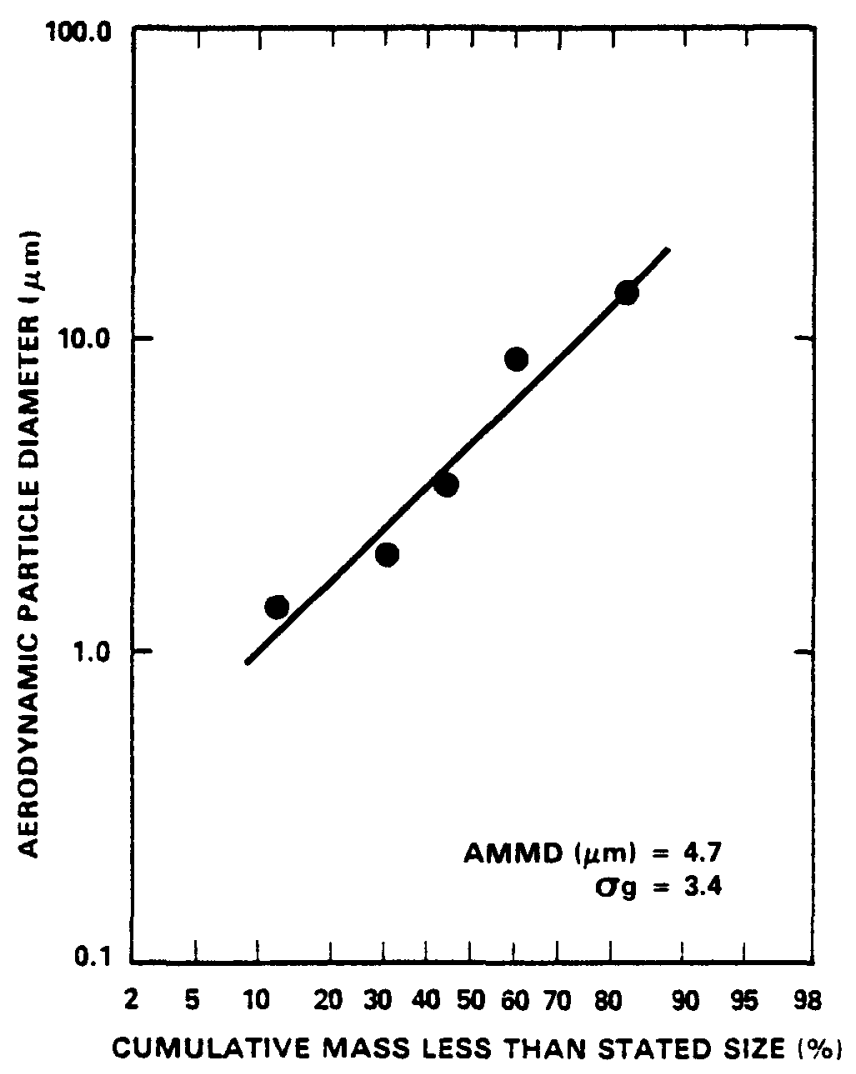

RECTANGULAR JET IMPACTOR TEST: SGS-E3 TIME: 60 MINUTES SCRUBBER OUTLET

LAB mg Na
0.250
0.340
0.280
0.200
0.270
0.190
0.050

CUM. FRACT.

LESS THAN

0.837

0.612

0.428

0.299

0.122

0.000
Dp, 50

MICROMETERS

14.985

9.157

3.663

2.206

1.415

0.791

TEMPERATURE ('F): $\mathbf{7 5 . 0 0}$

STAGE BACKGROUND (mg): $\quad 0.0120$

B.U. BACKGROUND (mg): $\quad 0.0500$

PRESSURE

FLOW

(PSIA): 13.5000

VISCOSITY

(SCFM): 0.3000

$(\mu \mathrm{p}): \quad 182.00$

FIGURE B-9. Particle Size Distribution Plot, SGS-E3.

HEDL 8007-104.24

8007969-15 


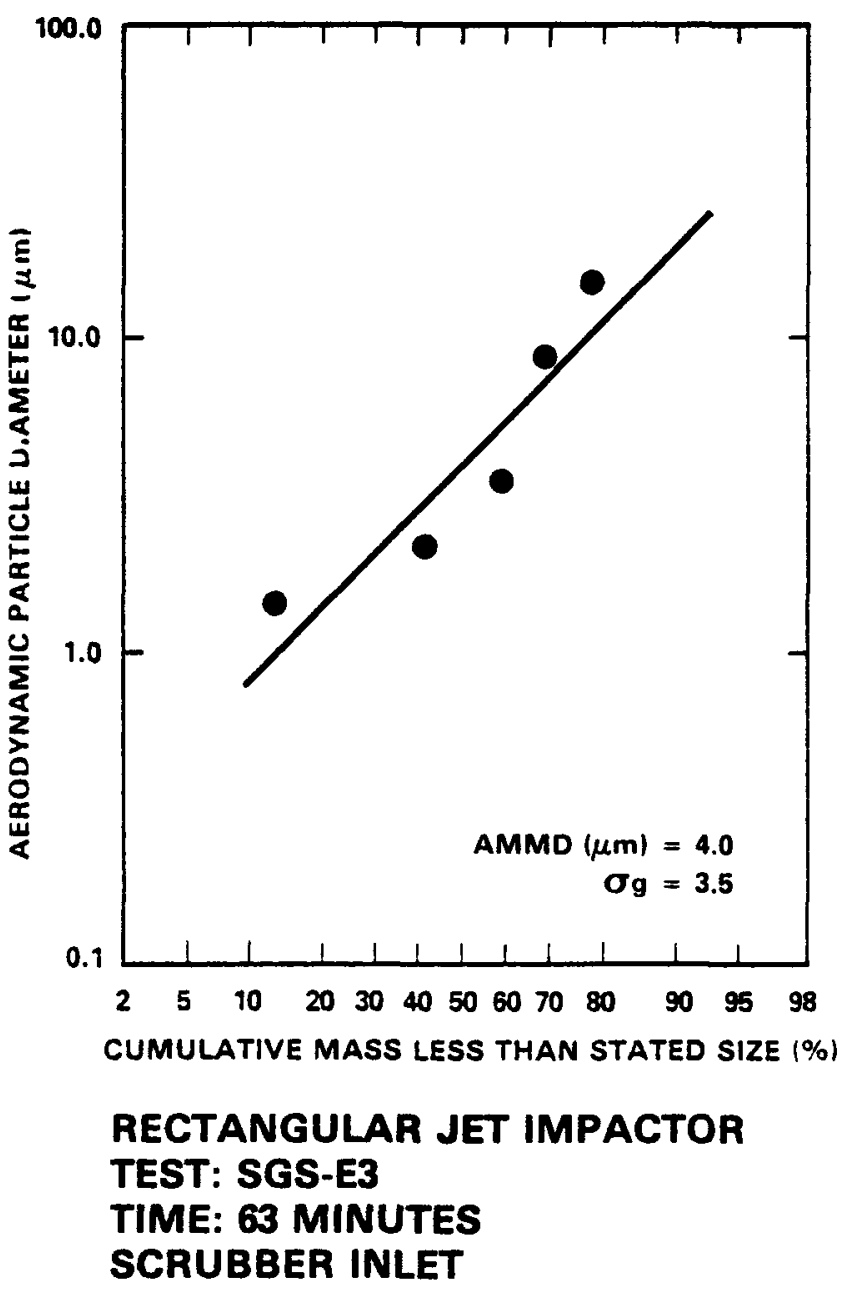

LAB

mg Na

0.400

0.170

0.210

0.350

0.520

0.220

0.070
CUM. FRACT.

LESS THAN

0.787

0.700

0.591

0.405

0.125

0.011
Dp, 50

MICROMETERS

15.427

9.428

3.771

2.271

1.457

0.814

TEMPERATURE

(ㅇ) $\quad 141.00$

STAGE BACKGROUND (mg): $\quad 0.0120$

B.U.BACKGROUND (mg): $\quad 0.0500$

PRESSURE

FLOW

VISCOSITY

(PSIA): $\quad 14.7000$

(SCFM): $\mathbf{0 . 3 0 0 0}$

( $\mu$ p): $\quad 199.00$

FIGURE B-10. Particle Size Distribution Plot, SGS-E3. HEDL 8007-104.7

8007969- 17 


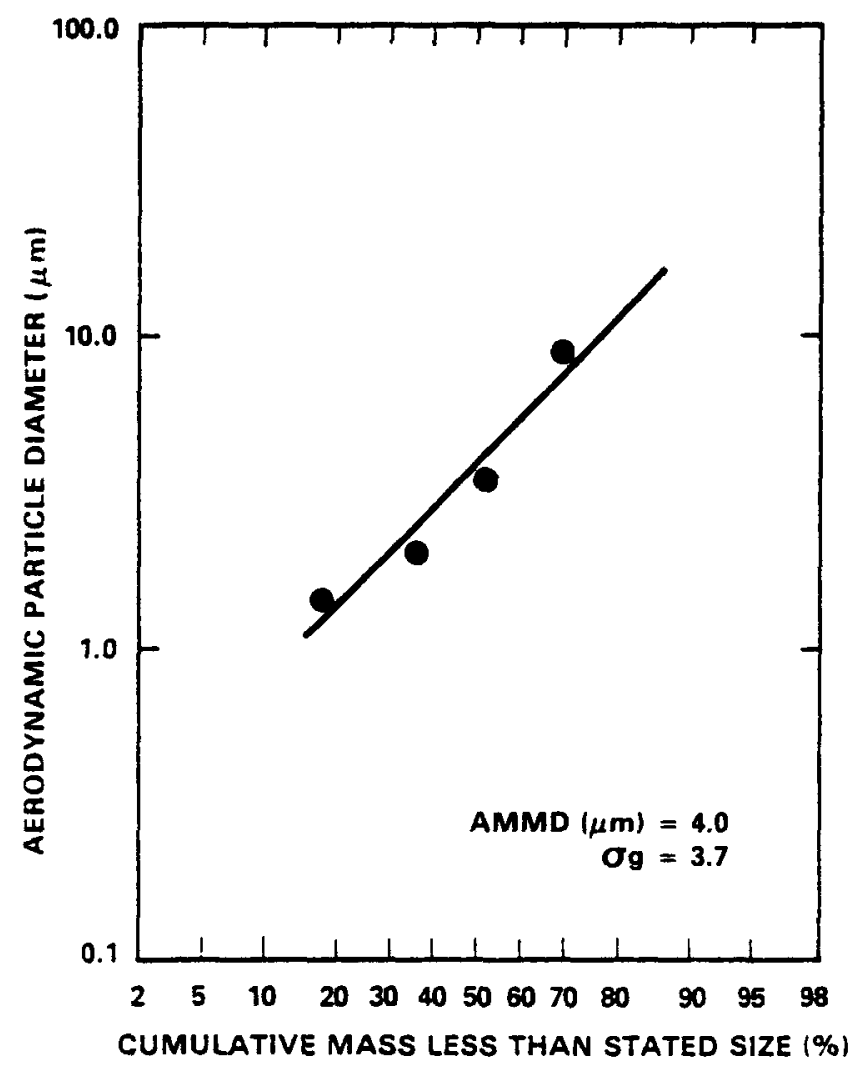

RECTANGULAR JET IMPACTOR

TEST: SGS-E3

TIME: 206 MINUTES

SCRUBBER OUTLET

LAB

mg Na

0.200

0.200

0.260

0.210

0.220

0.240

0.060
CUM. FRACT.

LESS THAN

0.852

0.703

0.508

0.352

0.188

0.008
Dp, 50

MICROMETERS

14.998

9.165

3.666

2.208

1.416

0.792

$\begin{array}{lll}\text { TEMPERATURE } & \left.\text { ( }{ }^{\circ} \mathrm{F}\right): & 77.00 \\ \text { STAGE BACKGROUND } & \text { (mg): } & 0.0120 \\ \text { B.U. BACKGROUND } & \text { (mg): } & \mathbf{0 . 0 5 0 0} \\ \text { PRESSURE } & \text { (PSIA): } & \mathbf{1 3 . 5 0 0 0} \\ \text { FLOW } & \text { (SCFM): } & \mathbf{0 . 3 0 0 0} \\ \text { VISCOSITY } & (\mu \mathrm{p}): & \mathbf{1 8 3 . 0 0}\end{array}$

FIGURE B-11. Particle Size Distribution Plot, SGS-E3.

HEDL 8007-104. 12 $8007969-15$ 


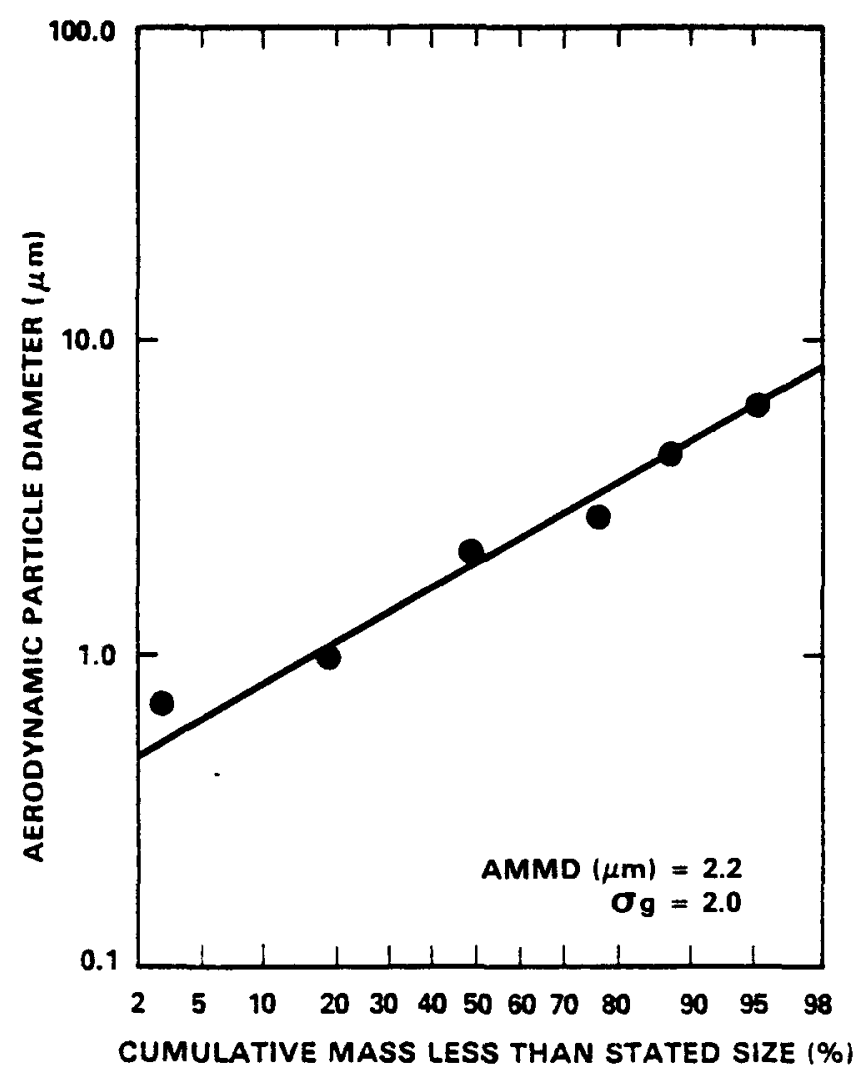

CIRCULAR JET IMPACTOR

TEST: SGS-AC4

TIME: 1155 MINUTES

SCRUBBER INLET

LAB

mg Na

0.450

0.630

1.390

2.160

4.420

5.530

3.020

0.560

0.430
CUM. FRACT. LESS THAN

0.989

0.967

0.897

0.780

0.522

0.194

0.024

0.006
Dp, 50

MICROMETERS

12.498

7.858

5.340

3.598

2.320

1.183

0.729

0.492

TEMPERATURE

$\left({ }^{\circ} \mathrm{F}\right): \quad \quad 151.00$

STAGE BACKGROUND (mg): $\quad 0.2730$

B.U.BACKGROUND (mg): $\quad 0.3390$

PRESSURE

FLOW

(PSIA): 14.6960

VISCOSITY

(SCFM): 0.5000

( $\mu$ p): $\quad 206.00$

FIGURE B-12. Particle Size Distribution Plot, SGS-AC4

HEDL 8007-104.20

8007969-20 


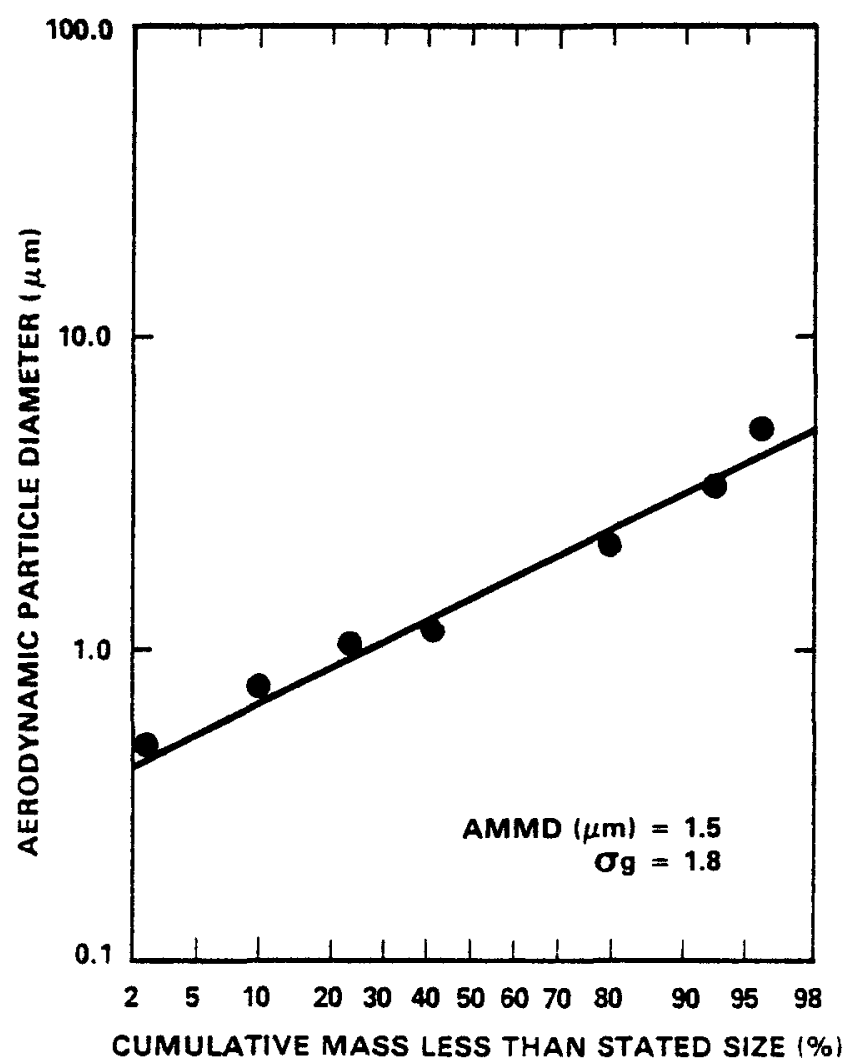

CIRCULAR JET IMPACTOR

TEST: SGS-AC4

TIME: 1427

SCRUBBER INLET

LAB

$\mathrm{mg} \mathrm{Na}$

0.430

0.340

0.530

0.630

1.970

5.130

4.000

1.180

0.580
CUM. FRACT.

LESS THAN

0.987

0.982

0.961

0.932

0.793

0.397

0.094

0.020
Dp, 50

MICROMETERS

12.427

7.814

5.310

3.577

2.306

1.17

0.725

0.490

\section{TEMPERATURE $\quad\left({ }^{\circ} \mathrm{F}\right): \quad 170.00$ \\ STAGE BACKGROUND (mg): $\quad 0.2730$ \\ B.U. BACKGROUND \\ PRESSURE \\ FLOW \\ VIScosity \\ (mg): $\quad 0.3390$ \\ (PSIA): 14.6960 \\ (SCFM): 0.5000 \\ $(\mu \mathrm{p}): \quad 210.00$}

FIGURE B-13. Particle Size Distribution Plot, SGS-AC4.

HEDL 8007-104.9

8007969-8 


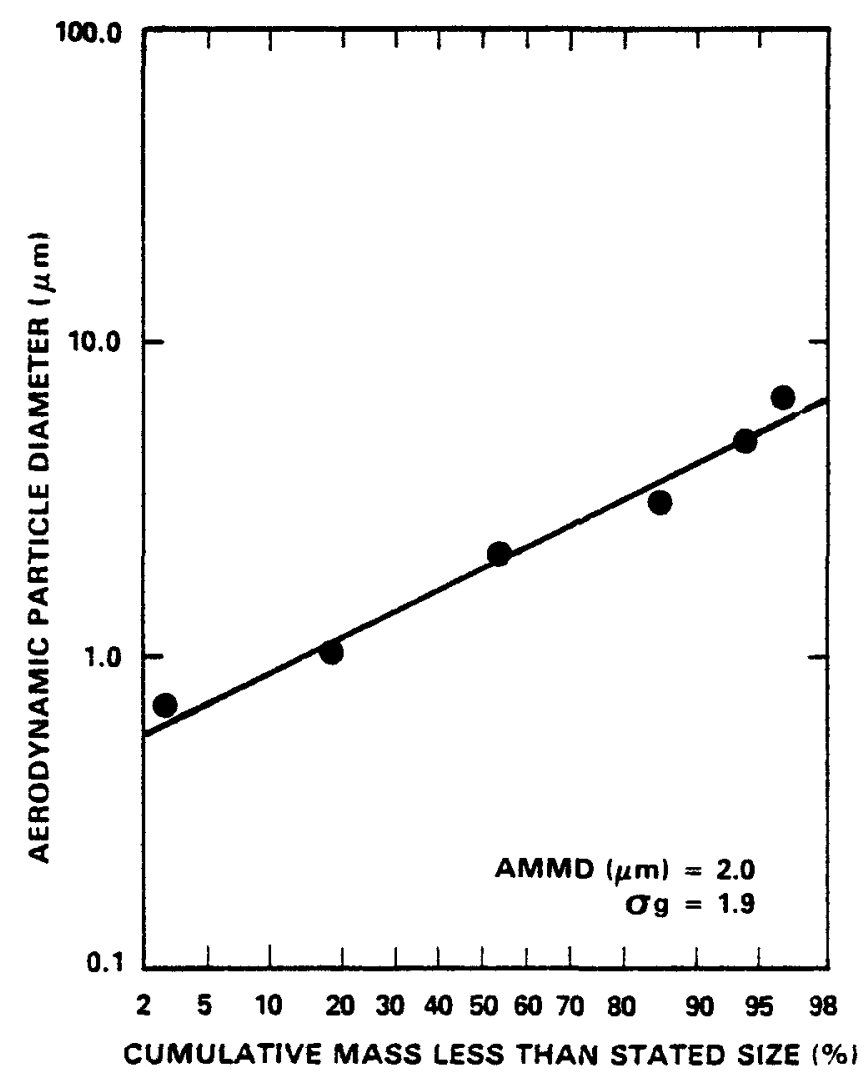

CIRCULAR JET IMPACTOR

TEST: SGS-AC4

TIME: 2000 MINUTES

SCRUBBER INLET

\begin{tabular}{|c|c|c|c|}
\hline $\begin{array}{c}\text { LAB } \\
\mathrm{mg} \mathrm{Na} \\
0.450 \\
0.440 \\
0.590 \\
1.110 \\
4.070 \\
5.200 \\
2.410 \\
0.470 \\
0.440\end{array}$ & $\begin{array}{c}\text { CUM. FRACT. } \\
\text { LESS THAN } \\
0.986 \\
0.973 \\
0.948 \\
0.882 \\
0.582 \\
0.192 \\
0.024 \\
0.024\end{array}$ & & $\begin{array}{c}\text { Dp, } 50 \\
\text { MICROMETERS } \\
12.519 \\
7.872 \\
5.349 \\
3.604 \\
2.324 \\
1.186 \\
0.730 \\
0.730\end{array}$ \\
\hline $\begin{array}{l}\text { TEMPE } \\
\text { STAGE } \\
\text { B.U. B } \\
\text { PRESS } \\
\text { FLOW } \\
\text { VISCO }\end{array}$ & $\begin{array}{ll}\text { E } & \text { ('F): } \\
\text { GROUND } & \text { (mg): } \\
\text { OUND } & \text { (mg): } \\
& \text { (PSIA): } \\
& \text { (SCFM): } \\
& \text { ( } \mu \mathrm{p}):\end{array}$ & $\begin{array}{l}143.00 \\
0.2730 \\
0.3390 \\
14.6960 \\
0.5000 \\
204.00\end{array}$ & \\
\hline
\end{tabular}

FIGURE B-14. Particle Size Distribution Plot, SGS-AC4. HEDL 8007-104.8 


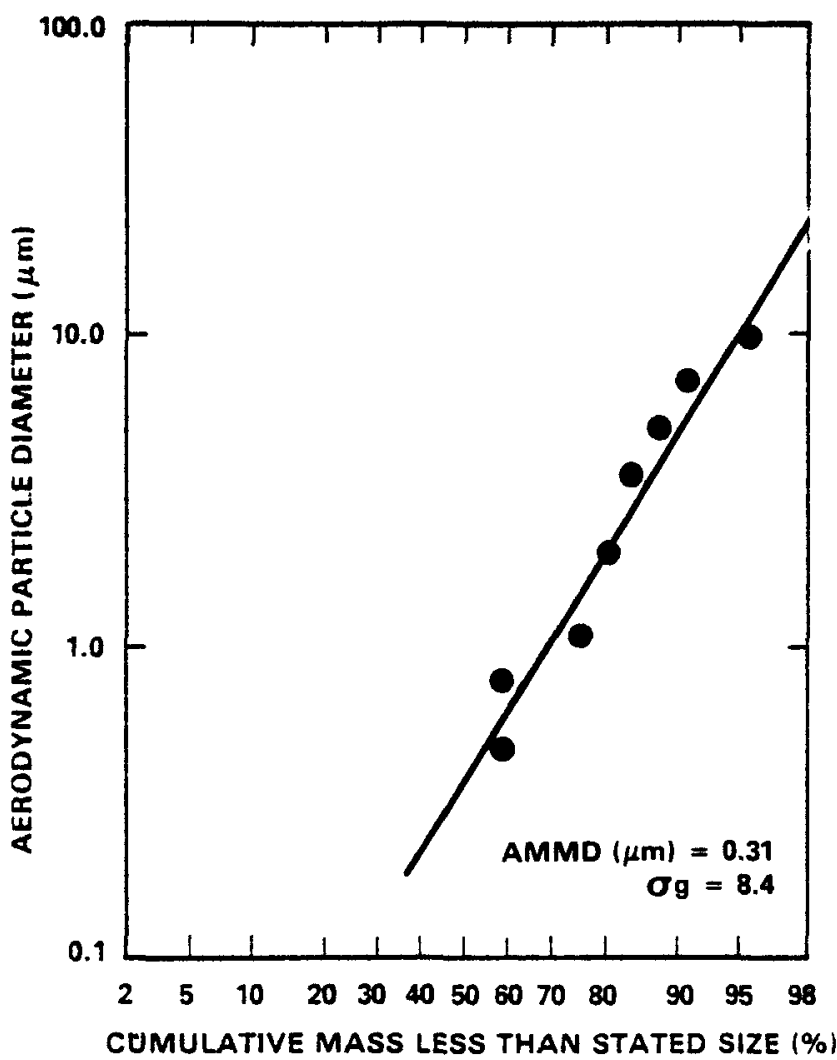

CIRCULAR JET IMPACTOR

TEST: SGS-AC6

TIME: 155 MINUTES

DEMISTER PAD OUTLET

LAB

mg $\mathbf{N a}$

0.230

0.220

0.220

0.220

0.260

0.270

0.490

0.250

1.650
CUM. FRACT.

LESS THAN

0.968

0.940

0.912

0.884

0.840

0.791

0.651

0.610
Dp, 50

MICROMETERS

12.605

7.926

5.386

3.629

2.340

1.194

0.735

0.497

$\begin{array}{lll}\text { TEMPERATURE } & \left({ }^{\circ} \mathrm{Fl}:\right. & 95.00 \\ \text { STAGE BACKGROUND } & (\mathrm{mg}): & \mathbf{8 0 . 0 0} \\ \text { B.U. BACKGROUND } & \text { (mg): } & \mathbf{0 . 1 5 3 9} \\ \text { PRESSURE } & \text { (PSIA): } & \mathbf{0 . 1 8 3 0} \\ \text { FLOW } & \text { (SCFM): } & \mathbf{1 3 . 6 1 0 0} \\ \text { VISCOSITY } & (\mu \mathrm{p}): & 0.4700 \\ & & 188.00\end{array}$

FIGURE B-15. Particle Size Distribution P1ot, SGS-AC6. 


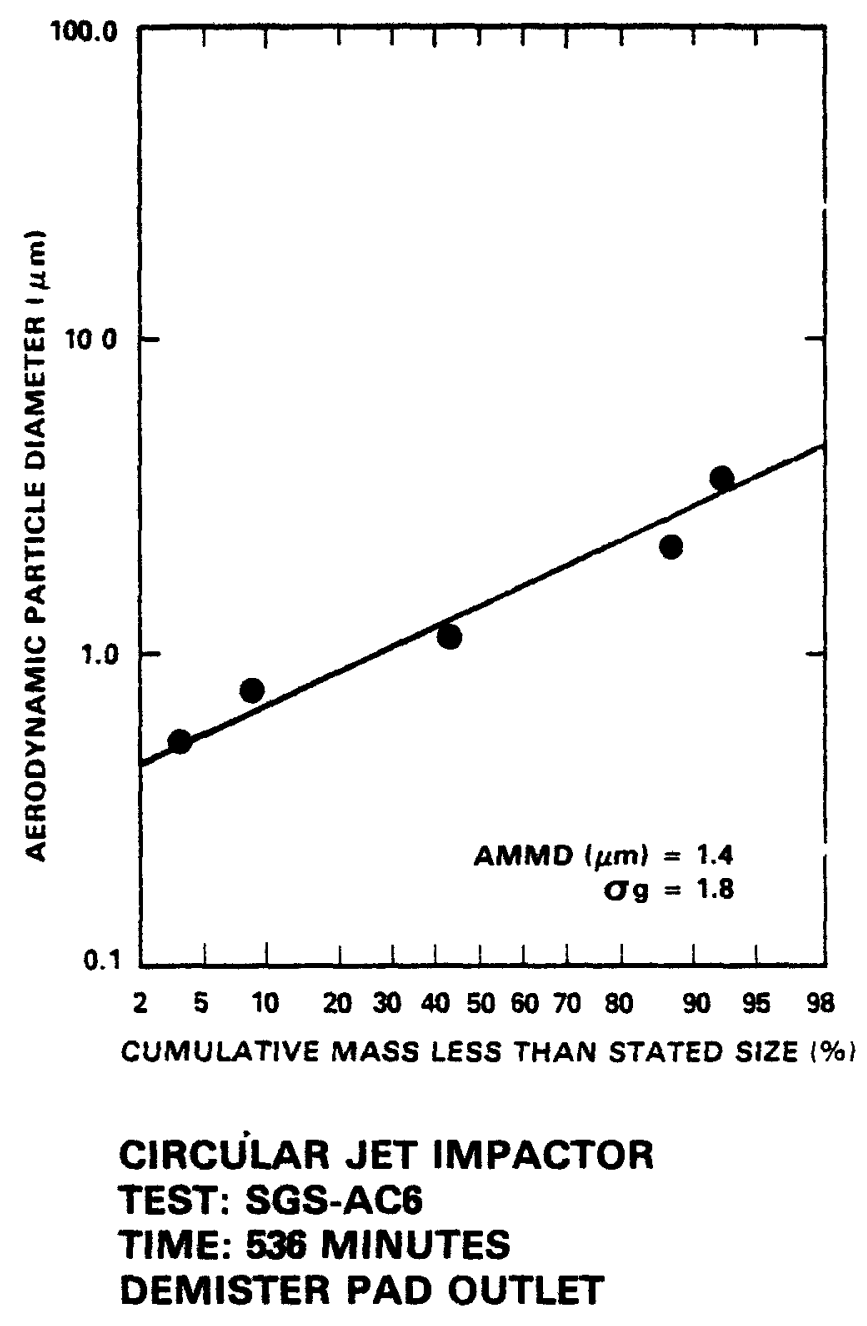

$\begin{array}{ccc}\text { LAB } & \text { CUM. FRACT. } & \text { Dp, 50 } \\ \text { mg Na } & \text { LESS THAN } & \text { MICROMETERS } \\ 0.170 & 0.996 & 12.598 \\ 0.180 & 0.990 & 7.921 \\ 0.180 & 0.984 & 5.383 \\ 0.330 & 0.946 & 3.627 \\ 0.360 & 0.901 & 2.338 \\ 2.220 & 0.449 & 1.193 \\ 1.810 & 0.086 & 0.735 \\ 0.380 & 0.037 & 0.496 \\ 0.350 & & \end{array}$

$\begin{array}{lll}\text { TEMPERATURE } & \left({ }^{\circ} \text { F): }\right. & 95.00 \\ \text { STAGE BACKGROUND } & (\mathrm{mg}): & 0.1530 \\ \text { B.U. BACKGROUND } & \text { (mg): } & 0.1830 \\ \text { PRESSURE } & \text { (PSIA): } & 13.6800 \\ \text { FLOW } & \text { (SCFM): } & 0.4700 \\ \text { VISCOSITY } & (\mu \mathrm{p}): & 192.00\end{array}$

FIGURE B-16. Particle Size Distribution Plot, SGS-AC6. 


\section{REFERENCES}

B-1. "Operating Manual for Andersen 2000, Inc., Mark II and Mark III Particle Sizing Stack Samplers," Report TR \#76-900023, Andersen 2000, Inc., Atlanta, GA, January 1, 1976.

B-2. K. M. Cushing et al. "Particulate Sizing Techniques for Control Device Evaluation: Cascade Impactor Calibrations, "Report EPA-600/2-76-280, Southern Research Institute, Birmingham, AL, October 1976.

B-3. T. T. Mercer, "The Interpretation of Cascade Impactor Data," Indus. Hygiene J., 26, 1965, pp. 236-241. 
A P PENDIX C

SPHERICAL BED MODEL DEVELOPMENT 
Removal of particles in a bed of spheres was attributed to impaction, interception, and Brownian diffusion. Key simplifying assumptions were:

- Gas flow rate was computed using an average temperature and assuming that the pressure was one atmosphere.

- Water vapor condensation and evaporation effects on particle growth and collection were neglected.

- The aerosol concentration was assumed uniform throughout any bed cross-section.

- Packing is assumed to be a collection of independent spheres.

\section{Modeling Approach}

For a unit cross section area of a packed bed, the aerosol mass balance is:

$$
\begin{aligned}
& \text { Input Rate }=\text { Output Rate }+ \text { Capture Rate } \\
& \left.Q C\right|_{x}=\left.Q C\right|_{X+d x}+\text { Capture Rate }
\end{aligned}
$$

The capture rate is given by:

$$
\text { Capture rate }=\frac{(\text { Cross section of rock) (C) (Q) Ef }}{\text { Tota } 1 \text { Flow Area }}
$$

Where:

$$
\begin{aligned}
& \text { Ef }=\text { Collection efficiency of a single sphere } \\
& \text { Volume of rock }=(1-\varepsilon) d x
\end{aligned}
$$




$$
\varepsilon=\text { bed void fraction }
$$

$$
\begin{aligned}
\text { Area of rock } & =\frac{\text { area sphere volume rocks }}{\text { volume sphere }}=\frac{3}{2} \frac{(1-\varepsilon) d x}{d_{R}} \\
d_{R} & =\text { diameter of rock }
\end{aligned}
$$

Thus, the capture rate is:

$$
\text { Capture Rate }=\frac{3}{2} \frac{C Q}{d R} \frac{(1-\varepsilon)}{\varepsilon} d x \text { Ef }
$$

And the aerosol balance becomes:

$$
Q C_{x}=\left.Q C\right|_{x+d x}+\frac{3}{2} \frac{d x}{d R} \frac{1-\varepsilon}{\varepsilon} \operatorname{CQEf}
$$

Rearranging and integrating:

$$
P t=\operatorname{Exp}\left[-\frac{3(1-\varepsilon) Z E f}{2 \varepsilon d_{R}}\right]
$$

Where:

$$
\begin{aligned}
Z & =\text { bed length, }(\mathrm{cm}) \\
E_{f} & =E_{R}+E_{I}+E_{B D} \\
E_{I} & =\text { collection efficiency by impaction } \\
E_{R} & =\text { collection efficiency by interception } \\
E_{B D} & =\text { collection efficiency by Brownian diffusion }
\end{aligned}
$$

\section{Capture Mechanisms}

Capture by Brownian diffusion was related to the Reynolds number and the Peclet number using an approximation $(C-1)$ to a boundary layer equation developed by Suneja $(\mathrm{C}-2)$. The capture efficiency due to diffusion was calculated by: 
Where:

$$
E_{D}=\frac{1}{P e}+1.727 \frac{R^{1 / 6}}{P e^{2 / 3}}
$$

$E_{D}=$ Sphere collection efficiency due to diffusion

$$
\begin{aligned}
\text { Pe } & =\text { Peclet Number } \frac{d_{R} V_{0}}{\theta} \\
R e & =\text { Reynolds number } \quad=\frac{d_{R} V_{0} \rho_{g}}{\mu_{g}} \\
d_{R} & =\text { Rock diameter } \\
V_{0} & =\text { bulk gas velocity }=\frac{Q}{A\left(\varepsilon-H_{d}\right)} \\
\theta & =\text { particle diffusivity } \\
\rho_{g} & =\text { gas density } \\
H_{g} & =\text { gas viscosity } \\
Q & =\text { gas volumetric flowrate } \\
A & =\text { bed cross-sectional area } \\
H d & =\text { Liquid volumetric holdup fraction } \\
E & =\text { bed void fraction }
\end{aligned}
$$

Interception was computed for potential flow according to an expression due to Ranz and Wong $(\mathrm{C}-3)$.

$$
E_{R}=3 \frac{d_{p}}{d_{R}}
$$

$$
\text { Where: } \quad \begin{aligned}
E_{R} & =\text { collection efficiency for interception. } \\
d_{p} & =\text { diameter of aerosol particle } \\
d_{R} & =\text { diameter of the rock. }
\end{aligned}
$$

The impaction parameter, also called the Stokes number, was used to calculate the impaction efficiency. The Stokes number is defined by: 


$$
S t k=\frac{\rho d_{p}^{2} v}{{ }_{9 \mu d_{R}}}
$$

Where: $\quad$ Stk $=$ Stokes number

$$
\begin{aligned}
\rho & =\text { Aerosol particle density } \\
V & =\text { Relative velocity between derosol and rock } \\
\mu & =\text { Gas viscosity }
\end{aligned}
$$

The impaction efficiency was computed from Langmuir's equation ( $\mathrm{C}-4)$ for potential flow:

$$
E_{I}=\frac{S t k^{2}}{(S t k+0.5)^{2}}
$$

The overall $E_{f}$ was the sum of the $E$ values for the three mechanisms:

$$
E_{f}=E_{R}+E_{I}+E_{B D}
$$

\section{References}

C-1. A. K. Postma, R. L. Ritzman, J. A. Gieseke, and E.W. Schmidt, Models for Predicting the Removal of Airborne Contaminants by Reactor Containment Sprays, BNWL-B-417, Battelle Pacific Northwest Laboratory, Richland, Washington, June, 1975.

C-2. M. Suneja, as quoted in: M. Kerker and V. Hamp 1, Scavenging of Aerosol Particles by a Falling Water Drop and Calculation of Washout Coefficients, J. Atm. Science, 31, pp 1368-1376, Ju1y, 1974.

C-3. W. E. Ranz, and J. B. Wong, Impaction of Dust and Smoke Particles on Surface and Body Collectors, Ind. Eng. Chem, 44, pp 1371-1381, 1952.

C-4. I. Langmuir, J. Meteor, 5 , p. 175, 1948. 
APPENDIX D

CHANNEL MODEL DEVELOPMENT

\author{
APPENDIX D
}




\section{APPENDIX D}

\section{CHANNEL MODEL DEVELOPMENT}

\section{Mode ling Approach}

The aerosol laden gas stream follows a torturous path as it flows up through the packed bed. A theoretical model of collection efficiency by Calvert and Jackson $(D-1)$ assumed the bed could be represented by a series of semicircular channels. The following key assumptions were made:

- Gas flow through the bed may be described as a series of $N$ semicircular channels of width "b".

- The number of semicircular bends, $N$, is related to the overall height of the packed bed, $z$, the packing diameter, $d_{R}$, and the channel width, b, by:

$$
N=\frac{z}{d_{R}+b}=\frac{\text { Total Height }}{\text { Size of one bend }}
$$

- The gas velocity through the channels, Vo, is inversely proportional to the void fraction:

$$
v_{0}=V_{G}\left(\frac{1}{\varepsilon-H_{d}}\right)
$$

Where: $V_{0}=$ Channel gas bulk velocity

$$
\begin{aligned}
V_{G} & =\text { Gas superficial velocity } \\
\varepsilon & =\text { Bed void fraction } \\
H_{d} & =\text { Fraction of total bed volume occupied by liquid }
\end{aligned}
$$

- Particles are collected on the channel walls by centrifugal force. 
- Turbulent gas flow causes uniform aerosol concentration through any $\mathrm{plane}$ perpendicular to the gas flow.

- The width of the semicircular channels, b, can be described as a fraction, $j$, of the packing diameter:

$$
b=j d_{R}
$$

- Electrostatic effects, Brownian and turbulent diffusion, settling, and particle growth are ignored.

For the case of turbulent mixing, if Stoke's law applies, then a force balance leads to:

$$
V_{t}=\frac{d p^{2} o_{p} a}{18 \mu_{g}}
$$

Where: $\quad v_{t}=$ particle terminal velocity

$d_{p}=$ particle diameter

$\rho_{p}=$ particle density

$\mathrm{a}=$ particle acceleration

$\mu_{g}=$ gas viscosity

The flux of particles against the outside wall of a bend is CVt, where $C$ is the aerosol concentration. For a differential channel element, an aerosol balance becomes:

$$
\left.\operatorname{VobC}\right|_{x}-\left.\operatorname{VobC}\right|_{x+d x}=C V \operatorname{trd\theta }
$$

Where: $R=$ Outside, radius of bend

$$
\Theta=\text { Angle, radians }
$$

Using the boundary conditions that $C=C$ when $\theta=0$, the equation integrates to:

$$
\frac{C}{C_{0}}=\exp -\left[\left(\frac{V t}{V_{0}}\right)\left(\frac{R \theta}{b}\right)\right]
$$


The normal acceleration of a stream at a velocity $V_{0}$ on a radius $R$ is $\left(V_{0}^{2} / R\right)$. By substitution:

$$
\frac{C}{C_{0}}=\exp -\left[\frac{d p^{2} \rho_{p} V_{0 \theta}}{18 \mu g b}\right]
$$

Where: $P t=$ aerosol penetration of a bend

For each bend, the wall consists of $\pi$ radians. Therefore, a bed channel of $\mathrm{N}$ bends has an aerosol penetration equivalent to:

$$
P t=\frac{C}{C_{0}}=\exp -\left[\frac{d_{p}{ }^{2} \rho_{p} V_{0} \pi N}{18 \mu g \quad b}\right]
$$

By substituting the expressions for $V_{0}, b$, and $N$, the following equation results:

$$
\begin{aligned}
& P t=\exp -\left[\frac{\pi}{2\left(j+j^{2}\right)\left(\varepsilon-H_{d}\right)} \frac{Z K p}{R}\right] \\
& \text { Where: } K p=\frac{V G d_{p}^{2} \rho p}{9{ }^{2} g^{d_{R}}}
\end{aligned}
$$

The experimental data of Jackson ${ }^{(D-1)}$ were analyzed ${ }^{(D-2)}$ to determine an appropriate value of $j$. Table $D-1$ gives the experimental values. For the SGS, $j$ was assumed to be 0.192 .

TABLE D-1

EXPERIMENTAL VALUES OF $\mathrm{J}$, CHANNEL WIDTH

Size $(\mathrm{cm})$

2.54

3.8

\section{Type of Packing}

Berl Saddles, marbles, Raschig Rings, Inta lox Sadd les

Berl Saddles, Raschig Rings, Pall Rings

Berl Rings, Raschig Rings, Pall Rings

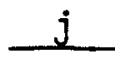

0.192

0.190

0.165 


\section{References}

D-1. Jackson, S. and Calvert, S., "Entrained Particle Collection in Packed Beds," AIChE Journal 12, 1075-1078 (November, 1966).

D-2. Calvert, S., J. Goldschmidt, D. Leith, and D. Mehta, "Scrubber Handbook", Available from NTIS, PB 213-016 (1972). 
Joint Center for Graduate Study

T00 Sprout Road

Richland, WA 99332

WL Kuhn

WA Scheff]er

University of Washington (2)

Dr. Charles Sleicher

Espt of Chemical Engineering

Seattle, WA 98105

HEDL (25)
JM Atwood
$W / C-45$
EA Evans
$W / C-23$
RK Hilliard
$W / 221 T-H E$
JD McCormack
$W / 221 T-H E$
LD Muhlestein (2) W/22 IT-HE
RK Owen (10)
AK Postma (2)
$W / 221 T-H E$
$W / 22$ IT $-H E$
Central Files (5) $W / C-110$
Pub 1 Services (2) $W / C-115$ 